\title{
FOURTH STRATEGIC PHASE REPORT
}

2015-2020
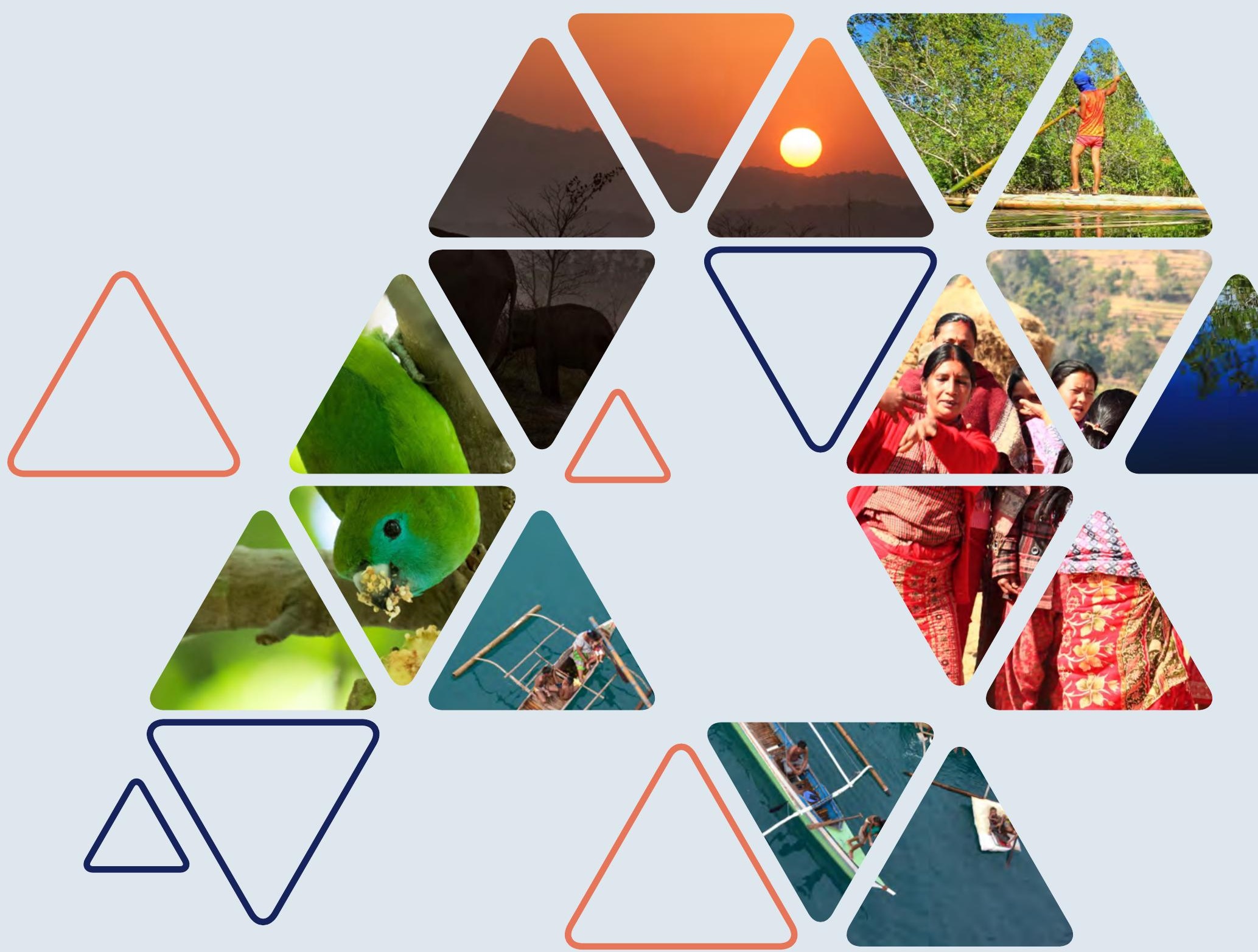

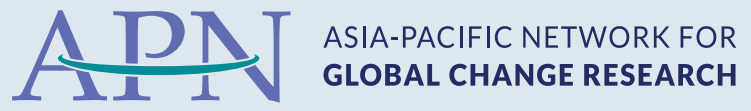




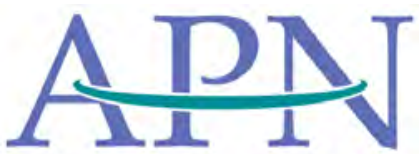

ASIA-PACIFIC NETWORK FOR

GLOBAL CHANGE RESEARCH

\section{Fourth Strategic Phase Report}

\section{(C) 2020 Asia-Pacific Network for Global Change Research}

Authors: Takeshi Abe, Henri Bastaman, Xiaojun Deng, Kensuke Fukushi, Lance C. Heath, Douglas P. Hill, Yukihiro Imanari, Kanayathu C. Koshy, Andrew Matthews, Soojeong Myeong, Juan M. Pulhin, Linda Anne Stevenson, Yasuo Takahashi, Peldon Tshering, Luis M. Tupas, and Keiko Yoshikawa

ISBN: 978-4-9902500-4-1

DOI: https://doi.org/10.30852/spr.4

APN seeks to maximize the discoverability and use of its knowledge and information. All publications are made available through its online repository (www.apn-gcr.org/publications-library/). Unless otherwise indicated, APN publications may be copied, downloaded and printed for private study, research and teaching purposes, or for use in non-commercial products or services. Appropriate acknowledgement of APN as the source and the copyright holder must be given, while APN's endorsement of users' views, products or services must not be implied in any way. For reuse requests: https://www.apn-gcr.org/contact-information/

The use of geographic names, boundaries and related data on maps, and in lists and tables within this publication are not warranted to be error-free, nor do they imply any endorsement by APN.

Cover photos: Meycel C. Amarille, Rajarshi Banerji, Allan F. Castañeda, Nammy Hang Kirat, and Don Geoff Tabaranza.

Other photos: Pat Whelen (p21), Marek Okon (p22), David Emrich (p36), Klara Avsenik (p39), Mohammad Rakibul Hasan (p51); others courtesy of APN project teams and APN Secretariat. 


\section{Message from the Chairperson of the 4th Strategic Phase Report Task Force and the Director of the APN Secretariat}

At the outset, it is our pleasure and honour to present the 4th Strategic Phase Report of APN. We want to express our heartfelt appreciation to all APN member countries, their national Focal Points, Scientific Planning Group Members and invited experts, as well as other APN partners and stakeholders for their support of APN during the 4th Strategic Phase (2015-2020).

In the first year of this phase, three important international initiatives related to global change, disaster risk reduction and sustainability were adopted by the international community: the Sendai Framework for Disaster Risk Reduction in June 2015, the Sustainable Development Goals in September 2015 and the Paris Agreement in December 2015.

In its 4th Strategic Phase, APN strived to contribute to the implementation of the aforementioned international initiatives by providing scientific findings for policy formulation, enhancing capabilities of scientists in addressing the diverse aspects of global change and sustainability, as well as serving as a platform for interaction between members of different societal groups. The achievements of this endeavour are summarized in the present report.

On the threshold of the 5th Strategic Phase (2020-2024), and while the international community is facing a difficult situation around the pandemic, APN is ready to continue addressing global change and sustainability challenges using holistic and transdisciplinary approaches. While doing so, the goal is not to return to the old "business as usual" attitude but contribute to making societies more resilient and sustainable in a "Build Forward Better" manner. APN is very much looking forward to meeting the new opportunities and challenges.

Finally, we would like to express our gratitude to the authors, listed on the inner cover of the report. Contribution in terms of their capacity as members of the 4th Strategic Phase Report Task Force and support from the APN Secretariat was essential to realize the report. In particular, we express our appreciation to Prof. Kanayathu C. Koshy and Dr Lance C. Heath for drafting major parts of the report, and Dr Luis M. Tupas and Ms Peldon Tshering, Coordinators of the Task Force, for their guidance in the course of the drafting work. Special thanks go to Dr Linda A. Stevenson, Mr Xiaojun Deng and Mr Yukihiro Imanari of APN Secretariat for their work in drafting various chapters, compiling them and editing the report in its entirety.

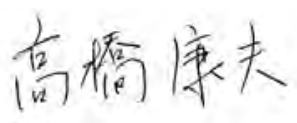

Yasuo Takahashi

Chairperson, 4th Strategic Phase

Report Task Force

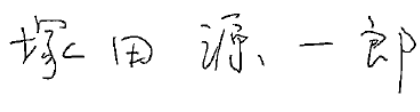

Gen'ichiro Tsukada

Director, APN Secretariat 


\title{
Executive Summary
}

\author{
A review of APN's 4th Strategic Phase from 2015 \\ to 2020 was undertaken by a specially convened \\ Task Force comprising members of the Steering \\ Committee (SC), Scientific Planning Group (SPG) \\ and invited experts. This report highlights the \\ accomplishments, strengths, opportunities and \\ challenges of APN during this reporting phase.
}

Since its inception, APN has successfully supported regional research projects and activities in global change and sustainability and, in doing so, has strengthened scientific capacity to help bridge the gap between policy-relevant scientific endeavours and policy development.

Over five years of the 4th Strategic Phase, APN has funded projects through its competitive calls for proposals, Collaborative Regional Research Programme (CRRP) and Capacity Development Programme (CAPaBLE). The funding support for these core programmes has forged successful collaboration among developing and developed country scientists and policymakers, which, in turn, has led to the creation of new scientific knowledge and improvements in scientific capacity of policymakers and practitioners for policy direction.

APN also implemented short-term programmes focused on thematic areas. These include the Biodiversity and Ecosystem Services Framework (B\&ES), the Low Carbon Initiatives Framework (LCI), and the Climate Adaptation Framework (CAF). CAF was initiated in response to the UNFCCC negotiations at COP16 in Cancun, Mexico in 2010, in recognition of the need to respond to the impacts of climate change through greater action on adaptation.

With direct engagement of over 1,600 scientists, policymakers and other actors, 119 projects were completed during the 4th Strategic Phase period. The present report highlights 27 CRRP, CAPaBLE and Framework projects for their outstanding contribution to the goals and objectives of APN. These activities have produced over 650 direct outputs including peer-reviewed manuscripts, science-policy briefs and toolkits, to name a few.

In recognition of the need to support early-career scientists (ECS), a Collaborative Research Programme for Young Scientists (CRYS) was piloted in 2017. This programme has provided a platform for ECSs to direct their knowledge and ideas towards addressing issues on global change and sustainability and offered a unique opportunity for peer-to-peer networking to develop and implement research proposals. The results of three projects are presented in this report.

In the 4th Strategic Phase, APN also conducted activities such as workshops and symposia with other organizations and entities. The Hyogo Prefectural 
Government, APN's second-largest donor after the Ministry of the Environment, Japan and host to the APN Secretariat, is one such entity that APN has actively engaged with during the course of the 4 th Strategic Phase. Other activities that have been integral to the on-going contribution to global change research and sustainability science have included the Science-Policy Dialogues (SPDs), designed to provide a platform for science-policy interaction through facilitated discussions.

International engagement in the region, through projects and other activities, is a priority of APN. To ensure that the products of successful collaboration are visible to the international community, APN has been striving to improve its communication and dissemination policy. In line with this endeavour, APN has propelled the publication of a special issue of 15 research papers derived from APN projects. The 2020 special issue entitled Climate Change Impacts, Vulnerability and Adaptation: Asian Perspective was published in Elsevier's Environmental Research Journal and is available online.

Throughout the 4th Strategic Phase, APN has continued to publish and provide its research products and science-policy information by digital means and through operational outreach activities, including via UNFCCC, IPBES and regional bodies such as APAN. As discussed in Chapter 2, APN has strengthened its digital communication capabilities and broadened the reach of its communication tools, especially in its member countries. The project and publications library (E-library), as an integral component of the APN website, has continued to play an important role in disseminating published material. There are indications that more practical products, such as guides and materials in local languages, have attracted more immediate attention, suggesting some merit in refining the structure of the website to reflect the diversity of products and to improve visibility. A comprehensive set of indicators are required to monitor the effectiveness of APN information products. Social media has enhanced the visibility of APN, although a dedicated social media strategy is also needed to further increase the effectiveness and uptake of information shared through social media.

APN has continued to improve its institutional structure by increasing the efficiency of its organs and suborgans. During the 4th Strategic Phase, a Task Force for the Future Development of APN was established to review the work of APN. The Task Force recommended enhancing the position of national Focal Points (nFPs) by strengthening their role in the $\mathrm{SC}$ and empowering the Subregional Committees (SRCs) with an enhanced level of responsibility. To implement this and other recommendations of the Task Force, APN amended its Framework Document in 2018.

Although APN has a strong presence in Asia, engagement with the Pacific remains challenging. Despite some engagement during the 4 th Strategic Phase with, for example, the 23rd Pacific Science Congress in 2016 and the Regional Preparatory Workshop in Fiji in 2018 for UNFCCC COP23, greater effort is required to ensure a Pacific presence in APN activities. A scoping meeting is being planned to establish a Pacific SRC, and this is a step in the right direction.

While many member countries have been providing APN with significant in-kind support, it has been recognized that the development of a more equitable arrangement to attract additional direct financial contribution from member countries is an area where APN can progress further as an institution.

Looking ahead to the 5th Strategic Phase, APN must continue strengthening partnerships, including with the private sector, and conduct activities that promote and foster regional-based research and capacity building projects and activities. To maximize the impact of its work, APN should explore the prospect of supporting, with its partners, larger projects that focus on high priority issues affecting the Asia-Pacific region in its response to global change and sustainable development.

At the time of completing the present report, the COVID-19 pandemic has become a major issue in the Asia-Pacific region in addressing global change and sustainability. The impacts of the pandemic, particularly post-recovery, could be considered when addressing new or emerging themes for the 5 th Strategic Phase.

Interest in global change and sustainability research is growing, and the increasing urgency to meet this demand has placed APN in an inimitable position in the Asia-Pacific region. APN has demonstrated through its unique and robust network of scientists and policymakers that it can meet the challenges in a world that is rapidly changing. 


\section{Contents}

\section{Message from the Chairperson of the 4th Strategic Phase Report Task Force and the Director of the APN Secretariat}

\section{Executive Summary}

6 Chapter 1. Science, policy and capacity development report

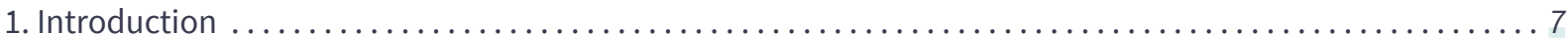



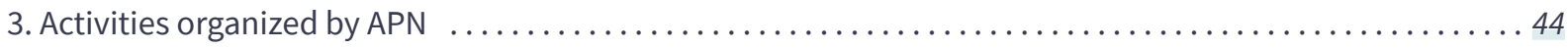

4. International engagement and alignment with global change and sustainability communities ........52



58 Chapter 2. Communication and outreach report



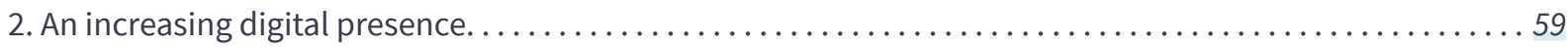

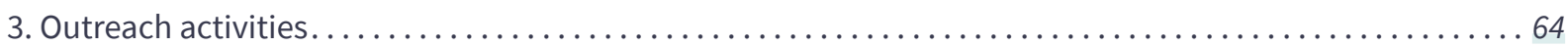



\section{Chapter 3. Institutional report}



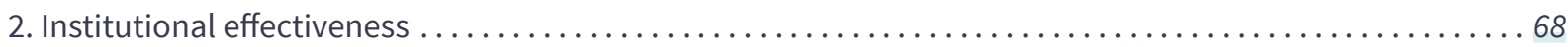

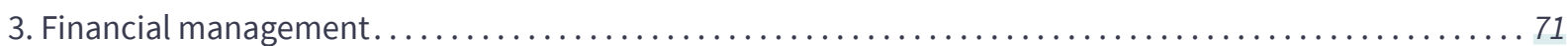

\section{Chapter 4. Strengths, challenges and opportunities}

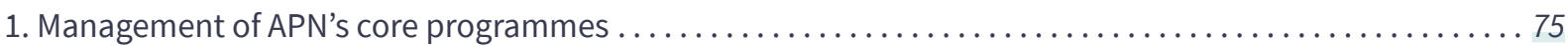

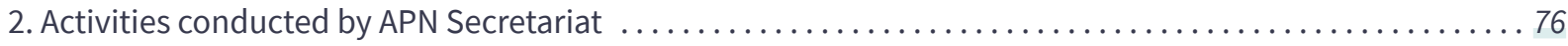

3. APN and the global change and sustainability communities............................ 77



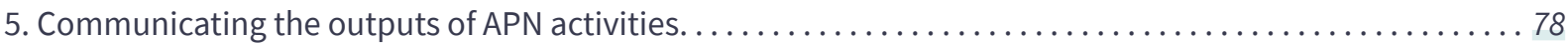

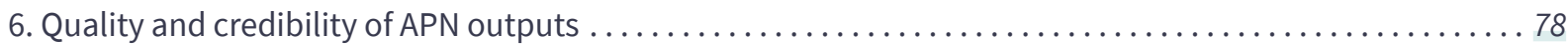

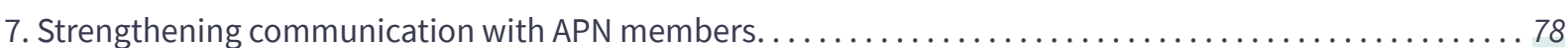

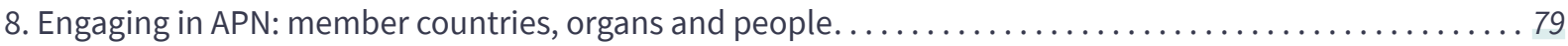



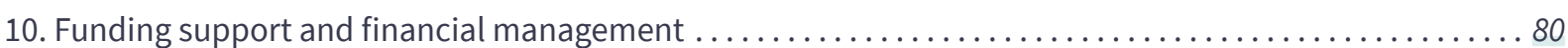

\section{Conclusions}

\section{Appendices}



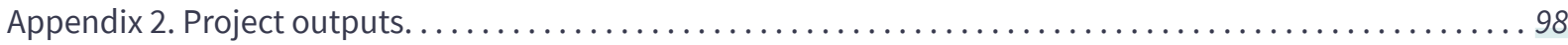



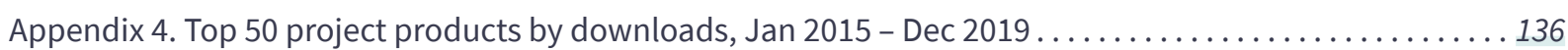

Appendix 5. Articles published in the media during the reporting period $\ldots \ldots \ldots \ldots \ldots \ldots \ldots \ldots \ldots \ldots$

Appendix 6. Acronyms.................................................... 140 


\section{FIGURES}

Figure 1.1. Phrase cloud showing member country priorities $(2016-2019) \ldots \ldots \ldots \ldots$

Figure 1.2. Process for calls for Proposals for APN's research and capacity development activities. ..........9

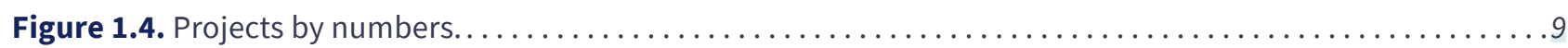

Figure 1.3. Call for Proposals: Full proposals submitted (blue line) and funded (orange line). . . . . . . . . . 10

Figure 1.5. Snapshot of country engagement in APN projects from FY 2015 to FY $2019 \ldots \ldots \ldots \ldots$







Figure 2.3. Contribution of sessions to APN website by major social media networks. . . . . . . . . . . 60

Figure 2.4. Top 50 downloaded products by type (Jan 2015 - Dec 2019) . . . . . . . . . . . . . . . 61

Figure 2.5. Page views on the APN Science Bulletin (web version) $\ldots \ldots \ldots \ldots \ldots \ldots \ldots \ldots \ldots \ldots \ldots \ldots \ldots \ldots \ldots \ldots \ldots \ldots$

Figure 2.6. Components of a communication plan (Source: Cassidy \& Ball, 2018). . . . . . . . . . . . .66

\section{TABLES}

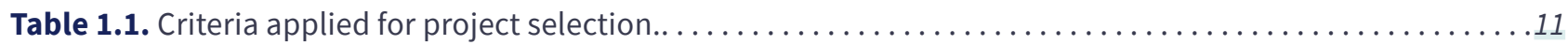

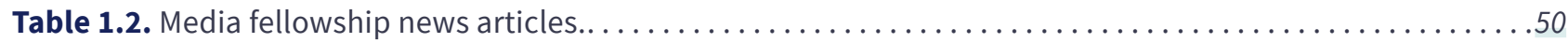

Table 3.1. Composition of subregional committees and their meetings in the 4 th Strategic Phase...........70

Table 3.2. Activities conducted with co-funding support from governments and organizations in member

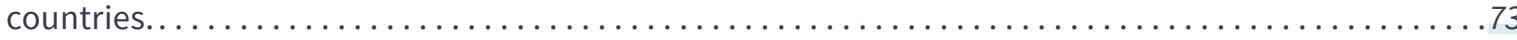


Chapter 1.

Science, policy

and capacity

development

report 


\section{Introduction}

APN continues to provide real benefit to its member countries in the Asia-Pacific region. The pillars of its work mainly focus on supporting regional research programmes in the global change sustainability space as well as supporting activities to strengthen the capability of scientists in the region to work in these fields thus enabling researchers to provide policyrelevant information to those dealing with issues of the region.

Chapter 1 provides an overview of the work conducted in the 4th Strategic Phase. It demonstrates how APN-funded projects are relevant to the four goals of APN, and APN's core strategies to achieve these goals, as outlined in the 4th Strategic Plan.

The chapter comprises five main sections: Research and capacity building and APN's call for proposals, project-based activities; activities organized by APN; capacity development of early-career professionals; and engagement with the international global change and sustainability communities. A brief conclusion follows, culminating in observations on APN's strengths, challenges and opportunities that are reflected in Chapter 4 of the report.

The report covers:

- Regional research and capacity building and APN's call for proposals

- Highlights of selected projects supported in the last five years that demonstrate the range and relevance of APN's core programmes within its portfolio

- Highlights of select activities from frameworks

- Activities organized by APN:

- Activities with the Hyogo Prefectural Government

- Science-policy dialogues

- Activities at the subregional level

- Capacity development of early-career professionals

- Global change and sustainability community engagement

- Collaboration and engagement with regional and global programmes and institutions such as WCRP, UNFCCC, IPCC and IPBES at the global level; and AIT, ANCST and APAN at the regional level

\section{Regional research and capacity building}

APN fosters the understanding of global environmental change through the implementation of regional-based research and capacity development activities. The network's activities promote policy-relevant research that improves understanding of the physical, biological and human dimensions of change in Earth system science that can also inform adaptation and mitigation decision-making. The APN research agenda has five broad themes that are interrelated and crosscutting:

- Climate change and climate variability

- Biodiversity and ecosystems

- Changes in the atmospheric, terrestrial and marine domains

- Resources utilization and pathways for sustainable development

- Risk reduction and resilience

In adopting transdisciplinary and interdisciplinary approaches, the research conducted under the themes has crossed the interface of natural, social, behavioural, economic, and political sciences. Further, APN continues to research on focussed issues that include climate adaptation, low carbon initiatives, and biodiversity and ecosystem services.

APN defines Global Change Research as "research on global change that involves the aggregation of natural and human-induced changes in the Earth's physical and biological systems that are significant at a global scale and its implications for sustainable development in the Asia-Pacific Region".

In 2016, APN adopted a new initiative to ensure that the topics highlighted in its calls for proposals are of significance at the subregional level. This is in line with APN's guiding principles of promoting both high scientific quality and regional relevance. APN subregional committee meetings provide opportunities for sharing knowledge and best practices and, at the same time, allow for dialogue and consideration of the collective global change and sustainability issues faced at the subregional level. There are four subregions in APN that include the Pacific, South Asia, Southeast Asia and Temperate East Asia. Chapter 3 provides an overview of the institutional makeup of the subregional committees established as organs of APN. 




Figure 1.1. Phrase cloud showing member country priorities (2016-2019).

Topics of global change significance are discussed at meetings of the Scientific Planning Group (SPG), and recommendations are presented at the Intergovernmental Meeting (IGM), the highest decision body of APN, for further consideration and approval by APN member countries. More recently, topics of significance discussed at the subregional committees to ensure that issues relevant at the subregional level are reflected in APN's annual call for proposals as priority issues for funding.

Adopting this strategy has provided an opportunity for APN to ensure that the research and capacity development it undertakes continues to be of high relevance to decision-making communities, particularly at subregional levels. The image to the right visualizes topics highly considered policy-relevant by the member countries in the period 2016-2019.

\subsection{APN calls for proposals: An overview}

APN's Mission Statement ${ }^{1}$ is to enable investigations of changes in the Earth's life support systems and their implications for sustainable development in the Asia-Pacific region through support for research and science-based response strategies and measures, effective linkages between science and policy, and scientific capacity development. APN, therefore, supports investigations that will:

1. Identify, explain, project and predict changes in the context of both natural and anthropogenic forcing;

1 https://www.apn-gcr.org/about
2. Assess the potential regional and global vulnerability of natural and human systems; and

3. Contribute, from the science perspective to the development of policy options for appropriate responses to global change and sustainable development.

Launched in April 1998 as a competitive process for funding under APN's comprehensive regional research programme, CRRP (formerly ARCP) provides funding opportunities to researchers in the Asia Pacific region. This programme continues to be the central scientific research pillar of APN to promote global change research and sustainability in the Asia-Pacific region. A second pillar, APN's capacity development programme (CAPaBLE), was established in 2003 following the landmark World Summit on Sustainable Development (WSSD) held in Johannesburg in 2003. These two pillars are the backbone of research and capacity building activities undertaken by APN. Throughout the 4th Strategic Phase, APN has continued to implement its annual calls for proposals for its two main pillars.

From time to time, APN implements short-term frameworks on focussed thematic areas. Currently, these are (1) Biodiversity and Ecosystem Services (B\&ES), (2) Low Carbon Initiatives (LCI), and (3) Climate Adaptation Framework (CAF). The Climate Adaptation Framework is currently ongoing, and projects are expected to be completed in the first year of the 5 th Strategic Phase (2020-2021). For the LCI Framework, a policy brief series of six reports was published in collaboration with the project leaders that provides useful policy-relevant information for policymakers and practitioners ${ }^{2}$. At present, for B\&ES, relevant proposals received under APN's annual call for proposals are assigned to the framework, as there is no specific funding allocation for this framework.

The procedure for submitting proposals (Figure 1.2) has been effectively streamlined and implemented entirely online via APN's online information system, APNIS. As proponents are required to register on the APNIS site before an application can be made, the system collects and stores registered information, providing a useful tool to track the interest of scientists, decision-makers, and practitioners across the region. The online advisory service, established in APN's 3rd Strategic Phase, is regularly used by applicants who have queries on the calls for proposals.

2 https://www.apn-gcr.org/r/lci-framework 




Figure 1.2. Process for calls for Proposals for APN's research and capacity development activities.

There are three main stages of the review that are undertaken by the members of the Scientific Planning Group (SPG) and Capacity Development Committee (CDC) for CRRP and CAPaBLE proposals, respectively. These are the review of Stage 1 summary proposals and the review of Stage 2 Full Proposals. At Stage 3, the CDC, SPG-SC and SPG gather in separate meetings to further discuss and select reviewed proposals for recommendation to the SC for funding. Additionally, when a proponent proceeds to Stage 2 and is invited to submit a full proposal, the same reviewers assigned to the stage 1 proposal are also assigned to review the full proposal. An important point to mention is the increasing contribution of external reviewers in the proposals review process. The number of proposals selected for funding and the rate of success is illustrated in Figure 1.3.

\subsection{Scientific research and capacity development projects}

The Collaborative Regional Research Programme (CRRP) is one of two main pillars of APN scientific activities. The programme fosters regional collaborative research and the international research community acknowledges CRRP (and its predecessor, ARCP) as a successful and useful mechanism that produces policy-relevant scientific knowledge, contributing to bridging gaps in global environmental change. While the average amount of annual financial is modest, the financial support has, as evidenced in the present report, successfully helped strengthen collaborative research of developing-country scientists in producing new scientific knowledge and improving scientific capacity.

APN's second pillar of activities is its capacity development programme (CAPaBLE), which is designed to enhance scientific capacity for global change and sustainable development in the



projects completed

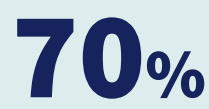

reported early-career scientist engagement

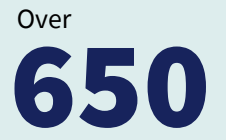

project outputs

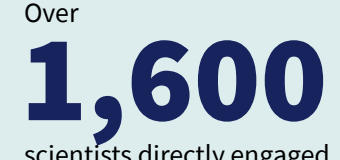

scientists directly engaged

Over



Over

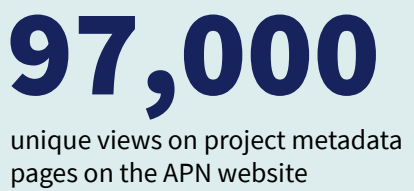

Figure 1.4. Projects by numbers. 


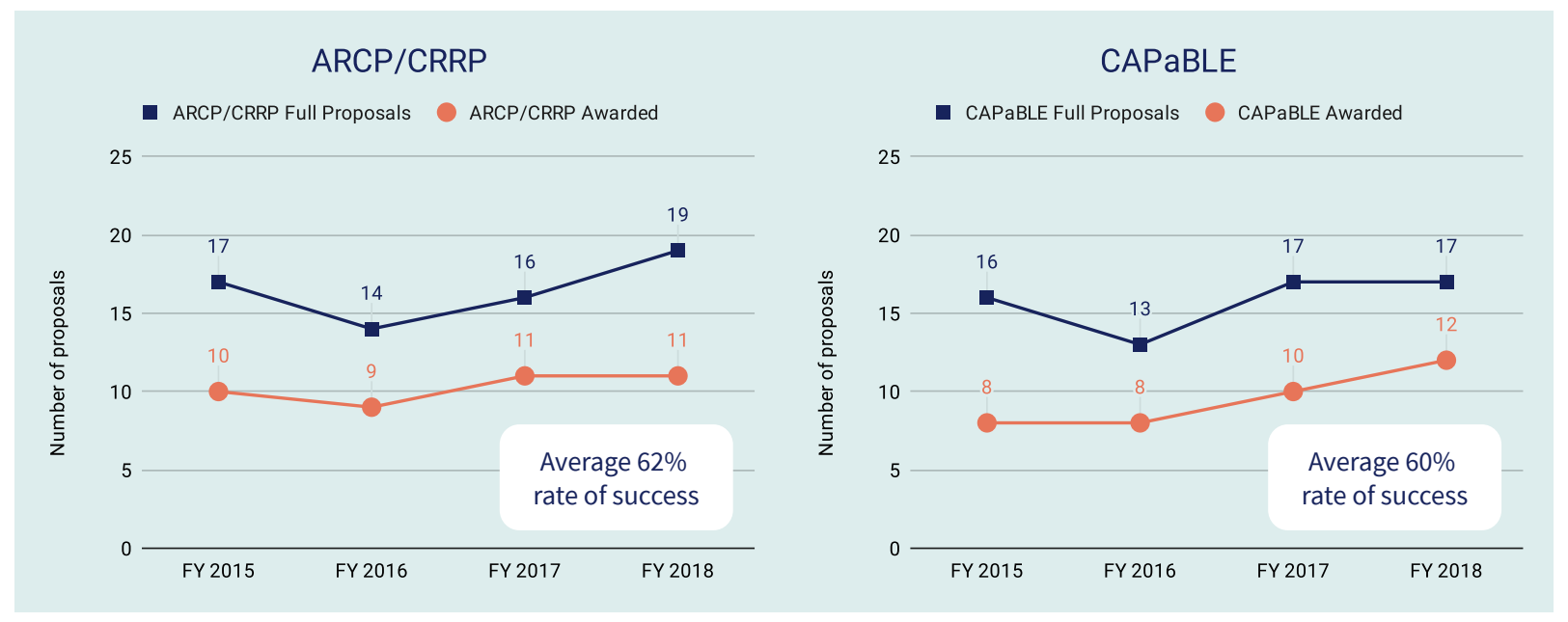

Figure 1.3. Call for Proposals: Full proposals submitted (blue line) and funded (orange line).

Asia-Pacific region. CAPaBLE is a well-received programme with high interest in both the policy and research communities. As evidenced in CAPaBLE projects, the positive feedback from decision-makers, researchers and ECS who have benefited from CAPaBLE reinforces the importance of capacity building in APN, particularly its second goal, which is to enhance capabilities to participate in global change and sustainability research and support science-based decision-making. This programme continues to meet the region's needs for scientific capacity development, particularly in developing countries.

During the 4th Strategic Phase, APN completed 119 projects selected through its core competitive calls for proposals, special calls for framework activities, including the CRYS programme. Figure 1.4 highlights the extent of engagement and outputs of activities conducted at the project-based level. Over 99,000 unique views have been recorded on project metadata pages (APN's web-based E-Library). Comprehensive information on the $\mathbf{1 1 9}$ projects is available in Appendix 1.

Figure 1.5 is a snapshot of the country engagement in projects from FY 2015 to FY 2019. While the involvement of researchers in Asia, particularly Southeast Asia, has grown in comparison with previous years (for example, Cambodia and Viet Nam), engagement of Pacific Island Countries, including Fiji, remains low. Strengthening the Pacific component of APN is crucial to continue to address its goals successfully. For this reason, more effort to engage the Pacific in APN activities is needed.

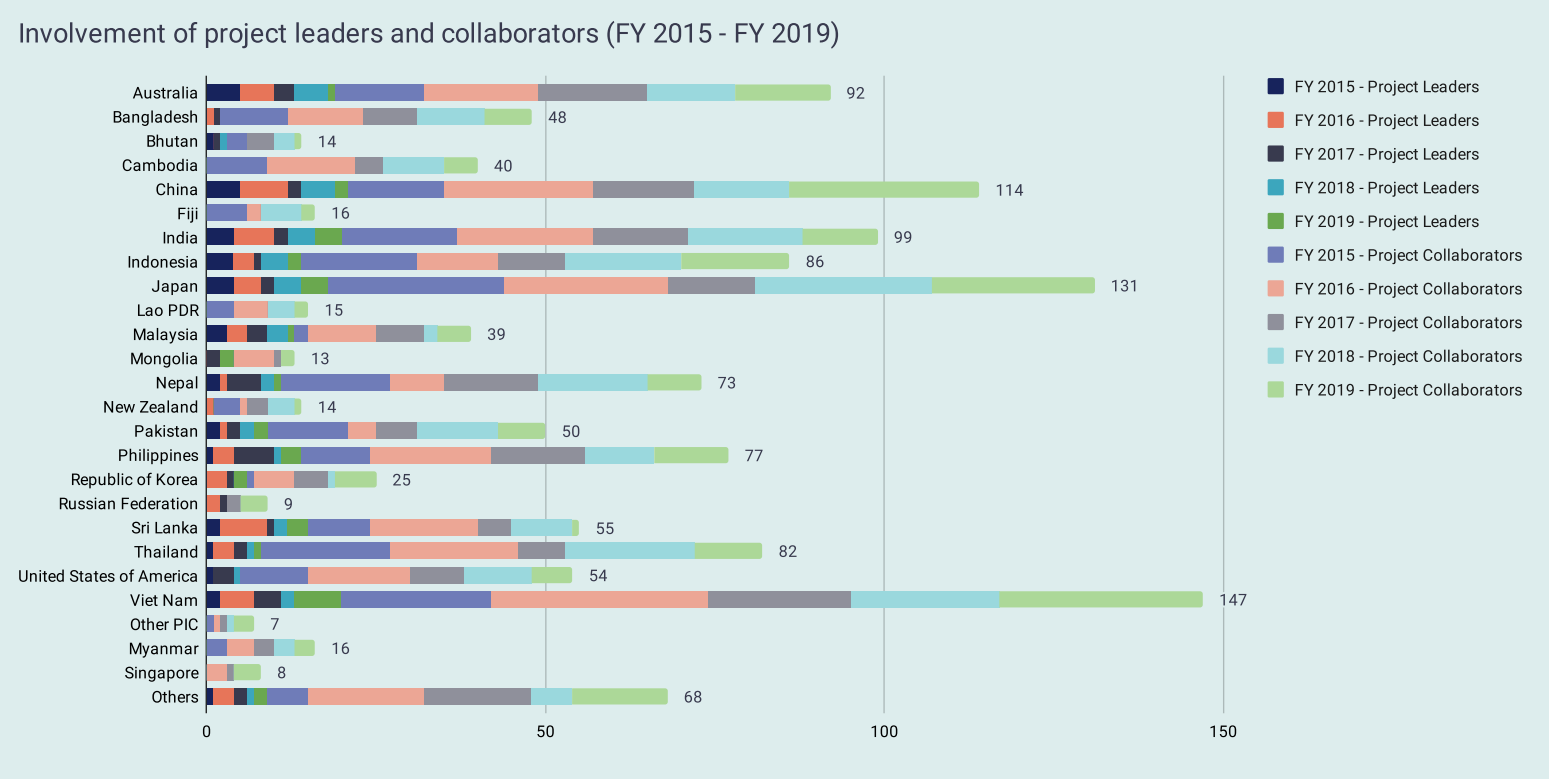

Figure 1.5. Snapshot of country engagement in APN projects from FY 2015 to FY 2019. 
Following a review by five experts from APN's SPG and CDC, 27 projects were selected for their significant contribution to the goals and objectives of APN. These projects were chosen against established criteria developed from APN's four main goals, and the agendas set out in the 4th Strategic Plan for research, capacity development, and communications and outreach (Table 1.1).
For the $\mathbf{2 7}$ selected projects, 191 unique products/ outputs were produced. These are illustrated in Figure 1.6, which breaks down the project outputs by year published and product type. Summaries of the projects are given with information on their relevance, outputs, and impacts they have had in the Asia-Pacific region. As of the end of April 2020, the number of citations and unique captures for these products is $\mathbf{2 , 0 6 8}$, and

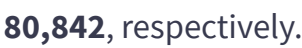

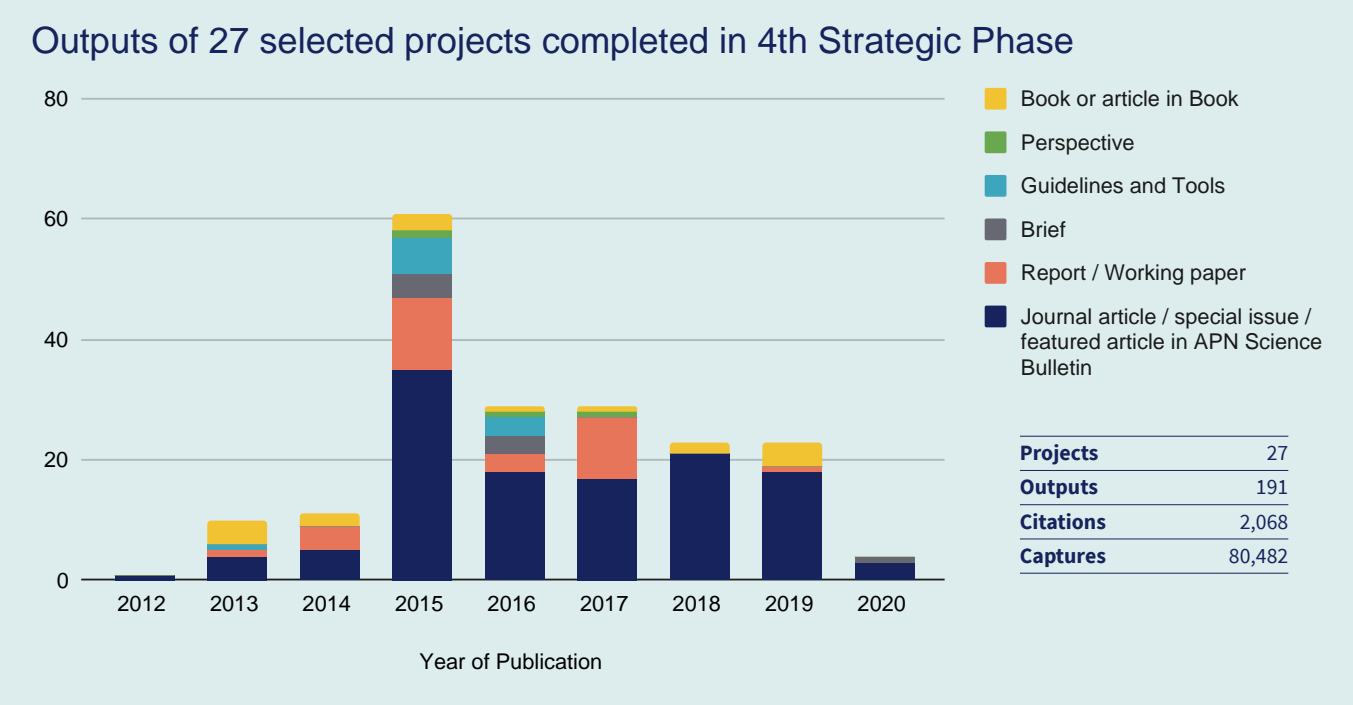

Figure 1.6. Output type and year published for the 27 selected projects.

\section{Contribution to APN goals in its 4th Strategic Phase}

Supporting regional and international cooperation in research and capacity development on global change and sustainability issues particularly relevant to the region (30\%)

Enhancing capabilities to participate in research on global change and sustainability 2 . and to support science-based decisionmaking (30\%)

Strengthening appropriate interactions among scientists and policymakers, and providing scientific input to policy decisionmaking and scientific knowledge to civil society and the public (20\%)

Cooperating with other global change and sustainability networks and organizations (20\%)

\section{Criteria applied}

1. Research or capacity building goals achieved

2. Project fulfils all APN funding requirements

3. Full participation of all identified project contributors

4. Project benefits a subregion or Asia-Pacific region
1. Peer-reviewed publications

2. Presentations at national and international meetings

3. Post-docs and students trained

4. Outreach and extension goals achieved
1. Project led to science-policy dialogue

2. Project outputs and products target science-based policy-making

3. Project led to useful and usable outcomes

4. Project addresses a major issue for the participating countries and region

1. Networks established and sustained

2. National and/or subregional collaborations formed

3. Project cited or contributory to IPCC or similar international reports

4. Project led to high visibility of APN as a scientific organization

Table 1.1. Criteria applied for project selection. 


\subsubsection{Collaborative Regional Research Programme (CRRP)}

The Collaborative Regional Research Programme (CRRP), formerly the Annual Regional Call for Research Proposals (ARCP), is one of the key scientific pillars of APN to encourage and promote global change and sustainability research in the Asia-Pacific region. In addition to enhancing the understanding of global change and its implications in the region, CRRP contributes to the scientific basis for the policymaking communities in the global change and sustainability arena. This competitive grant process selects the most important policyrelevant proposals for funding that addresses the critical thematic areas drawn not only from its strategic research agenda but also from discussions with government members to ensure the relevancy of the work. 


\section{CORDEX in Monsoon Asia}

- Project Page: https://www.apn-gcr.org/?p=4450

- APN Reference: ARCP2015-02CMY-Ailikun

- Project Leader: Ailikun, Monsoon Asia Integrated Regional Study (MAIRS), Institute of Atmospheric Physics (IAP), Chinese Academy of Sciences (CAS), China
ACTIVITIES: The project team trained about 130 ECS on climate modelling and downscaling in Kathmandu, Nepal; Bogor, Indonesia; and Beijing, China. They shared and exchanged data, experiences, and techniques on climate downscaling products to end-users with the WCRP CORDEX domains in Asia and organized science-policy dialogues focusing on climate adaptation during the training workshops. Practical training on various user modules such as hydrology, agriculture, economic impacts of climate change on agricultural production, land-use change, etc., were undertaken. The activities were designed to meet the requests of end-users on downscaled products covering a broad suite of issues including climate impacts, vulnerability, adaptation, natural variability and extremes events.

HIGHLIGHTS: The training activities on regional climate science considerably improved the capacity of early-career scientists to undertake climate research, the results of which can be utilized for vulnerable communities and ecosystems. With the technical improvements made to CORDEX, there now exists a real possibility for improving the current $50 \mathrm{~km}$ resolution to $25 \mathrm{~km}$ and even $12 \mathrm{~km}$ in other regions of Asia and the Pacific. The coordinated study of monsoon Asia's three regions will considerably improve the region's scope for climate research, vulnerability studies, responses to climatic impacts and APN's participation in UNFCCC activities. The activity has strengthened collaboration between APN, MAIRS and WCRP.






\section{Development of an evidence-based \\ climate change adaptation toolkit to help improve community resilience to climate change impacts in Uttarakhand, India}

- Project Page: https://www.apn-gcr.org/?p=4521

- APN Reference: ARCP2015-09CMY-Heath

- Project Leader: Lance Clive Heath, Sustineo/ Australian National University, Australia



$\square$ Community-based weather monitoring station in a village in the Ramgad watershed (photo: Prakash Tiwari).
ACTIVITIES: The project team developed the Ramgad Resilience Strategy using the ICLEI ACCCRN Process (IAP) toolkit. The IAP toolkit was applied in the rural Ramgad rural watershed in Uttarakhand, India.

Ramgad is the first rural jurisdiction to use the IAP, which produced over 40 resilience interventions for vulnerable communities. Further, a core climate and stakeholder group was established to implement the IAP; the degree of vulnerability and adaptive capacity was determined; over 40 rural intervention strategies were developed, and a recommendation was made for determining the effectiveness of the IAP toolkit in rural areas. Eight early-career scientists from Kumaun University were trained on using the IAP Toolkit. They also participated in Shared Learning Dialogues (SLDs) to identify risks concerning water supply, road connectivity, health, wellbeing and rural livelihoods, and forest resources.

HIGHLIGHTS: This project is of considerable value to the Himalaya-Tibetan Plateau's long-term implications for water, energy and food security. The project assisted communities in the Ramgad watershed to identify fragile rural systems, climate risks and vulnerable people and places, and to develop a series of resilience interventions. The IAP methodology or "workbook" used in the project is freely available on the ICLEI website. Results showed that adaptive capacity and resilience in Ramgad watershed are much lower compared to urban settings, perhaps because rural areas have fewer resources to measure threats, disruptions and impacts compared to their city counterparts. There is also a lack of information to help communities respond to climate-induced threats and disruptions. Because IAP was designed for use in cities and urban environments, the sensitivity of the Toolkit scoring system should be improved to reflect the rural setting better. Another limiting factor was data scarcity from existing weather stations. Overall, it was a unique project for APN, contributing to two thematic areas, and research and capacity development at the local level. The project outputs are to be published in an APN Special Issue Elsevier's Environmental Research Journal. 


\section{Coral reef and water quality status and community understanding of threats in the Eastern Gulf of Thailand}

- Project Page: https://www.apn-gcr.org/?p=4425

- APN Reference: ARCP2012-14NMY-Carter

- Project Leader: R.W. Carter, Sustainability Research Centre, University of the Sunshine Coast, Australia

ACTIVITIES: The following data and information needs were addressed in this study in the eastern Gulf of Thailand: (i) Baseline data on the status, especially health of coral reefs, including benthic community biodiversity and structure, key reef fish species and reef fish assemblages, (ii) Marine water quality parameters at coral reefs sites, population centres and freshwater flows, (iii) Fishing gear and trends in fisheries catch and effort for targeted species within the study area, (iv) Local fishing community perceptions of the status of fisheries and coral reefs between 2003 and 2013. This started with four research paradigms to explain reef status. Results of the evaluation were applied to the coastal islands in the Koh Chang archipelago in Trat Province, Thailand, Koh Kong and Preah Sihanouk Provinces in Cambodia and Phu Quoc Island in Kien Giang Province, Viet Nam. The team collected and analyzed data for coral reef fish type and whereabouts, benthic habitats, water quality, community-based surveys, and fish species and assemblages.



HIGHLIGHTS: The study found no appreciable change in corals dominating the benthos (bottom sediments of the sea). However, there is a $30 \%$ loss of seagrass, $16 \%$ loss of coral reefs and $16 \%$ loss of mangroves per decade resulting from increased levels of pesticides, fertilizer and sediment. Their $\mathrm{pH}$ measurements $\mathrm{pH}$ $<7.5$ ) suggest that the coral reefs are stressed by ocean acidification and low salinity. This is exacerbated by the increasing impacts of climate change - more intense storm activities further lowering salinity, coral bleaching, damage from the tourism industry, and increasing mechanical damage to the reefs. The project also identified old needs that have not yet been addressed such as (i) relaxation of the degrading pressures on coral reefs; (ii) encouraging coral reef resilience, (iii) providing stock to ensure capacity for reef recovery; (iv) fostering alternative livelihoods that are not resource exploitive or environmentally polluting; (v) developing sustainable, feasible and enforceable regulations that include the use of community knowledge and practices; (vi) establishing collaborative good governance, and (vii) monitoring reef health and success stories continuously for sustainable coral health. These are essential for a risk-reducing and resilience-enhancing approach for coastal systems. 


\section{Integrated solid waste management (SWM) system leading to zero waste for sustainable resource utilization in rapidly urbanized areas in developing countries}

- Project Page: https://www.apn-gcr.org/?p=4520

\section{- APN Reference: ARCP2015-12CMY-Sharp}

- Project Leader: Alice Sharp, Sirindhorn International Institute of Technology, Thammasat University, Thailand


Challenges in solid waste management practices in Ho Chi Minh City (HCMC)
ACTIVITIES: The major steps adopted in the project included: Development of train the trainer modules, baseline data collection, identification of solid waste management options, implementation of pilot projects, and SWM guidelines development in English and local languages. The objective was to identify appropriate integrated SWM systems for pilot trials that would contribute to zero-waste cities for Mongar, Bhutan and Ho Chi Minh City (HCMC), Viet Nam. This was achieved through field visits, stakeholder consultations and a pilot project carried out to ensure participation of a range of sectors. A train the trainer workshop was conducted in Bangkok, technological approaches to waste management developed, and pilot projects implemented in Bhutan and Viet Nam. Guidelines were developed for SWM practices in both local and English languages. Awareness-raising video clips were broadcast on local television and participatory workshops were held with stakeholders in both countries.

HIGHLIGHTS: Management of solid waste is a significant challenge both in households and municipalities. According to the project team, success factors for SWM include the collaboration of stakeholders, effective leadership, transparent management, and a prioritized approach to implementation depending on local conditions. The project achieved its overall objective of increasing the capacity of local stakeholders to improve existing SWM systems for sustainable development. In the two sites selected, the project team ensured the following sub-objectives were achieved: compilation of baseline data for technical, institutional, and financial situations SWM; identification of appropriate integrated SWM systems for various waste streams; scientific capacity development of local authorities via national workshops and guidelines; and development of a collaborative network for SWM in the region. The vernacular and English language editions of the guidelines is an excellent practical approach for effective waste management and should be encouraged as a best practice in other countries facing similar problems. 
Characterizing public and private adaptation to climate change and implications for long-term adaptive capacity in Asian megacities

Project Page: https://www.apn-gcr.org/?p=4461

- APN Reference: ARCP2013-26NSY-Patankar

- Project Leader: Archana Patankar, Regional Centre for Urban and Environmental Studies, All India Institute of Local Self Government, India

ACTIVITIES: The project focused on three cities of Mumbai, Bangkok and Manila and implementing a four-step process: (i) identification of adaptation measures through primary and secondary data collection for households and the commercial sector, including how they cope with recurring floods, what resilience adaptation measures they have in place and the costs involved; (ii) for the public adaptation measures, the team relied on secondary data obtained from government documents and reports; (iii) analysis of costs, benefits, cross-linkages between public and private adaptation, and participation of private sector in building public adaptation measures; and (iv) assessing the effectiveness of adaptation measures in light of recent floods in the three cities.
HIGHLIGHTS: This is an interesting project for climate adaptation involving the concept of Public-PrivatePartnership (PPP), which is increasingly being used for sustainable development. This study characterized public and private adaptation measures by using primary data from households, commerce/industries, and secondary data from government entities. Using their incurred costs, the burden on stakeholders, effectiveness over short to long-term and potential to enhance the future adaptation capacity, the team evaluated their effectiveness and contribution to long-term resilience. These findings have critical policy implications, in particular, the recurrent costs of adaptation and their short-term nature. Ample data is presented for effective science-policy interactions. Given the nature of current development, it is vital to ensure that the adaptive capacity of the cities to future climate risks is enhanced by the measures undertaken today. The policy environment for this is sensitive to the possibilities of maladaptation and thus offers excellent scope for follow-up.

\section{Public awareness,}

rigorous risk research and

aligned targets will help

policymakers to increase

resilience against natural

hazards. 


\section{An International Geosphere-Biosphere Programme (IGBP) Synthesis:}

\author{
Global environmental
}

change and sustainable development-barriers, needs and solutions to reducing vulnerability to global change for LDCs in the Asia-Pacific region

- Project Page: https://www.apn-gcr.org/?p=4303

APN Reference: ARCP2012-06CMY-IGBP

- Project Leader: Karen Smyth and Pauline Dube, IGBP, Sweden
ACTIVITIES: With the overall objective of enhancing capacity and generating policy-relevant information, the IGBP synthesis activity for Least Developed Countries (LDCS) and Small Island Developing States (SIDS) focused on the marine environment, coastal zone management, climate change extremes of drought and flood, and the role that indigenous knowledge systems can play. Information and experiences from both the grey literature and peer-reviewed journal articles were compiled and synthesized and the methodology incorporated capacity development through SLDs with fellow scientists, policymakers, stakeholders, and communities. The project had two main activities:

(i) An SLD in Maputo reviewed and developed a framework for the assessment methodologies through shared experiences; and (ii) An integrated literature review assessed relevant scientific project findings, case studies, policy reviews and adaptation practices as well as integrated interdisciplinary evidence.

HIGHLIGHTS: The project has allowed for new research through the integration of traditional and conventional practices for long-term solutions to climate extremes. A significant outcome of the project included the publication of ten peer-reviewed papers in the special issue of the Weather and Climate Extreme Journal of Elsevier. The approach to the work ensured the compilation of a synthesis that crossed scientific peer-reviewed research and traditional knowledge, culminating in a synthesis that can be used by the policy community, including UNFCCC climate change negotiations for LDCs and SIDS.

\section{The project collected, completed and interpreted scientific information, indigenous and traditional knowledge systems; ten peer-reviewed papers in a special issue of the weather and climate extreme journal of Elsevier.}






Farmer being interviewed in Ningxia, China

\section{Assessing land use functions for sustainable land management in Asian countries}

- Project Page: https://www.apn-gcr.org/?p=4555

\section{- APN Reference: CRRP2016-04MY-Zhen}

- Project Leader: Lin Zhen, Institute of Geographic Science and Natural Resources Research, Chinese Academy of Sciences, China
ACTIVITIES: A Land Use Function (LUF) approach was used to assess land use, economic, environmental and societal impacts on sustainability and policy implications relating to these changes. An analytical framework and indicator system were developed along with scenarios for quantitative assessment of policy impact on LUFs. Three sites in three countries of Japan, China and Bangladesh were chosen for implementing LUF approaches. Tools such as the Participatory Rural Appraisal (PRA), Key Informant Interview (KII), Framework for Participatory Impact Assessment (FoPIA), as well as satellite images, were used to generate quantitative data. Postgraduate students were also trained in modelling and research activities.

HIGHLIGHTS: Defined LUFs and their indicators at each site were developed. Land management scenarios were assessed for their impacts on regional LUFs, and an LUF policy brief was prepared. A capacity building programme was undertaken, resulting in the training of ECS in the modelling process. Best practices on land use and management were produced for the international audience, and research and collaboration networks were established among the countries engaged. These included collaboration with Future Earth's Global Land Programme (GLP) (formerly Global Land Project), the World Food Programme (WFP), the International Union for Conservation of Nature (IUCN) and the United Nations Environment Programme (UNEP), as well as NGOs and local governments in the study countries. Eight journal papers have been published as a result of this project. 


\section{Greenhouse gas budgets of South and Southeast Asia}

- Project Page: https://www.apn-gcr.org/?p=4298

- APN Reference: ARCP2013-01CMY-Patra/Canadell

- Project Leaders: Prabir K. Patra and Joseph Canadell; Research Institute for Global Change (JAMSTEC), Japan; Global Carbon Project (GCP), CSIRO, Australia

ACTIVITIES: The aim of this project was to compile and synthesize information relating to the production and role of greenhouse gas (GHG) emissions from climate-human systems. Mean estimates of GHGs balance at the regional scale and attribution to flux components were determined. The overall objective was to estimate the source and sinks of carbon dioxide $\left(\mathrm{CO}_{2}\right)$ and methane $\left(\mathrm{CH}_{4}\right)$ from both human and natural biospheric activities for South Asia. Such information is beneficial for the development of mitigation policies and to assist developing countries in negotiating their reduction targets by taking into account their biophysical characteristics. Workshops for data exchange and training on numerical model and analysis were incorporated as a key component of the project activities.
The project provided input to the Working Group I of the Fifth Assessment Report of the IPCC.

HIGHLIGHTS: This project undertook the most ambitious synthesis effort to date using global and regional datasets and model outputs to constrain regional GHG budgets of South and Southeast Asia, where the source/sink balance of GHGs has large uncertainties. Estimates of all major natural and anthropogenic carbon sources and sinks in South and Southeast Asia were determined using bottom-up and top-down methodologies and full carbon budgets for the two regions are available as an output of the project. The project has been able to create an international network of collaborators who are now working together beyond the APN grant, and so leaving a long-term legacy of APN's investment in supporting the establishment of robust and comprehensive GHG budgets. The project created an international network of collaborators and the published results were used in Chapter 6 of WGI of the IPCC 5th Assessment Report. 


\section{Assessing community risk insurance initiatives and identifying enabling policy and institutional factors for maximizing climate change adaptation and disaster risk reduction benefits from risk insurance}

- Project Page: https://www.apn-gcr.org/?p=4453

- APN Reference: ARCP2014-08CMY-Prabhakar

- Project Leader: SVRK Prabhakar; Institute for Global Environmental Strategies, JAPAN

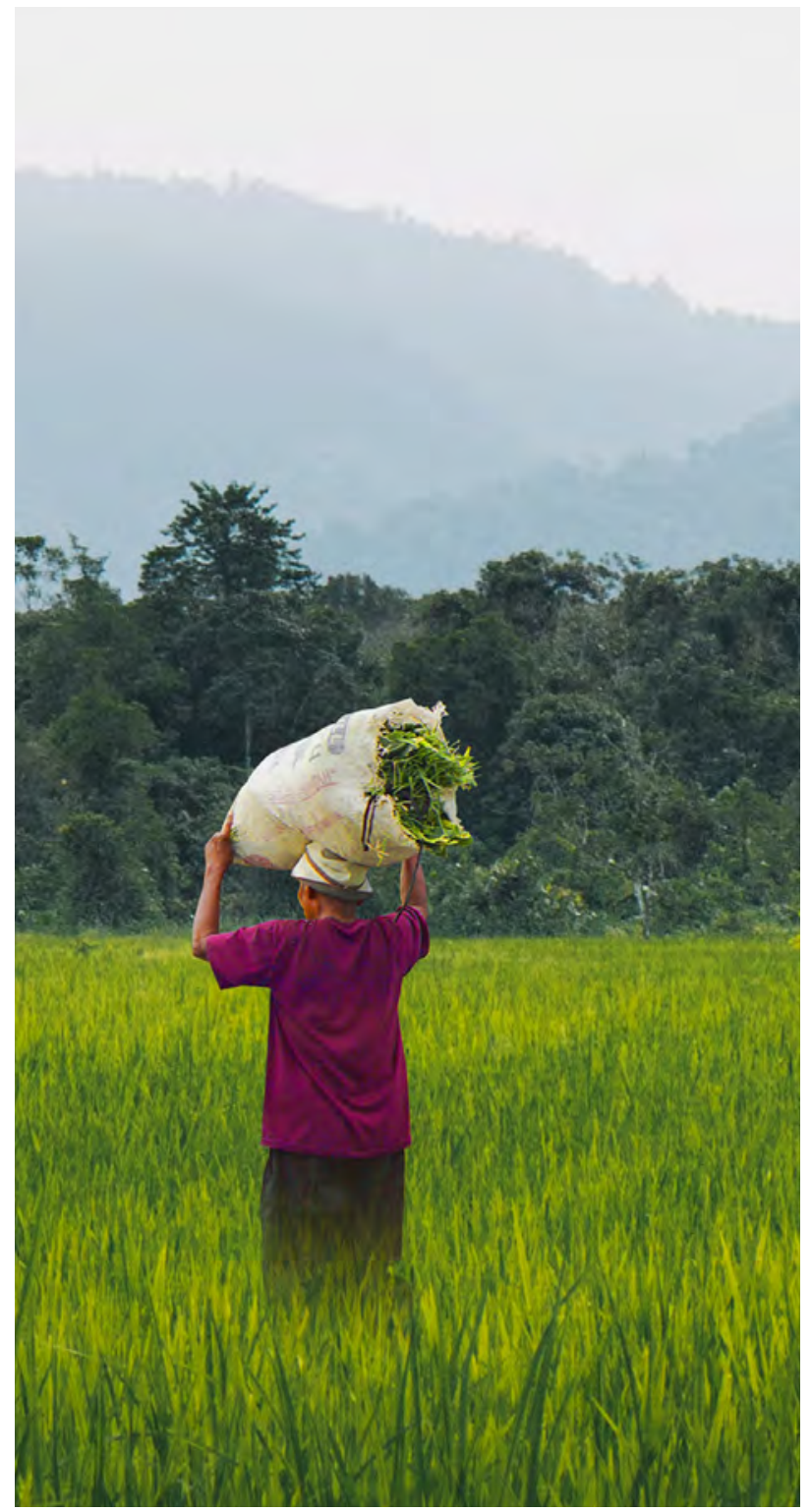

ACTIVITIES: This project assessed the benefits and barriers accrued through community-level risk insurance experiences in several Asia-Pacific countries. Inputs were also provided by the National Disaster Management Agency, Malaysia. A multi-country case study-based methodology was developed to examine country-specific circumstances of risk insurance, which was achieved through a regional consultation workshop and stakeholder surveys. A cost-benefit analysis was conducted to provide a basis of comparing the different scenarios of farmers with and without insurance, assuming with and without catastrophic events. Activities also included an on-going training course for eight early-career researchers to enhance their understanding of risk insurance and make an intellectual contribution to the project's outcomes. Policy-relevant fora were convened to formulate a policy agenda for the uptake of risk reduction insurance.

HIGHLIGHTS: The project identified and evaluated barriers that limited the penetration of risk insurance to reduce the vulnerability of communities to natural disasters. The project also identified interventions for greater insurance penetration leading to climate change adaptation and disaster risk reduction. The cost-benefit ratio of risk insurance for India, Philippines, Malaysia and Japan was quantified, thus allowing farmers and policymakers to make informed decisions associated with risk insurance. Major barriers were identified in scaling up risk insurance to include limited risk awareness and the inability to properly account for non-economic L\&D properly. The results confirmed that insurance might assist communities to recover and influence disaster risk reduction as the estimated benefits of insurance outweigh the estimated cost. 


\section{Risk and resilience in the Pacific:}

\section{Influence of peripherality on}

exposure and responses to global change

- Project Page: https://www.apn-gcr.org/?p=4554

\section{- APN Reference: CRRP2016-03MY-Nunn}

- Project Leader: Patrick D. Nunn

\section{ACTIVITIES: In order to understand the nature of} peripherality in PICs and its potential for enhancing the design of assistance for climate change adaptation, 73 communities in the Federated States of Micronesia and Fiji participated in a comprehensive questionnaire, the resulting data of which allowed Spaced out along coreperiphery gradients in these archipelagic countries, was administered in each community, data from which allowed the formulation of "peripherality indices" designed to capture community understanding of global climate change as well as their autonomous capacity for coping with environmental adversity. Results indicate that peripherality could be used in other geographical contexts, especially in developing countries to map community diversity and identify those that require most external, or least external, assistance. One thing became clear is how there are trends of increasing dependency (on funding and outside support) in most communities for coping with environmental adversity, including the effects of climate change. Given the likely funding futures, this trend is dangerous, even maladaptive, and should be reversed. It is in the interest of all actors to promote greater autonomy among such communities.
HIGHLIGHTS: Regarding peripherality, the research results show that peripherality captures community diversity, allows community risk and resilience profiling, and peripherality measurements can optimize future interventions. The project identified the diversity of community needs for achieving optimal adaptation to future climate change, and the communication of project results to governments and other agencies will result in better-aligned adaptation in the future. The project continues to actively disseminate the outcomes with over 30 outputs to date that include 14 journal articles and book chapters.

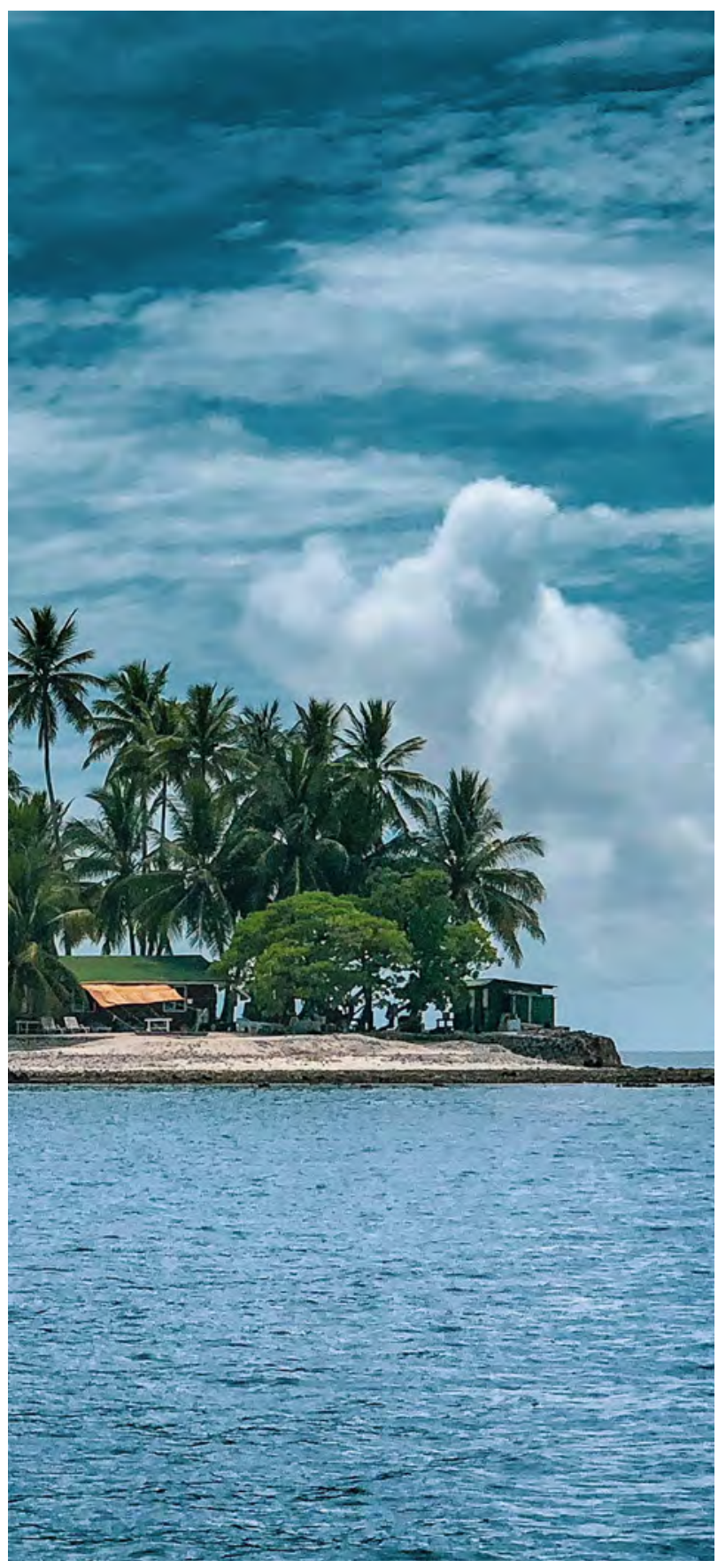




\subsubsection{Capacity Development Programme (CAPaBLE)}

CAPaBLE is a core programme of APN established in 2003 as a Type II Partnership Initiative under the World Summit on Sustainable Development (WSSD). The aim CAPaBLE is to enhance the capacity of scientists, policymakers and other stakeholders in the Asia-Pacific region, to identify and solutions to these issues through sustainable practices. CAPaBLE supports capacity development that enhances existing capacities of developing countries at three levels:

1. Individual-based capacity development

2. Group, organization, network-based capacity development

3. Societal, governance, system-level capacity development The objectives of APN's CAPaBLE activities are to perform functions, solve problems, adapt to and maintain capacity in global change and sustainability. APN encourages collaboration with developed countries to enhance developing country capabilities while, at the same time, ensuring ownership of initiatives by developing countries. The overall outcome of APN projects under CAPaBLE is the benefit provided to the region's developing countries to achieve sustainability. Ten CAPaBLE projects are highlighted in this section. 


\section{Facilitating the attendance, interaction, and training of young and developing nation scientists from Asia-Pacific at the ICRC- CORDEX 2016 conference}

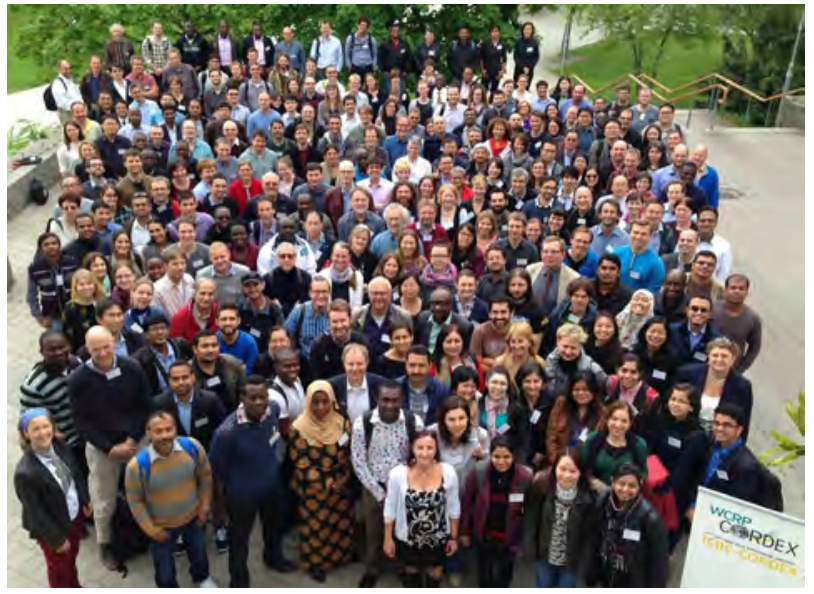

The conference shall

remain special for me as

a means for gaining new

skills and great exposure

to the international

community.
Project Page: https://www.apn-gcr.org/?p=4544

APN Reference: CBA2016-05SY-Kang

- Project Leader: Hyun-Suk Kang, NIMS, KMA, Republic of Korea

ACTIVITIES: Facilitated the attendance, interaction, and training of early-career and developing nation scientists from the Asia-Pacific region at the International Conference on Regional Climate. CORDEX is a programme within the World Climate Research Programme. As part of the conference, a special event for ECS promoted networking and mentoring for ECS embarking on a career in regional climate research. The focus of the event was science communication. Participants shared their thoughts and ideas and discussed and explained what their research entails with their peers in a simple and non-technical way. This led to the critical discussion of how to communicate research results in the policy arena in a way that avoids misinterpretation or miscommunication.

HIGHLIGHTS: About 90 participants from the Asia-Pacific region were supported to attend an important international meeting WCRP as part of its regional downscaling programme, CORDEX. This was an exceptional networking opportunity for ECS that enabled the establishment of career-long professional contacts. The project contributed to APN goals of enhancing regional cooperation and capacity and advancing climate science for societal needs. Participation via web streaming and social media made it possible for the broader audience to participate and interact remotely. ICRC-CORDEX 2016 offered a platform for capacity development, training, knowledge exchange and an opportunity for developing country ECS to expand their networks and build new relationships for future collaboration. 


\section{Adapting groundwater of Asian cities to climate change:}

\section{Bridging the science and} policy interface

- Project Page: https://www.apn-gcr.org/?p=4548

- APN Reference: CBA2016-07SY-Shrestha

- Project Leader: Sangam Shrestha, Asian Institute of Technology, Thailand
ACTIVITIES: The project assessed current and future climate scenarios, quantified changes in climatic drivers, analyzed the vulnerability of groundwater recharge systems to such changes, and formulated adaptation strategies to reduce groundwater resource vulnerability in these cities.

HIGHLIGHTS: According to the results, Ho Chi Minh City (HCMC) and Bandung are expected to receive less rainfall, while Lahore and Bangkok may expect more rainfall in the future. Observations from the Bangkok study showed that it is the only city in which minor fluctuations in future temperature are likely to be observed. Water balance/hydrological models were developed to simulate groundwater recharge and 23 adaptation options were created to increase groundwater management effectiveness in the four cities. In line with predicted rainfall patterns, groundwater recharge is expected to decrease in HCMC and Bandung, while projected to increase in Bangkok and Lahore.

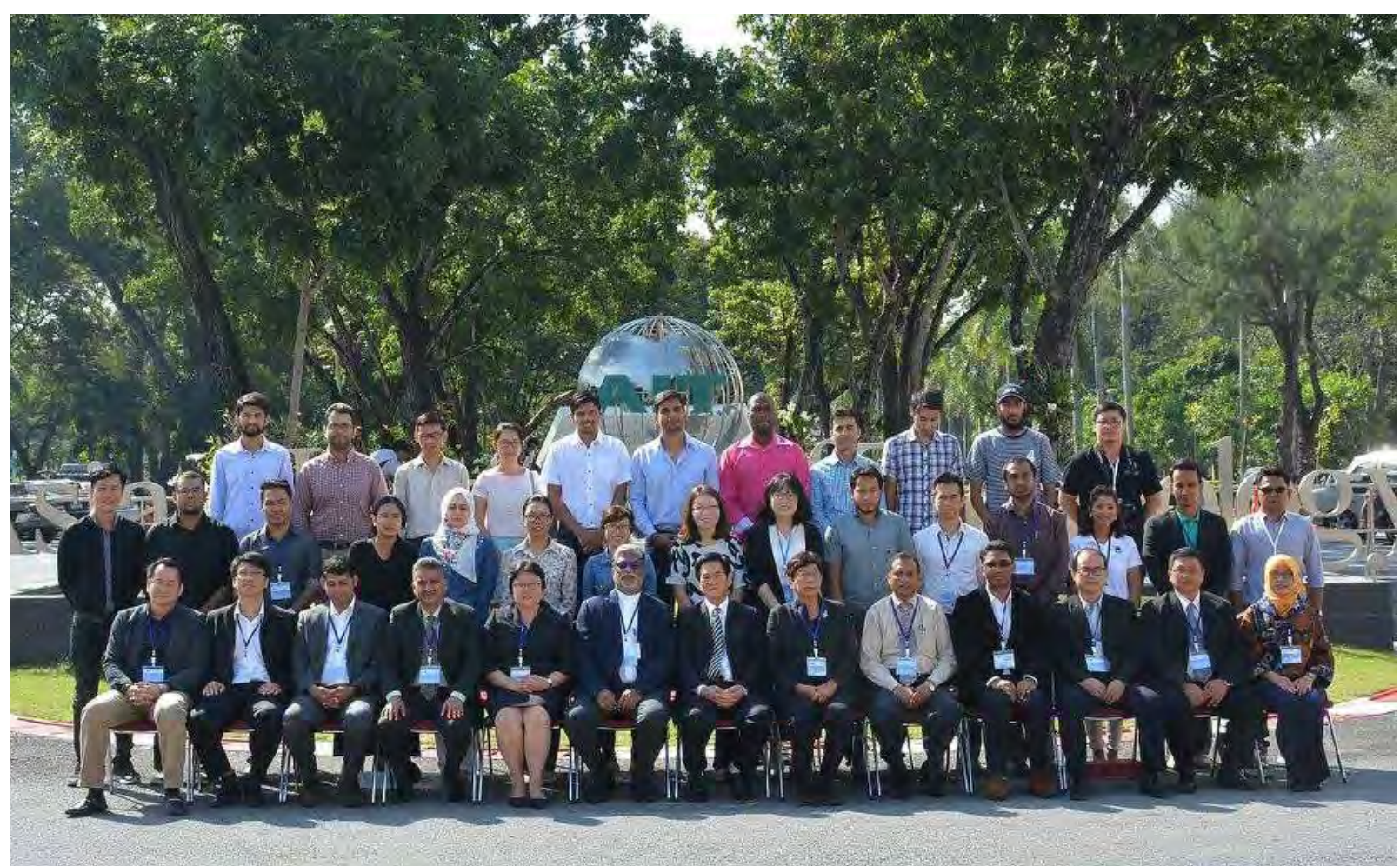




\section{Developing a training module to monitor forest cover and deforestation using advanced remote sensing techniques under UN-CECAR framework in support of REDD+ MRV system}

- Project Page: https://www.apn-gcr.org/?p=4526

- APN Reference: CBA2015-04NSY-Avtar

- Project Leader: Ram Avtar, United Nations University, Japan
ACTIVITIES: The project developed hands-on training modules to monitor forest cover and deforestation by using synthetic aperture radar data. Based on the modules developed, the project organized four training workshops in Cambodia, India and Sri Lanka to build the capacity of stakeholders in using synthetic aperture radars and optical sensors.

HIGHLIGHTS: A total of 133 participants from research institutions, government ministries, local communities and NGOs participated in the training activities. The Advanced Land Observing Satellite (ALOS) PALSAR was shown to be useful in monitoring biomass and its changes without limitations of clouds, and nationallevel biomass information is useful in implementing sustainable forest management practices required for REDD+. In addition, empirical, remote sensing and modelling studies can be helpful to generate biomass information for REDD+ MRV implementation.

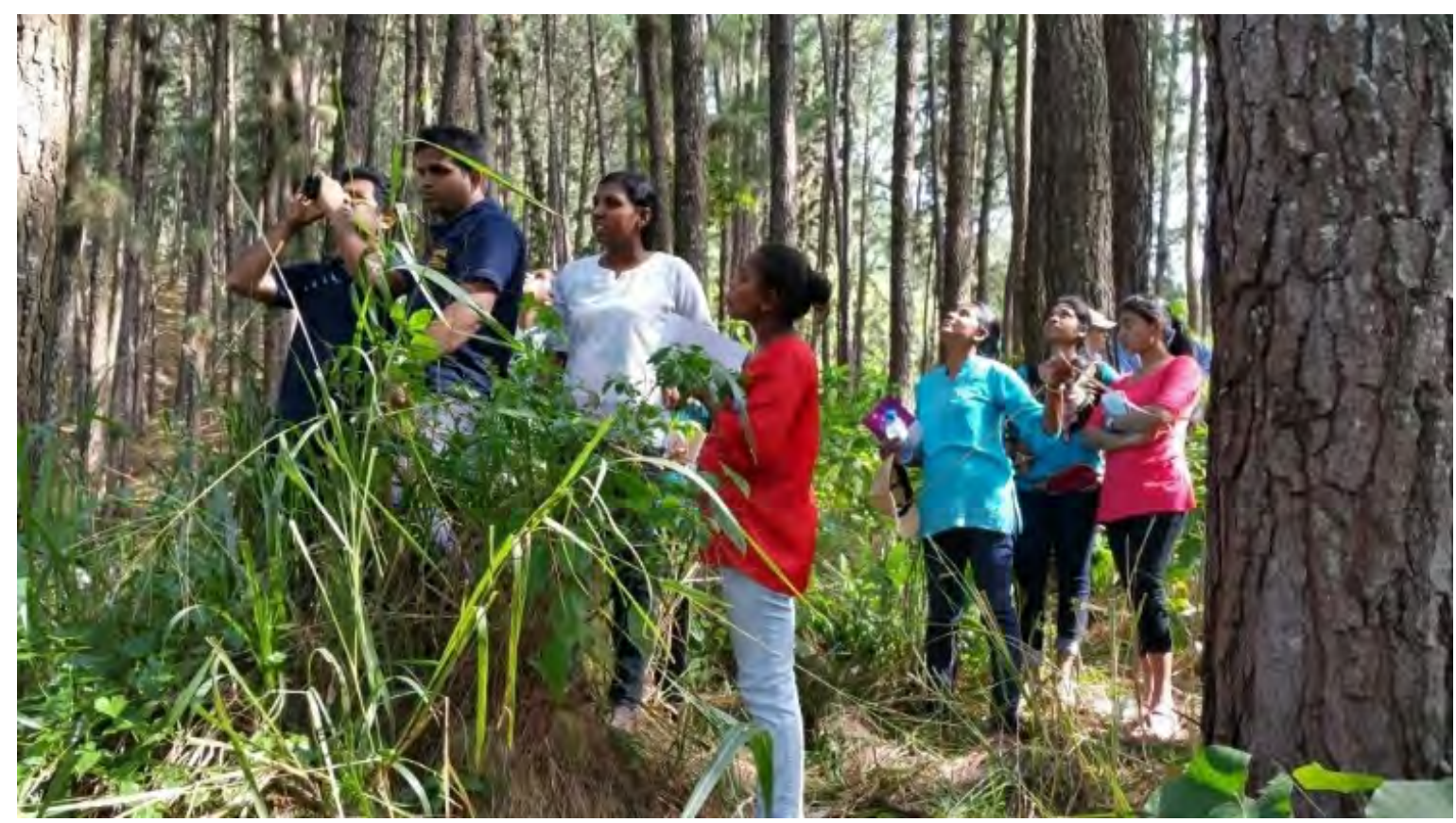

Hands-on training activity in India 


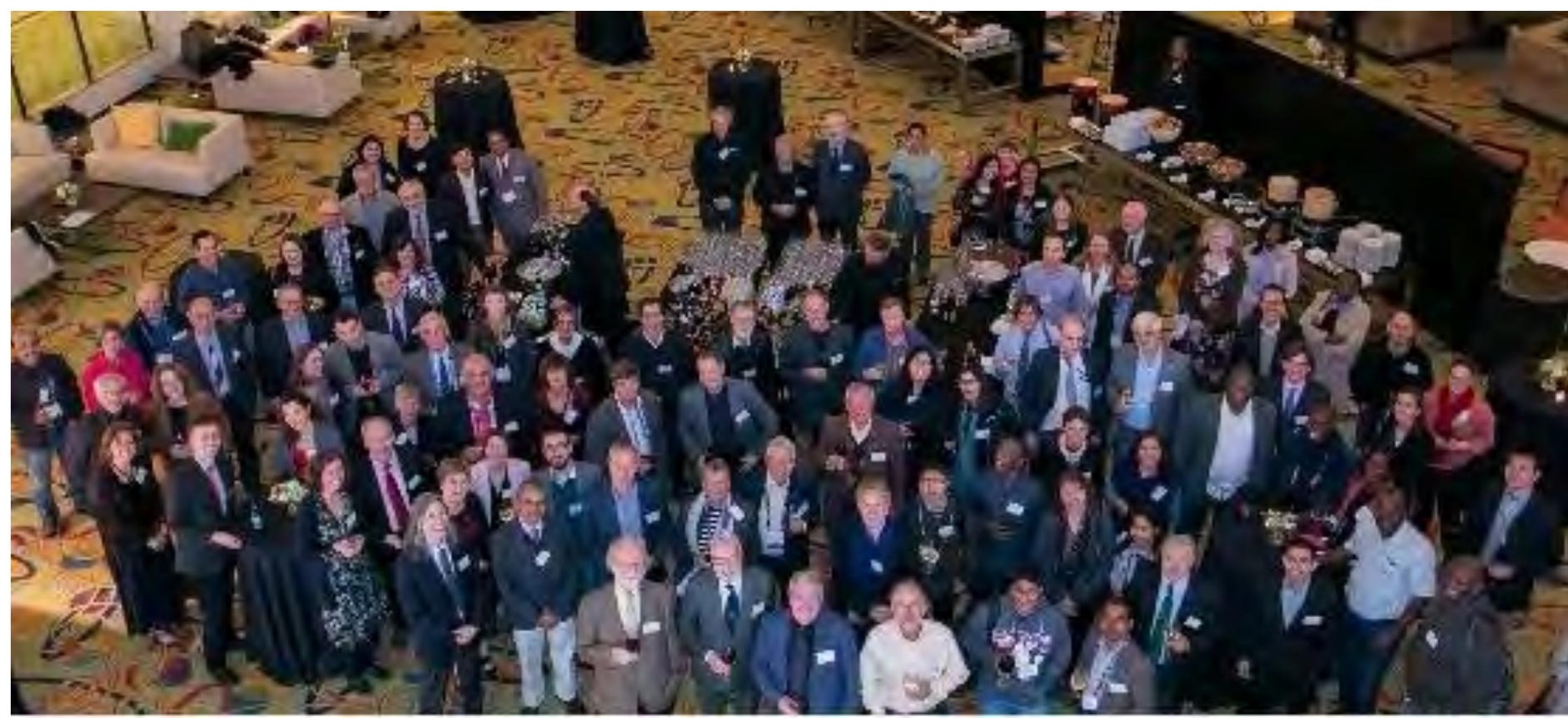

GLOBAL I C B P CHANGE

\section{Bringing early-career scientists to the fore:}

\section{Lessons learned from IGBP}

\section{landmark synthesis}

- Project Page: https://www.apn-gcr.org/?p=4527

- APN Reference: CBA2015-05NSY-Seitzinger

- Project Leader: Sybil Putnam Seitzinger, IGBP, Sweden
Science for a sustainable plane
ACTIVITIES: The project supported ten ECS from the Asia-Pacific region to attend the IGBP young and earlycareer scientists workshop at the annual American Geophysical Union (AGU) Fall Meeting in San Francisco in 2015. The event was held in collaboration with Future Earth as a way of disseminating information not only of the landmark work of IGBP spanning two decades but how IGBP would transition to Future Earth.

HIGHLIGHTS: IGBP used the occasion as an opportunity for developing country ECS to interact with the global environmental change community and senior personnel from IGBP and Future Earth. IGBP worked closely with Future Earth, now the new home for the next generation of interdisciplinary science research efforts, to develop and deliver a range of activities associated with the IGBP landmark synthesis event. 


\section{Pan-Asia Risk Reduction (PARR) Fellowship Program}

- Project Page: https://www.apn-gcr.org/?p=4515

- APN Reference: CBA2014-13NSY (AOF)-PARR

- Project Leader: Hassan Virji, International START Secretariat, USA

ACTIVITIES: The Pan-Asia Risk Reduction (PARR) Fellowship Program offered unique opportunities in research, training and education for Asian researchers, practitioners and policymakers to enhance their capabilities to advance and apply knowledge on critical issues of global change and risk reduction in Asia.
HIGHLIGHTS: This project enabled a cadre of earlycareer Asian scientists and professionals to obtain an advanced understanding and training in the management of the complex relationships between Global Environmental Change and human and environmental security. The project also strengthened the capacities of a spectrum of regional institutions (e.g., universities, research institutions, NGOs, government agencies, the private sector) to provide relevant opportunities for inter- and transdisciplinary research, education and application; and to nurture a collaborative and sustainable network of such individuals and institutions so that it becomes an active resource for promoting and facilitating future research, decision-making, and action in and for the region. The project also fostered South-South collaboration, exchange of information, knowledge and experience of the PARR fellows.
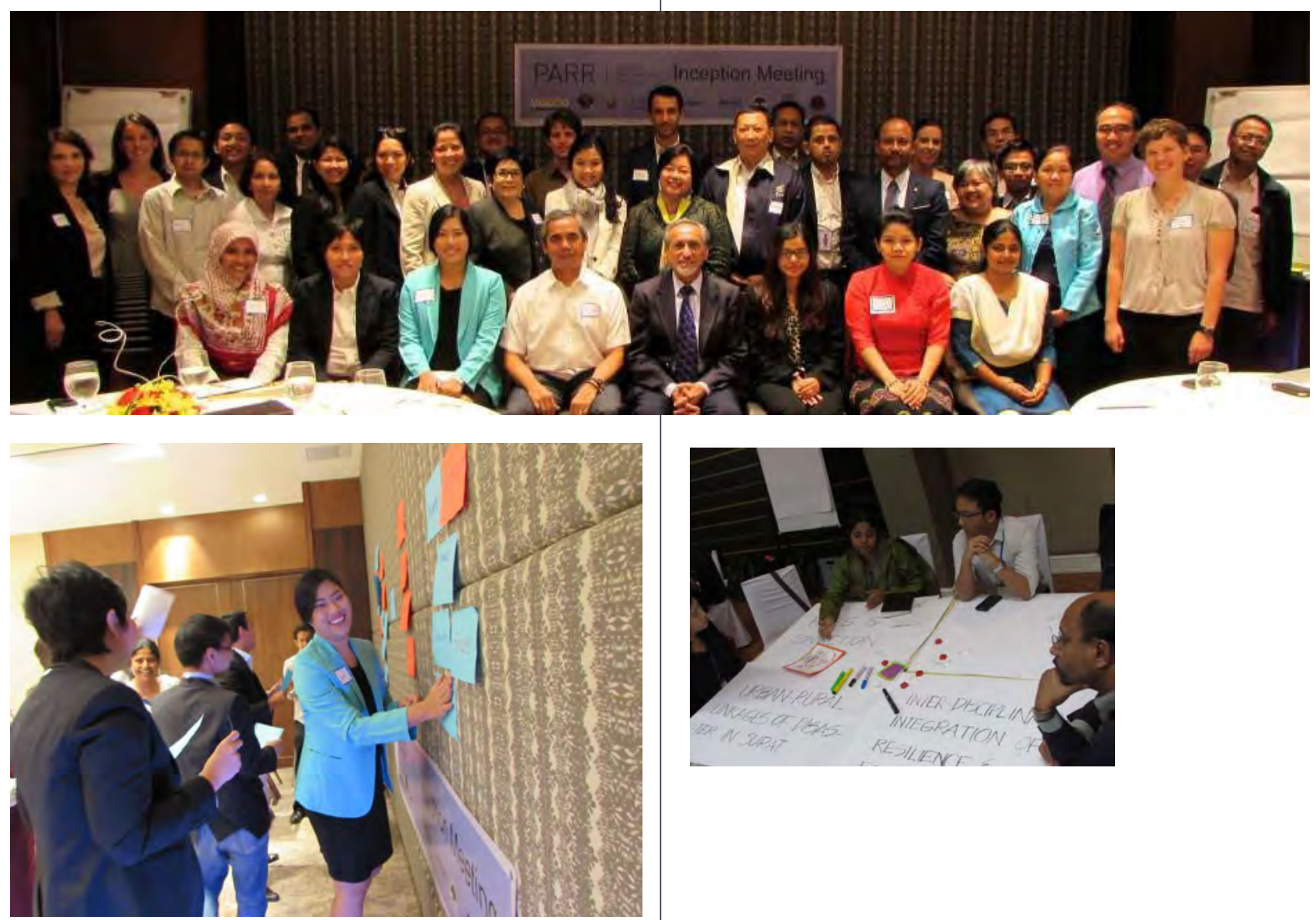


\section{Integrated, resilience- based planning for climate change mitigation and adaptation in Asia- Pacific cities}

Project Page: https://www.apn-gcr.org/?p=4531

- APN Reference: CBA2015-08NSY-Sharifi

- Project Leader: Ayyoob Sharifi, Global Carbon Project (Tsukuba International Office), National Institute for Environmental Studies, Japan



ACTIVITIES: Two significant activities were undertaken: (i) a comprehensive review of urban resilience literature, and (ii) a workshop that served as a learning opportunity and capacity building activity. A literature review was conducted to identify major resilience criteria and develop an integrated framework for assessing urban resilience, which was useful in providing a theoretical basis for the study. The workshop, on the other hand, convened scholars from various disciplines to discuss strategies for incorporating resilience thinking and climate change adaptation and mitigation into urban decision-making and planning process. The presentations and practical hands-on sessions encouraged active engagement among the participants to discuss important issues towards the development of a resilience assessment tool.

HIGHLIGHTS: The project enhanced local and regional scientific capacity of the leading researchers involved in the project and those early-career scientists and early-career professionals who attended the workshop. The several working groups that were organized during and after the workshop led to the establishment of a network of experts who are committed to exploring joint research in urban resilience. In terms of research contributions, five peer-reviewed publications have already been published in open-access scientific journals demonstrating the gaps in knowledge that the project is able to fill. These research outputs, including the metrics and assessment framework that were developed, provide valuable decision support tools that can aid policymakers in decision-making. All these are critical to ensure that society is equipped with the appropriate knowledge, tools and capacities address the impacts of climate change and ensure that we build the kind of resilience that is necessary to develop sustainably. 


\section{Atmospheric Circulation Reconstructions over the Earth (ACRE) Southeast Asia:}

\author{
Towards new weather
} and climate baselines for assessing weather and climate extremes, impacts and risks over Southeast Asia

- Project Page: https://www.apn-gcr.org/?p=4476

\section{- APN Reference: CBA2013-03NMY-D’Arrigo, CBA2014-01CMY-D'Arrigo}

- Project Leader: Roseanne D'Arrigo, LamontDoherty Earth Observatory, Columbia University, USA

ACTIVITIES: This initiative started from the development of a data inventory across the region which led to the formal project launch in the form of parallel workshops in Malaysia and Indonesia. The scope of the activities broadened to facilitate "the recovery of historical instrumental surface terrestrial and marine global weather observations to underpin $3 D$ weather reconstructions (reanalysis) spanning the last 200-250 years for climate applications and impact needs worldwide. Led by a consortium of nine core partners" ${ }^{3}$, and, in this context, links were forged with different meteorological organizations in the region and data rescue infrastructure was established. Digitization work was completed, and the project data, workshop results, etc. are on the ACRE website.

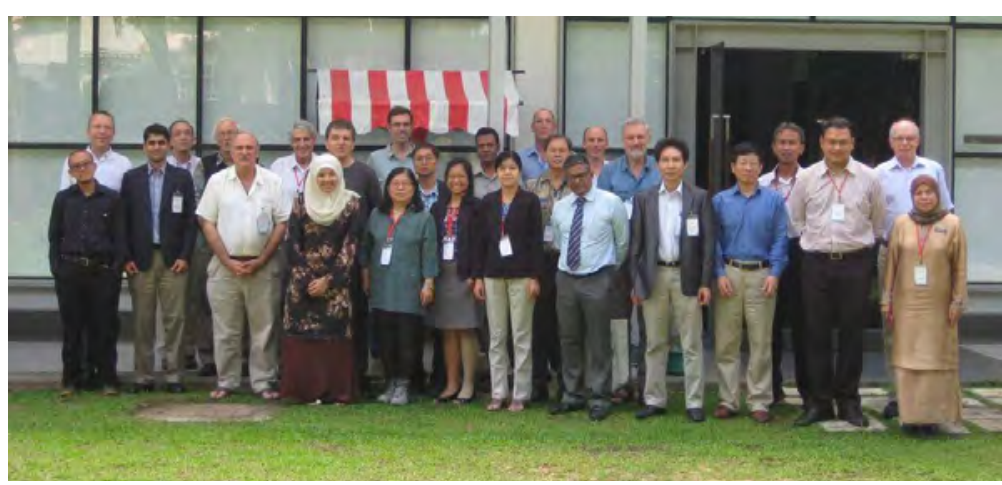

Meeting of the minds at the ACRE SEA Workshop, National University of Malaysia, May 2014.

HIGHLIGHTS: By closely working with the different Southeast Asian institutions, archives, agencies and National Meteorological Services (NMS), the project has helped build the scientific capacities for improving and extending historical, instrumental, documentary, and paleo databases of Southeast Asian weather and climate for production models and other useful applications. The work entailed research into sources of historical data and the recovery of extant documents in global archives and repositories. These datasets will contribute to the generation of highquality, high-resolution historical dynamical weather reconstructions (reanalyzes) that can be tailored or downscaled to seamlessly flow into other climate applications. In providing these new baselines and making them available and accessible to scientists and policymakers across the region, it becomes more feasible to project, simulate and address weather or climate extremes, impacts and risks in ways and over timespans not previously possible. ACRE SE Asia is unique in that no other organization similar to this exists in the region, with the same goals and scope of work. The overall initiative and the outputs that were generated are critical in advancing the physical science basis to understand better how climate is changing, considering all the uncertainties that surround its complex and dynamic process. 


\section{Capacity building for conservation of biodiversity and ecosystem services of wetlands in relation to Global Change}

- Project Page: https://www.apn-gcr.org/?p=4490

APN Reference: CBA2014-05NSY(B\&ES)-Gopal

- Project Leader: Brij Gopal, National Institute of Ecology, Centre for Inland Waters in South Asia, India

ACTIVITIES: The project focused on building the capacity of policymakers and other relevant stakeholders in conducting a rapid assessment of biodiversity and ecosystem services of wetlands in the Freshwater Ecoregions of the Ganga-Brahmaputra basin. Three workshops were organized in Kolkata, Guwahati and Kathmandu where the biodiversity and ecosystem services of their wetlands were assessed, with interactions with the local communities. Appropriate guidelines were prepared for the rapid assessment of major biodiversity category and main ecosystem services groups. A policy brief highlighting the ecosystem services of different kinds of wetlands and the relationships with biodiversity was disseminated at a concluding workshop with the participation of senior policymakers. A web page was designed with a database capability for setting up an online network of individuals and institutions interested in wetlands, their biodiversity and ecosystem services, anywhere in Asia.

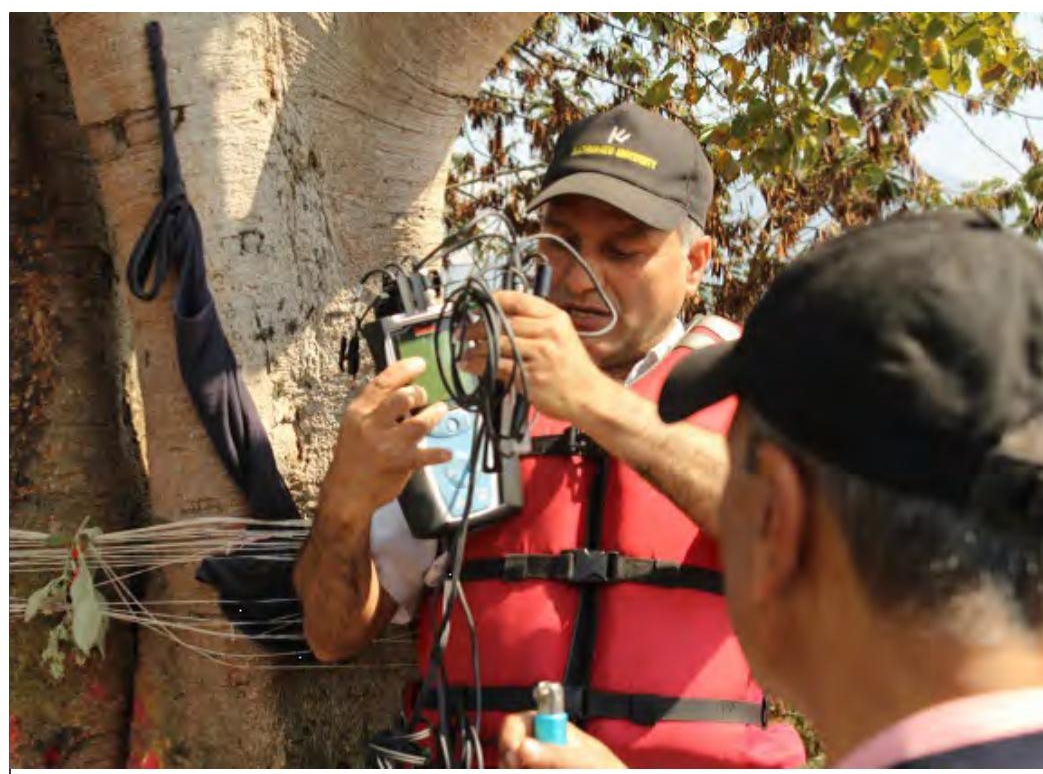

Fieldwork conducted at Lake Nagdaha

HIGHLIGHTS: The three capacity building workshops brought together more than 170 early-career researchers, senior scientists and experts, wetland managers, representatives of non-governmental organizations (NGOs) and government agencies, and policymakers to understand and discuss issues related to wetland biodiversity and ecosystem services management. These helped enhance their understanding of the problems and build their capacities to better manage and also monitor changes caused by land use/land cover change and other anthropogenic activities in and around the wetlands. The project has established a model that can be replicated and upscaled to other areas in India and neighbouring countries to ensure the integration of wetland concerns into national and regional policies for water resources management and other development projects. As for the online database, it facilitated stronger regional and international collaborations in terms of sharing of research data and forging new partnerships. Wetlands are recognized by the Ramsar Convention as essential for the critical role they have in the water cycle and climate change. If other initiatives, similar to this project, can be done in other countries in the region then we can optimize the contribution of wetlands and their rich biodiversity in keeping with the goals of the UN Convention on Biological Diversity (CBD) as well as the SDGs. 


\section{WCRP-ICTP Summer school on attribution and prediction of extreme events}

- Project Page: https://www.apn-gcr.org/?p=4522

\section{- APN Reference: CBA2014-08NSY-Koshy}

- Project Leader: Kanayathu Chacko Koshy, Centre for Global Sustainability Studies, Malaysia

ACTIVITIES: Focussing on 'Attribution and Prediction of Extreme Events' the summer school trained ECS who demonstrated outstanding potential in new analytical techniques to understand better observed and future changes in extremes and to attribute observed variability to extremes. The activity developed participants' skills to simulate scenarios in order to address important societal and scientific questions on extreme events that are receiving increased attention from the public and policymakers. Thirty-five international students attended, ten of whom were from Asia-Pacific developing countries. The school provided an exclusive learning opportunity that explored a variety of modalities of self-study, computer-based group activities, and peer-peer presentations. Skills enhancement to develop key data resources to place current extremes into a historical context were an integral part of the curriculum, and provided insights into near term predictions of flooding, drought, heatwaves, etc., thus transferring knowledge on improved planning and response to climate disasters.

HIGHLIGHTS: The summer school was the first of a series of capacity development activities on WCRP Grand Science Challenges towards training a cohort of ECS and practitioners in fostering their vocational training and techniques for policy outreach, particularly in their home countries. With WCRP's reputation in climate science and ICTP's experience in providing international training, the school attracted a range of sponsors. Given the unusual climatic conditions the global community is experiencing, and the resulting economic and human losses in AsiaPacific countries, the skills developed by the students to better understand observed data and scenarios of future changes in climate extremes are very timely. A special issue in the Elsevier journal 'Weather and Climate Extremes' was published, with seven papers coming from the summer school. Data and information generated are available on the school website.






\section{IMBER ClimEco4 \\ Summer School:}

Delineating the issues of

climate change and impacts to

marine ecosystems-Bridging

the gap between research,

assessment, policy and

\section{management}

Project Page: https://www.apn-gcr.org/?p=4486

APN Reference: CBA2014-11NSY (B\&ES)-Zhang

Project Leader: Jing Zhang, East China Normal University, China

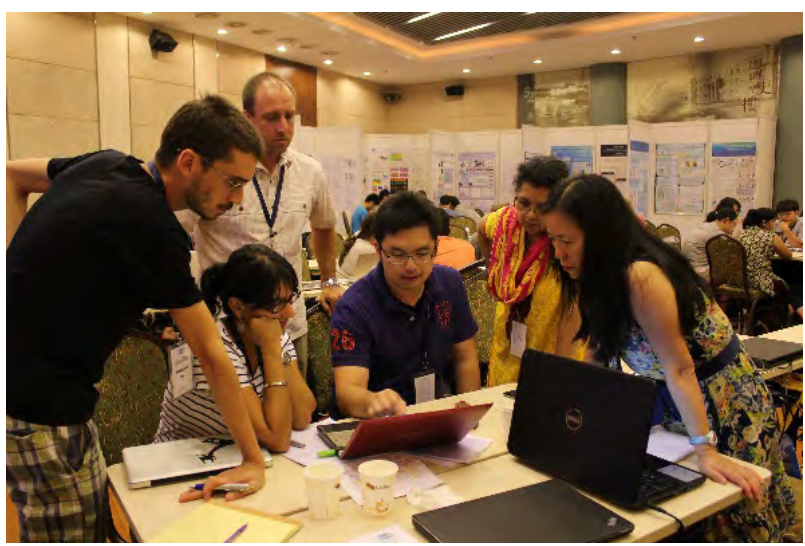

Peer research group activities

ACTIVITIES: The IMBER summer school comprised a broad range of social and natural scientists and specialists, including marine biologists, oceanographers, fisheries management specialists, ecologists, ecosystem modellers, social scientists and bioeconomists. The hands-on nature of the training, limited participation to 60 students who represented a range of disciplines from 26 countries across five continents. The course comprised lectures, practical exercises using different models and statistical techniques, and group projects that utilized techniques and methods to analyze data sets in socio-ecological systems. Trainees had the opportunity to share and discuss their own research activities with their peers.

HIGHLIGHTS: IMBER ClimEco4 Summer School contributed to building the scientific capacity of the next generation of multi-disciplinary marine researchers who are working at the interface of natural and human systems. The participants learned new techniques to evaluate climate change impacts on marine ecosystems and how to transform data into usable products, tools or advice. This will contribute to the improvement of information and knowledge transfer in global change research and help effectively manage the impacts and consequences to human and marine systems. The Summer School is also instrumental in expanding the participants' international and interdisciplinary networks that created more opportunities for collaborations in the future. The knowledge and skills gained, and the collaborative opportunities provided will contribute to bridging the gap between research, assessment, policy, and management at different scales. 


\subsubsection{Frameworks}

APN launched its first framework on Low Carbon Initiatives ( $\mathrm{LCl}$ ) to enhance mitigation across countries in the region towards the global vision for a low carbon, sustainable future and supported regional research, capacity development and outreach activities in the context of low carbon development. The second focussed activity, the Climate Adaptation Framework (CAF) identified needs and gaps for climate adaptation by adopting a needs-oriented and user-centred approach. In 2012 and 2013, a series of APN meetings and workshops identified important gaps in the region that could be addressed through comprehensive scientific research, capacity building and science-policy mechanisms. Two independent calls for proposals were launched, the first focussing interactions between adaptation, disaster risk reduction and loss \&damage. The second call adopted a broader range of adaptation themes. A third focussed activity, the B\&ES framework was developed as a partnership endeavour to address four thematic gaps of identifying drivers and pressures for biodiversity change that influence ecosystem services; assessing the impacts of biodiversity loss and vulnerability to the shrinking of ecosystem services; adaptation, response and mitigation of depletion of B\&ES; and prediction of changes in B\&ES through modelbased scenarios.

The frameworks were established to improve the input of sound scientific knowledge into policy-and decision-making processes focussing on new and emerging issues. All three frameworks adopted partnership approaches, which was considered a crucial component for success. In addition, these frameworks are APN's response to stakeholders' requests to enhance dialogue between science and policy that are relevant to APN and the Asia-Pacific region. Activities conducted under the frameworks follow similar approaches to the core programmes of APN. 


\subsubsection{Climate Adaptation Framework (CAF)}

Climate change adaptation has become one of the principal foci of UNFCCC, particularly for developing country parties. At COP17 in South Africa (2011), parties reaffirmed the Cancun Adaptation Framework and agreed on modalities for the Adaptation Committee. Supported by the Hyogo Prefectural Government, APN conducted a scoping workshop that explored ways to enhance adaptation action and develop capacity on adaptation issues. Needs, gaps and lessons for climate adaptation in the Asia-Pacific region were identified. A needs-oriented and user-centred approach emerged as a key message that was further discussed at APN's 18th IGM resulting in the establishment of the Climate Adaptation Framework (CAF). Two rounds of open calls for proposals called for proposals on regional research activities with a capacity element; capacity building activities at regional, national and local scales; and joint activities with partner organizations and networks. In the 4th Strategic Phase, 12 CAF projects have been completed, and three are highlighted in this section.

\section{Addressing non-economic loss and damage associated with climate change: Learning from the recent past extreme climatic events for future planning}

- Project Page: https://www.apn-gcr.org/?p=4492

APN Reference: CAF2015-RR08CMY-Chiba

- Project Leader: Yohei Chiba, Institute for Global Environmental Strategies, Japan

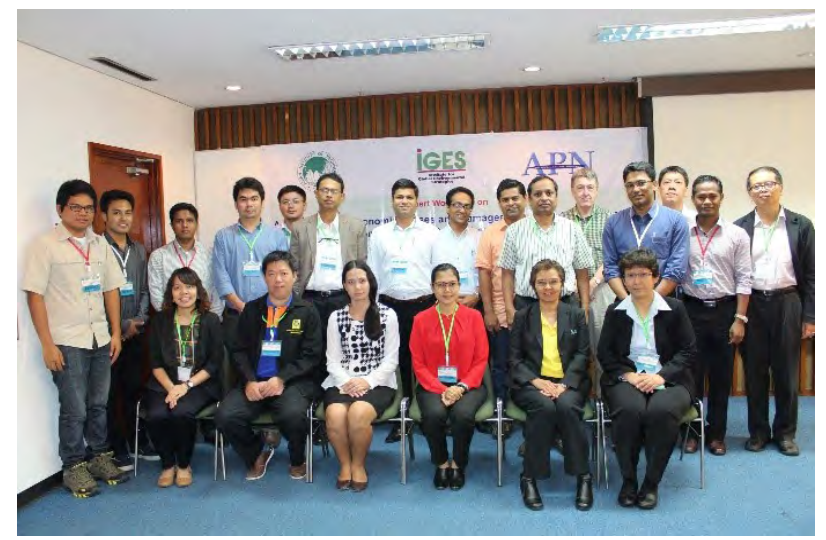

ACTIVITIES: The project studied non-economic L\&D associated with climate change through case studies of extreme climatic events in Bangladesh (floods), India (drought), Philippines and Japan (typhoons), and Thailand (urban floods). The research had three components (i) develop an assessment framework to identify and measure non-economic loss for vulnerable sectors (e.g., agriculture, water, livelihoods and gender), (ii) identify a range of best practices to address non-economic L\&D, and (iii) develop policy-relevant mainstreaming guidelines on non-economic L\&D for policymakers and practitioners.

HIGHLIGHTS: This research helped improve our understanding on non-economic damage associated with the rapid and slow onset extreme events and helped introduce changes needed in areas such as risk reduction, transfer and pooling measures including risk insurance, compensation and microfinance. The methodology developed for assessing non-economic damage associated with extreme events will help research, development and policy communities to advance climate change adaptation and disaster risk reduction strategies that address non-economic L\&D. 


\section{Integrating CCA, DRR and L\&D to address emerging challenges due to slow onset processes}

- Project Page: https://www.apn-gcr.org/?p=4498

\section{- APN Reference: CAF2016-RR03-CMY-Pereira}

- Project Leader: Joy Jacqueline Pereira, SEADPRIUniversiti Kebangsaan, Malaysia

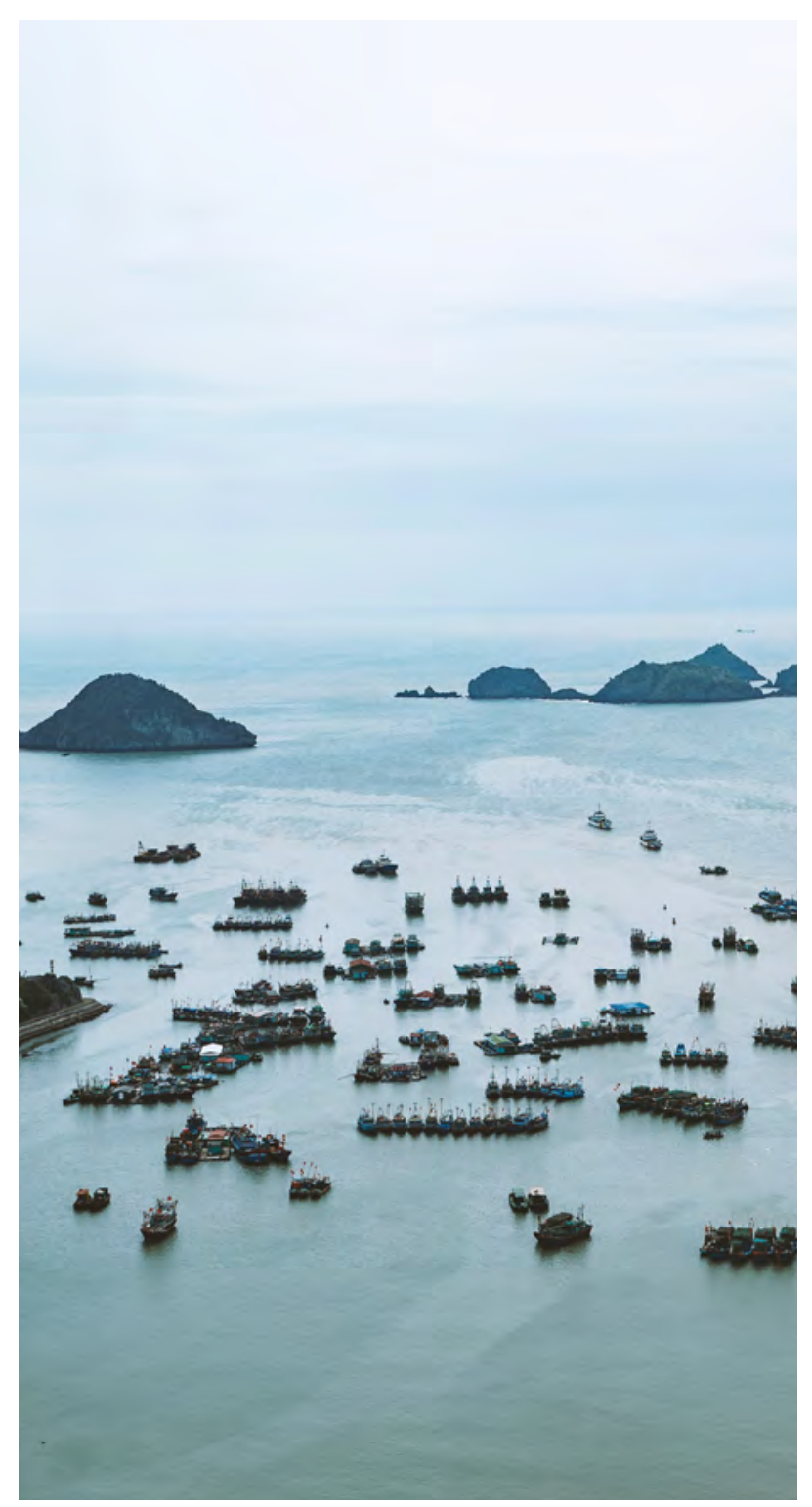

ACTIVITIES: The project activities identified characteristics, priorities and emerging issues related to slow onset processes in low-lying coastal areas, floodplains and highlands in Southeast Asia that impact the livelihood and wellbeing of communities. Adaptation limits were assessed based on the "best available science", and the project proposed risk-based approaches that integrate CCA and DRR. The project developed methodologies to evaluate prospective L\&D (economic and non-economic) associated with adverse climate impacts, drawing on lessons from disaster risk management, and discerning natural and anthropogenic causes of climate change. Policy and planning strategies to integrate CCA, DRR and L\&D into development plans in line with existing governance systems were developed.

HIGHLIGHTS: The research project was able to bring together distinct groups of biophysical and socioeconomic scientists to improve understanding of slow onset processes, especially its irreversible impacts that build over time with severe consequences on lives and livelihoods. It also identified new risk-based approaches integrating DRR and CCA, taking into account the limits to adaptation and building on community-based DRR and recommended to the international community robust methodologies on evaluating prospective L\&D (economic and non-economic), which differentiate natural and anthropogenic causes of climate change and take into account the cascading effects of climate extremes. The project also improved coordination and partnership between DRR and CCA institutions to provide routine inputs to the L\&D Forum, particularly at the national level and through regional networks such as APN, APAN, AUEDM, ANCST and ASEAN. 


\section{Optimizing climate change adaptation through enhanced community resilience}

Project Page: https://www.apn-gcr.org/?p=4537

- APN Reference: CAF2015-RR18-NSY-Jacobson

- Project Leader: Chris Jacobson, University of the Sunshine Coast, Australia
ACTIVITIES: The project developed a rapid assessment tool for community resilience to climate change and demonstrated that assessments of the resilience of rural communities could help identify the current status of resources and processes that mobilize support for adaptation to climate change. The tool was utilized as part of the annual Commune Investment Plans in Cambodia and Viet Nam. When implemented at a regional scale covering multiple communities, results could be used to inform sub-national planning by identifying communities that are most in need of intervention and by prioritizing different types of adaptation efforts. The sensitivity of the tool to detect changes in resilience based on adaptation activities was also examined.

HIGHLIGHTS: The project results demonstrate that building resilience requires context-based consideration of desired development outcomes and factors affecting their status. A benefit of the assessment and policy dialogue process is that it could be used as a rapid approach to monitor the effectiveness of aid projects designed to support community-based adaptation to climate change. For example, there are often many projects running simultaneously in any community, but a lack of coordination across projects sometimes exists. In this way, as illustrated by the resulting policy dialogue workshops, community members are able to express their needs more effectively and get the attention of their provincial, aid and NGO partners. Long-term use could also indicate whether adaptation path dependency is becoming an issue.



Community discussion group in Cambodia 


\subsubsection{Low Carbon Initiatives (LCI)}

APN launched its Low Carbon Initiatives (LCI) Framework with a view to enhancing mitigation actions across countries in the region to help achieve the global vision for a low carbon, sustainable future. Since 2012, the LCI has been supporting regional research, capacity development and networking activities related to low carbon development. This framework is under APN's thrust on climate change mitigation and has a three-pronged approach of regional research, including modelling low carbon development pathways and scenarios that also incorporates traditional knowledge; capacity building and training for formulating low carbon scenarios and pathways and developing educational toolkits on low carbon development; and communication and knowledge sharing with institutions, partners and member governments on common issues (e.g. LoCARNet, CTCN, among others). The framework developed a series of policy briefs as part of the activities, which provides helpful information for policymakers on problems specific to low carbon development, including suggested policy options to address common challenges, particularly in Asia. Two of the seven LCI projects are highlighted.

\section{Capacity building for implementing a} measurable, verifiable and reportable (MRV) model in a mid-sized Thai municipality

- Project Page: https://www.apn-gcr.org/?p=4477

- APN Reference: LCI2012-01NSY(C)-Maeda

- Project Leader: Toshizo Maeda, Kitakyushu Urban Centre/Institute for Global Environmental Strategies, Japan

ACTIVITIES: The project activities focused on building the capacity of a selected mid-sized Thai municipality to develop and implement an MRV framework. The project set up and maintained a GHG emission inventory and designed and implemented effective low carbon city policies and projects, as well as account for potential and actual reductions. A broader policy issue addressed by the project is ensuring progress by connecting local actions with national mitigation initiatives such as those outlined in Thailand's National Strategic Plan on Climate Change, including upcoming domestic market mechanisms which incorporate MRV

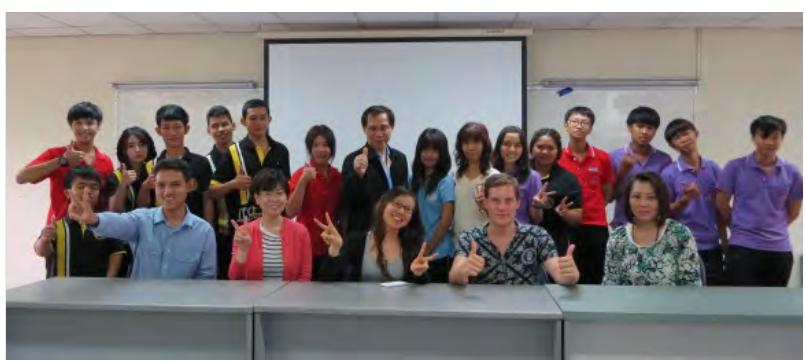

principles. The project initiated a broader initiative to devise a standard, comparable city-level MRV framework in East Asia, which was based on case studies in selected cities in Thailand, Viet Nam and Indonesia at an initial stage.

HIGHLIGHTS: A replicable model for building a local authority's capacity in GHG accounting was demonstrated by Phitsanulok City, Thailand, which was trained to collect reasonably complete data for an inaugural municipal-level GHG inventory by (i) establishing a cross-department working group led by skilled managerial and working-level coordinators, (ii) exchanging experience with a peer municipality (Nonthaburi Municipality), (iii) flexibly adjusting preexisting administrative and accounting procedures for GHG data collection, and (iv) developing an in-house energy use reporting system. By using a peer-to-peer approach connecting multiple Thai municipalities and providing a regional training opportunity involving other participants from APN member countries, the project promoted national-level cooperation. The project's additional research perspective on how to pave meaningful linkages between local MRV and emerging national/international MRV instruments is expected to deepen knowledge in this area. 


\section{Identification of policy and institutional gaps, drivers and strategies to scale-up low carbon and energy-efficient technology application in the construction and infrastructure sectors in South Asia}

\section{- Project Page: https://www.apn-gcr.org/?p=4479}

- APN Reference: LCI2013-01CMY(R)-Vashist

- Project Leader: Sanjay Vashist, Bangladesh Center for Advanced Studies (BCAS), Bangladesh

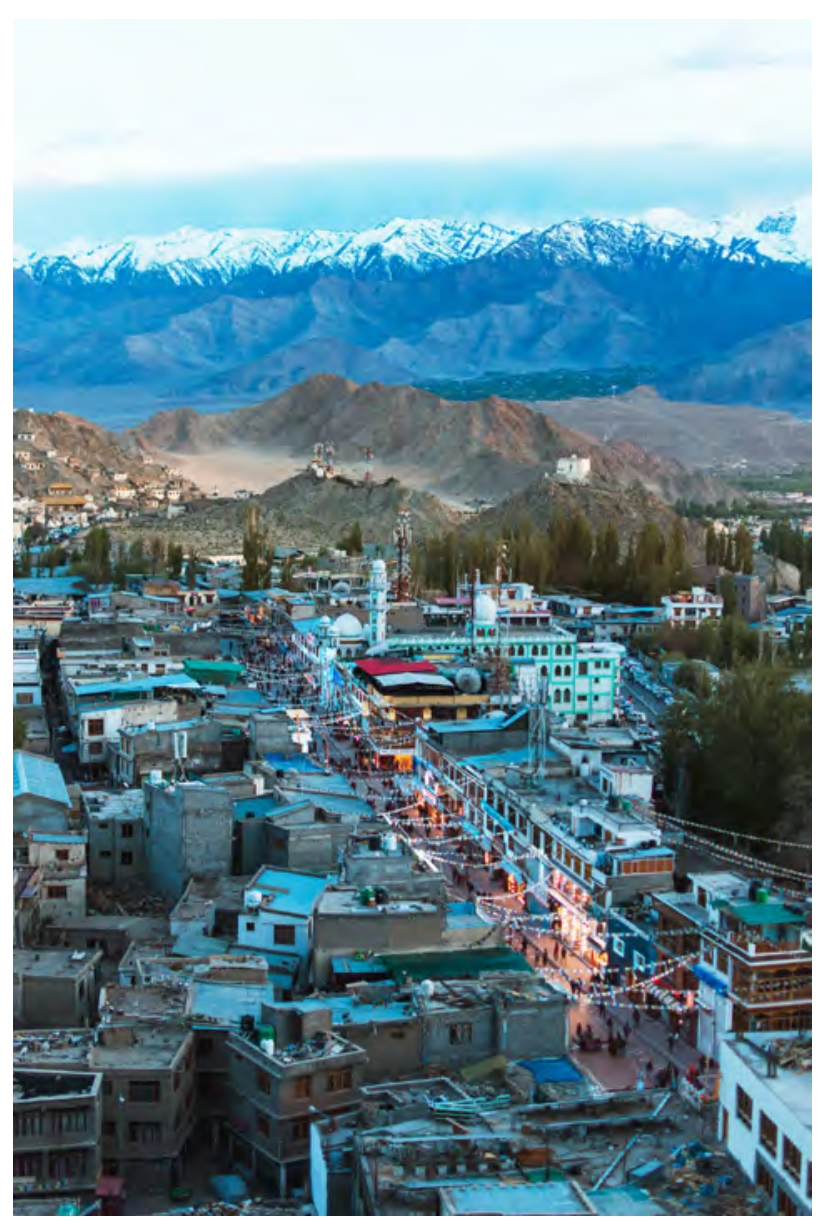

ACTIVITIES: The project studied rapidly growing construction and infrastructure sectors in selected APN developing countries with a focus on low carbon, resource and energy-efficient options. The project studied the policy mechanisms and national commitments towards transformation of sectors and barriers with respect to technology know-how, regulatory mechanisms, stakeholder capacity and market promotion. It also looked at drivers for change within the institutional mechanisms, financing systems, incentives and partnership arrangements to define the critical elements of the eco-system for promoting low carbon development pathways in the identified sectors. The project included literature studies, case studies of good practice applications and of conventional applications in identified geographical regions in each country situation and workshops to share experiences. While the country situations differed, a standard analytical frame was developed to derive country-specific as well as generic analysis and an intra-regional comparative analysis.

HIGHLIGHTS: The regional research looked at economic, technological, and regulatory and policy frames in different country situations and strengthened regional global change research by identifying critical gaps and areas for integrative research. Identified drivers for change highlighted areas for capacity building and partnerships for sustainable delivery of low carbon solutions for sustainable development. The analysis identified strategies to successfully mainstream low carbon options. These lessons learned were shared across the region. The drivers for change may be used in capacity building and partnership discussions to advance the delivery of low carbon solutions for sustainable development. 


\subsubsection{Biodiversity \& Ecosystem Services (B\&ES)}

The needs of policymakers to realize sustainable, green growth practices require effective mechanisms to link biodiversity and ecosystem services (B\&ES) to sustainable development and biodiversity, APN published an Opportunity Paper as a product of a two-year series of activities. The paper is presented as an invitation for partners to propose collaborative activities to address the gaps and issues identified in the B\&ES framework. These include identifying drivers and pressures for biodiversity change that influence ecosystem services; assessing impacts of biodiversity loss and vulnerability to the shrinking of ecosystem services; predicting changes in B\&ES through model-based scenarios, and identifying adaptation, response and mitigation strategies to address the depletion of biodiversity and ecosystem services. Projects were identified from APN's CAPaBLE and ARCP programmes as fitting with these themes, and two are highlighted below.

\section{International training on regional ecosystem-climate interactions}

Project Page: https://www.apn-gcr.org/?p=4491

APN Reference: CBA2013-07NSY(B\&ES)-Jia

- Project Leader: Jia Gensuo, START Regional Centre for Temperate East Asia (TEA), China



ACTIVITIES: The training activities provided ECS with an understanding of regional ecosystem-climate interactions through lectures and dialogue with senior scientists, hands-on modelling, and practical field experience. The activities focused on the science challenges of regional climate change and provided essential knowledge and skills to analyze the physical science basis of climate change and its impacts across all spheres of human activity.

HIGHLIGHTS: This training is very relevant to APN goal on scientific capacity development, and Biodiversity and Ecosystem Services program. The training on regional ecosystem-climate interactions enhanced the capabilities of researchers and practitioners from monsoon Asia countries with advanced knowledge and skills in this fast-moving field. It also contributed to improving the environmental capacity to train more early-career scientists in the region for regional sustainable development. It addressed various scientific aspects of regional ecosystems and climate change, including multi-platform observation, trends and impacts analysis, and ecosystem-climate modelling. 


\section{Coastal forest}

management in the

face of global change

based on case studies

in Japan, Myanmar and the Philippines

- Project Page: https://www.apn-gcr.org/?p=4505

- APN Reference: ARCP2015-10CMY(B\&ES)-Liang

- Project Leader: Liang Luohui, United Nations University Institute for the Advanced Study of Sustainability (UNU-IAS), Japan
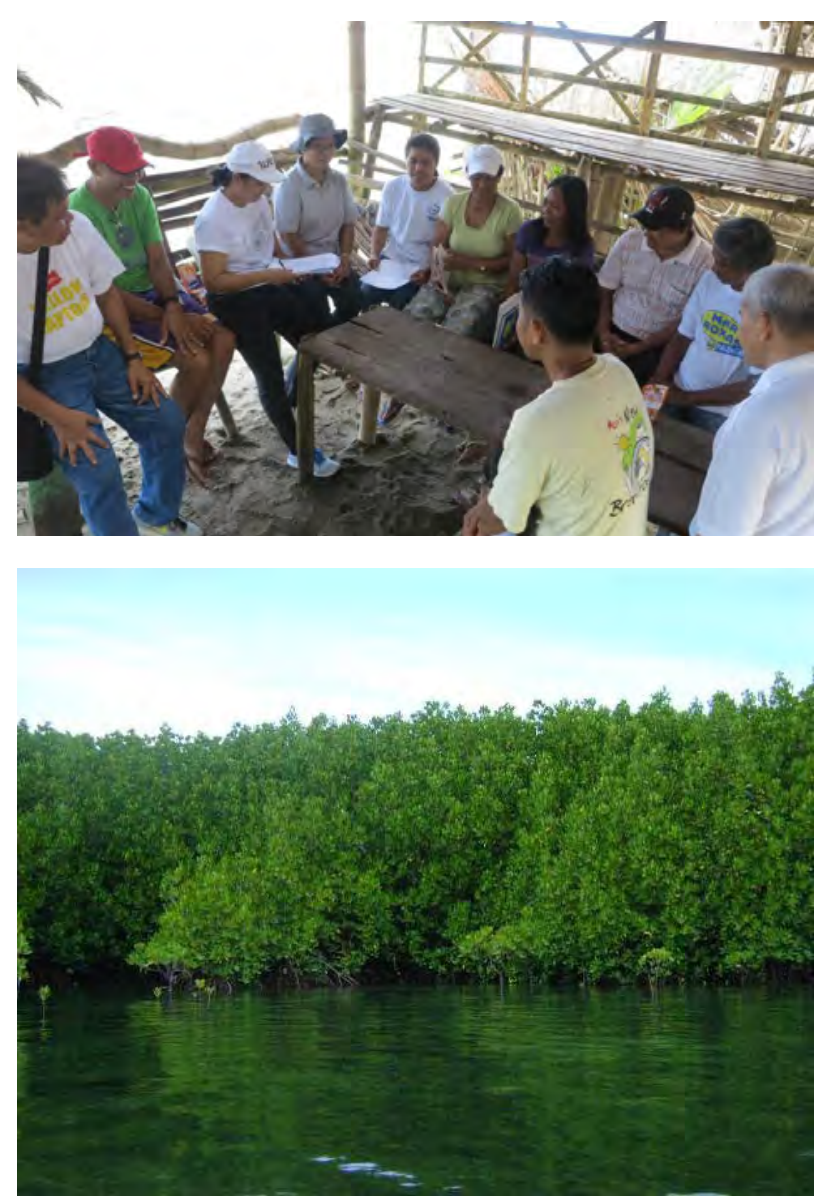

ACTIVITIES: The project activities addressed the importance of forests in the mitigation of coastal disasters. The three project sites in the Philippines, Myanmar and Japan, all suffer frequent typhoons or tropical cyclones, and a comparative perspective was developed on how these different countries and local communities facing a shared challenge address coastal forest management under similar biophysical conditions, but different socio-economic contexts. The research examined community-based forest management, including local knowledge in vulnerable communities to identify best practices in coastal forest management, integration with human settlement planning and facilities to strengthen community resilience to climate change impacts and evaluate effectiveness and needs of coastal forest management policy through a bottom-up process. The project assessed potential benefits of coastal forests to local livelihoods in relation to food, medicine and spiritual needs.

HIGHLIGHTS: The project supports the planning of local forest management and human settlement, and their integration through the involvement of local policymakers in the research. In addition, the project will disseminate its findings at a more extensive level through UNU-based networks in the region, including University Network on Climate and Ecosystem Change Adaptation Research (UN-CECAR) and the UNU On-the-Job Research Capacity Building Program for Food Security and Environmental Conservation in Developing Countries (OJCB). The research also improved the understanding of the interactions between forest ecosystems, agriculture and human settlements on the landscape and developed integrated approaches to harnessing forest regulating services in human settlement planning and agriculture practices, and combining benefits of forests in adaptation to and mitigation of climate change in coastal areas. The project addressed gaps in how forests and human settlements interact and how better integration can be realized as an adaptation option to climate impacts. 


\subsubsection{Collaborative Research Programme for Young Scientists (CRYS)}

APN initiated a small grants pilot programme on Collaborative Research for Young Scientists (CRYS) in 2017 to provide a platform for ECS to use their knowledge and ideas to address regional issues related to global change and sustainability and, at the same time, provide opportunities to network further with their peers. With a modest investment of USD 60,000, the programme projects produced four peer-reviewed journal articles, five presentations at the regional and international levels, and a smartphone mobile application for rainwater harvesting. In view of this achievement, APN's Steering Committee decided to continue the Small Grants Programme "Collaborative Research Programme for Early Career Scientists”, CRECS for another term.

Results of the three projects awarded are outlined on the succeeding pages. 


\section{CRYS2017-01MY-Panthi}

The project was entitled "Rainwater harvesting for mitigating drought in western Nepal" and was aimed at providing an enabling environment for policymakers and local stakeholders to harvest rainwater as a climate change mitigation measure.

Project Page: https://www.apn-gcr.org/?p=4568

\section{Outputs:}

- Mobile App: https://play.google.com/store/apps/ details?id=com.rwh.app Aakaashepani (or आकाशेपानी in Nepalese), is an android app developed to help in decision making for the installation of a rainwater harvesting system.

- Panthi, J., Khatiwada, K. R., Shrestha, M. L., \& Dahal, P. (2019). Water poverty in the context of climate change: a case study from Karnali river basin in Nepal Himalaya. International Journal of River Basin Management, 17(2), 243-250. doi:10.1080/15715124 .2018 .1531412

- The Small Earth Nepal (2018, October 14). SEN at Mtn Climate International Conference in Rocky Mountain, USA. Retrieved from http://www. smallearth.org.np/sen-at-mtnclimate-internationalconference-in-rocky-mountain-usa/

- APN (2018, October 29). Mobile Application for Rainwater Harvesting Systems in Nepal. Retrieved from https://www.apn-gcr.org/news/mobileapplication-for-rainwater-harvesting-systems-innepal/

- "Rainwater harvesting site suitability mapping for the Karnali basin" at Mountain Climate conference organized at Rocky Mountain Biological Laboratory (RMBL) in Colorado, USA, 17-21 September 2018.

- The scientific aspects of the Android mobile application developed for rainwater harvesting advisory were presented at the AGU Fall Meeting, 2018.

\section{CRYS2017-02SY-Almaden}

The project was entitled "Multidimensional Indicators of Adaptive Capacity of Rice Farming Households to Address Salt Water Intrusion in the Philippines and Viet Nam" and aimed at drawing policy recommendations based on an inventory of measures adapted by rural rice farmers in addressing saltwater intrusion.

Project Page: https://www.apn-gcr.org/?p=4571

\section{Outputs:}

- Almaden, C. R. C., Diep, T. T., Rola, A. C., Baconguis, R. D. T., Pulhin, J. M., Camacho, J. V., Ancog, R. C. (2018). Meso-level analysis on rice farmer's adaptive measures for slow onset hazards: The case of saltwater intrusion. In Pereira, J.J. \& Hunt, J.C.R. (eds.) 2019, Climate Science \& Technology in Asia: Current Status and Future Needs. Report of the Workshop on Status of Climate Science and Technology in Asia, 15-16 November 2018, Kuala Lumpur, Malaysia. LESTARI Publishers, Bangi, Malaysia.

- Almaden, C. R. C., Rola, A. C., Baconguis, R. D., Pulhin, J. M., Camacho Jr, J. V., \& Ancog, R. C. (2019). Determinants of Adaptation for Slow-Onset Hazards: The Case of Rice-Farming Households Affected by Seawater Intrusion in Northern Mindanao, Philippines. Asian Journal of Agriculture and Development, 16(1362-2019-2696), 110-132. Retrieved from https://ajad.searca.org/ read-articles/13-view-article?aid=963

\section{CRYS2017-03SY-Sing}

The project was entitled "Urban Biodiversity and Human Well-Being in Asia's Megacities" and aimed at understanding the impacts of urbanization on butterflies as a bio-indicator of urban health and the perception of urban health, and the perception of urban communities on sharing the same space with butterflies.

Project Page: https://www.apn-gcr.org/?p=4569

\section{Outputs:}

- Sing, K.-W., Luo, J., Wang, W., Jaturas, N., Soga, M., Yang, X., ... Wilson, J.-J. (2019). Ring roads and urban biodiversity: distribution of butterflies in urban parks in Beijing city and correlations with other indicator species. Scientific Reports, 9(1). doi:10.1038/s41598-019-43997-8 


\section{Activities organized by APN}

APN has implemented a range of activities, including collaborative events, scoping workshops, and training workshops with other partners. These activities have increased in recent years because they continue to bring added value to APN in terms of capacity enhancement, scoping important issues, strengthening science-policy linkages, and increasing motivation and regional coherence. 


\subsection{Activities with the Hyogo Prefectural Government}

The Hyogo Prefectural Government of Japan strongly supports APN in its capacity as host to the Secretariat, providing prefectural government staff, and contributing financial resources for APN's core activities. During the 4th Strategic Phase, it served as the second largest donor after the Ministry of the Environment of Japan.

A portion of the financial resources provided from the Hyogo Prefectural Government supports international events in the prefecture and engages local and international organizations, including residents of Hyogo. The events promote topics of local interest, including relevant environmental policies in the prefecture. These collaborative activities not only raise the international profile of Hyogo Prefecture and Kobe City but raises awareness of APN among the local communities in the prefecture.

One of the most successful initiatives was a collaborative five-year series of international seminars with Hyogo Prefecture's Hanshin-Kita District Administration Office. These international symposia discussed issues surrounding Satoyama ${ }^{1}$ and provided a platform for local residents to engage with experts drawn from Japan and the international community to discuss regional assets and revitalization in the context of Satoyama.

1 Satoyama (里山) is a Japanese term applied to the border zone or area between mountain foothills and arable flat land. Literally, sato (里) means village, and yama (山) means hill or mountain. Satoyama have been developed through centuries of small scale agricultural and forestry use (https://en.wikipedia.org/wiki/Satoyama)
In the 4th Strategic Phase, APN continued to partner with the Environmental Management of Enclosed Coastal Seas (EMECS) Secretariat in Hyogo Prefecture by participating in two of its biennial international conferences, organizing and contributing to AsiaPacific sessions, and engaging researchers from APN projects.

Another Hyogo Activity, co-organized with EMECS and Kobe University, was the International Symposium: Biodiversity of coastal seas and restoring environment, held in Kobe in February 2020. Invited experts from abroad and scientists from Kobe University and Kyoto University shared their research results with citizens of Kobe City and Hyogo Prefecture.

As a major financial donor, APN should continue to collaborate with the Hyogo Prefectural Government by organizing activities of global change and sustainability that are relevant in the local context and of importance to the residents of the prefecture and engaging with other international institutions based in Hyogo Prefecture on pressing global environmental issues.

Hyogo activities from 2015-2018 are shown in Appendix 3.

\subsection{Science-policy dialogues}

The science-policy dialogues (SPDs) engaged scientists, experts, policymakers, practitioners and members of the media to share and discuss collective knowledge and experience on focussed issues. The SPDs provide opportunities for scientists and policymakers to share their knowledge and expertise as well as provide a platform for regional

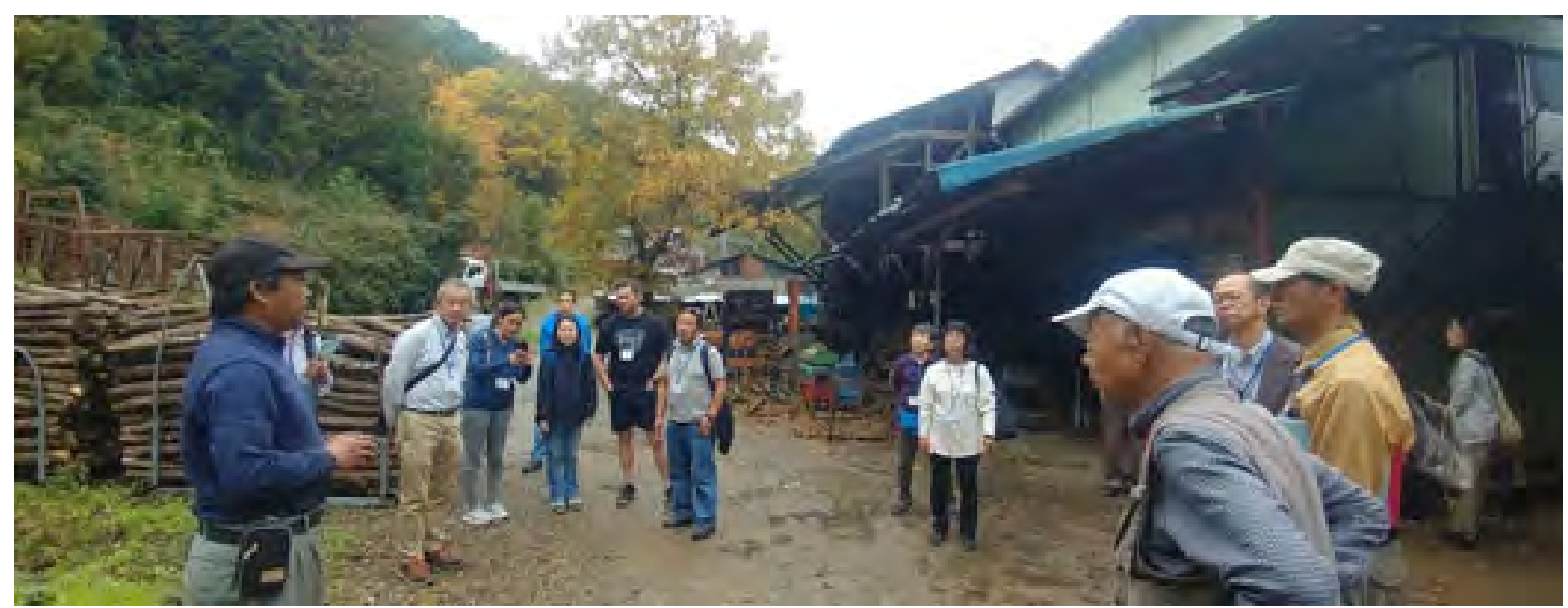

APN and Hyogo Prefecture regularly join hands to promote Satoyama-a place where nature and people exist in harmony 
experts and policymakers to share best practices and promote science-policy interactions through informal dialogue. These were realized through facilitated discussions and participatory game sessions/ ice-breakers on communicating recent advances in scientific knowledge pertaining to issues such as ecosystem services, climate change vulnerability and impacts, disaster risk reduction and management; and strategies for climate adaptation and low carbon technology. The first SPD focused on Southeast Asia in 2012, and an additional three were undertaken in the 4th Strategic Phase in 2015, 2016 and 2017.

\subsubsection{Science-policy dialogue in South Asia: Global environmental change: Reducing risk and increasing resilience (2015)}

APN held the South Asia SPD in Paro, Bhutan, with financial support from APN, the Climate Development Knowledge Network (CDKN) and the Low Carbon Asia Research Network (LoCARNet). The 3-day dialogue was attended by 50 scientists and policymakers from Bhutan, Bangladesh, India, Japan, Nepal, Pakistan and Sri Lanka. Under the theme "Global Environmental Change: Reducing Risk and Increasing Resilience", the Science-Policy Dialogue was designed around five activities that incorporated sessions on knowledgesharing and knowledge management, carousel-style discussion groups (café kiosks), roundtable and panel sessions, and participatory games. Three main themes on urban areas: climate impacts and risk reduction, food and water security in the rural context, and low carbon society and sustainable pathways were discussed in the context of rural and urban sectors with a cross-cutting theme on sustainability.

\subsubsection{Science-policy dialogue in East Asia: Land use and climate change in Temperate East Asia} (2016)

APN held the Temperate East Asia SPD in Ulaanbaatar, Mongolia in collaboration with the Ministry of Environment, Green Development and Tourism of Mongolia, and Mongolian Academy of Sciences and Institute for Sustainable Development, National University of Mongolia. The three-day dialogue and field visit were attended by 68 scientists including ECS, policymakers and other stakeholders from China, Mongolia, Japan, Russia Federation, Republic of Korea (ROK) and the USA. The dialogue identified that TEA countries have different regulations and action plans to address land change and climate change issues. All five countries are facing land use management issues due to rural-urban migration and decreasing population in rural areas. Therefore, land use studies should be designed with transdisciplinary and interdisciplinary approaches to cover all socio-economic areas related to land use and land change.

\subsubsection{Science-policy dialogue in South/ Southeast Asia: Climate change: low carbon \& adaptation initiatives (2017)}

APN held the South/Southeast Asia SPD and capacity building workshop at the AIT campus in Pathum Thani, Thailand in cooperation with LoCARNet, AIT RRC.AP and the Climate Change Asia (CCA) Initiative. Under the workshop, results were shared from activities of LoCARNet and APN'S LCI and CAF frameworks. The dialogue discussed, among others, the role of green investment in cities, low carbon and energy-efficient technology, and a better water energy carbon nexus.
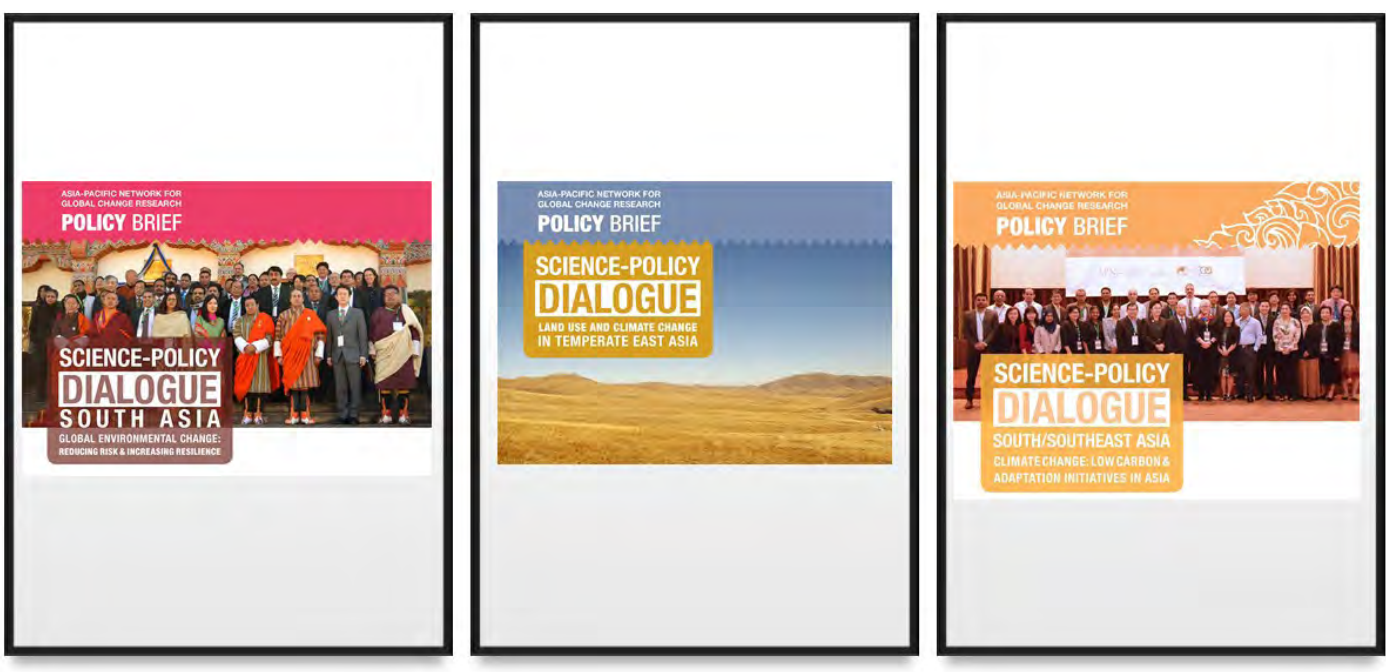

Policy briefs of Science-Policy Dialogues in SA, Bhutan (2015), TEA, Mongolia (2016) and SEA/SA, Thailand (2017). 
Forty-two participants joined the dialogue, which also shared views on effective strategies for engaging science and policy, narrowing existing gaps, sharing best practices on knowledge management, and undertaking communication and networking activities.

\subsubsection{Future science-policy dialogues}

For future consideration, partnerships developed with organizations including CDKN, ICCCAD, ICLEI, USAID, among others with common interests to APN could be sustained by continuing to organize SPDs on issues of global environmental change and sustainability, particularly in the subregional context. Continuing such events will allow for sustained partnerships in addition to providing informal platforms for experts, policymakers and practitioners to freely share best practices and accelerate dialogue among science, policy and practice for science-based policy options. Continued efforts to engage APN subregional committees is paramount to maximize the resources available and avoid duplication. On funding opportunities, there is most definitely value in added sponsorship (noting that CDKN for SA/Bhutan).

\subsection{Subregional activities}

APN's subregional committees in Southeast Asia, South Asia and Temperate East Asia organized activities during the 4th Strategic Phase using the opportunity to leverage on their respective annual subregional committee meetings. Further, one subregional activity was conducted with a grant funded from APN's CAPaBLE programme.

\subsubsection{Workshops on technology transfer in Asia and in Southeast Asia}

\subsubsection{Scoping workshop for technology transfer in Asia}

Held in December 2016, the scoping workshop addressed technology transfer needs of APN developing of member states with the aim of developing a robust collaborative regional research and capacity development framework under APN that will provide support for technology transfer research, synthesis, assessment and capacity development activities to respond to the needs of APN members and produce information for decision-makers that could lead to more robust solutions for an adaptable, sustainable, low carbon Asia-Pacific under a warming climate. The meeting was attended by researchers and experts on technology transfer coming from ADB, TERI, IGES, Kitakyushu Foundation for the Advancement of Industry, Science and Technology, IISD, Sustineo/ ANU, UNEP-IETC, APEC VC Japan, RRC.AP-AIT, CTCN, University of Southern Queensland, LoCARNet, Global Environment Centre Foundation, NIES, Viet Nam Academy of Science \& Technology (VAST), the Asia-Europe Foundation, Department of Science and Technology of the Philippines, National Environment Commission, Secretariat of Bhutan and Ministry of the Environment of Japan.

The workshop established gaps, challenges and opportunities for regional research and capacity development initiatives for technology transfer in the context of global change and sustainability. This initiative, which might be a stand-alone framework or embedded under CRRP and CAPaBLE programmes, would provide support for technology transfer research, synthesis, assessment and capacity development activities.

\subsubsection{Technology needs assessment workshop in Southeast Asia}

Supported by APN in collaboration with the Viet Nam Academy of Science and Technology, the workshop endeavoured to assist developing countries in identifying national priorities for both adaptation and mitigation, with a strong focus on technology transfer. Discussions were based on the understanding of the critical importance of conducting technology assessments that address cross-cutting issues in sectors such as energy, waste, water and tropical agricultural as well as some specific industrial processes.

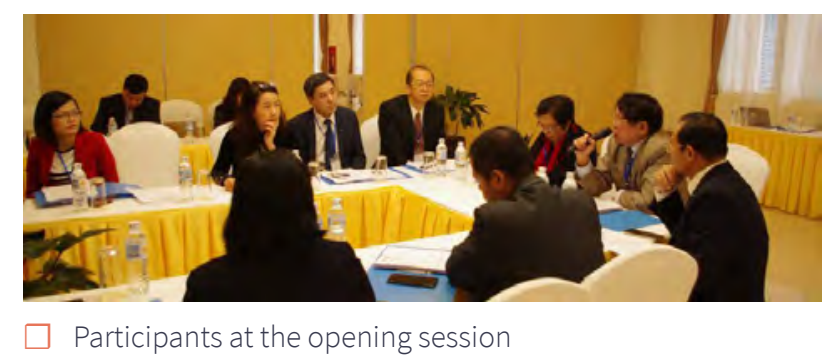

\subsubsection{Climate smart agriculture in South Asia}

Experts in the areas of climate change and agriculture from eight member countries of the South Asian Association for Regional Cooperation (SAARC) gathered 
in a conference on Regional Expert Consultation on Climate-Resilient Agricultural Policies, Strategies and Programmes" to explore practical ways for undertaking regional research and subsequent action on climate smart agriculture. The event was organized by the Ministry of Environment, Forest and Climate Change (MoEFCC), Government of India, the SAARC Agriculture Centre (SAC) and the Asia-Pacific Network for Global Change Research (APN), and hosted by the National Academy of Agriculture Research Management (NAARM).

By promoting the understanding of climate change impact on agriculture and evaluating agricultural policies that integrate climate change adaptation, the conference explored issues and gaps in climate change policy, research, capacity development and knowledge management, with the aim of developing a framework for collaborative action. The outcomes of the conference will contribute to developing partnership activities that enhance integration and mainstreaming of climate change issues into agricultural policies, especially towards South Asia's adaptation commitments under the Paris Agreement.

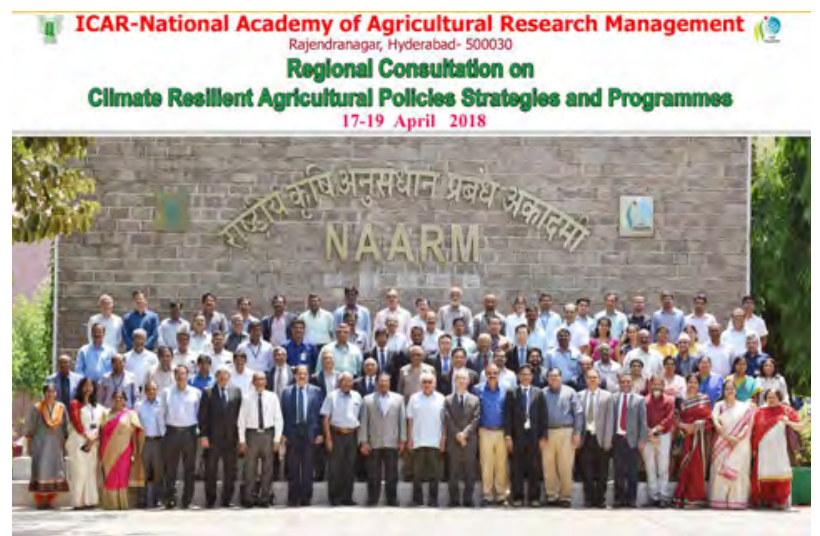

Consultation on climate resilient agricultural policies

\subsubsection{Special issue on climate change impacts, adaptation and vulnerability: Asian perspective}

Knowledge base in the region covering new climate information, policy gaps, and lessons learned are crucial and should be widely disseminated particularly to practitioners and policymakers. In line with this, APN embarked on an activity to compile the outputs of a number of its completed projects in a special issue for publication in the Elsevier journal Environmental Research. After an international seminar conducted at AIT, a writeshop was held with all contributing authors (former project leaders/collaborators) that culminated in the publication of the Special Issue Climate Change Impacts, Vulnerability and Adaptation: Asian Perspective $^{2}$ in 2020.

The special issue highlights findings of 14 APN projects across South Asia, Southeast Asia and Temperate East Asia, and includes a knowledge synthesis of 115 APN projects (2013-2018) authored by the APN Secretariat ${ }^{3}$. It is expected that the information will help support the formulation of adaptation policies to offset the negative impacts of climate change on natural and human systems, add value to the scientific literature, and help shape local, regional and global agendas on climate change.



Participants of the international symposium and writeshop

With the keen interest of members to see compilation and syntheses of APN's tangible outputs, APN should invest more time in conducting these kinds of activities. Indeed, the writeshop itself was a first of a kind that allowed project leaders from different subregions of Asia to discuss their research, peerreview manuscripts and strengthen their collaboration for future potential endeavours. The activity also forged stronger partnership with AIT, who was also instrumental in hosting the APN Science-Policy Dialogue at AIT in 2017 (see Section 3.2.3).

\footnotetext{
2 Shrestha, S., Stevenson, L. A., Shaw, R., \& Pulhin, J. (2020). Editorial of Special Issue on Climate Change Impacts, Vulnerability and Adaptation: Asian Perspective. Environmental Research, 109826. doi:10.1016/j.envres.2020.109826

3 Uchiyama, C., Stevenson, L. A., \& Tandoko, E. (2020). Climate Change Research in Asia: A knowledge synthesis of Asia-Pacific Network for Global Change Research (2013-2018). Environmental Research, 188, 109635. doi: 10.1016/j.envres.2020.109635
} 


\subsection{Capacity development of early-career professionals}

\subsubsection{Proposal development training workshops (PDTW)}

Introduced in 2008 to increase the capacity of earlycareer scientists (ECS) to develop research proposals for submission to APN's competitive grant process and funding programmes of other organizations. So far, APN has conducted 18 workshops and trained about 300 ECS. From 2014 PDTWs are organized annually, rotating among subregions.

Five PDTWs were conducted during the 4th Strategic Phase:

- 2015 Cambodia: Environmental Problems and Related Policy Issues, and Climate Change \& Associated Socio-Economic Impacts (33 nationallevel participants, seven ECS from other SEA countries)

- 2015 Mongolia: Land Use and Climate Change (21 ECS from TEA)

- 2016 Bhutan: Paleoclimate science and modern climate studies in South Asia (23 ECS from SA and co-funding from PAGES)

- 2017 Viet Nam: Disaster Risk Reduction and Community Resilience to Climate Change in Vulnerable Areas (23 ECS from SEA)

- 2018 Japan: Sendai, Paris and Beyond: Addressing Challenges of Water Security for Sustainability (21 ECS from TEA)

Based on ECS feedback through questionnaires, overall management, training workshop content and design was considered very good and well organized. A few participants expressed that the overall organization and content needed improvements, such as:

"Improve instructional methods."

"Make workshop activities more stimulating."

"Increase the time for the workshop and for collaborative group activities."
Generally, PDTWs are instrumental in achieving one of APN's goals to provide capacity building opportunities to researchers and scientists in the region, in particular, APN's Capacity Development Agenda on "individual-based capacity development". PDTWs offer opportunities for participants to find common interests, to learn the basics of proposal writing and development for application to APN funding, experience peer-review processes, and connect with international programmes and organizations. Furthermore, the 2016 TEA PDTW was co-funded by PAGES, a programme of Future Earth, who provided insight on communicating scientific research to policy.

Further, rotating PDTWs has served as a means for APN to introduce itself to the ECS and senior researchers in different member countries and promote its goals and objectives. Introducing APN and concepts of global change, regional research and science-policy interaction, as well as the importance of disseminating and popularizing research findings, have been well received by the ECS, mentors and APN members, and PDTWs conducted were useful avenues in that sense. Opportunities for co-funding/co-partnering should continue to be explored for future PDTWs.

One of the main challenges faced by APN following a PDTW is the continuity of mentoring between ECS and mentors, as well as sustaining peer-to-peer collaboration. In the future, establishing a PDTW alumni group linked with a pool of senior researchers (mentors) could be a strategy for strengthening APN's engagement with ECS.

\subsubsection{Mitra Award}

The Mitra Award for Global Change Research was established in 2010 in memory of Dr Ashesh Proshad Mitra, APN SPG Member for India from 1996 to 2007, and doyen in atmospheric research in India and recipient of the Padma Bhushan award by the Indian government in recognition of his distinguished services to the nation. The award recognizes outstanding earlycareer scientists conducting global change research in Asia-Pacific region. Early-career scientists from the host country of APN's Intergovernmental Meeting (IGM) are given the opportunity to present their research in a poster session to senior scientists, practitioners and policymakers attending the Meeting. Posters are judged by APN national Focal Points and SPG Members and winners are presented the Mitra Award in recognition of their outstanding work. 
In the 4th Strategic Phase, a total of 43 early career researchers were selected to present their work. The winners for 2016, 2017 and 2018 were:

\section{1st IGM, China (2016): APN-Henan Networking Session: Chinese Youth Poster Session}

- Lu Heli, College of Environment and Planning, Henan University, Kaifeng, China. A Spatially Explicit Modelling Framework of Cost-Benefit and Carbon Emissions from Land Use Coverage Changes for Implementing REDD+ in Southeast Asia

22nd IGM, India (2017): Challenges, Gaps and Solutions for Climate Change Adaptation in Water and Agriculture Sectors

- Shaikhom Inaotombi, ICAR-Directorate of Coldwater Fisheries Research, Bhimtal District Nainital Uttarakhand India. Climate Change and Its Impact on Aquatic Ecosystems in the Central Himalayas

\section{3rd IGM, Thailand (2018): Making Cities and Communities Sustainable in the Anthropocene}

- Alisa Sahavacharin, Chulalongkorn University, Bangkok, Thailand. Landscape infrastructure for planning the sustainable coastal cities: SpatioTemporal Analysis and Modelling for Sustainability of Andaman Coastal City and Forest

\subsubsection{Media fellowship}

The first SPD held in Thailand (2012) identified communications gaps in conveying information between scientists and policymakers. In response, and to celebrate the 20th anniversary of APN, a media fellowship programme was approved at 20th IGM in Kathmandu in 2015 with the aim of tackling the challenge and providing an opportunity to disseminate the results and key messages of the projects to the public via media channels. A call for application from journalists in South Asia was launched in March 2016. From 284 applications, eight journalists were selected from Sri Lanka, Bhutan, India, Maldives, Nepal, Pakistan. Following the activity in Sri Lanka, news features were written by the fellows and published in the media channels in Table 1.2.

\begin{tabular}{|c|c|c|c|}
\hline Country & Media & Title & URL \\
\hline Bangladesh & $\begin{array}{l}\text { Dhaka Tribune (www. } \\
\text { dhakatribune.com) }\end{array}$ & $\begin{array}{l}\text { Home gardens: ensuring food security in a } \\
\text { changing climate }\end{array}$ & https://shorturl.at/jnD67 \\
\hline Bhutan & $\begin{array}{l}\text { Bhutan Broadcasting Service } \\
\text { (www.bbs.bt/news) }\end{array}$ & $\begin{array}{l}\text { Living with nature: A love story of a } \\
\text { Kandyan Home Garden }\end{array}$ & n/a (hard copy available) \\
\hline Maldives & $\begin{array}{l}\text { Public Service Media (www. } \\
\text { psmnews.mv) }\end{array}$ & $\begin{array}{l}\text { Television Maldives: Environment and } \\
\text { Home Gardening }\end{array}$ & $\mathrm{n} / \mathrm{a}$ \\
\hline Nepal & $\begin{array}{l}\text { Nepal Republic Media Pvt Ltd } \\
\text { (www.myrepublica.com) }\end{array}$ & Home gardening: It pays & https://shorturl.at/hAB03 \\
\hline Pakistan & $\begin{array}{l}\text { Associated Press of Pakistan } \\
\text { (APP) }\end{array}$ & $\begin{array}{l}\text { Home Gardens: A sound approach to food } \\
\text { security }\end{array}$ & https://shorturl.at/ao016 \\
\hline \multirow{2}{*}{ Sri Lanka } & $\begin{array}{l}\text { Associated Newspapers } \\
\text { of Ceylon Ltd. (www. } \\
\text { sundayobserver.lk) }\end{array}$ & $\begin{array}{l}\text { Climate change in Sri Lanka: Food security } \\
\text { alert! }\end{array}$ & https://shorturl.at/bhEZ3 \\
\hline & $\begin{array}{l}\text { Sri Lanka Broadcasting } \\
\text { Corporation (www.slbc.lk) }\end{array}$ & $\begin{array}{l}\text { SLBC News: Home gardening would } \\
\text { increase crop production during adverse } \\
\text { climate conditions }\end{array}$ & n/a (recording available) \\
\hline
\end{tabular}

Table 1.2. Media fellowship news articles. 


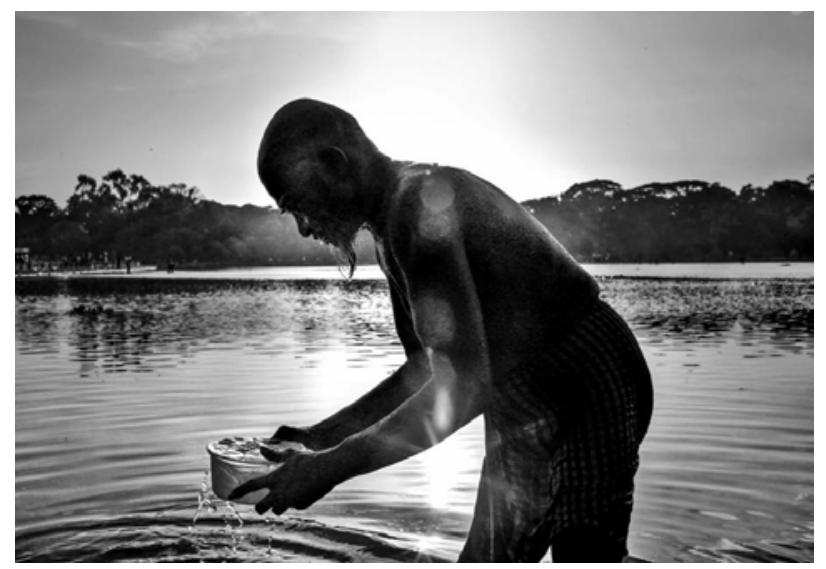

Winning photo of the L. B. Brown Memorial Photo Contest by Mr. Mohammad Rakibul Hasan, Bangladesh.

\subsubsection{B. Brown memorial photo contest}

In 2016, APN organized a photo contest in memory of the late Mr L. B. Brown, former national Focal Point for the USA, while celebrating the power of photography in raising public awareness on global change issues. Between May and December 2015, a total of 100 entries were submitted by photographers from 14 countries to the monthly contests under different themes. Nine winners of the monthly contests were selected based on reviews by APN members and external judges, and the top winner was chosen by APN members at the 21st IGM/SPG Meeting held in Zhengzhou, China, in April 2016. Mr Mohammad Rakibul Hasan, a documentary photographer, based in Dhaka, Bangladesh, was awarded the L. B. Brown Memorial Award for his photograph submitted under the theme of "Water for Sustainability".

\subsubsection{Student fellowship for capacity building}

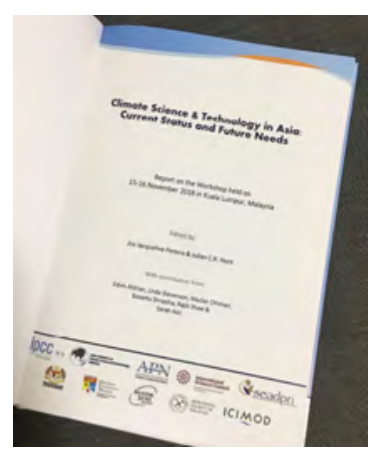

Climate Science \& Technology in Asia: Current Status and Future Needs.

As an outcome of the 23rd IGM/SPG Meeting in Thailand, APN provided a three-month fellowship opportunity to a postgraduate student of UNU-IAS. The fellow conducted a synthesis of APN's project outputs relevant to the IPCC process, the SDGs and Paris Agreement through the research on data, information, lessons learned, and good practices resulting from its supported projects. Preliminary results of synthesis were submitted and presented at the Workshop on Status of Climate Science and Technology in Asia in Malaysia in November 2018, which was sponsored by a cohort of international partners, including ACCCRN, APN, ICIMOD and IPCC. The abstract and presentation of the synthesis were published in Climate Science \& Technology in Asia: Current Status and Future Needs.

\section{Highlights:}

- Engaging early-career researchers to synthesize APN products is an opportunity to develop the capacity of early-career researchers, provide exposure to the international expert communities while packaging relevant APN outputs into tangible and policy-relevant products that can be shared with the regional and international science and policy communities.

- Provided an opportunity to engage with WGII Chapter 10 Authors of the IPCC AR6.

- The workshop report ${ }^{4}$ is an annexe to the progress report on Communication and Outreach Activities submitted to governments by the Secretary of the IPCC at its 49th Session in Kyoto, Japan, 18-13 March 2019.

- At the post-fellowship discussion with the Director of UNU-IAS, it was suggested that these kinds of opportunities continue to be explored in the future.

- A peer-reviewed article developed by the Secretariat has been published in a Special Issue in the Elsevier journal "Environmental Research" in July 2020.

- This innovative practice could be considered as an essential component of the work of APN in the future with a view to strengthening partnerships, publishing policy-relevant work, while at the same time, developing the capacity of early-career researchers.

4 Pereira, J.J \& Hunt, J.C.R. (eds.) (15-16 November 2019). Climate Science \& Technology in Asia: Current Trends and Future Needs. Report of the Workshop on Status of Climate Science and Technology in Asia. Bangi, Malaysia: LESTARI publishers. 


\section{International engagement and alignment with global change and sustainability communities}

APN places significant importance on networking nationally, regionally and internationally.

Engagement has ranged from participation and/ or presentation in events, convening sessions at events, providing scientific input to organizations/ bodies, among others. 


\subsection{Fourth Strategic Plan (2015-2020)}

Section 4.4 of APN's 4th Strategic Plan outlines a strategy for aligning activities with the global change and sustainability communities. The strategy has four main objectives:

1. Communicate and collaborate closely with organizations in the evolving global change and sustainability communities

2. Encourage APN-supported projects to proactively seek collaboration with institutions and organizations that provide co-sponsorship and in-kind contributions

3. Seek active involvement of relevant institutions to collaborate in activities

4. Establish partnerships, as appropriate, with programmes of the global change and sustainability research community

\subsection{Engagement}

APN places significant importance on networking nationally, regionally and internationally as well. Engagement has ranged from participation and/or presentation in events, convening sessions at events, providing scientific input to organizations/bodies, among others. While the effectiveness of participation, alignment and engagement is outside the scope of the report, the level of involvement shows how APN has fared vis-à-vis strategic alignment with select bodies among the global change research and sustainability communities. Observations on the strengths and challenges are discussed.

\subsubsection{Science}

WCRP: With an investment of over USD 600,000 for 11 research and capacity building activities in the 3rd and 4th Strategic Phase, APN continues to forge strong collaboration with WCRP in expanding its work in the region. This support for WCRP science in the region is recognized and acknowledged globally by WCRP who views APN as a crucial partner for the region. In December 2019, APN participated in WCRP's 40th Anniversary Symposium and introduced the contribution of APN to the objectives of WCRP through the funding of projects on policy-relevant research and capacity development projects in the Asia-Pacific region. WCRP welcomed the crucial role of APN in supporting the advancement of climate change projections and downscaling in the region and in building the capacity of early-career scientists working in climate research.

Future Earth: During the writing phase of the 3rd Strategic Phase review and the 4th Strategic Plan, ICSU's four core Global Change Programme (IGBP, IHDP, DIVERSITAS and ESSP) were in the process of transitioning into a 10-year initiative, Future Earth. This initiative is in the form of an international platform for research, innovation, and collaboration working to accelerate transformations to sustainability. The existing core projects of the former global change programmes officially became global research projects of Future Earth in 2015. APN played an essential role in the scoping workshop organized to address the needs of the scientific community in the Asia-Pacific region under the aegis of Future Earth. In terms of collaboration, APN supports Future Earth and its research projects including GCP, IGAC, MAIRS, SOLAS, IMBER, ESG, GECHH (all core/joint projects of the former GC programmes). Support is provided through APN's calls for proposals, and more than USD 400,000 has been awarded in the 4th Strategic Phase.

Recently, the Secretariat has become engaged in discussions with Future Earth (Global and Regional Hubs in Japan) on how to enhance collaboration between APN and Future Earth. APN is currently discussing cooperation with Future Earth, in particular Future Earth Asia, based in Kyoto, Japan. With the two core functions of Future Earth being (i) research coordination focused on international sustainability science, and (ii) capacity building to support the field of Sustainability Science with national, regional and global communities, a partnership approach for APN and Future Earth could be mutually beneficial.

Belmont Forum: APN is well known to the Belmont Forum. APN is invited to and attends annual Belmont Forum meetings. In terms of the extent of collaboration, this has remained at the meeting level allowing for dialogue and information exchange. Generally, APN attends the meetings in the capacity as an observer and has opportunities to exchange dialogue with participants from other related organizations offline (for example, IAI, START). At the most recent meeting in October 2019, the Secretariat was made aware that India and Thailand are now members of the Belmont Forum (Japan has been a member since Belmont Forum was established). This increase in membership from Asia may present an opportunity to explore further collaborative 
engagement with the Belmont Forum. Further, earlier in 2019, the Executive Director of the Belmont Forum Secretariat visited the APN Secretariat and expressed the idea to develop a Small Islands initiative that could engage APN, IAI and the Belmont Forum. While it is unclear what collaborative activities APN and Belmont Forum could embark upon; from discussions between the Secretariats, it was agreed that this an important issue that needs to be explored. Talks have been ongoing since early 2019 in this regard.

Asia Pacific Adaptation Network (APAN): APAN was formed as an arm of the Global Adaptation Network (GAN), and APN was instrumental during the initial scoping phase to establish the Network. Since then, APN has become actively engaged in the work of APAN and continues to organize side events during the biennial APAN forums. In 2016 in Sri Lanka, APN organized two side events promoting the outputs of its Climate Adaptation Framework. In 2018 in the Philippines, APN shared its activities on community adaptation and resilience. The impact and exposure of APN's work at these regional events is more significant than at similar global events like the "Adaptation Futures" conferences, held biennially. The seventh forum of APAN is scheduled to be held in March 2021. APN is encouraged to use the opportunity to broaden its participation in APAN activities.

\subsubsection{Science-policy linkages}

\subsubsection{Intergovernmental Panel on Climate Change (IPCC)}

APN's engagement in IPCC has grown significantly in the present phase, and the Secretariat has been proactive in promoting APN products in IPCC reports. This has been realized through collaboration with the Asian Institute of Technology (AIT) and with ANCST to ensure that the results of APN work are visible in the IPCC AR6 (see also Section 3.4.5). This collaboration has also prompted the engagement of both project leaders and early-career scientists in the IPCC AR6 cycle. In the present assessment round (IPCC AR6), approximately 30 members, project leaders and collaborators in APN activities are authors, lead authors, coordinating lead authors or reviewers. It is expected that the completed work will also cite peerreview publications of relevant APN-funded research. APN worked together with AIT to prepare a Special Issue of 15 research papers from work conducted in APN projects. The guest editors of the Special
Issue are authors of Chapter 10 of Working Group II of the IPCC AR6 report. The Special Issue "Climate Change Impacts, Vulnerability and Adaptation: Asian Perspective" is published in the Elsevier journal "Environmental Research". APN Secretariat has also taken the initiative to contribute to the review of the IPCC AR6 WGII draft report.

Contribution to IPCC AR6:

- Three members of the Secretariat registered as reviewers of the First Order Draft (FOD) of WG2 of IPCC AR6 and provided over 90 review comments to the assessment report.

- Comments/questions on clarity and substantial comments on the FOD content itself and references were made.

- Fifty (50) publications/papers from the APN-funded projects were put forward or used as supporting literature/references when the Secretariat made substantial comments.

- APN Science Bulletin articles were used as a basis when providing comments and questions on content in addition to high-impact journal publications by project leaders.

\subsubsection{United Nations Framework Convention on Climate Change (UNFCCC)}

- COP: Increasing engagement at member country pavilion events (2019 - China, Japan and Thailand).

- Subsidiary Body for Scientific and Technological Advice (SBSTA):

- Nairobi Work Programme (a partner who contributes adaptation outputs for dissemination).

- Annual International Research Dialogue with the Parties (held at "even-numbered" SBSTA meetings).

- Collaboration with SBSTA at the COP meetings with most recent being at the SBSTA-mandated event at UNFCCC COP 25, December 2019, in Madrid, Spain, under the theme "Earth 
observation for science, policy and practice: Cases from the Asia-Pacific region. ${ }^{5}$

- International Warsaw Mechanism - indirectly through APN's Loss \& Damage projects under its Climate Adaptation Framework.

- National Determined Contributions (NDCs) Capacity building for developing NDCs (under three CAPaBLE projects).

\subsubsection{Intergovernmental Science-Policy Platform on Biodiversity and Ecosystem Services (IPBES)}

APN is an observer member of IPBES and a partner organization of its Stakeholder Forum. APN is also a contributing partner in IPBES' capacity-building rolling plan, which relies on support and collaboration with a range of institutions conducting capacity building activities. APN has attended all IPBES' plenaries, the most recent being in Colombia in 2018, and the IPBES Capacity Building Forums in India (2015), New York (2016) and Paris (2018). APN also attended the AsiaPacific regional dialogue meeting in 2017, which was intended to strengthen government engagement in the production and use of the IPBES regional assessments.

Another important partnership endeavour was the undertaking of Component 3 of a project entitled "Capacity Building Project for the Implementation of IPBES Asia-Pacific Regional Assessment", and funded by the Japan Biodiversity Fund through the Secretariat of the CBD. Partnering with IGES and IPBES-TSU for Asia-Pacific, three science-policy dialogues for South Asia \& West Asia, Oceania, and Northeast Asia \& Southeast Asia, were held in Nepal, Australia and Thailand, respectively, with the aim of facilitating the understanding of the findings of the IPBES Asia-Pacific Assessment. The dialogues adopted a "challengessolutions" structure that provided meaningful interactions to address gaps across knowledge, policy, and practice.

Based on the outcomes of a series of biodiversity science-policy dialogues drafted by APN and IGES, two policy briefs are in the final stages of preparation:

5 https://unfccc.int/topics/science/events-meetings/systematic-observation/ earth-information-day-2019
- Policy brief: Biodiversity challenges and solutions in Asia and the Pacific ${ }^{6}$

- Policy brief: Raising awareness of the IPBES Regional Assessment for Asia and the Pacific ${ }^{7}$

\subsection{Observations}

APN has made efforts to align with the global change research and sustainability communities. Significant engagement with IPCC and UNFCCC is encouraging because of APN's goals to provide scientific research results that are policy-relevant. In the policy arena, APN's collaboration with bodies such as UNFCCC (SBSTA and NWP), IPCC and IPBES continues to grow, and APN is well known among these international science-policy bodies. On the other hand, trends in engagement with the international science community are less encouraging. For example, APN does not have the same level of interaction as it once did with the former Global Change Core Programmes under ISC (formerly ICSU). Engagement with START at regional scales in TEA and SEA continues, although collaboration with START International has decreased, perhaps as their regional focus has shifted towards Africa. The last significant activity with START was the Pan Asia Risk and Resilience programme as a CAPaBLE activity. Summarizing, APN's engagement at the regional level, particularly in Asia, has developed significantly.

\subsubsection{Regional recognition}

APN has a strong presence in the regional context of "Asia" and "Asia-Pacific", the latter being more aligned with attendance and strategic engagement at events such as APAN biannual adaptation fora, and annual GEOSS-AP (now AOGEO) symposia. APN is a wellknown and respected (even considered prestigious) network in Asia, a status that has been realized through its calls for proposals and invitations to project and regional partner events. Dialogue at these events has been fruitful, resulting in APN becoming engaged directly with a growing list of institutions in the region, including AIT, SAARC, CDKN, LEAD, etc. While some

6 Mader, A. D., \& Uchiyama, C. (2020). Biodiversity challenges and solutions in Asia and the Pacific (Policy Brief). Institute for Global Environmental Strategies.

7 Mader, A. D., Stevenson, L. A., \& Uchiyama, C. (2020). Raising awareness of the IPBES Regional Assessment for Asia and the Pacific (Policy Brief). Institute for Global Environmental Strategies. 


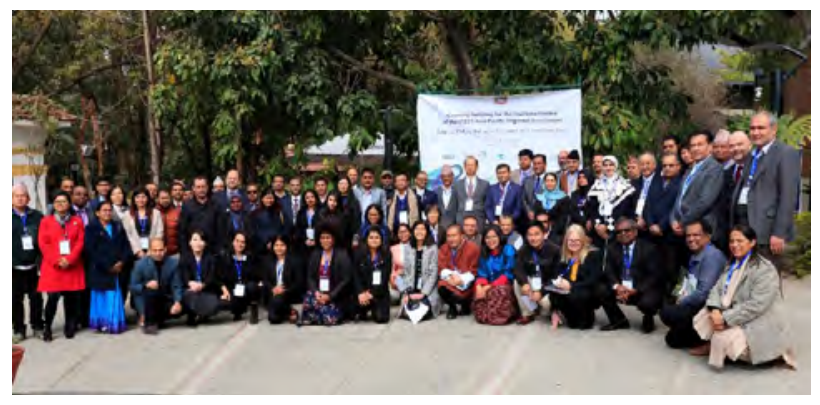

Science-Policy Dialogue for South Asia \& West Asia, Kathmandu, Nepal, 20-21 February 2018

activities are ongoing in the Pacific, APN is less known in this region (see Section 4.3.3).

\subsubsection{Science-policy linkages}

APN's profile in the science-policy community has grown significantly compared with past years. This can be attributed to the collaboration with regional bodies such as AIT and ANCST in promoting the work and engaging more with APN in the IPCC, in particular, the current 6 th assessment cycle. APN is a partner organization of the UNFCCC Nairobi Work Programme (NWP) and IPBES. APN and SBSTA engagement is strong, particularly in connections with the Secretariat in Bonn and collaboration is increasing, with the most recent involvement in the UNFCCC Earth Observations day at COP25 in Madrid, Spain in December 2019.

The above said, in the context of pursuing a higher level of engagement and formal recognition in UNFCCC, the most significant challenge faced by APN is its inability to register observer status. While there have been attempts in past years, APN is not recognized as a legal entity, meaning that it cannot organize its own side events at COP and SBSTA meetings, but instead is dependent on other organizations. Currently, APN, through IGES, can obtain a one-week pass to attend COP meetings. However, in so doing, APN cannot be recognized as an independent intergovernmental entity, which hinders international recognition in the policy arena. This is also the situation with IPCC.

\subsubsection{APN engagement in the Pacific}

Engagement with the Pacific remains a challenge, and the "Pacific" component of APN in terms of working with strategic partners is missing. APN has had some engagement with the Pacific Science Congress and, in 2017, attended a Regional Workshop on the preparation for COP23 in Bonn, Germany (hosted by Fiji), and held in Suva, Fiji. Further, awareness of APN is low in the Pacific community, which is evident from the lack of proposals from this region, and through conversations with government representatives from the Pacific who attended the workshop in Suva in 2017. To this end, while some activities are ongoing in the Pacific, APN is less known in this region compared with Asia, and enhanced awareness and collaboration with Pacific-based institutions are needed to ensure the Pacific component of APN benefits from the network and its activities

\subsubsection{APN, the Sustainable Development Goals and the Sendai Framework}

The SDGs and Sendai Framework came into action in 2015 just before the launch of APN's 4th Strategic Phase and are, therefore, not mentioned explicitly in the 4th Strategic Plan. The challenge presented here is that APN needs to be more dynamic in its work in order to keep abreast of the changing global arena. In APN annual reports, the Secretariat makes efforts to align the outputs of its projects with the 17 SDGs to show the relevance of APN's activities towards achieving the SDG targets. As for the Sendai Framework, APN is aligned through one of its research agenda themes on risk reduction and resilience, and has had significant focus in the annual call for proposals in the period of the 4th Strategic Phase.

\subsubsection{APN, Future Earth and the Belmont Forum}

While APN continues to provide funding for the core projects of Future Earth, direct engagement at the institutional level has been challenging. In the 4th Strategic Phase, APN has provided approximately USD 420,000 to eight core projects of Future Earth. With this knowledge and the need to strategically align activities with the international research community and global agendas, direct contact with the national, regional and global hubs established in the Asia-Pacific region is needed. Engagement with the Belmont Forum has primarily been at the knowledge-sharing level and opportunities have been presented to share information and network with like-minded organizations at Belmont Forum meetings. APN needs to consider a more concrete strategy if it wishes to develop a deeper and more meaningful partnership with the Belmont Forum beyond the level of showand-tell. Discussions as recent as October 2019 has confirmed that collaboration should move to a more engaging level. 


\section{Conclusion}

Chapter 1 describes the significant initiatives of APN that enables the promotion of its vision to address the challenges of global change and sustainability as the member countries accelerate their development aspirations. APN's efforts to achieve this vision has taken different forms of structured and semi-structured initiatives and designed to understand, predict and respond to both natural and anthropogenic forcing, assess the vulnerability of both natural and human systems, and provide evidence-based policy options for relevant interventions. The activities engaged scientists, policymakers and communities in understanding and implementing vulnerability and adaptation tools that applied both science and traditional knowledge and produced custom-made models, tools and other products. These outcomes were possible by centralising the 4th Strategic Phase goals into the core of APN activities thus effectively addressing regional cooperation for global change and sustainability research; capacity enhancement for science-policy engagement and promoting partnerships among global change and sustainability networks.

APN's two core programmes continue to be the main pillars for funding, i.e. for CRRP and CAPaBLE with its origin as a WSSD Type II partnership initiative. The third set of initiatives called framework activities was also reported. Following an established assessment and selection mechanism, 30 projects from 119 completed in the 4th Strategic Phase were highlighted, including ten from CRRP, ten from CAPaBLE, seven from frameworks (CAF, LCI and B\&ES) and three from CRYS. These projects were selected to provide readers with a feel for the kind of work that APN engages in, and how this work has contributed to the core goals and objectives outlined in the 4th Strategic Phase.
The APN Secretariat itself has been responsible for a host of significant activities. These have included events with stakeholders of APN, including the Hyogo Prefectural Government; subregional science-policy dialogues, capacity building opportunities for earlycareer professionals through various programmes and mechanisms such as CRYS programme, PDTWs, fellowship opportunities, and other innovative activities that have engaged policy communities including IPCC, SBSTA/UNFCCC, among others. The Secretariat has also secured funding from co-sponsors, including Future Earth's core project PAGES, and CDKN in two of its subregional activities in South Asia.

As the preceding paragraph has demonstrated, the list of activities of APN's international engagement detailed is long, although a complete account necessitates an even longer list that would include the global 2030 sustainable development agenda in the form of the 17 SDGs, networks such as SDSN and CSD; the Paris Agreement, and the Sendai Framework for Disaster Risk Reduction.

It is evident that APN continues to address its goals effectively, contributes successfully to policy, regional research and addresses local issues in a regional context. APN is contributing to the capacity development of ECS and thus equipping the next generation with the knowledge to address current, emerging and future challenges in global change. Finally, with the rationale that as long as knowledgebased capacity helps Asia-Pacific communities to manage energy, oceans and land sustainably, make cities smarter for ecosystems, deal effectively with the vagaries of a changing climate and disaster risk reduction, while ensuring food security and overall wellbeing, then APN is serving its member countries. 
Chapter 2.

Communication

and outreach

report 


\section{Introduction}

As a network of governments and scientists in the Asia-Pacific region, APN brings together and engages policymakers, researchers and practitioners in its various activities. It is therefore crucial that any communication and outreach effort reaches these diverse yet interconnected groups and contributes to effective information exchange and dialogue among them.

In the 4th Strategic Phase, APN continued to publish and make available research products and science policy-information, mostly digitally, which are promoted through various channels such as social media, email and in outreach activities and international events. Section 2 of this chapter reviews the work undertaken in communicating APN information and evaluates its effectiveness. This is mainly done by looking at web monitoring data during the reporting period. Section 3 discusses the outreach activities, which are mostly linked to activities discussed under Chapter 1 . Section 4 provides an analysis of the data and results presented in previous sections. Based on the review, challenges and opportunities are presented for possible uptake and action in the next Strategic Phase.
The data used in this chapter are mainly provided by Google Analytics for the period between 1 January 2015 and 31 December 2019 ${ }^{1}$. Download data is generated by AwStats based on server access logs. Social media data are provided either by Google Analytics or by individual social media platforms.

\section{An increasing digital presence}

APN has significantly strengthened its digital communications capabilities in the 4th Strategic Phase by reducing print publications and increasing its emphasis on engaging members and other audiences online. The Secretariat continued to maintain and update its electronic library (E-Lib), which has become a key component of the APN website in terms of contribution to the website traffic. The APN Science Bulletin is digitized, with full-text articles available online. The Secretariat established a workflow for sharing customized messages on APN products via email and social media channels. The following sections discuss these digital communication activities in detail.

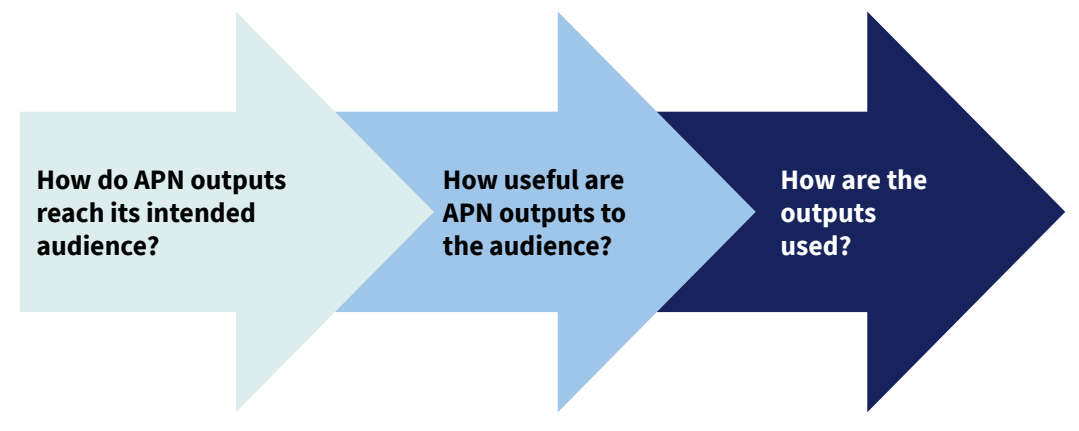

Figure 2.1. Key questions asked (adapted from Cassidy \& Ball, 2018).

To understand the effectiveness of communication and outreach, this chapter asks the following three essential questions based on the Communications Monitoring, Evaluation and Learning (MEL) Toolkit published by the Overseas Development Institute: How do APN products reach its intended audience? How useful are APN products to the audience? How are the products used? See Figure 2.1.

\subsection{The reach of APN public information}

\subsubsection{Website}

For the APN website as a whole, more than 80 percent $(80.1 \%)$ of all users $(145,923)$ are from APN member countries or approved countries (for this chapter, "APN countries" for short) during the data collection

\footnotetext{
1 Due to technical reasons, Google Analytics data for the main content management system (excluding E-Library, Science Bulletin, APN information system and other components) are missing between 16 June 2017 to 30 April 2018. Google Analytics data for the E-Library between 5 March 2015 and 7 September 2015 are missing. Visits from the APN Secretariat office are excluded from Google Analytics data. The definitions of users, sessions and page views used in this Chapter are in line with those on the Google Analytics help centre: https://support.google.com/analytics/.
} 
period (Figure 2.2). Analytics data suggest that the APN website performs better than benchmark websites within the "Climate change and global warming" category over the reporting period, particularly in terms of the number of pages per session and the average duration per session, which can be interpreted as user interest and engagement.

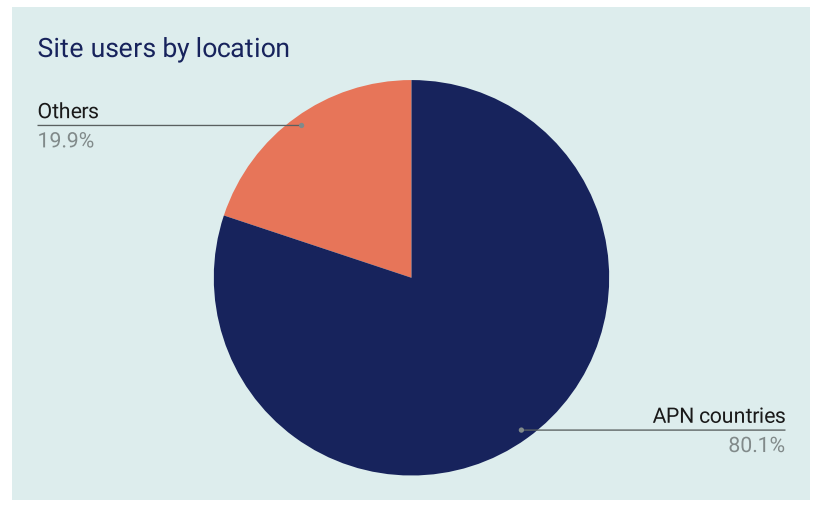

Figure 2.2. Site users by location, APN member countries and other countries.

\subsubsection{Email campaigns}

An average public email announcement is sent to 2,778 subscribers and viewed by 732 subscribers (26.3\%). The actual proportion of viewers among active users may be higher due to the existence of inactive email accounts in the mailing list. An average APN email announcement brings about 200 users to the APN website. Announcements about calls for proposals, drew many more users to the website, averaging 850 each, with the top one reaching 1,249. Users drawn from the call for proposals announcements also spent more time on the site than average. In contrast, six policy briefs published under the Low Carbon Initiatives (LCI) Framework that were disseminated individually using email campaigns had poorer responses. Each of these emails drew 95 users on average to the website, although products from two $\mathrm{LCI}$ projects rank high in the top downloads list (see section 2.1.4.2 below).

\subsubsection{Social media}

The Secretariat uses Facebook, Twitter and LinkedIn to disseminate news, announcements and products. Of these three platforms, Facebook contributed about $80 \%$ of user sessions $(21,583)$ and page views $(37,854)$, according to Google Analytics (Figure 2.3). Users from these channels stayed on the website for a shorter period than the site average. Interestingly, users tend to stay much longer if they are referred to the APN website from other social networks where APN-related contents are generated voluntary by external users, for example, ResearchGate, Reddit and WordPress.
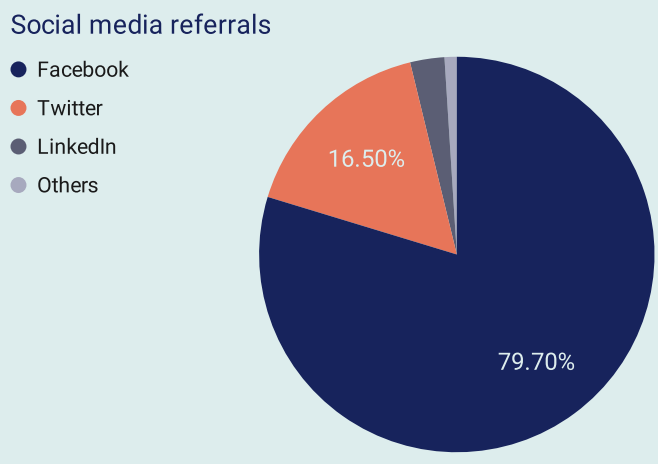

Figure 2.3. Contribution of sessions to APN website by major social media networks.

Facebook users who liked the APN page has been steadily increasing, with a total of 2,908 likes by the end of December 2019. For the period between June 2017 and December 2019, 365 posts were published via Twitter, generating 555 URL clicks, 288 likes, 182 retweets, and nine replies. At the time of writing, APN Twitter and LinkedIn accounts have 1,098 and 273 followers, respectively.

\subsubsection{APN products}

\subsubsection{Overview}

The overall reach of APN hosted products ${ }^{2}$ by country is similar when it comes to APN knowledge products. Of the 36,953 users of APN products (25.3\% of total), more than three quarters (77.5\%) come from APN member countries; of these users, $66.3 \%$ are from APN developing countries. Users from Viet Nam, Thailand, Australia and Malaysia access more APN products than all pages in general.

\subsubsection{Downloads}

Of the top 50 downloaded products (Appendix 4), a third (17) are final reports of APN funded projects, and the rest is a mix of different types of product produced from APN-funded projects, notably guides/guidelines, toolkits, case studies, proceedings, and journal articles. A third (18) of the top 50 publications were published in 2015 or later, with older dating back to as early as 2001.

2 For simplicity, this Chapter considers users of the E-Library and APN Science Bulletin as users of APN products, because most APN products are housed under these two components of the APN website. 
Of the 18 products published after 2015, the majority (13) are case studies, guides/guidelines, policy briefs, or infographics (Figure 2.4). Full-length final reports take up over half of those that were published before 2015. Four publications on the list are "institutional" products such as annual reports, the 4th Strategic Plan, and IGM proceedings.

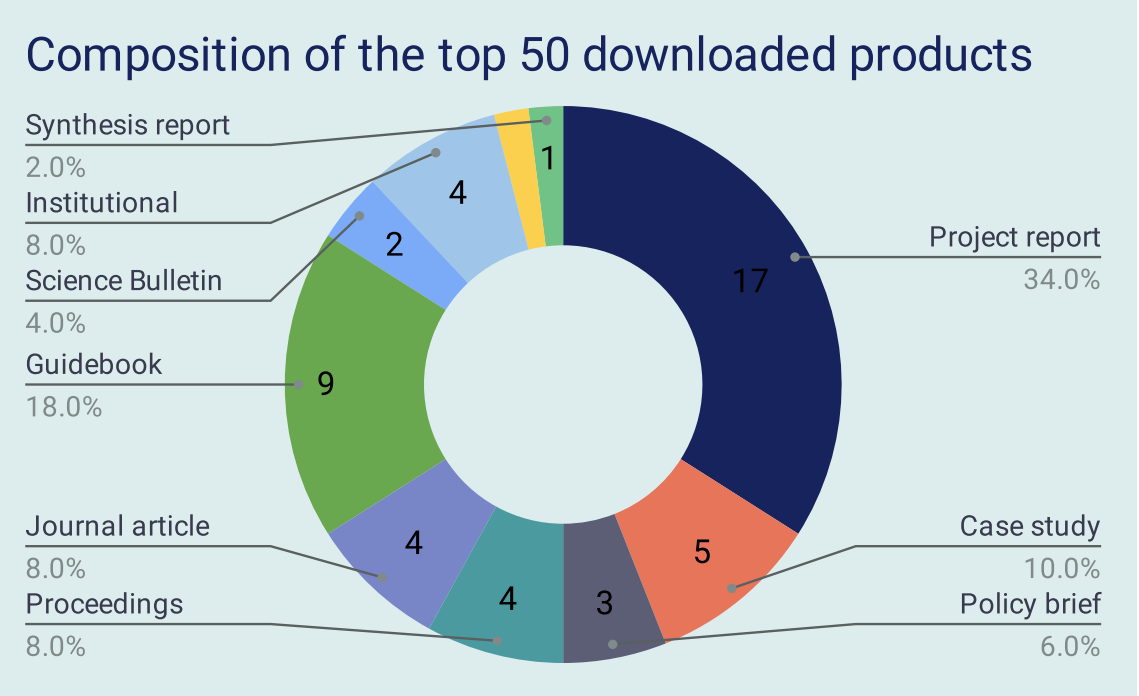

Figure 2.4. Top 50 downloaded products by type (Jan

2015 - Dec 2019).

It is also worth noting that not all top publications are written in English. Increasing National Capacity of Adaptation for Climate Change through Cross-Sectoral and Regional Cooperation, a proceedings prepared in Bahasa Indonesia, for example, recorded 6,248 total downloads from 2015-2019, ranking 4th. Guidelines for Technology Selection for Sustainable Solid Waste Management in Ho Chi Minh City, Viet Nam (in Vietnamese), and A Guide for Technology Selection and Implementation of Urban Organic Waste Utilization Projects in Cambodia (in Khmer) also recorded over 4,000 and 2,500 downloads respectively, which is significant considering the potential audience size of those languages.

Among in-house scientific publications, two issues of the APN Science Bulletin (2014 and 2016) made the top 50 list, with 3,661 and 2,283 downloads respectively ${ }^{3}$. The synthesis report Climate in Asia and the Pacific: A Synthesis of APN Activities (2011) received 2,187 downloads, ranking 34th on the list. As a comparison, APN's book Climate in Asia and the Pacific, Security,

3 Since the 2017 issue, the APN Science Bulletin have been available both in PDF version and in the form of full-text web pages. More details about the web version of APN Science Bulletin is provided in Section 2.1.4.3.
Society and Sustainability (2014), which is available through Springer, received 4,164 downloads from 2015 to 2018.

\subsubsection{APN Science Bulletin}

The APN Science Bulletin has adopted a peer review process since 2016 and started to publish full-text web content online in 2017. To improve the visibility of these articles, especially among the research community, each article has been assigned a Digital Object Identifier (DOI) with metadata deposited at Crossref. Since its launch as an online publication in December 2017, readers have been steadily increasing, as can be seen in the increased sessions and page views over time (Figure 2.5). Visitors to the Science Bulletin account for a significant $13.6 \%$ of all users since the web version was launched. As all articles are available in both web and PDF formats, the reach and impact of these articles are likely to be much larger than if they were published only in one single format. Of the 30 Science Bulletin articles published since late 2017, Crossref has reported 15 citations at the time of writing. 


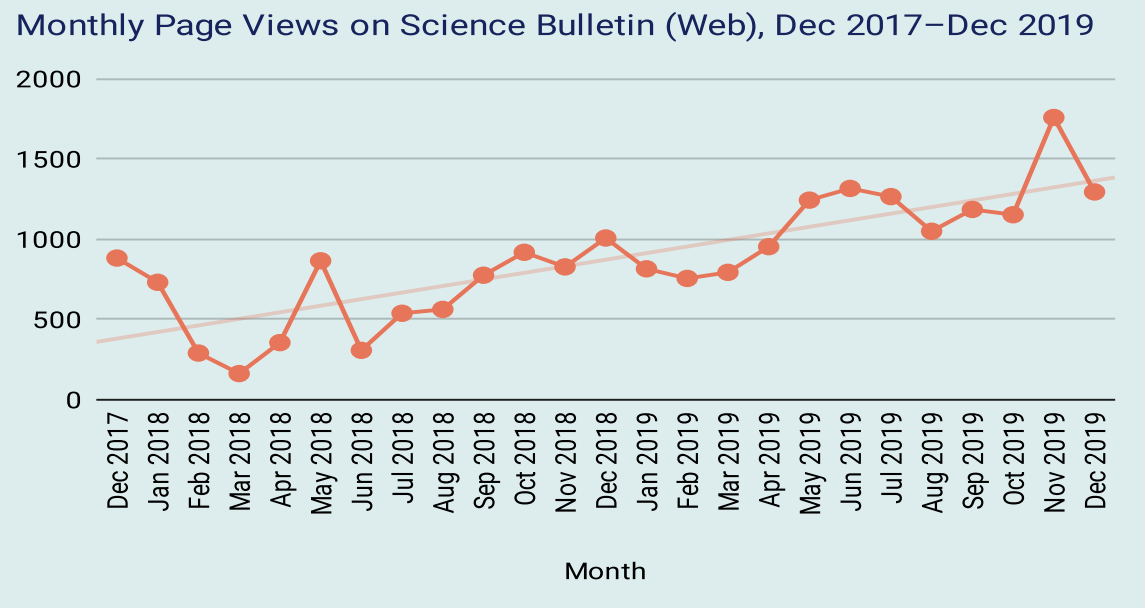

Figure 2.5. Page views on the APN Science Bulletin (web version)

\subsubsection{Communication with members}

In addition to face-to-face reporting provided at various meetings, APN members are regularly informed by email communications, including on recently closed projects, products, summaries of meetings, opportunities for funding, and upcoming events. Since mid-2018, the Secretariat improved its workflow of producing short, concise messages based on recent updates, for regular dissemination via a "membersonly" broadcast list. At the time of writing, over 80 such messages have been compiled and disseminated. This special mailing list seems to perform slightly better than the public list, where on average $30.7 \%$ of emails were viewed, and when members visit the APN website, they spend much more time on the site than average.

It is difficult to quantitatively measure how knowledge products of APN activities reach its member countries by analyzing web analytics data, because such data do not reveal visitor identity. A questionnaire survey conducted by the Secretariat in 2016 that involved 30 former and current members may provide some insight into policymakers' perceptions in this regard. Results of the survey show that half of the respondents agreed, or somewhat agreed, that "outcomes of APN activities effectively reach the policymaking community in their countries". Among those who remained neutral or negative, some cited the challenge of reaching the right level of the policymaking community, while others suggested that policymakers should be engaged in the co-design process at the project design phase. Indeed, effectively communicating outcomes of scientific research to support decision-making has been a challenge not only for APN, but also for other similar networks, and indeed the global research community, working at the interface between science, policy and action. To facilitate science-based decision-making in the next Strategic Phase, APN will continue to explore and adopt effective mechanisms to communicate outcomes of its activities to policy-and decision-makers in the Asia-Pacific region.

\subsection{The quality and usefulness of APN products}

While it is important to ensure the reach of APN products, it is equally important that these products are of high quality, in terms of both content and presentation, if they are to be taken up and used by its diverse groups of stakeholders. This section discusses the quality and usefulness of APN products by referring to the key questions and indicators provided in the MEL Toolkit.

\subsubsection{Editorial and production process}

An effective editorial and production process is essential to ensure the quality of products. In 2017, an editorial style guide was developed and promoted across the Secretariat. The guide has helped improve consistency in materials prepared by the Secretariat, but there is still a heavy burden on editors because members of the Secretariat have different language styles.

As a further step to improve the quality of all products-not just in-house products-a publication 
guide was approved in 2018, offering high-level guidance on language and style, scientific integrity, copyright and licensing notices, as well as design and layout. The publication guide also provided standard templates for the copyright notice, disclaimer, an official description of APN, including the full name, acronym and logo. The guide is to be actively promoted among APN project teams.

In-house publications, particularly annual reports, went through a full production process from the compilation of materials and data, drafting, copyediting, to design and desktop publishing. The style guide, for example, has been enforced in the proceedings of Intergovernmental Meetings and annual reports during the editorial process. As for products submitted by APN-funded projects, they are required to be professionally edited before they are submitted to APN. However, editorial quality varies even after professional editing.

\subsubsection{Peer review}

Most journal articles published by project teams through third-party publishers are peer-reviewed. In addition, the APN Science Bulletin has adopted a peer review process that involves external reviewers since 2016. Normally, three reviewers are invited to review submissions and provide constructive feedback for improving the manuscript. After two rounds of revision, the draft is edited and approved by the Secretariatbased managing editor, before being published online.

\subsection{The usage of APN products}

\subsubsection{Citation in research articles}

Citation of APN products can provide some indication of their usage, particularly among the research community. So far, over 1,400 articles mentioning APN have been indexed in Google Scholar, and nearly 600 of them are published after 2015. Among them, and at the time of writing, articles published under the APN Science Bulletin collectively received 66 citations. Chapter 1 provides details on the citations of peer-reviewed articles published by 27 selected APN projects through third-party publishers.

\subsubsection{Indexing and usage by major platforms}

APN-funded research products are openly accessible and have been cited by many academic research platforms, which has further improved their visibility and possible usage. These platforms include Google Scholar (nearly 600 products by searching for mentions of APN), CORE, a not-for-profit service delivered by The Open University and Jisc of UK (203), Bielefeld Academic Search Engine (BASE, 62), ResearchGate (42), JSTOR (58) and UNDRR's PreventionWeb (61).

APN products are also fed into international organizations such as UNFCCC (especially SBSTA and the NWP), IPBES, Asia-Pacific Adaptation Network (APAN), Asia-Pacific Adaptation Information Platform (AP-PLAT), among others. This is done by presentations at international meetings organized by these bodies, by organizing side sessions to share outcomes of APNfunded projects, or by providing compiled information in response to requests by these organizations.

\subsubsection{Usage by the media}

According to information provided by Google Alerts and Google News, APN is seen on local, national and international media during the reporting period (Appendix 5). This media is based in eight countries during the reporting period, including Australia (The Conversation), Bangladesh (Dhaka Tribune, The Daily Observer), Germany (Deutsche Welle), India (The Hindu, The Times of India, etc.), Nepal (My Republica), New Zealand (The New Zealand Herald), Pakistan (Pakistan Today, The Nation), and Sri Lanka (Sunday Observer). One article published on The Conversation by a project leader has attracted over 1,800 Facebook shares, over 100 retweets, and 65 comments by the time of reporting. Five articles are published as a result of the South Asia Media Fellowship event organized in 2016. Increased knowledge management, including exploring effective knowledge management tools, is required to better understand APN's position in the media landscape of all member countries.

\subsubsection{Usage by policymakers}

Many APN products have certainly contributed directly or indirectly to global assessment processes such as 
the Assessment Reports of IPCC and IPBES, and thus created an impact on the policymaking community. One example of usage by policymakers is the National Adaptation Plan of Sri Lanka submitted to UNFCCC, which cited a research product on Kandyan home gardens published in the APN Science Bulletin ${ }^{4}$. To systematically gauge the degree of such impact, it is necessary to develop indicators for monitoring and evaluation, and administer surveys, interviews and evaluations at the organization level.

\section{Outreach activities}

In this chapter, we define outreach as raising awareness and fostering dialogue at different levels with governments, civil society and the public, media, academia, educators, students and other stakeholders. In many cases, outreach is a component of larger activities. It may be part of a proposal development training workshop, a poster session at IGMs, a science-policy dialogue, a side session or a booth at international conferences (such as UNFCCC, ISAP, APAN, EMECS), a media event (such as the media fellowship and early-career communicator grant), or a local event (such as Satoyama symposia in collaboration with the Hyogo Prefectural Government, Japan). Many events organized by project teams also have an outreach component to raise awareness within academia and policymaking communities. According to reports submitted by project teams, activities conducted by APN-funded projects alone have reached over 1,800 and 2,000 people in fiscal years $2016^{5}$ and $2017^{6}$, respectively. While a detailed review of such activities has been provided in Chapter 1 , it should be noted that APN greatly relies on its member countries and project teams to undertake these activities, which have raised the APN profile significantly.

\footnotetext{
4 Weerahewa, J., Pushpakumara, G., Silva, P., Daulagala, C., Punyawardena, R., Premalal, S.,

\& Marambe, B. (2012). Are homegarden ecosystems resilient to climate change? An analysis of the adaptation strategies of homegardeners in Sri Lanka. APN Science Bulletin 2, 22-27

5 Asia-Pacific Network for Global Change Research. (2017). APN Annual Report, FY 2016. Kobe: APN. doi:10.30852/ar.2016.

6 Asia-Pacific Network for Global Change Research. (2018). APN Annual Report, FY 2017. Kobe: APN. doi:10.30852/ar.2017.
}

\section{Review and discussion}

\subsection{APN website as a knowledge platform}

The information presented above shows that as a knowledge platform, the APN website provides timely and relevant information that effectively reaches audiences in APN member countries. Many project reports tend to have a lasting impact that span across strategic phases, which is evident in their proportion in top downloads. As discussed in Section 2.1.4.2 and shown in Figure 2.4, the impact of some reports lasts for decades after its publication.

On the other hand, shorter-form, policy-oriented and more practical information, such as guides and case studies, draw more immediate attention from the audience than full project reports. In this regard, it will be useful to refine the information structure of the website to accommodate the diversity of APN products and to improve its usability as a knowledge platform.

Although a vast majority of products are published in English, some practical information provided in local languages seem to be very popular reference material in individual member countries. To serve APN's vision of enabling countries to successfully address the challenges of global change and sustainability, it will be useful to encourage the development of quality products in local languages to increase reach, usefulness and impact.

While the available information is helpful to understand the reach of APN products, what remains unclear is how these products reach different types of audiences, such as researchers, policymakers, practitioners, the media, civil society and the public. From the survey mentioned in Section 2.1.5 above, it can be inferred that further efforts could be invested to improve the reach of APN products to the policymaking community. In this regard, APN can increasingly place greater emphasis on developing more policy papers and policy briefs with clear key messages or recommendations. To further understand the reach and impact of APN products, which mainly consist of results and outcomes from the core CRRP and CAPaBLE programmes, designing and implementing a carefully developed mechanism to measure and collect audience feedback on APN products throughout a strategic phase will be very useful in the future. As web analytics data alone does not provide much insight 
into the usefulness and usage of APN products, such a mechanism is crucial for APN to understand and respond to the needs of its audience and take strategic action in response to such understandings. For example, a more systematic survey could be developed for continuous monitoring of feedback by different audience groups. For the survey to be effective, a set of carefully developed indicators must be developed in advance.

\subsection{APN website as a network of policymakers, researchers and practitioners}

\section{In 2015, a discussion forum "Friends of APN" was} launched to facilitate interaction among policymakers, researchers and practitioners within the APN community. The forum was closed in 2017 because of security issues and a general lack of activity, which may be a result of the lack of promotion and moderation due to human-resource constraints, combined with an ineffective user interface.

\subsection{Engaging users through email and social media}

Email announcements and social media effectively contribute to expanding the reach of APN products and information. Emails are very effective in disseminating information on funding opportunities, particularly the annual call for proposals. From a member perspective in keeping them informed of APN activities, personalized emails may be more effective than general email announcements.

Although APN does not have a dedicated strategy for social media engagement in the 4th Strategic Phase plan, social media sites still contributed significantly to the visibility of APN, with Facebook and Twitter being the top channels with the most user interaction. This said, caution should be given to social media because users drawn from Secretariat-managed social media sources seem to spend less time on, and interact with, the APN website than users from other sources such as search results, or direct visits. The only exception is users drawn from purely user-generated content, who appear to be very interested in the content on our website. Therefore, in addition to "broadcasting" in social media sites, it is worthwhile to promote usergenerated content in social networks. As an example, this could be done by integrating social sharing and commenting features on the APN website. In the future, APN can consider using more professional social media management tools to improve monitoring.

\subsection{Publications}

Having understood the lasting impact of many APN products available on the internet, it is crucial that these products are of high quality in terms of both content and presentation. In the 4th Strategic Phase, the style guide and editorial requirements mentioned in Section $\mathbf{2 . 2}$ have improved the quality of APN products to some extent, especially considering the diverse nationalities of members of APN project teams.

The above said, a comprehensive production process should be developed and implemented, including by improving the publication guide, to ensure compliance with those requirements, ultimately to improve the quality of APN-funded products as well as ensure that APN continues to be perceived as a credible source for information. Particularly, an improved publication process would require APN-funded projects to include a brief communication strategy that clarifies the problem statement, objectives of their products, the target audience, the key messages and indicators of success (Figure 2.6). This process must also keep in mind the requirement for different types of products.

Many public funding agencies require articles to be published as open access products. For example, the National Science Foundation (NSF) of USA requires all articles to be published via Green OA (self-archiving) for proposals submitted after January 2016. ${ }^{7}$ The European Research Council also promotes open access to its products and data. ${ }^{8} \mathrm{APN}$ has adopted an open access policy for research data with limited scope. As for APN-funded articles and other products published by a third party, while open access is always encouraged, APN does not have a policy to make it a requirement. In 2018, with the approval of the publication guide, APN-published products will be clearly indicated as open access publications using the Creative Commons license, while no requirements were made to third-party publications. To maximize the reach and usage of APN-funded products published by third parties, an open access policy is required. For

7 https://www.nsf.gov/news/special_reports/public_access/

8 https://erc.europa.eu/funding-and-grants/managing-project/open-access 
example, APN should require peer-reviewed articles to be published in open access journals (either Gold OA, Green OA or other types of open access arrangements).

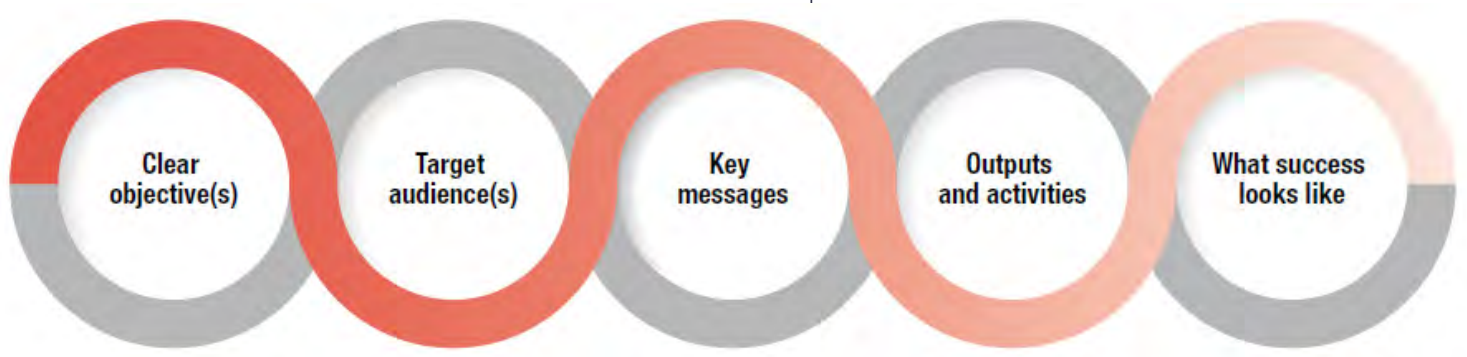

Figure 2.6. Components of a communication plan (Source: Cassidy \& Ball, 2018).

As for the APN Science Bulletin, while it is becoming increasingly recognized as a quality and credible in-house peer-reviewed publication, further steps can be taken to standardize it as an open access journal that is included in major repositories such as the DOAJ (Directory of Open Access Journals), JSTOR Sustainability Collection, among others. For example, to be indexed by DOAJ, APN must publish information and policies that demonstrate the quality and transparency of the editorial process. These include information about the editors and the editorial board, a description of the peer review process, a description of the goals and purpose of the journal, instructions to authors and reviewers, a policy for screening for plagiarism, etc. While the Science Bulletin is being operated as an open access journal, the above information needs to be developed, compiled and made public in order for it to be indexed.

\subsection{Engaging the media}

As can be seen in Section 2.3.3 above, the mass media, such as newspapers and television, creates a strong impact on public awareness. In the future, APN project and activities could include a brief plan for engaging the mass media, which should include, as suggested in the MEL toolkit, a clear problem statement, objectives, target audience, key messages, products and activities, and indicators of success. The media fellowship, described in Chapter 1, Section 3.4.3, has successfully drawn attention from journalists working with major national media outlets in South Asia. To attract more media attention and train a new generation of science journalists, APN, in the future, can consider organizing more media fellowship events in other subregions beyond South Asia. Other than purely media

independent events, an additional and viable option is to ensure invitations are extended to media persons at different APN events. 
Chapter 3.

Institutional report 


\section{Introduction}

APN member countries and the Secretariat have always been striving to improve APN's performance. APN has been very successful in enhancing the capabilities of scientists in the Asia-Pacific region by supporting collaborative regional research projects and capacity development activities for over 20 years. To continue the successful work in the coming years, APN will make further efforts to respond to the rapidly changing needs of its member countries and increase its efforts in supporting them to achieve their policy goals related to global change and sustainability.

The 21st Intergovernmental Meeting (IGM), held in Zhengzhou, China, in April 2016, decided to establish a Task Force for the Future Development of APN. In two workshops, conducted in 2016 and 2017, the Task Force reviewed the work of APN, identified challenges and possible opportunities, and came up with recommendations. They were presented to and approved by the 22nd IGM, held in New Delhi, India, in April 2017.

The following sections describe, partly based on the findings of the Task Force, the strengths, challenges and opportunities in the institutional performance of APN: member countries and APN; APN's internal structure and the overall management of the network.

\section{Institutional effectiveness}

\subsection{Member countries}

Throughout the 4th Strategic Phase (2015-2020), the total number of APN's member countries remained the same. Twenty-two countries in the Asia-Pacific region are members of APN, and four additional countries are approved member countries. ${ }^{1}$

The member countries are at the core of APN. Their active participation in the strategic discussions has been essential for the success of APN. To continue

\footnotetext{
Full members of APN are Australia, Bangladesh, Bhutan, Cambodia, China, Fiji, India, Indonesia, Japan, Lao PDR, Malaysia, Mongolia, Nepal, New Zealand, Pakistan, Philippines, Republic of Korea, Russian Federation, Sri Lanka, Thailand, United States of America and Viet Nam. The Pacific Island Countries (PICs), Maldives, Myanmar and Singapore are 'approved member countries' whose scientists can lead and collaborate in APN funded activities. However, their governments are neither directly represented in the network management of APN nor engaged in the strategic discussions of the network.
}

being successful, APN must maintain the level of their commitment to the work.

During its history, APN has been working to increase and maintain the interest in and visibility of APN in the member countries. This task was challenging when the national Focal Points (nFPs) and Scientific Planning Group (SPG) members changed, and the vacant positions were not filled promptly. Over the 4th Strategic Phase, APN has made some significant efforts to reconnect to those member countries that had no representation for some length of time, through, for example, courtesy calls with their governments.

On a positive and encouraging note, many other member countries were actively engaged in the strategic discussions, promoting APN in their countries, encouraging their scientists to utilize APN's calls for proposals to conduct research and capacity development activities, etc.

\subsection{Organs and suborgans}

\subsubsection{Intergovernmental Meeting (IGM) and Scientific Planning Group (SPG): Representatives of the member countries}

APN has two main organs, i.e., the IGM, consisting of the nFPs, and SPG. This structure is unique but entirely in line with the international trend of emphasizing the importance of closer interaction between the policymaking and scientific communities.

Each of the APN member countries delegates one nFP who is usually a policymaker working with the ministry or department that is engaged in the environmental and sustainable development policies of the government of that country, to the IGM. During the 4th Strategic Phase, the Framework Document was amended to enhance the essential role of the IGM in providing strategic guidance and determining the overall direction of APN.

The second delegate of a member country is the SPG member, a scientist conducting or overseeing research in areas related to global change or sustainable development and is connected to the scientific community of their country. The nFPs appoint the SPG members of their countries, respectively. The SPG oversees the overall scientific activities of APN and provides advice to ensure that APN's scientific 
direction is relevant to the issues of the Asia-Pacific region.

The importance of the proactive work of the nFPs and SPG members is evident as other organs and suborgans, i.e., the Steering Committee (SC), the Subregional Committees (SRCs), SPG and Capacity Development Committee (CDC) mainly comprises of members from these two organs, the IGM and SPG.

Often, nFPs change after a couple of years, as they move on to new positions within the governmental structure of their countries. In most cases, the successors are appointed swiftly. However, due to the discontinuity in the institutional memory from one $\mathrm{nFP}$ to the next, the continuous engagement of nFPs is challenging.

Generally, SPG members stay active in and supportive of APN over many years. They are committed to the work of the network and have guaranteed the remarkable success of the research and capacity development activities of APN. Notably, the SPG members have been ensuring the high quality and integrity of APN funded activities over the years by reviewing the proposals APN has received.

In the 4th Strategic Phase, the diversity and specialization of the proposals received started to increase; also, their quality improved. Tackling this situation, the SPG members contributed to APN being acknowledged as an active organization in enhancing the capabilities of scientists in the Asia-Pacific region.

To make efforts to streamline the procedure of reviewing proposals and decrease the workload of the SPG members and other reviewers further, Step 2 of the review process was removed in FY 2019. Additionally, SPG members were given the option to delegate the work of reviewing proposals to other persons with appropriate expertise. However, this option was not applied often.

\subsubsection{Steering Committee (SC)}

While the IGM is the supreme decision-making organ of APN, the SC acted on behalf of the IGM discussing issues related to APN's activities, finances, etc., particularly in the inter-sessional periods of the IGM. The SC was composed of selected nFPs, the two SPG Co-Chairs, nFPs of donor member countries and invited experts.
Many SC members, especially those who were also nFPs, were often occupied with their day job, resulting in, for example, lower attendance rate in the meetings.

The Task Force for the Future Development of APN took up this challenge and recommended to increase the number of nFPs serving on the SC. The 22nd IGM Meeting adopted this recommendation. It also decided to transfer important IGM mandates to the SC, for example, approving proposals for funding and the work programme and budget plan. Accordingly, the Framework Document was amended to reflect these changes.

\subsubsection{Subregional Committees (SRCs)}

The idea to establish SRCs was first proposed at the 11th IGM, and a "Liaison Model" was introduced for a trial period in Southeast Asia. The primary purpose for such a model was to enhance the flow of communications within the subregion, as well as to discuss, identify and address regional research priorities and capacity development needs common at the subregional level.

Deemed successful, the model evolved over the years, and SRCs were established in Southeast Asia (2007), South Asia (2009) and Temperate East Asia (2013). The start of their work resulted in the decision, at the 19th IGM, to formally establish SRCs as organs of APN. Each SRC comprises nFPs and SPG members from their respective subregions (see Table 3.1). At the time of writing, the establishment of a Subregional Committee for the Pacific is being planned².

According to the initiatives of SRCs, annual meetings have been followed by activities such as knowledgesharing events and workshops organized by host countries. Proposal Development Training Workshops (PDTWs) were also held, with the assistance and contribution of the host countries and the participation of SRC members as mentors. These activities are reported in Chapter 1, Section 3.1.

Past experiences indicate that SRC meetings should be efficiently organized without the additional burden of cost and workloads. It should be noted that the participation by key international organizations could

2 The Pacific group of APN member countries comprises Australia, Fiji, New Zealand and the United States of America. 


\begin{tabular}{|c|c|c|}
\hline Subregional Committee & Countries & Meetings \\
\hline Southeast Asia & $\begin{array}{l}\text { Cambodia, Indonesia, } \\
\text { Lao PDR, Malaysia, } \\
\text { Philippines, Thailand, } \\
\text { Viet Nam }\end{array}$ & $\begin{array}{l}\text { 8th SEA-SRC, 7-8 September 2015, Indonesia } \\
\text { 9th SEA-SRC, 9-10 February 2017, Thailand (In-kind } \\
\text { support from RRC.AP) } \\
\text { 10th SEA-SRC, } 3 \text { March 2018, Viet Nam } \\
\text { 11th SEA-SRC, 16-17 May 2019, Lao PDR } \\
\text { 12th SEA-SRC, 21-22 November 2019, Cambodia }\end{array}$ \\
\hline South Asia & $\begin{array}{l}\text { Bangladesh, Bhutan, India, } \\
\text { Nepal, Pakistan, Sri Lanka }\end{array}$ & $\begin{array}{l}\text { 7th SA-SRC*, } 13 \text { December 2016, Bhutan } \\
\text { 8th SA-SRC, 19-20 April 2018, India (Co-funding from } \\
\text { SAARC) } \\
\text { 9th SA-SRC, 28-29 March 2019, Sri Lanka } \\
\text { 10th SA-SRC**, 9-10 April 2020, Pakistan } \\
\text { * Postponed in 2015; ** Postponed in 2020. }\end{array}$ \\
\hline Temperate East Asia & $\begin{array}{l}\text { China, Japan, Mongolia, } \\
\text { Republic of Korea, Russian } \\
\text { Federation }\end{array}$ & $\begin{array}{l}\text { 1st TEA-SRC, } 4 \text { November 2015, Mongolia (Co-funding } \\
\text { from PAGES) } \\
\text { 2nd TEA-SRC, } 15 \text { September 2018, Japan (Co-funding } \\
\text { from Kurita Water Foundation) } \\
\text { 3rd TEA-SRC, } 28 \text { January 2020, Kobe }\end{array}$ \\
\hline
\end{tabular}

Table 3.1. Composition of subregional committees and their meetings in the 4th Strategic Phase.

improve the flow of information among members of APN at the subregional level and have strengthened collaboration with partners.

The makeup of the SRCs and the meetings conducted in the 4th Strategic Phase are presented above.

The Task Force for the Future Development of APN concluded that many nFPs are more proactive at SRC events, as SRCs are better tailored to respond to subregion needs and priorities. Given these findings, recommendations were made to further strengthen the SRCs by providing more responsibilities. These include, among others, delegating two nFPs from each SRC to represent the respective subregion on the SC, and assigning a capacity development expert to serve on the CDC as a full member.

The Framework Document also stipulates that the SRCs consider and decide themes for scientific research and capacity development activities in response to policy needs in their subregions, respectively. However, this exercise was a challenge as the proposed themes range too widely.

Given the budget and human resources needed to implement SRC activities, further thorough consideration on how to maximize the effectiveness of SRCs is required.

\subsubsection{SPG Subcommittee (SPG-SC) and Capacity Development Committee (CDC)}

The SPG-SC and CDC, reportable to the SPG and SC, respectively, are small yet have performed important tasks during the 4th Strategic Phase. With invited experts as additional full members, they were in charge of overseeing the two main pillars of APN's activities, i.e. the Collaborative Regional Research Programme (CRRP) and Capacity Development Programme (CAPaBLE). Their review of the proposals received was essential for the success of the two programmes mentioned above.

\subsubsection{Invited experts}

APN has engaged a number of experts to support the work through their expertise and experience. In some cases, they had previously served APN as nFPs or SPG members.

Although, strictly speaking, they do not constitute an organ or suborgan, the invited experts contributed substantially to the success of APN while serving on the SC, SPG or CDC as full individual members. As 
they were not appointed by the nFPs, they do not directly represent a member country. Through their longstanding engagement in APN, they continued to help maintain the institutional memory and provide advice throughout the 4th Strategic Phase.

Also, it is noteworthy that very often, the invited experts are working voluntarily, especially those serving on the SPG and CDC and reviewing proposals. Given the increased diversity in the topics of proposals received to its calls, APN needs to pay attention to possible high workload as it could diminish the commitment of the reviewers to APN over the longer term.

\subsubsection{Secretariat}

A questionnaire, conducted in 2016 to find out the overall quality of APN's work, revealed the performance of the Secretariat as good. Among the answers received, some voices expressed concern that, in the face of the expanded scope of APN activities in the 4th Strategic Phase, the pressure of work on the secretariat staff could have become too high. Similar comments were repeatedly made on several occasions.

Notably, the Secretariat staff working on the management of the scientific and capacity development programmes of APN have been challenged by the increased diversity and specialization of the topics of the proposals received. APN must consider strategies to address the new development, as the staff are not experts in many specific thematic fields.

Also, the increased number of meetings amplified the amount of work of the Secretariat staff.

In the course of drafting this report, careful analyses were proposed to review the work and functions of APN organs, including the Secretariat. Noteworthy, it was felt that the operation of the Secretariat must not become too widely spread and thus less efficient. In this context, a lot of crucial work, for example, developing high-quality publications for the better visibility of APN's successful work could not be taken up, mainly due to lack of time and human resources.

\subsection{Recognition of APN}

The question of whether APN should or does not need to have an independent legal status was discussed often $^{3}$. Although in the past the supposedly missing status was felt advantageous in some ways (more freedom in operating as a loose network of countries), for some member countries this was seen as the highest hurdle to recognize APN officially.

It was challenging when APN was trying to receive official recognition with the international initiatives of global change and sustainability. For example, to be able to attend important events of international policy fora, such as the COPs of UNFCCC, APN has been dependent on Institute for Global Environmental Strategies (IGES) in securing entry permits to access the venue.

In the 4th Strategic Phase, APN received direct financial support from three national ministries and one local government. The contribution from one member country government covered more than $90 \%$ of the resources made available to APN. There was difficulty in receiving direct financial support from some other member countries: the question about an independent legal status was considered the main obstacle. As a result, it led to the increased dependency of APN from the few member countries that had been supporting APN with direct financial contributions over the years. However, it should be questioned whether the absence of an independent legal status is a crucial reason for not providing direct financial support to APN.

\section{Financial management}

\subsection{Direct financial contributions and in-kind support by member countries}

Since its establishment, the annual resources made available to APN in the form of direct financial contributions had increased steadily over the years. Thanks to its donor member countries and the Hyogo Prefectural Government, APN was able to

3 APN Secretariat was always operating under the administrative umbrella of organizations that are officially registered as legal entities in Japan. Since April 2004, the Institute for Global Environmental Strategies (IGES) is the organization with whose administrative support the APN Secretariat has been operating. Therefore, the assumption that APN is working without a legal status is not correct. 
provide funding support to a significant number of collaborative research projects and capacity development activities, as well as international, regional, subregional and local events, including training workshops and public symposia, etc.

However, after the second-biggest donor member country discontinued its funding support to APN towards the end of the 3rd Strategic Phase, the overall amount of new resources dropped to just above USD 2 million per year. APN remains grateful for the continued commitment of the remaining donor countries and the Hyogo Prefectural Government. However, ways must be found to achieve a broader distribution of the financial burden among as many member countries as possible, as the extremely high dependency from one donor country is not appropriate.

The 4th Strategic Phase started in FY 2015. It was the first fiscal year after the second-biggest donor member country at that time discontinued its direct financial contributions. In FY 2014, this member country supported APN with USD 360,000.

As a result of this discontinuation of support but also by the significant depreciation of the Japanese currency to US Dollar, the total amount of new resources made available to APN decreased by almost USD 500,000 (from USD 2.8 million in FY 2014 to USD 2.3 million in FY 2015).

The recovered exchange rate of the Japanese Yen to the US Dollar in the following few years, i. e. from USD 1/JPY 126 in FY 2015 to USD 1/JPY 113 in FY 2018, helped to stabilize the level of the income at about USD 2 million/fiscal year. Also, it is noteworthy that the governments of the donor countries succeeded in maintaining the same level of their direct financial support.

Although many member countries did not provide any direct financial contributions to APN, it is essential to acknowledge that they contribute to APN by providing significant in-kind support. The time the nFPs, SPG members and other committee members spent on APN business to attend APN meetings, review proposals, etc., were covered by the governments, research institutes, universities, etc., of member countries. In several cases, member country governments also shouldered the travel costs of their APN members.
Due to the different level of the costs of living and remunerations among the member countries, it is not easy to put an accurate monetary value of this in-kind support.

Another type of in-kind support the member countries provided APN with was when they allowed APN to use their facilities for events, etc.: meeting rooms, office equipment, meeting assistance by staff, use of official cars, etc.

\subsection{Other models}

Having experienced in the past that some member countries were not able to make any direct financial contributions to APN for various reasons, discussions on how to address these challenges have been ongoing for several years.

In July 2014, under the 3rd Strategic Phase (2010-2015), a memorandum of understanding (MoU) was drawn between the Ministry of Environment, Government of Cambodia, and APN Secretariat for a bi-lateral "Partnership for Co-financing Regional Research and Capacity Building Activities on Global Change Research". As a notable result of this MoU, a Proposal Development Training Workshop (PDTW) was held in Siem Reap, Cambodia, in October 2015.

The objective of the Ministry of Environment of Cambodia was to enhance opportunities for Cambodian scientists to participate in APN funded activities through closer collaboration in, and pledging co-finance support to, these activities. The Ministry decided this strategic move, realizing that the rate of Cambodian scientists in successfully receiving funds through APN calls for proposals had to be improved. APN was favourable towards this partnership as it demonstrated an interesting pathway to overcome the challenge in APN's financial structure.

In the 4th Strategic Phase, four APN-led activities were conducted with co-funding support from Governments and organizations of member countries ${ }^{4}$.

\footnotetext{
4 Many research and capacity development projects, selected for funding, received co-funding support from other organizations, including those of the Project Leaders and Collaborators. Listed here are only those activities for which agreements were signed and co-funding was mentioned explicitly.
} 


\section{Co-funding Partner}

Ministry of Environment, Kingdom of Cambodia

Past Global Changes (PAGES)

\section{Co-funded Activity}

Proposals Development Training Workshop (PDTW), 5-8

October 2015, Siem Reap, Cambodia

November 2015, Ulaanbaatar, Mongolia

South Asian Association for Regional Cooperation Agriculture Centre (SAC)

Regional Expert Consultation on Climate Smart Agriculture, 17-19 April 2018, Hyderabad, India

Kurita Water and Environment Foundation, Japan

Proposals Development Training Workshop (PDTW), 12-14

September 2018, Tokyo, Japan

Table 3.2. Activities conducted with co-funding support from governments and organizations in member countries.

\subsection{Risk management}

APN manages its accounts in US Dollar, basically (all remittances for funded projects are processed in US Dollar). However, the most significant part of the annual direct financial contributions it receives is in Japanese Yen. Although rather conservative exchange rates ${ }^{5}$ are decided at the beginning of each fiscal year, an unexpected magnitude of exchange rate fluctuations always bears the risk of substantial exchange rate losses. To be efficient and resilient, APN introduced a strategy in the 4th Strategic Phase to determine the exchange rate for the conversion between the US and Japanese currencies as follows:

$105 \%$ of the average exchange rate derived from three months before the timing of preparing the work programme and budget plan of a fiscal year.

For the actual purchasing of US Dollars, the Secretariat implemented a strategy to make one single transaction in the range of the value that is needed to support all proposals that were approved for funding in a specific fiscal year (for example, in FY 2018 almost USD 1.5 million). This strategy helped to become more resilient to possible fluctuations in the exchange rates and provided more stability and transparency in the management of the resources.

A pool of available funds that can be added to the budgetary planning of a new fiscal year is available from grants that are not used by the funded projects and activities, savings made in the daily operation of the network, operational funds allocated but not used

5 "Conservative" in the meaning of the Japanese currency being assumed with less value than the actual exchange rates USD/JPY. (for example travel budget), and possible unintended gains through exchange rate fluctuations, etc.

At the time of the preparation of a budget plan of a new fiscal year, the exact amount of the carryover from the previous fiscal year is not yet determined ${ }^{6}$. To tackle this situation, the SC decided to skip one fiscal year, for example, the carryover from FY 2018 would be fed into the budgetary planning of FY 2020.

\subsection{Other changes, related to the financial management}

In the past, APN operated on the fiscal year system that Japan applies, usually from 1 April to 31 March of the following year.

Effective 1 July 2017, the Institute for Global Environmental Strategies (IGES), under whose administrative support APN Secretariat is operating, changed its fiscal year to from 1 July to 30 June of the following year. ${ }^{7}$

APN adopted this fiscal year system which brought some advantages. One of them is that at the time of preparing the budget plan of the following fiscal year (now around April/May), the donor member countries have already transferred their direct financial contributions to APN's bank account, enabling APN to start dispensing funds soon after the beginning of the new fiscal year in July.

\footnotetext{
6 When the budgetary planning for the following fiscal year starts around April/May, the financial books of the running fiscal year are not closed yet.

7 This shift in the fiscal year resulted in the extended length of FY 2016 by three months: it lasted from 1 April 2016 to 30 June 2017.
} 
Chapter 4.

Strengths,

challenges and

opportunities 
As the previous three chapters document, the 4th Strategic Phase was successful and helped APN progress further. They reveal APN's ability to address topics of high policy relevance of its member countries. By considering these topics for the calls for proposals and other activities, APN enhanced the capability of the researchers to provide sound scientific findings that are needed for evidence-based policymaking processes. APN's visibility has grown through finely tuned communication strategies to share its products with the policy and science community, as well as the general public and other societal groups.

At the same time, the 4th Strategic Phase disclosed those areas in which APN can improve itself further.

Following sections describe the strengths and challenges, as well as forward-looking opportunities, which are critical for shaping the strategy for the 5th Phase and beyond.

\section{Management of APN's core programmes}

\subsection{Call for proposals}

APN's core programmes of regional research (CRRP) and capacity development (CAPaBLE) continue to mature. The call for proposals continues to be streamlined, both for proponents to prepare and submit proposals, and for reviewers, in what is a sevento-nine month review process. Clear guidelines are in place for proposal submission, and solid regulations guarantee the transparency, integrity, and fairness of the system so as to select the best proposals for funding.

To ensure policy relevance of the scientific topics identified in the annual calls for proposals, a new system was adopted in the 4th Strategic Phase whereby subregional committees select thematic areas that are of significance and are common at the subregional level. This ensures, too, that the research implemented is indeed of regional relevance, common to all countries.

The above said, in order to respond to the increased diversity of topics, as well as the growing trend in the number of proposals received ${ }^{1}$, a more rigorous management process has had to be implemented. This has resulted in an increased workload not only for the Secretariat in terms of managing both the call for proposals and project implementation but also by way of increased pressure on SPG and CDC members. Furthermore, SPG members expertise is not sufficiently broad enough to cover those emerging transdisciplinary and interdisciplinary areas that are of increasing importance to the members. This has been addressed by engaging external experts from APN's growing database, which adds a new dimension to the review process and its management.

The increased diversity of subregional priority topics and the holistic approaches adopted in proposal methodology not only amplifies the workload of the SPG members but also increases the pressure on SPG and CDC members to review proposals that are not directly related to their areas of expertise. This makes it difficult for the Secretariat to assign proposals as well. Section 8.5 Scientific Planning Group (SPG) of this chapter suggests establishing "SPG Teams" to ease the workload of SPG members, and such a system may also broaden the scope of the expertise needed to perform the review process. The system need not be complicated and would be the responsibility of the SPG member to add to their team if necessary. Such a system may train team members to become the official SPG member in the future.

It is noteworthy that the higher demand required in the review process is alleviated by the increased level of external reviewer involvement in the review process. In fact, with the current 2:1 ratio of SPG/CDC to external reviewers engaged in a proposal review, APN somewhat relies on external reviewer engagement. As such, strategies to ensure the continuous engagement and support of external reviewers should be considered in the 5th Strategic Phase.

\subsection{Research and capacity development projects}

CRRP projects have been successful in providing policyrelevant scientific knowledge for decision-making communities, and the programme's competitive grant

1 Refer to Figure 1.3, Chapter 1 "Science, policy and capacity development report". 
process is based on a well-developed mechanism to support the most important policy-relevant proposals.

Scientific knowledge is needed for decision-making processes at all levels. Findings of many CRRP projects have also managed to support decision-making at the local and national levels, both in rural and urban communities. The summaries of the selected CRRP projects in Chapter 1, Section 2.2.1 document nicely that CRRP projects produce knowledge that is useful for people on the ground.

Positive feedback from those who have benefited from the CAPaBLE programme reinforces the importance of capacity development in the Asia-Pacific region. CAPaBLE continues to meet the needs for capacity building in developing ${ }^{2}$ countries, ensuring enhanced capability of the beneficiaries to participate effectively in scientific research and capacity building activities.

Furthermore, as CRRP projects have capacity development components built into their activities, for example, by inclusion of early-career scientists, this ensures that capacity needs are met across the board of APN's core programmes while providing policyrelevant outputs that can support policy formulation.

The average grant provided for projects may be considered as modest, but it is evident that the financial support is sufficient to strengthen the collaborative research capabilities of developing country scientists, both in terms of the ability to conduct transnational research and produce new, policy-relevant scientific knowledge.

Remarkably, many CRRP and CAPaBLE projects succeeded in enhancing the engagement and participation of regional and local policymakers and communities in their project activities. Some examples include (1) raising awareness through video clips, local media (newspapers, television, social media); (2) sharing weather data through smartphone apps in local vernacular; and (3) developing guidelines in vernacular and English languages for local authorities and governments.

\section{Activities conducted by APN Secretariat}

\subsection{Science-policy dialogues (SPDs)}

SPDs provide a forum for scientists, policymakers, practitioners, media and other interested parties, to share their knowledge, perspectives and best practices, and provide networking opportunities to enhance communication and interaction among members of different societal groups.

The informal nature of the dialogues and unique activities such as ice-breaker game sessions, free and informal exchange of views in small group discussions (café kiosks), etc. are conducive to an atmosphere that promotes interaction among the different stakeholder groups.

For SPDs to be more sustainable and useful, sound networking and communication between the organizers, resource persons and participants before, during and after the events are of key importance. Midto long-term plans for strategic follow ups, including maintaining communication channels, are areas in which APN could advance effectively.

\subsection{Scoping workshops}

In response to emerging policy needs, APN conducts scoping workshops. In the 4th Strategic Phase, one such workshop on technology transfer was deemed successful by all who attended. However, while the outputs were excellent, APN did not conduct any follow-up activities to either continue the discussions and/or implement recommended activities. This seems like a missed opportunity. Scoping workshops provide immense opportunities to strengthen collaboration with key actors, yet no focussed activities were pursued.

If APN does not have the resources to follow up on such scoping exercises by way of the collective recommendations, then perhaps APN should consider either utilizing the Core Programmes or only holding scoping workshops when it is evident that financial resources are available to act on any suggested recommendations. 


\subsection{Proposal Development Training Workshops (PDTWs)}

Proposal training workshops vis-à-vis APN's PDTWs are an excellent mechanism to provide early-career scientists (ECSs) with training to develop regional research proposals, while also offering a unique forum to meet, network and collaborate with peers and mentors from other member countries.

To make the PDTW more impactful, a long-term strategy to improve and maintain communication between mentors and trainees requires careful consideration. Such communication is crucial to provide the necessary advice to trainees to develop their proposal writing skills and encouragement to submit proposals to APN.

\section{APN and the global change and sustainability communities}

As Chapter 1 documents, APN collaborates with many international and regional (Asia-Pacific) organizations to support research and capacity development projects. In those instances where projects received funding support from more than one source, APN does this as a co-funder. Alternatively, APN has worked as a partner in those instances where support was directly provided to specific programmes or organizations.

These examples are evidence that APN is a respected and recognized partner in the global change arena. Being aware of the importance of cooperation and bundling of efforts, APN should continue to forge fruitful collaboration and partnerships.

The above said, perception of APN as a research network (and not only a funding agency) is essential to underpin APN's presence and position within the international community of global change and sustainability science. APN must also work on ensuring appropriate recognition by the international community for the work it undertakes, in both capacities as a partner and/or sponsor of projects and activities.

While most individual leaders and collaborators of APN-funded projects duly acknowledge APN for its financial support in the products they produce, there remain instances in which APN's contributions are incorrectly acknowledged or even not acknowledged at all.

In the 5th Strategic Phase, APN must continue to strengthen its strategy to ensure due recognition and true perception of who APN is and what APN does.

\section{Thoughts on the strategy and opportunities for activities}

As APN approaches its 5th Strategic Phase, it must reconsider which areas to focus on, by carefully looking at current practices and their continued relevance based on need, and by seeking and introducing new initiatives. In this context, some ideas are presented in the subsections below. Further consideration of these ideas should be considered as an essential task in the period of the 5th Strategic Phase.

\subsection{Research and capacity development}

Including components of capacity development is one of the crucial conditions to make proposals eligible for submission to CRRP, APN's programme to support scientific research. The possible priority topics APN may want to focus during the 5th Strategic Phase must be not only transdisciplinary and holistic but link research and capacity development needs of the member countries.

The following outlines some examples of priority areas derived from findings of completed projects, discussions with nFPs, SPG and CDC members, including (1) Food security under climate change, the role of gender in rural planning, and climate-smart agriculture (2) Disaster risk reduction and climate change (adaptive recovery); (3) Technology transfer in areas such as solid waste management (SWM); (4) Nexus: Water-Food-Energy-Climate or a combination of these; and (5) Ecosystem-based adaptation, etc.

\subsection{Synthesizing knowledge products and providing opportunities for collaboration and networking}

APN embarked on an activity that culminated in the compilation of 14 manuscripts and a synthesis of APN activities (2013-2018) that were published in a 
reputable journal. Such activities need to continue in the 5th Strategic Phase as they provide a range of benefits that include: (1) providing concise peer-review information on policy-relevant research for APN members, (2) providing concise peer-review literature of APN outputs for policy-relevant bodies such as IPCC, IPBES, UNCBD, UNFCCCC; (3) strengthening collaboration with regional organizations; and (4) providing opportunities for project leaders to meet and discuss similar interests and promote future collaboration.

Furthermore, engaging early-career scientists in these activities provided opportunities to network with senior researchers and practitioners in an international context and should continue to be promoted by APN.

\subsection{New opportunities for partnerships}

Exploring new research and capacity development initiatives to support larger scale projects in a partnership approach could be considered. In this context, APN could scope opportunities for broader collaboration with other organizations, keeping in mind the level of financial investment that APN could bring to such "flagship" endeavours. In this context, a definition of "flagship" that is suitable for APN would be appropriate so that partnering organizations could understand the scope of APN.

APN has been invited by the Ministry of the Environment, Japan (MOEJ) to engage with the Asia-Pacific Climate Change Adaptation Information Platform (AP-PLAT) ${ }^{3}$ as a partner and provider of scientific results from its climate change adaptation activities. This will be explored further in the 5 th Strategic Phase of APN.

Engaging the private sector in APN projects and activities has been an ongoing discussion over the years. APN collaboration with public authorities and the private sector by, for example, "Private-Public Partnerships", could be explored at the project and institutional levels. This approach is beneficial in the context of developing new mechanisms that could attract financial contributions and in-kind support from the new partners.

\footnotetext{
3 AP-PLAT aims to serve as an online platform for information to support effective climate risk management through adaptation. For details: https:// ap-plat.nies.go.jp
}

\section{Communicating the outputs of APN activities}

While recognizing the long-term impact of comprehensive project reports and journal publications, APN should encourage diversification in the types of outputs produced through its projects and activities, especially policy- or action-oriented information, such as policy briefs, opinions, guides and case studies. To this end, a refined information structure for the APN website will be crucial for the success of communicating APN outputs and key messages to its intended audiences.

As discussed in Chapter 2, there is a need to further understand the reach and impact of APN products, which can be done by designing and implementing a carefully developed mechanism to measure and collect audience feedback on such products. For example, a more systematic survey could be developed for continuous monitoring of feedback by different audience groups.

\section{Quality and credibility of APN outputs}

Having understood the lasting impact of many APN products available on the Internet, it is crucial that these products are of high quality in terms of both content and presentation. A comprehensive production process should be developed and implemented to improve the quality of APN-funded products and in-house publications, so as to ensure that APN continues to be perceived as a credible source for information.

\section{Strengthening communication with APN members}

Mailing lists and social media channels could be further utilized to increase the engagement of APN members in communicating and disseminating APN products and information. For successful communication with members, personalized communication and active social media engagement - as opposed to one-way broadcasting - will be useful. With the advance of digital technology, video conferences and webinars should also be explored. For communications to 
be effective, it will be useful to understand the key priorities of each country and develop content that is timely and relevant to those countries.

\section{Engaging in APN: member countries, organs and people}

\subsection{Engagement of member countries in APN activities}

The active engagement of the member countries in APN activities at all levels is essential. To maintain their interest and level of involvement, APN must develop strategies to increase its value by organizing, for example, country- or subregion- focused activities (ideally in a co-financing manner) to share knowledge, perspectives and best practices. At these activities, interactive sessions could be held that involve participants from all relevant societal groups. Like-minded local institutions can be engaged as co-organizers.

The engagement of local experts (other than APN nFPs and SPG members), both as organizers and participants, is the key in this kind of venture to visualize APN and its work. Project leaders or collaborators of APN-supported projects from the respective member countries should be invited to present their findings.

As the active cooperation of the nFPs and SPG members would be crucial to organize such events, they would help increase their understanding and ownership feeling of APN.

\subsection{Intergovernmental Meeting (IGM)}

The Intergovernmental Meeting (IGM), composed of the $n F P s$, is evolving. While it remains the highest decisionmaking body of APN, the last amendment of the Framework Document provided the nFPs with a higher level of responsibility at the subregional level and SC that engages in the management work of APN.

That being said, the fundamental role of IGM as the organizational centre of APN must be retained, and considerations on the new mandate of the IGM as an organ is necessary.

\subsection{Steering Committee (SC)}

The SC, with its composition of elected nFPs and nFPs of donor countries, the two SPG Co-Chairs and invited experts, is suited to perform the critical duty of steering APN. With the last amendment of the Framework Document, along which the majority of the SC members being delegated by the SRCs to serve on the $\mathrm{SC}$ by representing their subregions, respectively, the $\mathrm{SC}$ is an effective organ with a right mix of members from the four APN subregions and different organs.

\subsection{Subregional Committees (SRCs)}

The SRCs were granted a greater responsibility to better address and respond to the subregion-specific issues by delegating two nFPs to serve on the $\mathrm{SC}$ and one capacity development expert to the CDC.

However, the SRCs must receive support to adjust to the new role. They may not have taken in yet the magnitude of the last amendment of the Framework Document that assigned them with more responsibilities. Through discussions among APN members, the SRCs should strive for more strategic, operational and institutional efficiency and sustainability.

In the 5th Strategic Phase, SRCs could put forth their unique positions further and feed APN with useful insight from the subregions, respectively. For example, the SRCs could connect APN to the regional intergovernmental organizations for collaborative activities on topics of common interest, such as food and water security, waste management, etc.

\subsection{Scientific Planning Group (SPG)}

As the SPG members tend to stay in their positions with APN longer than their nFPs, they are the key to communications with the Network and the scientific communities of their countries. Supporting the vital work of the SPG members but also thinking ahead and providing training to potential successors in the positions of the SPG members, the member countries may be encouraged to form "SPG Teams". These teams could comprise a few additional members, for example, early-career scientists, who could assist the 
SPG members in reviewing proposals ${ }^{4}$, attending APN meetings on behalf of SPG members, if they are not available, communicating with their nFPs and helping avoid any vacancy emerging when an SPG member steps down.

\subsubsection{Scientific Planning Group Sub-Committee (SPG-SC)}

The SPG-SC is a five-member subset of the Scientific Planning Group that comprises the SPG Co-Chairs and three other members of the SPG. The work of the SPG-SC is mainly to review the progress of multi-year projects and to recommend proposals for funding under the CRRP programme. The work of the SPG-SC is extremely important and, because of the high level of responsibility, could benefit one more SPG member to the team. Perhaps, in this respect, one member from each of the subregions could be appointed together with the SPG Co-Chairs. This appointment process should remain within the SPG agenda.

\subsection{The Capacity Development Committee (CDC)}

The CDC comprises two SPG Co-Chairs and, from 2021, four experts nominated each from the subregional committees and the Pacific group. To date, the work of the CDC has been efficient in determining what proposals to recommend under the CAPaBLE programme for funding. This said, capacity building discussions among the Committee are lacking, and the CDC and CAPaBLE programme requires more attention in order to ensure that it evolves with the global agendas for capacity building, particularly for developing nations and early-career scientists and practitioners.

\subsection{Invited experts}

Recognizing the contributions of the Invited Experts through their expertise in global change, sustainability and capacity development, and longstanding experience in APN activities at all levels, APN should consider how to maximize the potential of engaging
Invited Experts and secure their interest in the work of APN. At the same time, ways should be developed to attract new experts to become interested in APN.

\subsection{Secretariat}

Over the years, the duties and diversity of the tasks of the APN Secretariat have increased. To continue the successful work of APN in the 5th Strategic Phase, discussions are necessary on how to secure the functionality of the Secretariat. This could be achieved by easing it from too much management work and instead focusing on essential tasks related to its strategic activities.

\section{Enhanced presence in the international community}

Knowing that the key to the continued success of APN is increased attention by the international initiatives that discuss global change, SDGs, disaster risk reduction, etc., it must continue making efforts to improve its visibility by actively participating in the events hosted by these initiatives. Support from member countries and partners to, for example, secure APN's access to these events is crucial.

\section{Funding support and financial management}

To strengthen its financial foundation, APN must continue to encourage its member country governments to support APN through direct financial contributions. Furthermore, a strategic mechanism must be developed and implemented to seek financial support from other sources, including the private sector. Given that securing funding is a challenging task that demands experience, sensibility and negotiation skills, APN is required to consider investing in fundraising.

\footnotetext{
4 The APN Secretariat has been observing the increase of the diversity and specialization in the submitted proposals in the recent couple of years. This may become another justified reason to investigate the idea of "national SPG Teams". Refer to Figure 1.3, Chapter 1 "Science, policy and capacity development report".
} 


\section{Conclusions}

In the first year of APN's 4th Strategic Phase, the international community adopted three significant frameworks ${ }^{1}$. During this phase, in its efforts to contribute to the implementation of these frameworks by providing sound scientific findings for policymaking and fora for interactions between decision-makers, scientists and other stakeholders, APN progressed further in achieving its goals and objectives. Its programmes to support scientific and capacity development activities were improved to meet the needs of its member countries more effectively.

APN's visibility and the extent of the impact of its products have also improved, thanks to the enhanced communication and outreach strategy. Regarding its institutional structure, efforts were made to increase the efficiency of APN organs and suborgans by re-addressing their roles and operations.

One of the recommendations of two workshops of the Task Force for APN's Future Development held in 2016 and 2017 was for APN to think of developing a mechanism to support largescale projects on high priority topics through partnerships with like-minded organizations. Such a mechanism could help to increase the interest of member country governments and provide opportunities to partner with APN. APN must consider this endeavour in its 5th Strategic Phase.

1 The Sendai Framework for Disaster Risk Reduction was adopted in June 2015, the Sustainable Development Goals (SDGs) in September 2015, and the Paris Agreement by the 21st COP of the UNFCCC in December 2015.
In support of the above, APN should continue to enhance its communication strategy to optimize its visibility and showcase the findings of its activities. Further refinement of the information structure of its website, and a better understanding of the reach and impact of its diversified products are substantial areas to focus on in the 5th Strategic Phase.

Likewise, the continuation of efforts in optimizing the institutional efficiency of APN would be essential for its success in the future. These considerations must cover all aspects of APN: the operational management of the network, the organs/suborgans, and the more proactive engagement of the member countries. Developing new financial resources is another crucial area of work.

At the time of writing this report, the international community is facing a pandemic that is impacting all aspects of society. The goal of the international community is not to return to a pre-pandemic world but design and implement recovery measures with a "build forward better" approach in addressing global change and sustainable development.

In its 5th Strategic Phase, APN should join in efforts to tackle the new challenge, as well as continue to address the existing challenges through partnerships and collaboration with its member countries, and like-minded regional and international organizations. To assess these efforts and its overall performance, APN should consider developing a monitoring and evaluation system with realistic indicators. 
Appendices 


\section{Appendix 1. APN-funded projects in its 4th Strategic Phase}

\begin{tabular}{|c|c|c|c|c|c|c|c|c|}
\hline Project Reference Number & Project Leader & Email Address & Title & Science Agenda & Countries & Metadata link & Award & $\begin{array}{l}\text { Year } \\
\text { Completed }\end{array}$ \\
\hline \multicolumn{9}{|c|}{ CRRP/ARCP Regional Research } \\
\hline ARCP2013-28RUF-David & Laura David & Idavid@upmsi.ph & $\begin{array}{l}\text { Integrated Vulnerability Assessment of Coastal } \\
\text { Areas in the Southeast Asia and East Asian Region }\end{array}$ & CCCV, CATMD & $\begin{array}{l}\text { Cambodia, Indonesia, } \\
\text { Philippines, Singapore, } \\
\text { Thailand, Viet Nam, } \\
\text { Germany }\end{array}$ & $\begin{array}{l}\text { http://www.apn-gcr. } \\
\text { org/resources/items/ } \\
\text { show/1542 }\end{array}$ & 80,000 & 2014 \\
\hline $\begin{array}{l}\text { ARCP2011-11NMY-Patra/Canadell } \\
\text { ARCP2012-01CMY-Patra/Canadell } \\
\text { ARCP2013-01CMY-Patra }\end{array}$ & $\begin{array}{l}\text { Prabir K. Patra } \\
\text { Josep Canadell }\end{array}$ & $\begin{array}{l}\text { prabir@jamstec.go.jp } \\
\text { pep.canadell@csiro.au }\end{array}$ & $\begin{array}{l}\text { Greenhouse gas budgets of South and Southeast } \\
\text { Asia }\end{array}$ & CC\&V, CATMD & $\begin{array}{l}\text { Japan, Australia, } \\
\text { Bangladesh, China, } \\
\text { Indonesia, India, } \\
\text { Singapore, Sri Lanka, } \\
\text { United States of America, } \\
\text { Thailand, Netherlands, } \\
\text { United Kingdom }\end{array}$ & $\begin{array}{l}\text { http://www.apn-gcr. } \\
\text { org/resources/items/ } \\
\text { show/1592 }\end{array}$ & 145,000 & 2015 \\
\hline $\begin{array}{l}\text { ARCP2011-12NMY-Fortes } \\
\text { ARCP2012-02CMY-Fortes } \\
\text { ARCP2013-02CMY-Fortes }\end{array}$ & Miguel Fortes & miguelfortes@gmail.com & $\begin{array}{l}\text { Seagrass-Mangrove Ecosystems: Bioshields } \\
\text { against Biodiversity Loss and Impacts of Local } \\
\text { and Global Change along Indo-Pacific Coasts (the } \\
\text { Seagrass-Mangrove Bioshield Project, SMBP) }\end{array}$ & CCCV, EBLU & $\begin{array}{l}\text { Philippines, Australia, Japan, } \\
\text { India, Indonesia }\end{array}$ & $\begin{array}{l}\text { https://www.apn-gcr. } \\
\text { org/resources/items/ } \\
\text { show/1593 }\end{array}$ & 121,750 & 2016 \\
\hline $\begin{array}{l}\text { ARCP2011-13NMY-Herath } \\
\text { ARCP2012-03CMY-Herath } \\
\text { ARCP2013-03CMY-Herath }\end{array}$ & $\begin{array}{l}\text { Anura Srikantha } \\
\text { Herath }\end{array}$ & herath@unu.edu & $\begin{array}{l}\text { Developing Ecosystem based Adaptation } \\
\text { Strategies for Enhancing Resilience of Rice Terrace } \\
\text { Farming Systems against Climate Change }\end{array}$ & CCCV, EBLU & Japan, Philippines, China & $\begin{array}{l}\text { http://www.apn-gcr. } \\
\text { org/resources/items/ } \\
\text { show/1594 }\end{array}$ & 135,000 & 2015 \\
\hline $\begin{array}{l}\text { ARCP2011-14NMY-Salik } \\
\text { ARCP2012-04CMY-Salik }\end{array}$ & $\begin{array}{l}\text { Kashif Majeed } \\
\text { Salik }\end{array}$ & $\begin{array}{l}\text { Kashif.majeed@gcisc.org.pk } \\
\text { kashif.salik@gmail.com }\end{array}$ & $\begin{array}{l}\text { Impact of Climate Change on Mangroves } \\
\text { Ecosystem in South Asia }\end{array}$ & CCCV, EBLU & $\begin{array}{l}\text { Pakistan, United States } \\
\text { of America, Sri Lanka, } \\
\text { Bangladesh }\end{array}$ & $\begin{array}{l}\text { http://www.apn-gcr. } \\
\text { org/resources/items/ } \\
\text { show/1595 }\end{array}$ & 85,000 & 2015 \\
\hline $\begin{array}{l}\text { ARCP2011-16NMY-IGBP } \\
\text { ARCP2012-06CMY-IGBP }\end{array}$ & $\begin{array}{l}\text { Karen Smyth } \\
\text { Pauline Dube }\end{array}$ & $\begin{array}{l}\text { nigabhan@gmail.com } \\
\text { dubeop@mopipi.ub.bw }\end{array}$ & $\begin{array}{l}\text { An International Geosphere-Biosphere } \\
\text { Programme Synthesis Theme on: Global } \\
\text { Environment Change and Sustainable } \\
\text { Development: Barriers, needs and potential } \\
\text { solutions to reducing vulnerability to global } \\
\text { environment change for least developed } \\
\text { countries in the Asia-Pacific Region }\end{array}$ & RUSD & $\begin{array}{l}\text { Afghanistan, Australia, } \\
\text { Bangladesh, Bhutan, } \\
\text { Cambodia, Fiji, Kiribati, } \\
\text { Lao PDR, Maldives, } \\
\text { Myanmar, Nepal, Samoa, } \\
\text { Solomon Islands, Tuvalu, } \\
\text { Vanuatu, Yemen }\end{array}$ & $\begin{array}{l}\text { http://www.apn-gcr. } \\
\text { org/resources/items/ } \\
\text { show/1597 }\end{array}$ & 90,000 & 2015 \\
\hline
\end{tabular}




\begin{tabular}{|c|c|c|c|c|c|c|c|c|}
\hline Project Reference Number & Project Leader & Email Address & Title & Science Agenda & Countries & Metadata link & Award & $\begin{array}{l}\text { Year } \\
\text { Completed }\end{array}$ \\
\hline $\begin{array}{l}\text { ARCP2011-17NMY-Mathukumalli } \\
\text { ARCP2012-07CMY-Ramanathan }\end{array}$ & $\begin{array}{l}\text { Alagappan } \\
\text { Ramanathan }\end{array}$ & arljnu@gmail.com & $\begin{array}{l}\text { Tracing Nitrogen and Carbon Biogeochemical } \\
\text { Processes in the Inter-tidal Mangrove Ecosystem } \\
\text { (Sundarban) of India and Bangladesh: } \\
\text { Implications of the Global Environmental Change }\end{array}$ & CCCV, EBLU & $\begin{array}{l}\text { United States of America, } \\
\text { India, Bangladesh }\end{array}$ & $\begin{array}{l}\text { http://www.apn-gcr. } \\
\text { org/resources/items/ } \\
\text { show/1598 }\end{array}$ & 90,000 & 2014 \\
\hline $\begin{array}{l}\text { ARCP2012-09NMY-Meinke } \\
\text { ARCP2013-04CMY-Meinke } \\
\text { ARCP2014-01CMY-Meinke }\end{array}$ & Holger Meinke & $\begin{array}{l}\text { holger.meinke@utas.edu.au } \\
\text { David.Parsons@utas.edu.au }\end{array}$ & $\begin{array}{l}\text { Improving the Robustness, Sustainability, } \\
\text { Productivity and Eco-Efficiencies of Rice Systems } \\
\text { throughout Asia }\end{array}$ & CCCV, EBLU, Cl & $\begin{array}{l}\text { Australia, India, Indonesia, } \\
\text { Japan, Pakistan, Sri Lanka }\end{array}$ & $\begin{array}{l}\text { http://www.apn-gcr. } \\
\text { org/resources/items/ } \\
\text { show/1748 }\end{array}$ & 162,050 & 2018 \\
\hline $\begin{array}{l}\text { ARCP2012-11NMY-Quynh } \\
\text { ARCP2013-06CMY-Quynh } \\
\text { ARCP2014-03CMY-Quynh }\end{array}$ & $\begin{array}{l}\text { Le Tgu Ohuong } \\
\text { Quynh }\end{array}$ & quynhltp@yahoo.com & $\begin{array}{l}\text { Carbon Fluxes and Emission from the Red River } \\
\text { (Viet Nam and China): Human Activities and } \\
\text { Climate Change }\end{array}$ & EBLU, RUSD & $\begin{array}{l}\text { Viet Nam, Singapore, China, } \\
\text { France }\end{array}$ & $\begin{array}{l}\text { http://www.apn-gcr. } \\
\text { org/resources/items/ } \\
\text { show/1750 }\end{array}$ & 120,000 & 2017 \\
\hline $\begin{array}{l}\text { ARCP2012-12NMY-Roy } \\
\text { ARCP2013-07CMY-Roy }\end{array}$ & Joyashree Roy & joyashreeju@gmail.com & $\begin{array}{l}\text { Coastal Ecosystem and Changing Economic } \\
\text { Activities: Challenges for Sustainability Transition }\end{array}$ & CATMD, $\mathrm{Cl}$ & $\begin{array}{l}\text { India, Sri Lanka, Bangladesh, } \\
\text { China }\end{array}$ & $\begin{array}{l}\text { http://www.apn-gcr. } \\
\text { org/resources/items/ } \\
\text { show/1751 }\end{array}$ & 86,000 & 2016 \\
\hline $\begin{array}{l}\text { ARCP2012-13NMY-DeCosta } \\
\text { ARCP2013-08CMY-DeCosta }\end{array}$ & G.S. DeCosta & rdecosta@unitec.ac.nz & $\begin{array}{l}\text { A Study on Loss of Land Surface and Changes to } \\
\text { Water Resources Resulting from Sea Level Rise } \\
\text { and Climate Change }\end{array}$ & CCCV, EBLU & $\begin{array}{l}\text { New Zealand, Sri Lanka, } \\
\text { India, Indonesia, Japan }\end{array}$ & $\begin{array}{l}\text { http://www.apn-gcr. } \\
\text { org/resources/items/ } \\
\text { show/1752 }\end{array}$ & 75,150 & 2016 \\
\hline $\begin{array}{l}\text { ARCP2012-14NMY-Carter } \\
\text { ARCP2013-09CMY-Carter }\end{array}$ & RW (Bill) Carter & bcarter@usc.edu.au & $\begin{array}{l}\text { Coral reef and water quality status and } \\
\text { community understanding of threats in the } \\
\text { eastern Gulf of Thailand }\end{array}$ & CATMD,RUSD & $\begin{array}{l}\text { Australia, Thailand, } \\
\text { Cambodia, Viet Nam }\end{array}$ & $\begin{array}{l}\text { http://www.apn-gcr. } \\
\text { org/resources/items/ } \\
\text { show/1753 }\end{array}$ & 60,000 & 2015 \\
\hline $\begin{array}{l}\text { ARCP2012-15NMY-Yoo } \\
\text { ARCP2013-10CMY-Yoo }\end{array}$ & Jin Ho Yoo & $\begin{array}{l}\text { jhyoo@apcc21.net } \\
\text { yoo.jinho38@gmail.com }\end{array}$ & $\begin{array}{l}\text { Toward a Fire and Haze Early Warning System for } \\
\text { Southeast Asia }\end{array}$ & CCCV, CATMD & $\begin{array}{l}\text { Japan, United States } \\
\text { of America, Republic of } \\
\text { Korea, Indonesia, Malaysia, } \\
\text { Singapore }\end{array}$ & $\begin{array}{l}\text { http://www.apn-gcr. } \\
\text { org/resources/items/ } \\
\text { show/1754 }\end{array}$ & 73,000 & 2015 \\
\hline $\begin{array}{l}\text { ARCP2012-16NMYYYabe } \\
\text { ARCP2013-11CMY-Yabe }\end{array}$ & Shizu Yabe & yabe.shizu@jaxa.jp & $\begin{array}{l}\text { GEOSS/Asian Water Cycle Initiative/Water Cycle } \\
\text { Integrator (GEOSS/AWCI/WCI) }\end{array}$ & $\mathrm{CCCV}$ & $\begin{array}{l}\text { Bangladesh, Bhutan, } \\
\text { Cambodia, India, Indonesia, } \\
\text { Japan, Republic of Korea, } \\
\text { Lao PDR, Malaysia, } \\
\text { Mongolia, Myanmar, Nepal, } \\
\text { Pakistan, Philippines, } \\
\text { Sri Lanka, Thailand, } \\
\text { Uzbekistan, Viet Nam }\end{array}$ & $\begin{array}{l}\text { http://www.apn-gcr. } \\
\text { org/resources/items/ } \\
\text { show/1755 }\end{array}$ & 90,000 & 2015 \\
\hline
\end{tabular}




\begin{tabular}{|c|c|c|c|c|c|c|c|c|}
\hline Project Reference Number & Project Leader & Email Address & Title & Science Agenda & a Countries & Metadata link & Award & $\begin{array}{l}\text { Year } \\
\text { Completed }\end{array}$ \\
\hline $\begin{array}{l}\text { ARCP2012-17NMY-Burnett } \\
\text { ARCP2013-12CMY-Burnett }\end{array}$ & William C. Burnett & $\begin{array}{l}\text { wburnett@fsu.edu } \\
\text { william.c.burnett@gmail.com }\end{array}$ & $\begin{array}{l}\text { Assessing the Impact of Climate Change and } \\
\text { Development Pressures on Nutrient Inputs into } \\
\text { the Mekong River and Tonle Sap }\end{array}$ & CC\&CV, CATMD & $\begin{array}{l}\text { United States of America, } \\
\text { Thailand, Lao PDR, } \\
\text { Cambodia }\end{array}$ & $\begin{array}{l}\text { https://www.apn-gcr. } \\
\text { org/resources/items/ } \\
\text { show/1756 }\end{array}$ & 68,100 & 2015 \\
\hline $\begin{array}{l}\text { ARCP2012-18NMY-Sase } \\
\text { ARCP2013-13CMY-Sase }\end{array}$ & Hiroyuki Sase & sase@acap.asia & $\begin{array}{l}\text { Dynamics of Sulphur Derived From Atmospheric } \\
\text { Deposition and Its Possible Impacts on the East } \\
\text { Asian Forests }\end{array}$ & EBLU, CATMD & Malaysia, Thailand, Japan & $\begin{array}{l}\text { http://www.apn-gcr. } \\
\text { org/resources/items/ } \\
\text { show/1757 }\end{array}$ & 88,000 & 2014 \\
\hline ARCP2012-19NSY-Kamal & $\begin{array}{l}\text { Abu Hena Mustafa } \\
\text { Kamal }\end{array}$ & abuhena@epm.edu & $\begin{array}{l}\text { Assessing Climate Change Impacts on Salt Marsh } \\
\text { and Seagrass Ecosystems in the South and South } \\
\text { East Asian Coasts }\end{array}$ & CCCV, CATMD & $\begin{array}{l}\text { Malaysia, Bangladesh, India, } \\
\text { Viet Nam, Thailand, Japan }\end{array}$ & $\begin{array}{l}\text { http://www.apn-gcr. } \\
\text { org/resources/items/ } \\
\text { show/1758 }\end{array}$ & 45,000 & 2015 \\
\hline ARCP2012-20NSY-Musafer & Namiz Musafer & $\begin{array}{l}\text { namiz.musafer@ } \\
\text { practicalaction.org.lk }\end{array}$ & $\begin{array}{l}\text { Sustainable Biochar Systems in Developing } \\
\text { Countries }\end{array}$ & RUSD & $\begin{array}{l}\text { Sri Lanka, Nepal, Thailand, } \\
\text { United Kingdom }\end{array}$ & $\begin{array}{l}\text { http://www.apn-gcr. } \\
\text { org/resources/items/ } \\
\text { show/1759 }\end{array}$ & 45,000 & 2015 \\
\hline $\begin{array}{l}\text { ARCP2013-14NMY-Miyata } \\
\text { ARCP2014-04CMY-Miyata } \\
\text { ARCP2015-01CMY-Miyata }\end{array}$ & Akira Miyata & amiyat@niaes.affrc.go.jp & $\begin{array}{l}\text { Toward CarboAsia: Integration and Syntheses } \\
\text { of Terrestrial Ecosystem Flux Data in Tropics/ } \\
\text { Subtropics and Croplands in Asia by Activating } \\
\text { Regional Tower-based Observation Networks }\end{array}$ & EBLU & $\begin{array}{l}\text { Japan, Republic of Korea, } \\
\text { China, Philippines, Viet Nam, } \\
\text { Thailand, Malaysia, } \\
\text { Indonesia, Bangladesh, India }\end{array}$ & $\begin{array}{l}\text { http://www.apn-gcr. } \\
\text { org/resources/items/ } \\
\text { show/1882 }\end{array}$ & 125,000 & 2015 \\
\hline $\begin{array}{l}\text { ARCP2013-15NMY-Manton } \\
\text { ARCP2014-05CMY-Ailikun } \\
\text { (Manton) } \\
\text { ARCP2015-02CMY-Ailikun }\end{array}$ & Ailikun & aili@mail.iap.ac.cn & $\begin{array}{l}\text { Coordinated Regional Climate Downscaling } \\
\text { Experiment (CORDEX) in Monsoon Asia }\end{array}$ & CATMD & $\begin{array}{l}\text { Australia, India, China, } \\
\text { Republic of Korea, Nepal }\end{array}$ & $\begin{array}{l}\text { http://www.apn-gcr. } \\
\text { org/resources/items/ } \\
\text { show/1883 }\end{array}$ & 125,000 & 2017 \\
\hline $\begin{array}{l}\text { ARCP2013-16NMY-Li } \\
\text { ARCP2014-06CMY-Li } \\
\text { ARCP2015-03CMY-Li }\end{array}$ & Jianlong Li & $\begin{array}{l}\text { jlli2008@nju.edu.cn } \\
\text { jianlongli@sina.com }\end{array}$ & $\begin{array}{l}\text { Assessing Spatiotemporal Variability of NPP, NEP } \\
\text { and Carbon Sinks of Global Grassland Ecosystem } \\
\text { in Response to Climate Change in 1911-2011 }\end{array}$ & EBLU, CATMD & $\begin{array}{l}\text { China, Mongolia, Uzbekistan, } \\
\text { United States of America, } \\
\text { Australia }\end{array}$ & $\begin{array}{l}\text { http://www.apn-gcr. } \\
\text { org/resources/items/ } \\
\text { show/1884 }\end{array}$ & 101,200 & 2017 \\
\hline $\begin{array}{l}\text { ARCP2013-17NMY-Tangang } \\
\text { ARCP2014-07CMY-Tangang } \\
\text { ARCP2015-04CMY-Tangang }\end{array}$ & Fredolin Tangang & ftangang@gmail.com & $\begin{array}{l}\text { Southeast Asia Regional Climate Downscaling } \\
\text { Project (SEACLID) }\end{array}$ & CATMD & $\begin{array}{l}\text { Malaysia, Philippines, } \\
\text { Indonesia, Thailand, } \\
\text { Cambodia, Lao PDR, } \\
\text { Viet Nam }\end{array}$ & $\begin{array}{l}\text { http://www.apn-gcr. } \\
\text { org/resources/items/ } \\
\text { show/1886 }\end{array}$ & 125,000 & 2018 \\
\hline $\begin{array}{l}\text { ARCP2013-19NMY-Gomboev } \\
\text { ARCP2014-09CMY-Gomboev }\end{array}$ & Bair O. Gomboev & bgom@binm.bscnet.ru & $\begin{array}{l}\text { Boreal and Tropical Forest and Forest-Steppes } \\
\text { in East Asia: A Comparative Study on Climate } \\
\text { Impacts and Adaptation }\end{array}$ & EBLU & $\begin{array}{l}\text { Russian Federation, } \\
\text { Mongolia, China }\end{array}$ & $\begin{array}{l}\text { http://www.apn-gcr. } \\
\text { org/resources/items/ } \\
\text { show/1890 }\end{array}$ & 85,000 & 2017 \\
\hline
\end{tabular}




\begin{tabular}{|c|c|c|c|c|c|c|c|c|}
\hline Project Reference Number & Project Leader & Email Address & Title & Science Agenda & Countries & Metadata link & Award & $\begin{array}{l}\text { Year } \\
\text { Completed }\end{array}$ \\
\hline $\begin{array}{l}\text { ARCP2013-20NMY-Shrestha } \\
\text { ARCP2014-10CMY-Shrestha }\end{array}$ & $\begin{array}{l}\text { Madan Lall } \\
\text { Shrestha }\end{array}$ & $\begin{array}{l}\text { infor@smallearth.org.np } \\
\text { madanls@hotmail.com }\end{array}$ & $\begin{array}{l}\text { Runoff Scenario and Water Based Adaptation } \\
\text { Strategies in South Asia }\end{array}$ & EBLU, CATMD & $\begin{array}{l}\text { Nepal, Pakistan, Bangladesh, } \\
\text { United States of America }\end{array}$ & $\begin{array}{l}\text { http://www.apn-gcr. } \\
\text { org/resources/items/ } \\
\text { show/1891 }\end{array}$ & 40,000 & 2017 \\
\hline $\begin{array}{l}\text { ARCP2013-21NMY-Yamada } \\
\text { ARCP2014-11CMY-Yamada }\end{array}$ & Masato Yamada & myamada@nies.go.jp & $\begin{array}{l}\text { Adaptation of Solid Waste Management to } \\
\text { Frequent Floods in Vulnerable Mid-Scale Asian } \\
\text { Cities }\end{array}$ & $\begin{array}{l}\text { CC\&V, EBLU, } \\
\text { RUSD }\end{array}$ & Japan, Thailand, Viet Nam & $\begin{array}{l}\text { https://www.apn-gcr. } \\
\text { org/resources/items/ } \\
\text { show/1892 }\end{array}$ & 70,000 & 2016 \\
\hline $\begin{array}{l}\text { ARCP2013-22NMY-Sellers } \\
\text { ARCP2014-12CMY-Sellers }\end{array}$ & Jeffery M. Sellers & sellers@usc.edu & $\begin{array}{l}\text { Mega-Regional Development and Environmental } \\
\text { Change in China and India }\end{array}$ & EBLU & $\begin{array}{l}\text { United States of America, } \\
\text { India, China }\end{array}$ & $\begin{array}{l}\text { http://www.apn-gcr. } \\
\text { org/resources/items/ } \\
\text { show/1893 }\end{array}$ & 68,500 & 2018 \\
\hline $\begin{array}{l}\text { ARCP2013-23NMY-Sthiannopkao } \\
\text { ARCP2014-13CMY-Sthiannopkao }\end{array}$ & $\begin{array}{l}\text { Suthipong } \\
\text { Sthiannopkao }\end{array}$ & suthisuthi@gmail.com & $\begin{array}{l}\text { Developing Scientific and Management Tools to } \\
\text { Address Impacts of Changing Climate and Land } \\
\text { Use Patterns on Water Quality in East Asia's River } \\
\text { Basins }\end{array}$ & CC\&V, EBLU & $\begin{array}{l}\text { Republic of Korea, United } \\
\text { States of America, Indonesia, } \\
\text { Thailand, Philippines, Lao } \\
\text { PDR }\end{array}$ & $\begin{array}{l}\text { http://www.apn-gcr. } \\
\text { org/resources/items/ } \\
\text { show/1894 }\end{array}$ & 76,000 & 2016 \\
\hline ARCP2013-24NSY-Fidelman & Pedro Fidelman & pedro.fidelman@usc.edu.au & $\begin{array}{l}\text { Supporting Governance Institutions for Adaptive } \\
\text { Capacity to Environmental Change }\end{array}$ & ECG, AC & $\begin{array}{l}\text { Australia, Viet Nam, } \\
\text { Cambodia }\end{array}$ & $\begin{array}{l}\text { http://www.apn-gcr. } \\
\text { org/resources/items/ } \\
\text { show/1895 }\end{array}$ & 46,000 & 2016 \\
\hline ARCP2013-25NSY-Shahid & $\begin{array}{l}\text { Shamsuddin } \\
\text { Shahid }\end{array}$ & sshahid@utm.my & $\begin{array}{l}\text { Climate Change Vulnerability and Adaptation in } \\
\text { Groundwater-dependent Irrigation System in } \\
\text { Asia-Pacific Region }\end{array}$ & EBLU, CC\&V & $\begin{array}{l}\text { Malaysia, Bangladesh, } \\
\text { China, India, Indonesia }\end{array}$ & $\begin{array}{l}\text { https://www.apn-gcr. } \\
\text { org/resources/items/ } \\
\text { show/1896 }\end{array}$ & 40,000 & 2015 \\
\hline ARCP2013-26NSY-Patankar & Archana Patankar & $\begin{array}{l}\text { archana.patankar09@ } \\
\text { gmail.com }\end{array}$ & $\begin{array}{l}\text { Characterizing Public and Private Adaptation to } \\
\text { Climate Change and Implications for Long-Term } \\
\text { Adaptive Capacity in Asian Megacities }\end{array}$ & CC\&V & India, Thailand, Philippines & $\begin{array}{l}\text { http://www.apn-gcr. } \\
\text { org/resources/items/ } \\
\text { show/1897 }\end{array}$ & 34,000 & 2015 \\
\hline ARCP2013-27NSY-Liu & Lin Liu & liul@fio.org.cn & $\begin{array}{l}\text { The impact of global warming on ocean- } \\
\text { atmosphere feedback strength at tropical Indian } \\
\text { Ocean }\end{array}$ & CC\&V, CATMD & $\begin{array}{l}\text { China, Malaysia, United } \\
\text { States of America, Thailand, } \\
\text { Pakistan }\end{array}$ & $\begin{array}{l}\text { https://www.apn-gcr. } \\
\text { org/resources/items/ } \\
\text { show/1898 }\end{array}$ & 29,000 & 2015 \\
\hline ARCP2014-14NMY(B\&ES)-Salmo & $\begin{array}{l}\text { Severino G. } \\
\text { Salmo III }\end{array}$ & ssalmo@ateneo.edu & $\begin{array}{l}\text { Influence of Mangrove Biodiversity on } \\
\text { Accumulation of Carbon and Resilience to Sea } \\
\text { Level Rise: A Comparative Assessment among } \\
\text { Disturbed, Restored and Intact Mangrove Systems }\end{array}$ & B\&ES, ARCP & $\begin{array}{l}\text { Philippines, Malaysia, } \\
\text { Indonesia, Australia, } \\
\text { Singapore, United States of } \\
\text { America }\end{array}$ & $\begin{array}{l}\text { http://www.apn-gcr. } \\
\text { org/resources/items/ } \\
\text { show/1940 }\end{array}$ & 40,000 & 2017 \\
\hline
\end{tabular}




\begin{tabular}{|c|c|c|c|c|c|c|c|c|}
\hline Project Reference Number & Project Leader & Email Address & Title & Science Agenda & Countries & Metadata link & Award & $\begin{array}{l}\text { Year } \\
\text { Completed }\end{array}$ \\
\hline $\begin{array}{l}\text { ARCP2014-16NMY-Babel } \\
\text { ARCP2015-07CMY-Babel }\end{array}$ & Mukand S. Babel & msbabel@ait.asia & $\begin{array}{l}\text { Developing an operational water security index, } \\
\text { and its application in selected diverse regions of } \\
\text { Asia }\end{array}$ & $\begin{array}{l}\text { EBLU,RUSD, } \\
\text { SPL }\end{array}$ & Thailand, Viet Nam, India & $\begin{array}{l}\text { http://www.apn-gcr. } \\
\text { org/resources/items/ } \\
\text { show/2013 }\end{array}$ & 80,000 & 2017 \\
\hline $\begin{array}{l}\text { ARCP2014-17NMY-Dey } \\
\text { ARCP2015-08CMY-Dey }\end{array}$ & Dipayan Dey & drdipayandey@gmail.com & $\begin{array}{l}\text { Impacts of Crop Residue Removal for Biomass } \\
\text { Energy on Soil Function: Studies to recommend } \\
\text { Climate Adaptive Agricultural Waste Management }\end{array}$ & CC\&CV & India, Bhutan, Philippines & $\begin{array}{l}\text { http://www.apn-gcr. } \\
\text { org/resources/items/ } \\
\text { show/1947 }\end{array}$ & 75,000 & 2018 \\
\hline $\begin{array}{l}\text { ARCP2014-18NMY-Heath } \\
\text { ARCP2015-09CMY-Heath }\end{array}$ & Lance Clive Heath & Iheath@grapevine.com.au & $\begin{array}{l}\text { Development of an evidence-based climate } \\
\text { change adaptation toolkit to help improve } \\
\text { community resilience to climate change impacts } \\
\text { in Uttarakhand, India }\end{array}$ & $\mathrm{CC} \& \mathrm{~V}, \mathrm{SPL}$ & $\begin{array}{l}\text { Australia, India, China, } \\
\text { Nepal, Bangladesh }\end{array}$ & $\begin{array}{l}\text { http://www.apn-gcr. } \\
\text { org/resources/items/ } \\
\text { show/1991 }\end{array}$ & 85,000 & 2017 \\
\hline $\begin{array}{l}\text { ARCP2014-19NMY(B\&ES)-Liang } \\
\text { ARCP2015-10CMY(B\&ES)-Liang }\end{array}$ & Luohui Liang & liang@unu.edu & $\begin{array}{l}\text { Coastal forest management in the face of global } \\
\text { change based on case studies in Japan, Myanmar } \\
\text { and the Philippines }\end{array}$ & EBLU, CATMD & Philippines, Myanmar, Japan & $\begin{array}{l}\text { http://www.apn-gcr. } \\
\text { org/resources/items/ } \\
\text { show/1964 }\end{array}$ & 80,000 & 2017 \\
\hline $\begin{array}{l}\text { ARCP2014-20NMY-Mishra } \\
\text { ARCP2015-11CMY-Mishra }\end{array}$ & $\begin{array}{l}\text { Binaya Kumar } \\
\text { Mishra }\end{array}$ & mishra@unu.edu & $\begin{array}{l}\text { Climate Change Adaptation through Optimal } \\
\text { Stormwater Capture Measures: Towards a New } \\
\text { Paradigm for Urban Water Security }\end{array}$ & EBLU, RUSD & $\begin{array}{l}\text { Japan, Thailand, Viet Nam, } \\
\text { Lao PDR }\end{array}$ & $\begin{array}{l}\text { https://www.apn-gcr. } \\
\text { org/resources/items/ } \\
\text { show/1972 }\end{array}$ & 65,000 & 2017 \\
\hline $\begin{array}{l}\text { ARCP2014-21NMY-Sharp } \\
\text { ARCP2015-12CMY-Sharp }\end{array}$ & Alice Sharp & alice.sharp@cmu.ac.th & $\begin{array}{l}\text { Integrated solid waste management system } \\
\text { leading to zero waste for sustainable resource } \\
\text { utilization in rapid urbanized areas in developing } \\
\text { countries }\end{array}$ & RUSD & Thailand, Bhutan, Viet Nam & $\begin{array}{l}\text { http://www.apn-gcr. } \\
\text { org/resources/items/ } \\
\text { show/1989 }\end{array}$ & 75,000 & 2018 \\
\hline $\begin{array}{l}\text { ARCP2014-22NMY-Zhou } \\
\text { ARCP2015-13CMY-Zhou }\end{array}$ & Xin Zhou & zhou@iges.or.jp & $\begin{array}{l}\text { Assessment of Climate-Induced Long-term Water } \\
\text { Availability in Ganges Basin and Impacts on } \\
\text { Energy Security in South Asia }\end{array}$ & RUSD, EBLU & $\begin{array}{l}\text { Bangladesh, India, Nepal, } \\
\text { Japan }\end{array}$ & $\begin{array}{l}\text { http://www.apn-gcr. } \\
\text { org/resources/items/ } \\
\text { show/1968 }\end{array}$ & 75,000 & 2018 \\
\hline ARCP2014-23NSG-Huang & Cunrui Huang & c.huang@griffith.edu.au & $\begin{array}{l}\text { Scoping Workshop to Develop Proposal: Assessing } \\
\text { the Health Effects of Extreme Temperatures and } \\
\text { the Development of Adaptation Strategies to } \\
\text { Climate Change in the Asia Pacific Region }\end{array}$ & CC\&V & $\begin{array}{l}\text { Bangladesh, China, } \\
\text { Viet Nam, Australia }\end{array}$ & $\begin{array}{l}\text { http://www.apn-gcr. } \\
\text { org/resources/items/ } \\
\text { show/1967 }\end{array}$ & 12,000 & 2014 \\
\hline ARCP2014-24NSG-Lokupitiya & $\begin{array}{l}\text { Erandathie } \\
\text { Lokupitiya }\end{array}$ & erandi@sci.cmb.ac.lk & $\begin{array}{l}\text { Scoping Workshop: Identification of the best } \\
\text { agricultural management practices with better } \\
\text { greenhouse gas benefits in salinity affected areas } \\
\text { of South Asia }\end{array}$ & EBLU, CATMD & $\begin{array}{l}\text { Sri Lanka, Bangladesh, } \\
\text { Pakistan, India, United } \\
\text { States of America }\end{array}$ & $\begin{array}{l}\text { https://www.apn-gcr. } \\
\text { org/resources/items/ } \\
\text { show/1973 }\end{array}$ & 15,000 & 2015 \\
\hline
\end{tabular}




\begin{tabular}{|c|c|c|c|c|c|c|c|c|}
\hline Project Reference Number & Project Leader & Email Address & Title & Science Agend & Countries & Metadata link & Award & $\begin{array}{l}\text { Year } \\
\text { Completed }\end{array}$ \\
\hline CRRP2016-03MY-Nunn & Patrick D. Nunn & pnunn@usc.edu.au & $\begin{array}{l}\text { Risk and Resilience in the Pacific: Influence of } \\
\text { Peripherality on Exposure and Responses to } \\
\text { Global Change }\end{array}$ & CCCV, RRR & $\begin{array}{l}\text { Australia, Federated States } \\
\text { of Micronesia, Fiji }\end{array}$ & $\begin{array}{l}\text { http://www.apn-gcr. } \\
\text { org/resources/items/ } \\
\text { show/2049 }\end{array}$ & 140,000 & 2018 \\
\hline CRRP2016-04MY-Zhen & Lin Zhen & zhenl@igsnrr.ac.cn & $\begin{array}{l}\text { Assessing land use functions for sustainable land } \\
\text { management in Asian countries }\end{array}$ & CATMD & Japan, China, Bangladesh & $\begin{array}{l}\text { http://www.apn-gcr. } \\
\text { org/resources/items/ } \\
\text { show/2050 }\end{array}$ & 84,000 & 2018 \\
\hline CRRP2016-05MY-Rowlings & David Rowlings & d.rowlings@qut.edu.au & $\begin{array}{l}\text { Managing Organic Amendments to Reduce } \\
\text { Greenhouse Gas Emissions and Supplement } \\
\text { Fertilizer Nitrogen Inputs in Tropical Indian and } \\
\text { Sri Lankan Agricultural Soils }\end{array}$ & CATMD & Australia, Sri Lanka, India & $\begin{array}{l}\text { http://www.apn-gcr. } \\
\text { org/resources/items/ } \\
\text { show/2051 }\end{array}$ & 80,000 & 2018 \\
\hline CRRP2016-06MY-Kumar & Manish Kumar & manish.env@gmail.com & $\begin{array}{l}\text { Development of new water supply strategies in } \\
\text { two major cities of India and Sri Lanka in the } \\
\text { context of climate change, rapid urbanization and } \\
\text { population growth: a vulnerability assessment } \\
\text { approach }\end{array}$ & RUSD, CC\&CV & India, Sri Lanka, Japan & $\begin{array}{l}\text { http://www.apn-gcr. } \\
\text { org/resources/items/ } \\
\text { show/2052 }\end{array}$ & 75,000 & 2018 \\
\hline CRRP2016-07MY-Ishigaki & Tomonori Ishigaki & ishigaki@nies.go.jp & $\begin{array}{l}\text { Appropriate Solid Waste Management towards } \\
\text { flood risk reduction through recovery of drainage } \\
\text { function in tropical Asian urban cities }\end{array}$ & RUSD, EBLU & Japan, Viet Nam, Thailand & $\begin{array}{l}\text { http://www.apn-gcr. } \\
\text { org/resources/items/ } \\
\text { show/2053 }\end{array}$ & 80,000 & 2018 \\
\hline CRRP2016-10MY-Huang & Cunrui Huang & huangcr@mail.sysu.edu.cn & $\begin{array}{l}\text { Assessing the health effects of extreme } \\
\text { temperatures and the development of adaptation } \\
\text { strategies to climate change in the Asia-Pacific } \\
\text { region }\end{array}$ & CC\&V & $\begin{array}{l}\text { China, Viet Nam, Australia, } \\
\text { Bangladesh }\end{array}$ & $\begin{array}{l}\text { http://www.apn-gcr. } \\
\text { org/resources/items/ } \\
\text { show/2056 }\end{array}$ & 82,000 & 2018 \\
\hline CRRP2017-09SY-Ahmed & Iftekhar Ahmed & $\begin{array}{l}\text { ifte.ahmed@newcastle. } \\
\text { edu.au }\end{array}$ & $\begin{array}{l}\text { Understanding the opportunities and challenges } \\
\text { of compliance to safe building codes for disaster } \\
\text { resilience in South Asia - the cases of Bangladesh } \\
\text { and Nepal }\end{array}$ & RRR & Australia, Bangladesh, Nepal & $\begin{array}{l}\text { http://www.apn-gcr. } \\
\text { org/resources/items/ } \\
\text { show/2081 }\end{array}$ & 43,000 & 2019 \\
\hline
\end{tabular}

\section{Capacity Development Pogramme (CAPaBLE)}

\begin{tabular}{|c|c|c|c|c|c|c|c|c|}
\hline $\begin{array}{l}\text { CBA2011-07NMY-Abawi } \\
\text { CBA2012-01CMY-Abawi }\end{array}$ & Yahya Abawi & $\begin{array}{l}\text { y.abawi@bom.gov.au } \\
\text { yahya.abawi@usq.edu.au }\end{array}$ & $\begin{array}{l}\text { Building Scientific Capacity in Seasonal Climate } \\
\text { Forecasting (SCF) for Improved Risk Management } \\
\text { Decisions in a Changing Climate }\end{array}$ & $\mathrm{CCCV}$ & $\begin{array}{l}\text { Australia, Bangladesh, } \\
\text { Indonesia, Philippines }\end{array}$ & $\begin{array}{l}\text { http://www.apn-gcr. } \\
\text { org/resources/items/ } \\
\text { show/1685 }\end{array}$ & 70,000 & 2014 \\
\hline
\end{tabular}




\begin{tabular}{|c|c|c|c|c|c|c|c|c|}
\hline Project Reference Number & Project Leader & Email Address & Title & Science Agenda & Countries & Metadata link & Award & $\begin{array}{l}\text { Year } \\
\text { Completed }\end{array}$ \\
\hline $\begin{array}{l}\text { CBA2012-03NMY-Rasul } \\
\text { CBA2013-01CMY-Rasul }\end{array}$ & Ghulam Rasul & rasulpmd@gmail.com & $\begin{array}{l}\text { Impact of Climate Change on Glacier Melting and } \\
\text { Water Cycle Variability in Asian River Basins }\end{array}$ & $\mathrm{CCCV}, \mathrm{SPL}$ & $\begin{array}{l}\text { Pan Asia-Pacific, Republic } \\
\text { of Korea }\end{array}$ & $\begin{array}{l}\text { http://www.apn-gcr. } \\
\text { org/resources/items/ } \\
\text { show/1763 }\end{array}$ & 80,000 & 2014 \\
\hline $\begin{array}{l}\text { CBA2012-09NMY-Hashim } \\
\text { CBA2013-02CMY-Hashim }\end{array}$ & $\begin{array}{l}\text { Jamal Hisham } \\
\text { Hashim }\end{array}$ & jamal@unu.edu & $\begin{array}{l}\text { Global Environmental Change and Human Health: } \\
\text { Extreme Events and Urbanization in the APN } \\
\text { Region }\end{array}$ & CCCV, GEC & $\begin{array}{l}\text { Malaysia, Australia, China, } \\
\text { India }\end{array}$ & $\begin{array}{l}\text { http://www.apn-gcr. } \\
\text { org/resources/items/ } \\
\text { show/1769 }\end{array}$ & 68,073 & 2016 \\
\hline $\begin{array}{l}\text { CBA2013-03NMY-D’Arrigo } \\
\text { CBA2014-01CMY-D’Arrigo }\end{array}$ & $\begin{array}{l}\text { Roseanne } \\
\text { D’Arrigo }\end{array}$ & rdd@ldeo.columbia.edu & $\begin{array}{l}\text { Atmospheric Circulation Reconstructions over } \\
\text { the Earth (ACRE) SE Asia - towards new weather } \\
\text { and climate baselines for assessing weather } \\
\text { and climate extremes, impacts and risks over } \\
\text { Southeast Asia }\end{array}$ & $\mathrm{CCV}$ & $\begin{array}{l}\text { United States of America, } \\
\text { Australia, New Zealand, } \\
\text { Indonesia, China, Malaysia, } \\
\text { Philippines, Singapore, } \\
\text { Viet Nam, Japan }\end{array}$ & $\begin{array}{l}\text { http://www.apn-gcr. } \\
\text { org/resources/items/ } \\
\text { show/1912 }\end{array}$ & 36,000 & 2018 \\
\hline CBA2013-04NSY-WCRP & R. Krishnan & $\begin{array}{l}\text { krish@tropmet.res.in } \\
\text { mrixen@wmo.int }\end{array}$ & $\begin{array}{l}\text { International Conference on Regional Climate } \\
\text { CORDEX } 2013\end{array}$ & CCCV & All APN member countries & $\begin{array}{l}\text { http://www.apn-gcr. } \\
\text { org/resources/items/ } \\
\text { show/1899 }\end{array}$ & 39,985 & 2013 \\
\hline CBA2013-05NSY-Sutrisno & $\begin{array}{l}\text { Dewayany } \\
\text { Sutrisno }\end{array}$ & dewayany@gmail.com & $\begin{array}{l}\text { The Implementation of Multi Sensors Remote } \\
\text { Sensing Technology for Sustainable Disaster } \\
\text { Management }\end{array}$ & RUSD, CATMD & Indonesia, Japan, Singapore & $\begin{array}{l}\text { http://www.apn-gcr. } \\
\text { org/resources/items/ } \\
\text { show/1900 }\end{array}$ & 38,000 & 2014 \\
\hline CBA2013-06NSY-Shrestha & Sangam Shrestha & $\begin{array}{l}\text { sangam@ait.ac.th } \\
\text { sangamshrestha@gmail.com } \\
\text { kataoka@iges.or.jp }\end{array}$ & $\begin{array}{l}\text { Enhancing the Groundwater Management } \\
\text { Capacity in Asian Cities through the Development } \\
\text { and Application of Groundwater Sustainability } \\
\text { Index in the Context of Global Change }\end{array}$ & RUSD & $\begin{array}{l}\text { Japan, Thailand, Indonesia, } \\
\text { Viet Nam }\end{array}$ & $\begin{array}{l}\text { http://www.apn-gcr. } \\
\text { org/resources/items/ } \\
\text { show/1901 }\end{array}$ & 42,000 & 2015 \\
\hline CBA2013-07NSY-Dahal & Khem Raj Dahal & $\begin{array}{l}\text { info@smallearth.org.np } \\
\text { smallearthnepal@gmail.com }\end{array}$ & $\begin{array}{l}\text { Policy Brief Writeshop for Researchers: An } \\
\text { Approach to Promote Greater Science-Policy } \\
\text { Interfacing in South Asia }\end{array}$ & SPL & $\begin{array}{l}\text { Nepal, United States of } \\
\text { America, Thailand, Australia }\end{array}$ & $\begin{array}{l}\text { http://www.apn-gcr. } \\
\text { org/resources/items/ } \\
\text { show/1902 }\end{array}$ & 36,000 & 2014 \\
\hline CBA2013-08NSY-SOLAS & Minhan Dai & mdai@xmu.edu.cn & $\begin{array}{l}\text { Capacity Building on Surface Ocean-Lower } \\
\text { Atmosphere Study: The SOLAS Summer School }\end{array}$ & CATMD, $\mathrm{Cl}$ & All APN member countries & $\begin{array}{l}\text { http://www.apn-gcr. } \\
\text { org/resources/items/ } \\
\text { show/1903 }\end{array}$ & 23,000 & 2013 \\
\hline CBA2013-09NSY-Pascoe & Sean Pascoe & Sean.Pascoe@csiro.au & $\begin{array}{l}\text { Building Capacity for Socio-Ecological Resilience } \\
\text { to Coral Bleaching Events in Indonesia, Malaysia, } \\
\text { and Thailand }\end{array}$ & CATMD, Cl & $\begin{array}{l}\text { Australia, United States } \\
\text { of America, Indonesia, } \\
\text { Malaysia, Thailand }\end{array}$ & $\begin{array}{l}\text { http://www.apn-gcr. } \\
\text { org/resources/items/ } \\
\text { show/1904 }\end{array}$ & 44,000 & 2014 \\
\hline
\end{tabular}




\begin{tabular}{|c|c|c|c|c|c|c|c|c|}
\hline Project Reference Number & Project Leader & Email Address & Title & Science Agenda & Countries & Metadata link & Award & $\begin{array}{l}\text { Year } \\
\text { Completed }\end{array}$ \\
\hline CBA2013-11NSY-Pakharkova & Nina Pakharkova & $\begin{array}{l}\text { nina.pakharkova@ } \\
\text { yandex.ru }\end{array}$ & $\begin{array}{l}\text { Scale in Earth System Governance: Local Case } \\
\text { Studies and Global Sustainability }\end{array}$ & $\mathrm{Cl}$ & Russian Federation & $\begin{array}{l}\text { http://www.apn-gcr. } \\
\text { org/resources/items/ } \\
\text { show/1906 }\end{array}$ & 38,000 & 2014 \\
\hline CBA2013-12NSY-MAIRS & Ailikun & aili@mairs-essp.org & $\begin{array}{l}\text { Promoting the Sustainability Science in Monsoon } \\
\text { Asian Region }\end{array}$ & $\mathrm{CCCV}$ & $\begin{array}{l}\text { China, Malaysia, Mongolia, } \\
\text { Japan, India, United States } \\
\text { of America, Australia }\end{array}$ & $\begin{array}{l}\text { http://www.apn-gcr. } \\
\text { org/resources/items/ } \\
\text { show/1907 }\end{array}$ & 38,000 & 2014 \\
\hline CBA2013-13NSY-Varma & Navarun Varma & navarun@teri.res.in & $\begin{array}{l}\text { Building Capacity for Adaptive Governance } \\
\text { through Participatory Modelling: Rural and Urban } \\
\text { Flooding in India }\end{array}$ & CATMD, SPL & $\begin{array}{l}\text { India, Bangladesh, Sri Lanka, } \\
\text { Nepal, Singapore }\end{array}$ & $\begin{array}{l}\text { http://www.apn-gcr. } \\
\text { org/resources/items/ } \\
\text { show/1908 }\end{array}$ & 40,000 & 2014 \\
\hline CBA2013-16NSY-Dargantes & $\begin{array}{l}\text { Buenaventura B. } \\
\text { Dargantes }\end{array}$ & $\begin{array}{l}\text { vsu_iwrm_program@ } \\
\text { yahoo.com.ph } \\
\text { vsuwaterresearch@ } \\
\text { yahoo.com.ph }\end{array}$ & $\begin{array}{l}\text { Strengthening the Capability of Colleges of } \\
\text { Agriculture in Incorporating Food and Water } \\
\text { Security and Climate Change and Climate } \\
\text { Variability into Curricular Programmes, Research } \\
\text { and Extension Projects and Teaching Modules }\end{array}$ & CCCV, RUSD & $\begin{array}{l}\text { Philippines, Indonesia, } \\
\text { Cambodia, Japan }\end{array}$ & $\begin{array}{l}\text { http://www.apn-gcr. } \\
\text { org/resources/items/ } \\
\text { show/1911 }\end{array}$ & 43,000 & 2014 \\
\hline CBA2013-14NSY-Maity & Ashoka Maity & safeinch@gmail.com & $\begin{array}{l}\text { Promoting Algaculture in Trapped Waters as } \\
\text { Sustainable Aquafarming and Adaptive Climate } \\
\text { Mitigation in Inundated Coastal Areas }\end{array}$ & CCCV, CATMD & $\begin{array}{l}\text { India, Bangladesh, Sri Lanka, } \\
\text { Republic of Korea }\end{array}$ & $\begin{array}{l}\text { http://www.apn-gcr. } \\
\text { org/resources/items/ } \\
\text { show/1909 }\end{array}$ & 35,000 & 2014 \\
\hline $\begin{array}{l}\text { CBA2013-15NSY-Heinrich- } \\
\text { Sanchez }\end{array}$ & $\begin{array}{l}\text { Eduardo } \\
\text { Heinrich-Sanchez }\end{array}$ & $\begin{array}{l}\text { edo@okinawaocean.org } \\
\text { chiefnavi@gmail.com }\end{array}$ & $\begin{array}{l}\text { Building Capacity on Marine Litter Management } \\
\text { in the NOWPAP (Northwest Pacific Action Plan) } \\
\text { Region }\end{array}$ & CATMD & $\begin{array}{l}\text { China, Japan, Republic of } \\
\text { Korea, Russian Federation }\end{array}$ & $\begin{array}{l}\text { http://www.apn-gcr. } \\
\text { org/resources/items/ } \\
\text { show/1910 }\end{array}$ & 33,000 & 2014 \\
\hline CBA2013-17NSY-Bodeker & Gregory Bodeker & $\begin{array}{l}\text { greg@bodekerscienctific. } \\
\text { com }\end{array}$ & $\begin{array}{l}\text { SPARC (Stratosphere-troposphere Processes And } \\
\text { their Role in Climate) General Assembly } 2014\end{array}$ & CCCV, CATMD & $\begin{array}{l}\text { New Zealand, Malaysia, } \\
\text { China, Bangladesh, China }\end{array}$ & $\begin{array}{l}\text { http://www.apn-gcr. } \\
\text { org/resources/items/ } \\
\text { show/1929 }\end{array}$ & 20,000 & 2014 \\
\hline $\begin{array}{l}\text { CBA2014-02NMY-Singhruck } \\
\text { CBA2015-01CMY-Singhruck }\end{array}$ & $\begin{array}{l}\text { Patama } \\
\text { Singhruck }\end{array}$ & patama@cckm.or.th & $\begin{array}{l}\text { Strengthening Adaptive Capacity of Local } \\
\text { Agricultural Communities through the } \\
\text { Development of Seasonal Climate Prediction } \\
\text { System }\end{array}$ & $\mathrm{CCCV}$ & Thailand & $\begin{array}{l}\text { https://www.apn-gcr. } \\
\text { org/resources/items/ } \\
\text { show/1952 }\end{array}$ & 40,000 & 2015 \\
\hline CBA2014-05NSY(B\&ES)-Gopal & Brij Gopal & brij44@gmail.com & $\begin{array}{l}\text { Capacity Building for Conservation of Biodiversity } \\
\text { and Ecosystem Services of Wetlands in Relation to } \\
\text { Global Change }\end{array}$ & EBLU & Bhutan, India, Nepal & $\begin{array}{l}\text { http://www.apn-gcr. } \\
\text { org/resources/items/ } \\
\text { show/1941 }\end{array}$ & 40,000 & 2015 \\
\hline
\end{tabular}




\begin{tabular}{|c|c|c|c|c|c|c|c|c|}
\hline Project Reference Number & Project Leader & Email Address & Title & Science Agenda & Countries & Metadata link & Award & $\begin{array}{l}\text { Year } \\
\text { Completed }\end{array}$ \\
\hline CBA2014-08NSY-Koshy & $\begin{array}{l}\text { Kanayathu } \\
\text { Chacko Koshy }\end{array}$ & $\begin{array}{l}\text { kanayathu.koshy@gmail. } \\
\text { com }\end{array}$ & WCRP-ICTP Summer School on Climate Extremes & $\mathrm{CCV}$ & $\begin{array}{l}\text { Australia, Canada, } \\
\text { France, Malaysia, Spain, } \\
\text { Switzerland, United States of } \\
\text { America }\end{array}$ & $\begin{array}{l}\text { http://www.apn-gcr. } \\
\text { org/resources/items/ } \\
\text { show/1992 }\end{array}$ & 29,378 & 2015 \\
\hline CBA2014-11NSY(B\&ES)-Zhang & Jing Zhang & jzhang@sklec.ecnu.edu.cn & $\begin{array}{l}\text { IMBER ClimEco4 Summer School - Delineating the } \\
\text { Issues of Climate Change and Impacts to Marine } \\
\text { Ecosystems: Bridging the Gap Between Research, } \\
\text { Assessment, Policy and Management }\end{array}$ & CATMD & $\begin{array}{l}\text { Australia, China, United } \\
\text { States of America }\end{array}$ & $\begin{array}{l}\text { http://www.apn-gcr. } \\
\text { org/resources/items/ } \\
\text { show/1937 }\end{array}$ & 35,000 & 2014 \\
\hline CBA2014-10NSY-Carandang & $\begin{array}{l}\text { Wilfredo M. } \\
\text { Carandang }\end{array}$ & wmcarandang@gmail.com & $\begin{array}{l}\text { Capacity Development of Local Climate } \\
\text { Change Communicators in Vulnerable Upland } \\
\text { Communities in Southeast Asia }\end{array}$ & $\mathrm{CCCV}$ & $\begin{array}{l}\text { Indonesia, Philippines, Lao } \\
\text { PDR, Viet Nam }\end{array}$ & $\begin{array}{l}\text { http://www.apn-gcr. } \\
\text { org/resources/items/ } \\
\text { show/1983 }\end{array}$ & 40,000 & 2015 \\
\hline CBA2014-12NSY-Bora & Ganesh C. Bora & ganesh.bora@ndsu.edu & $\begin{array}{l}\text { Scoping Workshop to Develop an APN Proposal } \\
\text { on Capacity Building in Climate Change Mitigation } \\
\text { through Precision Agriculture }\end{array}$ & $\begin{array}{l}\text { CCCV, RUSD, } \\
\text { SPL }\end{array}$ & $\begin{array}{l}\text { United States of America, } \\
\text { Thailand, India }\end{array}$ & $\begin{array}{l}\text { http://www.apn-gcr. } \\
\text { org/resources/items/ } \\
\text { show/1773 }\end{array}$ & 15,000 & 2014 \\
\hline CBA2014-13NSY (AOF)-PARR & $\begin{array}{l}\text { Hassan Virji } \\
\text { Rodel A. Lasco }\end{array}$ & rdlasco@yahoo.com & Pan Asia Risk Reduction Fellowship Programme & $\mathrm{CCl}$ & $\begin{array}{l}\text { United States of America, } \\
\text { Chinese Taipei, Japan, } \\
\text { Philippines, Thailand }\end{array}$ & $\begin{array}{l}\text { http://www.apn-gcr. } \\
\text { org/resources/items/ } \\
\text { show/1979 }\end{array}$ & 30,000 & 2016 \\
\hline CBA2014-09NSY-Mathai & Manu V. Mathai & mathai@unu.edu & $\begin{array}{l}\text { Training workshop and edited volume on "Green } \\
\text { Growth: Political Ideology, Political Economy and } \\
\text { Policy Alternatives" }\end{array}$ & RUSD & $\begin{array}{l}\text { Australia, Brazil, China, } \\
\text { France, Germany, India, } \\
\text { Indonesia, Japan, Nepal, } \\
\text { Philippines, Republic of } \\
\text { Korea, Spain, Switzerland, } \\
\text { Thailand, United Kingdom }\end{array}$ & $\begin{array}{l}\text { http://www.apn-gcr. } \\
\text { org/resources/items/ } \\
\text { show/1939 }\end{array}$ & 40,000 & 2017 \\
\hline CBA2014-03NSY-Cruz & Rex Victor O. Cruz & rexcruz@yahoo.com & $\begin{array}{l}\text { Collaborative Monitoring System for Enhanced } \\
\text { Watershed Management in the Philippines }\end{array}$ & EBLU & Philippines & $\begin{array}{l}\text { http://www.apn-gcr. } \\
\text { org/resources/items/ } \\
\text { show/1948 }\end{array}$ & 44,950 & 2016 \\
\hline CBA2014-04NSY-Divya Sharma & Divya Sharma & divyas@teri.res.in & $\begin{array}{l}\text { A Comprehensive Capacity Building Program on } \\
\text { Urban Climate Change Resilience in India }\end{array}$ & CCCV, RRR & $\begin{array}{l}\text { India, Bangladesh, United } \\
\text { Kingdom, United States of } \\
\text { America }\end{array}$ & $\begin{array}{l}\text { http://www.apn-gcr. } \\
\text { org/resources/items/ } \\
\text { show/1966 }\end{array}$ & 34,995 & 2015 \\
\hline CBA2014-06NSY-Hien & Than Thi Hien & tthien@mcdvietnam.org & $\begin{array}{l}\text { Scientific Capacity Building in Climate Change } \\
\text { Research Techniques for Non-Governmental } \\
\text { Organizations (NGOs) in Viet Nam }\end{array}$ & $\mathrm{CCl}$ & Viet Nam & $\begin{array}{l}\text { http://www.apn-gcr. } \\
\text { org/resources/items/ } \\
\text { show/1950 }\end{array}$ & 35,000 & 2017 \\
\hline
\end{tabular}




\begin{tabular}{|c|c|c|c|c|c|c|c|c|}
\hline Project Reference Number & Project Leader & Email Address & Title & Science Agenda & Countries & Metadata link & Award & $\begin{array}{l}\text { Year } \\
\text { Completed }\end{array}$ \\
\hline CBA2014-07NSY(B\&ES)-Jia & Gensuo Jia & jiong@tea.ac.cn & $\begin{array}{l}\text { International Training on Regional Ecosystem- } \\
\text { Climate Interactions }\end{array}$ & B\&ES & $\begin{array}{l}\text { China, United States of } \\
\text { America, Philippines, } \\
\text { Pakistan }\end{array}$ & $\begin{array}{l}\text { http://www.apn-gcr. } \\
\text { org/resources/items/ } \\
\text { show/1942 }\end{array}$ & 45,000 & 2015 \\
\hline $\begin{array}{l}\text { CBA2015-03NMY-Adiningsih } \\
\text { CBA2016-01CMY-Boonjawat }\end{array}$ & $\begin{array}{l}\text { Erna Adiningsih } \\
\text { Jariya Boonjawat }\end{array}$ & $\begin{array}{l}\text { ernasri@lapan.go.id } \\
\text { ernasri@yahoo.com } \\
\text { jariya@start.or.th }\end{array}$ & $\begin{array}{l}\text { Building Capacity for Urban Climate Change } \\
\text { Adaptation in Southeast Asia }\end{array}$ & CC\&CA & $\begin{array}{l}\text { Indonesia, Thailand, } \\
\text { Malaysia, Cambodia, Lao } \\
\text { PDR, Philippines, Viet Nam }\end{array}$ & $\begin{array}{l}\text { https://www.apn-gcr. } \\
\text { org/resources/items/ } \\
\text { show/2024 }\end{array}$ & 80,000 & 2019 \\
\hline CBA2015-04NSY-Avtar & Ram Avtar & avtar@unu.edu & $\begin{array}{l}\text { Developing a Training Module to Monitor Forest } \\
\text { Cover and Deforestation using Advanced Remote } \\
\text { Sensing Techniques under UN-CECAR Framework } \\
\text { in support of REDD+ MRV System }\end{array}$ & EBLU & $\begin{array}{l}\text { Japan, Sri Lanka, Cambodia, } \\
\text { India }\end{array}$ & $\begin{array}{l}\text { http://www.apn-gcr. } \\
\text { org/resources/items/ } \\
\text { show/2000 }\end{array}$ & 40,000 & 2016 \\
\hline CBA2015-05NSY-Seitzinger & $\begin{array}{l}\text { Sybil Putnam } \\
\text { Seitzinger }\end{array}$ & picsdir@uvic.ca & $\begin{array}{l}\text { Bringing Early-Career Scientists to the Fore: } \\
\text { Lessons Learned from International Geosphere- } \\
\text { Biosphere Programme (IGBP) Landmark } \\
\text { Synthesis Event }\end{array}$ & $\mathrm{CCl}$ & Pan Asia-Pacific & $\begin{array}{l}\text { http://www.apn-gcr. } \\
\text { org/resources/items/ } \\
\text { show/2001 }\end{array}$ & 37,500 & 2016 \\
\hline CBA2015-06NSY-Silva & E.I.L Silva & eils.wrst@gmail.com & $\begin{array}{l}\text { Escalating Small Hydropower Development and } \\
\text { Aquatic Biodiversity of Mountain Streams in Sri } \\
\text { Lanka }\end{array}$ & RUSD, BES & Sri Lanka & $\begin{array}{l}\text { http://www.apn-gcr. } \\
\text { org/resources/items/ } \\
\text { show/2010 }\end{array}$ & 20,000 & 2017 \\
\hline CBA2015-08NSY-Sharifi & Ayyoob Sharifi & sharifi@hiroshima-u.ac.jp & $\begin{array}{l}\text { Integrated, Resilience-based Planning for Climate } \\
\text { Change Mitigation and Adaptation in Asia-Pacific } \\
\text { Cities }\end{array}$ & CCCV, RRR & $\begin{array}{l}\text { Japan, Australia, United } \\
\text { States of America, China, } \\
\text { Thailand }\end{array}$ & $\begin{array}{l}\text { http://www.apn-gcr. } \\
\text { org/resources/items/ } \\
\text { show/2011 }\end{array}$ & 38,000 & 2016 \\
\hline CBA2016-05SY-Kang & Hyun-Suk Kang & $\begin{array}{l}\text { hyunsuk306.kang@gmail. } \\
\text { com }\end{array}$ & $\begin{array}{l}\text { Facilitating the attendance, interaction and } \\
\text { training of young and developing nation scientists } \\
\text { from Asia Pacific at the International Conference } \\
\text { on Regional Climate - CORDEX } 2016 \text { (ICRC-CORDEX } \\
\text { 2016) }\end{array}$ & $\begin{array}{l}\text { CCCV, BES, } \\
\text { CATMD, RUSD, } \\
\text { RRR }\end{array}$ & $\begin{array}{l}\text { Pan Asia-Pacific, Republic } \\
\text { of Korea }\end{array}$ & $\begin{array}{l}\text { http://www.apn-gcr. } \\
\text { org/resources/items/ } \\
\text { show/2038 }\end{array}$ & 25,000 & 2016 \\
\hline CBA2017-06SY-Hofmann & $\begin{array}{l}\text { Eileen E. } \\
\text { Hofmann }\end{array}$ & hofmann@ccpo.odu.edu & $\begin{array}{l}\text { IMBeR IMBIZO V Workshop: Management Strategy } \\
\text { Evaluation: Achieving Transparency in Natural } \\
\text { Resource Management by Quantitatively Bridging } \\
\text { Social and Natural Science Uncertainties }\end{array}$ & $\begin{array}{l}\text { CCCV, BES, } \\
\text { RUSD, RRR }\end{array}$ & $\begin{array}{l}\text { Australia, China, India, } \\
\text { Japan, New Zealand, } \\
\text { Philippines, Republic of } \\
\text { Korea, Russian Federation, } \\
\text { United States of America, } \\
\text { United Kingdom, Canada, } \\
\text { South Africa, France, Norway }\end{array}$ & $\begin{array}{l}\text { http://www.apn-gcr. } \\
\text { org/resources/items/ } \\
\text { show/2067 }\end{array}$ & 25,000 & 2018 \\
\hline
\end{tabular}




\begin{tabular}{|c|c|c|c|c|c|c|c|c|}
\hline Project Reference Number & Project Leader & Email Address & Title & Science Agenda & Countries & Metadata link & Award & $\begin{array}{l}\text { Year } \\
\text { Completed }\end{array}$ \\
\hline CBA2016-07SY-Shrestha & Sangam Shrestha & sangam@ait.asia & $\begin{array}{l}\text { Adapting groundwater of Asian cities to climate } \\
\text { change: bridging the science and policy interface }\end{array}$ & CCCV, RUSD & $\begin{array}{l}\text { Thailand, Indonesia, } \\
\text { Viet Nam, Japan, Pakistan }\end{array}$ & $\begin{array}{l}\text { http://www.apn-gcr. } \\
\text { org/resources/items/ } \\
\text { show/2042 }\end{array}$ & 40,000 & 2018 \\
\hline CBA2016-09SY-Ngo & Ngo Tho Hung & $\begin{array}{l}\text { hung@aitcv.ac.vn } \\
\text { ngothohung@gmail.com }\end{array}$ & $\begin{array}{l}\text { Ecosystem Based Adaptation approach for } \\
\text { Sustainable Management and Governance of } \\
\text { Coastal Ecosystems (ENGAGE ) }\end{array}$ & $\begin{array}{l}\text { CCCV, BES, } \\
\text { RUSD, RRR }\end{array}$ & $\begin{array}{l}\text { Viet Nam, Canada, India, } \\
\text { China, Republic of Korea }\end{array}$ & $\begin{array}{l}\text { http://www.apn-gcr. } \\
\text { org/resources/items/ } \\
\text { show/2044 }\end{array}$ & 35,000 & 2017 \\
\hline CBA2016-10SY-Sutrisno & $\begin{array}{l}\text { Dewayany } \\
\text { Sutrisno }\end{array}$ & dewayany@gmail.com & $\begin{array}{l}\text { Rapid mapping technique for disaster observation } \\
\text { and environmental change data acquisition }\end{array}$ & RRR & $\begin{array}{l}\text { Indonesia, Malaysia, Chinese } \\
\text { Taipei, Netherlands }\end{array}$ & $\begin{array}{l}\text { http://www.apn-gcr. } \\
\text { org/resources/items/ } \\
\text { show/2045 }\end{array}$ & 35,000 & 2016 \\
\hline CBA2017-04MY-Akbar & Ghani Akbar & ghani_akbar@hotmail.com & $\begin{array}{l}\text { Improving skills for promoting sustainable } \\
\text { watershed management practices in South Asia }\end{array}$ & $\mathrm{CCCV}$ & $\begin{array}{l}\text { Japan, Nepal, Pakistan, Sri } \\
\text { Lanka }\end{array}$ & $\begin{array}{l}\text { http://www.apn-gcr. } \\
\text { org/resources/items/ } \\
\text { show/2065 }\end{array}$ & 50,000 & 2019 \\
\hline CBA2017-08SG-Tshering & $\begin{array}{l}\text { Kuenzang } \\
\text { Tshering }\end{array}$ & kuenzangshering@rtc.bt & $\begin{array}{l}\text { Scoping workshop to develop the proposal: } \\
\text { Identifying the Wetlands Types in Bhutan to } \\
\text { Highlight Their Role in Carbon Emission and } \\
\text { Sequestration }\end{array}$ & B\&ES & Bhutan & $\begin{array}{l}\text { http://www.apn-gcr. } \\
\text { org/resources/items/ } \\
\text { show/2083 }\end{array}$ & 13,000 & 2018 \\
\hline \multicolumn{9}{|c|}{ Climate Adaptation Framework } \\
\hline CAF2013-01NSYL+D(F)-Huq & Saleemul Huq & saleemul.huq@iied.org & Asia Pacific Forum on Loss and Damage & CAF, DRR, L\&D & $\begin{array}{l}\text { Countries in the Asia-Pacific } \\
\text { region }\end{array}$ & $\begin{array}{l}\text { http://www.apn-gcr. } \\
\text { org/resources/items/ } \\
\text { show/1981 }\end{array}$ & 47,500 & 2016 \\
\hline $\begin{array}{l}\text { CAF2014-CD01-Wijenayake } \\
\text { CAF2015-CD01-CMY-Vashist }\end{array}$ & Sanjay Vashist & sanjay@cansouthasia.net & $\begin{array}{l}\text { Enhancing Capacity of Policy Makers and } \\
\text { practitioners in India, Sri Lanka and Nepal on Loss } \\
\text { and Damage Related to Slow Onset Events in the } \\
\text { Region }\end{array}$ & CAF, DRR, L\&D & Nepal, India, Sri Lanka & $\begin{array}{l}\text { http://www.apn-gcr. } \\
\text { org/resources/items/ } \\
\text { show/1980 }\end{array}$ & 82,400 & 2017 \\
\hline CAF2015-CD02CMY-Nhat & Le Minh Nhat & vnadaptation@gmail.com & $\begin{array}{l}\text { Capacity Building for National, Provincial } \\
\text { Stakeholders and Local Communities on Loss and } \\
\text { Damage Related to Disaster Risk Reduction and } \\
\text { Climate Change Adaptation }\end{array}$ & CAF, DRR, L\&D & Viet Nam & $\begin{array}{l}\text { http://www.apn-gcr. } \\
\text { org/resources/items/ } \\
\text { show/1953 }\end{array}$ & 78,400 & 2017 \\
\hline
\end{tabular}




\begin{tabular}{|c|c|c|c|c|c|c|c|c|}
\hline Project Reference Number & Project Leader & Email Address & Title & Science Agenda & Countries & Metadata link & Award & $\begin{array}{l}\text { Year } \\
\text { Completed }\end{array}$ \\
\hline $\begin{array}{l}\text { CAF2014-CD03-NMY-Ibrahim } \\
\text { CAF2015-CD03-CMY-Ibrahim }\end{array}$ & $\begin{array}{l}\text { Kamarulazizi } \\
\text { Ibrahim }\end{array}$ & kamarul@usm.my & $\begin{array}{l}\text { Building Capacity for Reducing Loss and Damage } \\
\text { Resulting from Slow and Rapid Onset Climatic } \\
\text { Extremes through Risk Reduction and Proactive } \\
\text { Adaptation within the Broader Context of } \\
\text { Sustainable Development }\end{array}$ & CAF, DRR, L\&D & $\begin{array}{l}\text { Malaysia, Cambodia, } \\
\text { Viet Nam, Lao PDR }\end{array}$ & $\begin{array}{l}\text { http://www.apn-gcr. } \\
\text { org/resources/items/ } \\
\text { show/1946 }\end{array}$ & 68,000 & 2016 \\
\hline CAF2014-CD04-NSY-Sharma & Vigya Sharma & v.sharma@uq.edu.au & $\begin{array}{l}\text { Can Traditional Livelihoods and Mining Co-exist in } \\
\text { a Changing Climate: Strengthening Public-Private } \\
\text { Partnerships in Mongolia to Reduce Risk and } \\
\text { Address Loss and Damage }\end{array}$ & CAF, DRR, L\&D & Australia, Mongolia & $\begin{array}{l}\text { http://www.apn-gcr. } \\
\text { org/resources/items/ } \\
\text { show/1938 }\end{array}$ & 30,000 & 2017 \\
\hline CAF2015-RR01CMY-Basnayake & $\begin{array}{l}\text { Senaka } \\
\text { Basnayake }\end{array}$ & $\begin{array}{l}\text { senaka_basnayake@ } \\
\text { adpc.net }\end{array}$ & $\begin{array}{l}\text { Developing Climate Inclusive Potential Loss and } \\
\text { Damage Assessment Methodology for Flood } \\
\text { Hazards }\end{array}$ & CAF, DRR, L\&D & Nepal, Sri Lanka, Thailand & $\begin{array}{l}\text { http://www.apn-gcr. } \\
\text { org/resources/items/ } \\
\text { show/1975 }\end{array}$ & 125,750 & 2020 \\
\hline $\begin{array}{l}\text { CAF2014-RR03-NMY-Pereira } \\
\text { CAF2015-RR03-CMY-Pereira } \\
\text { CAF2016-RR03-CMY-Pereira }\end{array}$ & $\begin{array}{l}\text { Joy Jacqueline } \\
\text { Pereira }\end{array}$ & joy@ukm.edu.my & $\begin{array}{l}\text { Integrating CCA, DRR and } L+D \text { to Address } \\
\text { Emerging Challenges due to Slow Onset Processes }\end{array}$ & CAF, DRR, L\&D & $\begin{array}{l}\text { Malaysia, Viet Nam, } \\
\text { Philippines, Cambodia, } \\
\text { Myanmar, Japan }\end{array}$ & $\begin{array}{l}\text { http://www.apn-gcr. } \\
\text { org/resources/items/ } \\
\text { show/1949 }\end{array}$ & 135,500 & 2018 \\
\hline $\begin{array}{l}\text { CAF2014-RR04-NMY-Thomalla } \\
\text { CAF2015-RR04-CMY-Thomalla }\end{array}$ & Frank Thomalla & $\begin{array}{l}\text { frank.thomalla@ } \\
\text { sei-international.org }\end{array}$ & $\begin{array}{l}\text { An analysis of longer-term (5-10 years) recovery } \\
\text { following major disasters in the Asia Pacific } \\
\text { Region: Lessons for resilient development }\end{array}$ & CAF, DRR, L\&D & $\begin{array}{l}\text { Thailand, Viet Nam, } \\
\text { Cambodia, Myanmar, } \\
\text { Indonesia }\end{array}$ & $\begin{array}{l}\text { http://www.apn-gcr. } \\
\text { org/resources/items/ } \\
\text { show/1969 }\end{array}$ & 87,500 & 2017 \\
\hline $\begin{array}{l}\text { CAF2014-RR05-NMY-Lasco } \\
\text { CAF2015-RR05-CMY-Lasco }\end{array}$ & Rodel A. Lasco & rlasco@omlopezcenter.org & $\begin{array}{l}\text { Assessing the Linkages between Climate Change } \\
\text { Adaptation (CCA), Disaster Risk Reduction (DRR), } \\
\text { and Loss and Damage (L\&D): Case Studies in the } \\
\text { Low-Lying Coastal Cities of Indonesia, Philippines, } \\
\text { Thailand and Viet Nam }\end{array}$ & CAF, DRR, L\&D & $\begin{array}{l}\text { Indonesia, Philippines, } \\
\text { Thailand, Viet Nam }\end{array}$ & $\begin{array}{l}\text { http://www.apn-gcr. } \\
\text { org/resources/items/ } \\
\text { show/1945 }\end{array}$ & 77,600 & 2018 \\
\hline CAF2015-RR07-CMY-Lotia & Hina Lotia & hlotia@lead.org.pk & $\begin{array}{l}\text { Methods Toolbox for Assessing Loss and Damage } \\
\text { at Local Level }\end{array}$ & CAF, DRR, L\&D & Pakistan, India, Nepal & $\begin{array}{l}\text { http://www.apn-gcr. } \\
\text { org/resources/items/ } \\
\text { show/1944 }\end{array}$ & 80,840 & 2018 \\
\hline $\begin{array}{l}\text { CAF2014-RR08-NMY-Chiba } \\
\text { CAF2015-RR08-CMY-Chiba }\end{array}$ & Yohei Chiba & y-chiba@iges.or.jp & $\begin{array}{l}\text { Addressing Non-Economic Losses and Damages } \\
\text { Associated with Climate Change: Learning from } \\
\text { the Recent Past Extreme Climatic Events for } \\
\text { Future Planning }\end{array}$ & CAF, DRR, L\&D & $\begin{array}{l}\text { Bangladesh, India, Japan, } \\
\text { Philippines, Thailand }\end{array}$ & $\begin{array}{l}\text { http://www.apn-gcr. } \\
\text { org/resources/items/ } \\
\text { show/1943 }\end{array}$ & 80,000 & 2017 \\
\hline
\end{tabular}




\begin{tabular}{|c|c|c|c|c|c|c|c|c|}
\hline Project Reference Number & Project Leader & Email Address & Title & Science Agenda & Countries & Metadata link & Award & $\begin{array}{l}\text { Year } \\
\text { Completed }\end{array}$ \\
\hline CAF2015-RR09-CMY-Huong & $\begin{array}{l}\text { Lam Vu Thanh } \\
\text { Noi }\end{array}$ & lamuem@1980@gmail.com & $\begin{array}{l}\text { Climate change risk assessment and adaptation } \\
\text { for loss and damage of urban transportation } \\
\text { infrastructure (UTI) in Southeast Asia (SEA) }\end{array}$ & CAF, DRR, L\&D & $\begin{array}{l}\text { Viet Nam, Thailand, } \\
\text { Cambodia }\end{array}$ & $\begin{array}{l}\text { http://www.apn-gcr. } \\
\text { org/resources/items/ } \\
\text { show/1951 }\end{array}$ & 78,400 & 2018 \\
\hline $\begin{array}{l}\text { CAF2015-RR13-NMY-Dautova } \\
\text { CAF2016-08CMY-Dautova }\end{array}$ & $\begin{array}{l}\text { Tatiana N. } \\
\text { Dautova }\end{array}$ & tndaut@mail.ru & $\begin{array}{l}\text { Developing life-supporting marine ecosystems } \\
\text { along the East Asia's coasts: A synthesis of } \\
\text { physical and biological data regarding coral reef } \\
\text { ecosystems for the science-based management } \\
\text { and socio-ecological policy making in terms of } \\
\text { global sustainability }\end{array}$ & CAF & $\begin{array}{l}\text { Philippines, Russian } \\
\text { Federation, Viet Nam }\end{array}$ & $\begin{array}{l}\text { http://www.apn-gcr. } \\
\text { org/resources/items/ } \\
\text { show/2033 }\end{array}$ & 76,000 & 2018 \\
\hline $\begin{array}{l}\text { CAF2015-RR17-NMY-Arifwidodo } \\
\text { CAF2016-RR12-CMY-Arifwidodo }\end{array}$ & $\begin{array}{l}\text { Sigit D. } \\
\text { Arifwidodo }\end{array}$ & sigit.d@ku.ac.th & $\begin{array}{l}\text { Understanding Urban Heat Island Effect and } \\
\text { Its Implications to Climate Change Adaptation } \\
\text { Strategies in Major Southeast Asian Cities }\end{array}$ & CAF & Thailand, Japan, Indonesia & $\begin{array}{l}\text { http://www.apn-gcr. } \\
\text { org/resources/items/ } \\
\text { show/2029 }\end{array}$ & 80,000 & 2018 \\
\hline CAF2015-RR18-NSY-Jacobson & Chris Jacobson & cjacobso@usc.edu.au & $\begin{array}{l}\text { Optimizing Climate Change Adaptation through } \\
\text { Enhanced Community Resilience }\end{array}$ & CAF, RRR & $\begin{array}{l}\text { Australia, Viet Nam, } \\
\text { Cambodia }\end{array}$ & $\begin{array}{l}\text { http://www.apn-gcr. } \\
\text { org/resources/items/ } \\
\text { show/2028 }\end{array}$ & 45,000 & 2016 \\
\hline
\end{tabular}

\section{Focused Activity: Resources Utilization and Pathways for Sustainable Development}



\section{Focused Activity: Ecosystems, Biodiversity and Landuse}

\begin{tabular}{|c|c|c|c|c|c|c|c|c|}
\hline EBLU2012-01CMY(R)-Takeuchi & $\begin{array}{l}\text { Kazuhiko } \\
\text { Takeuchi }\end{array}$ & $\begin{array}{l}\text { Takeuchi@unu.edu } \\
\text { liang@unu.edu }\end{array}$ & $\begin{array}{l}\text { Critical analysis of effectiveness of REDD+ for } \\
\text { forest communities and shifting cultivation based } \\
\text { on lessons learnt from conservation efforts in } \\
\text { Laos and Thailand }\end{array}$ & EBLU & Japan, Thailand, Lao PDR & $\begin{array}{l}\text { http://www.apn-gcr. } \\
\text { org/resources/items/ } \\
\text { show/1706 }\end{array}$ & 120,000 & 2015 \\
\hline EBLU2012-02CMY(R)-Scheyvens & Henry Scheyvens & scheyvens@iges.or.jp & $\begin{array}{l}\text { Participatory Approaches to Forest Carbon } \\
\text { Accounting to Mitigate Climate Change, } \\
\text { Conserve Biodiversity, and Promote Sustainable } \\
\text { Development }\end{array}$ & EBLU, CATMD & $\begin{array}{l}\text { Japan, Indonesia, Lao PDR, } \\
\text { Viet Nam }\end{array}$ & $\begin{array}{l}\text { http://www.apn-gcr. } \\
\text { org/resources/items/ } \\
\text { show/1707 }\end{array}$ & 120,000 & 2015 \\
\hline
\end{tabular}




\begin{tabular}{|c|c|c|c|c|c|c|c|c|}
\hline Project Reference Number & Project Leader & Email Address & Title & Science Agenda & Countries & Metadata link & Award & $\begin{array}{l}\text { Year } \\
\text { Completed }\end{array}$ \\
\hline \multicolumn{9}{|c|}{ Low Carbon Initiatives Framework } \\
\hline LCI2012-01NSY(C)-Maeda & Toshizo Maeda & maeda@iges.or.jp & $\begin{array}{l}\text { Capacity Building for Implementing a } \\
\text { "Measurable, Verifiable and Reportable (MRV)" } \\
\text { Model in a Mid-Sized Thai Municipality }\end{array}$ & $\mathrm{LCl}$ & Thailand, Japan & $\begin{array}{l}\text { https://www.apn-gcr. } \\
\text { org/resources/items/ } \\
\text { show/1913 }\end{array}$ & 28,000 & 2014 \\
\hline $\begin{array}{l}\text { LCI2012-01NMY(R)-Vashist } \\
\text { LCI2013-01CMY(R)-Vashist }\end{array}$ & Sanjay Vashist & knagrath@devalt.org & $\begin{array}{l}\text { Identification of Policy and Institutional Gaps, } \\
\text { Drivers and Strategies to Scale-up Low Carbon } \\
\text { and Energy Efficient Technology Application in } \\
\text { the Construction and Infrastructure Sectors in } \\
\text { South Asia }\end{array}$ & $\mathrm{LCl}$ & $\begin{array}{l}\text { India, Nepal, Pakistan, } \\
\text { Bangladesh }\end{array}$ & $\begin{array}{l}\text { http://www.apn-gcr. } \\
\text { org/resources/items/ } \\
\text { show/1915 }\end{array}$ & 83,600 & 2016 \\
\hline $\begin{array}{l}\text { LCI2012-02NMY(R)-Dhakal } \\
\text { LCI2013-02CMY(R)-Dhakal }\end{array}$ & $\begin{array}{l}\text { Shobhakar } \\
\text { Dhakal }\end{array}$ & shobhakar@ait.asia & $\begin{array}{l}\text { Understanding and Quantifying the Water-Energy- } \\
\text { Carbon Nexus for Low Carbon Development in } \\
\text { Asian Cities }\end{array}$ & $\mathrm{LCl}$ & $\begin{array}{l}\text { Thailand, Japan, India, } \\
\text { Nepal }\end{array}$ & $\begin{array}{l}\text { http://www.apn-gcr. } \\
\text { org/resources/items/ } \\
\text { show/1916 }\end{array}$ & 80,600 & 2017 \\
\hline LCI2012-03NMY(R)-Lopez & $\begin{array}{l}\text { Marilou J. Ang } \\
\text { Lopez }\end{array}$ & mjanglopez@hotmail.com & $\begin{array}{l}\text { Assessment of Carbon Sequestration through } \\
\text { Vermitechnology in Organic Farming }\end{array}$ & $\mathrm{LCl}$ & $\begin{array}{l}\text { Philippines, Viet Nam, } \\
\text { Republic of Korea }\end{array}$ & $\begin{array}{l}\text { http://www.apn-gcr. } \\
\text { org/resources/items/ } \\
\text { show/1917 }\end{array}$ & 45,000 & 2014 \\
\hline $\begin{array}{l}\text { LCI2012-04NMY(R)-Macandog } \\
\text { LCI2013-04CMY(R)-Macandog }\end{array}$ & $\begin{array}{l}\text { Damasa B.M. } \\
\text { Macandog }\end{array}$ & $\begin{array}{l}\text { dmmacandog@uplb.edu.ph } \\
\text { demi_macandog@yahoo.com }\end{array}$ & $\begin{array}{l}\text { Integrated Sustainability Assessment of Bioenergy } \\
\text { Potentials in Asia: An Application of a Hybrid } \\
\text { Approach on Trade-offs and Pathway }\end{array}$ & $\mathrm{LCl}$ & $\begin{array}{l}\text { Thailand, Philippines, } \\
\text { Germany, China, India }\end{array}$ & $\begin{array}{l}\text { http://www.apn-gcr. } \\
\text { org/resources/items/ } \\
\text { show/1918 }\end{array}$ & 90,000 & 2017 \\
\hline $\begin{array}{l}\text { LCI2012-05NMY(R)-Jupesta } \\
\text { LCI2013-05CMY(R)-Jupesta }\end{array}$ & $\begin{array}{l}\text { Joni Jupesta } \\
\text { Takako Wakiyama }\end{array}$ & $\begin{array}{l}\text { Jupesta@ias.unu.edu } \\
\text { wakiyama@iges.or.jp }\end{array}$ & $\begin{array}{l}\text { Low Carbon Urban Infrastructure Investment: } \\
\text { Cases of China, Indonesia, and Japan }\end{array}$ & $\mathrm{LCl}$ & Japan, Indonesia, China & $\begin{array}{l}\text { http://www.apn-gcr. } \\
\text { org/resources/items/ } \\
\text { show/1919 }\end{array}$ & 83,700 & 2015 \\
\hline \multicolumn{9}{|c|}{ Other Activities } \\
\hline AOA2012-08NSY-Lansigan & Felino P. Lansigan & fplansigan@yahoo.com & $\begin{array}{l}\text { International Conference on Climate Change } \\
\text { Impacts and Adaptation for Food and } \\
\text { Environmental Security }\end{array}$ & Adaptation & Philippines, Thailand & $\begin{array}{l}\text { http://www.apn-gcr. } \\
\text { org/resources/items/ } \\
\text { show/1881 }\end{array}$ & 10,000 & 2012 \\
\hline
\end{tabular}




\begin{tabular}{|c|c|c|c|c|c|c|c|c|}
\hline Project Reference Number & Project Leader & Email Address & Title & Science Agenda & Countries & Metadata link & Award & $\begin{array}{l}\text { Year } \\
\text { Completed }\end{array}$ \\
\hline AOA2018-01SY-Pereira & $\begin{array}{l}\text { Joy Jacqueline } \\
\text { Pereira }\end{array}$ & $\begin{array}{l}\text { pereirajoy@yahoo.com } \\
\text { joy@ukm.edu.my }\end{array}$ & $\begin{array}{l}\text { Capacity Building for Research in Relation to IPCC, } \\
\text { SDGs and the Paris Agreement }\end{array}$ & $C C \& C V \& S D$ & Malaysia, Pan Asia-Pacific & $\begin{array}{l}\text { https://www.apn-gcr. } \\
\text { org/resources/items/ } \\
\text { show/2135 }\end{array}$ & 40,000 & 2019 \\
\hline AOA2019-01SY-Shrestha & Sangam Shrestha & $\begin{array}{l}\text { sangam@ait.ac.th } \\
\text { sangamshrestha@gmail.com }\end{array}$ & $\begin{array}{l}\text { Special issue on climate impacts, vulnerability } \\
\text { and adaptation }\end{array}$ & $\mathrm{CC} \& \mathrm{CV}$ & Thailand, Pan Asia & $\begin{array}{l}\text { https://www.apn-gcr. } \\
\text { org/resources/items/ } \\
\text { show/2136 }\end{array}$ & 20,000 & 2019 \\
\hline \multicolumn{9}{|c|}{ Comprehensive Research for Young Scientists } \\
\hline CRYS2017-02MY-Phanti & Jeeban Panthi & $\begin{array}{l}\text { panthijeeban@gmail.com } \\
\text { jeeban@smallearth.org.np }\end{array}$ & $\begin{array}{l}\text { Rainwater Harvesting for Mitigating Drought in } \\
\text { Western Nepal }\end{array}$ & CRYS & $\begin{array}{l}\text { India, Nepal, United States } \\
\text { of America }\end{array}$ & $\begin{array}{l}\text { http://www.apn-gcr. } \\
\text { org/resources/items/ } \\
\text { show/2069 }\end{array}$ & 29,850 & 2019 \\
\hline CRYS2017-03SY-Sing & Sing Kong Wah & garysingkongwah@qq.com & $\begin{array}{l}\text { Urban Biodiversity and Human Well-Being in } \\
\text { Asia's Megacities }\end{array}$ & CRYS & $\begin{array}{l}\text { China, Japan, Thailand, } \\
\text { Viet Nam }\end{array}$ & $\begin{array}{l}\text { http://www.apn-gcr. } \\
\text { org/resources/items/ } \\
\text { show/2070 }\end{array}$ & 15,000 & 2019 \\
\hline CRYS2017-02SY-Almaden & $\begin{array}{l}\text { Catherine } \\
\text { Roween C. } \\
\text { Almaden }\end{array}$ & calmaden@xu.edu.ph & $\begin{array}{l}\text { Multidimensional Indicators of Adaptive Capacity } \\
\text { of Rice Farming Households to Address Salt Water } \\
\text { Intrusion in the Philippines and Viet Nam }\end{array}$ & CRYS & Philippines, Viet Nam & $\begin{array}{l}\text { http://www.apn-gcr. } \\
\text { org/resources/items/ } \\
\text { show/2072 }\end{array}$ & 15,000 & 2019 \\
\hline
\end{tabular}


Appendix 2. Project outputs

\section{ANNUAL REGIONAL CALL FOR RESEARCH PROPOSALS (ARCP) / COMPREHENSIVE REGIONAL RESEARCH PRGRAMME (CRRP)}

\section{$\square$ Integrated Vulnerability Assessment of Coastal Areas in the Southeast Asia and East Asian Region} ARCP2006-09NMY, ARCP2007-04CMY, ARCP2008-02CMYDavid, ARCP2013-28RUF-David

1. David, L. T., Maneja, R., Goh, B., Lansigan, F., Sereywath, P., Radjawane, I. M., ... Hinkel, J. (2008). Sea level rise vulnerability of Southeast Asian coasts. LOICZ INPRINT, 2008(3). Retrieved from http://www.loicz.org/ products/publication/newsletter/index.html.en

\section{Greenhouse Gas Budgets of South and Southeast Asia}

ARCP2011-11NMY-Patra/Canadell, ARCP2012-01CMY-Patra/ Canadell, ARCP2013-01CMY-Patra

2. Calle, L., Canadell, J. G., Patra, P., Ciais, P., Ichii, K., Tian, H., ... Poulter, B. (2016). Regional carbon fluxes from land use and land cover change in Asia, 19802009. Environmental Research Letters, 11(7), 074011. doi:10.1088/1748-9326/11/7/074011

3. Kondo, M., Ichii, K., Patra, P. K., Canadell, J. G., Poulter, B., Sitch, S., ... Rödenbeck, C. (2018). Land use change and El Niño-Southern Oscillation drive decadal carbon balance shifts in Southeast Asia. Nature Communications, 9(1). doi:10.1038/s41467-018-03374-x

4. Kondo, M., Ichii, K., Patra, P. K., Poulter, B., Calle, L., Koven, C., ... Wiltshire, A. (2018). Plant regrowth as a driver of recent enhancement of terrestrial $\mathrm{CO} 2$ uptake. Geophysical Research Letters, 45(10), 4820-4830. doi:10.1029/2018gl077633

5. Kondo, M., Patra, P. K., Sitch, S., Friedlingstein, P., Poulter, B., Chevallier, F., ... Ziehn, T. (2019). State of the science in reconciling top-down and bottom-up approaches for terrestrial $\mathrm{CO} 2$ budget. Global Change Biology, 26(3), 1068-1084. doi:10.1111/gcb.14917

6. Patra, P. K., Canadell, J. G., Houghton, R. A., Piao, S. L., Oh, N.-H., Ciais, P., ... Lasco, R. (2013). The carbon budget of South Asia. Biogeosciences, 10(1), 513-527. doi:10.5194/bg-10-513-2013

7. Patra, P. K., Canadell, J. G., \& Lal, S. (2012). The rapidly changing greenhouse gas budget of Asia. Eos, Transactions American Geophysical Union, 93(25), 237-237. doi:10.1029/2012eo250006

8. Patra, P. K., Canadell, J., Thompson, R. L., Kondo, M., \& Poulter, B. (2016). Greenhouse gas budgets of South and Southeast Asia. APN Science Bulletin, 6(1), 4-7. doi:10.30852/sb.2016.4

9. Sarma, V. V. S. S., Lenton, A., Law, R. M., Metzl, N., Patra, P. K., Doney, S., ... Valsala, V. (2013). Sea-air CO2 fluxes in the Indian Ocean between 1990 and 2009. Biogeosciences, 10(11), 7035-7052. doi:10.5194/bg-107035-2013

10. Sarma, V. V. S. S., Lenton, A., Law, R., Metzl, N., Patra, P. K., Doney, S., ... Valsala, V. (2013). Sea-air CO2 fluxes in the Indian Ocean between 1990 and 2009. Biogeosciences Discussions, 10(7), 10759-10810. doi:10.5194/bgd-10-10759-2013

11. Takata, K., Patra, P. K., Kotani, A., Mori, J., Belikov, D., Ichii, K., ... Aoki, S. (2017). Reconciliation of top-down and bottom-up $\mathrm{CO} 2$ fluxes in Siberian larch forest. Environmental Research Letters, 12(12), 125012. doi:10.1088/1748-9326/aa926d

12. Thompson, R. L., Patra, P. K., Chevallier, F., Maksyutov, S., Law, R. M., Ziehn, T., ... Ciais, P. (2016). Top-down assessment of the Asian carbon budget since the mid 1990s. Nature Communications, 7(1). doi:10.1038/ ncomms 10724

Seagrass-Mangrove Ecosystems: Bioshields against Biodiversity Loss and Impacts of Local and Global Change along Indo-Pacific Coasts (the Seagrass-Mangrove Bioshield Project, SMBP)

ARCP2011-12NMY-Fortes, ARCP2012-02CMY-Fortes, ARCP2013-02CMY-Fortes:

13. Mizuno, K., Asada, A., Matsumoto, Y., Sugimoto, K., Fujii, T., Yamamuro, M., ... Jimenez, L. A. (2017). A simple and efficient method for making a highresolution seagrass map and quantification of dugong feeding trail distribution: A field test at Mayo Bay, Philippines. Ecological Informatics, 38, 89-94. doi:10.1016/j.ecoinf.2017.02.003

14. Asaeda, T., Barnuevo, A., Sanjaya, K., Fortes, M. D., Kanesaka, Y., \& Wolanski, E. (2016). Mangrove plantation over a limestone reef - Good for the ecology? Estuarine, Coastal and Shelf Science, 173, 57-64. doi:10.1016/j.ecss.2016.02.017

15. Fortes, M. D. (2013). A Review: Biodiversity, Distribution and conservation of Philippine seagrasses. Philippine Journal of Science, 142(Special Issue), 95-111.

16. Fortes, M. D., Gay, A. G., Bolisay, K., Nakaoka, M., Uy, W. H., Lopez, M. R., ... Edralin, M. (2012). Seagrass response to mariculture-induced physico-chemical gradients in Bolinao, northwestern Philippines. In Proceedings of the 12th International Coral Reef Symposium, Cairns, Australia, 9-13 July 2012. Cairns, Australia.

17. ECO-SMILE. (2017). ECO-SMILE project. Retrieved from https://www.youtube.com/watch?v=9af7AgwtgvM 
Developing Ecosystem based Adaptation Strategies for Enhancing Resilience of Rice Terrace Farming Systems against Climate Change

ARCP2011-13NMY-Herath, ARCP2012-03CMY-

Herath, ARCP2013-03CMY-Herath

18. Gu, H., Jiao, Y., \& Liang, L. (2012). Strengthening the socio-ecological resilience of forest-dependent communities: The case of the Hani Rice Terraces in Yunnan, China. Forest Policy and Economics, 22, 53-59. doi:10.1016/j.forpol.2012.04.004

19. Jiao, Y., Li, X., Liang, L., Takeuchi, K., Okuro, T., Zhang, D., \& Sun, L. (2012). Indigenous ecological knowledge and natural resource management in the cultural landscape of China's Hani Terraces. Ecological Research, 27(2), 247-263. do:10.1007/s11284-011-0895-3

20. Jiao, Y., Liang, L., Takeuchi, K., \& Okuro, T. (2012). Evolution of Satoyama landscape in Japan and its enlightenment for Hani terrace landscape in China. In Proceedings of The First Terraced Landscapes Conference (Honghe, China) paper collection. Honghe, China: Yunnan People's Press.

21. Wang, D., Jiao, Y., He, L., Zong, L., Xiang, D., \& Hu, Z. (2014). Assessment on water source stability of the Hani Terrace landscape based on river-ditch connectivity. Chinese Journal of Ecology, 33(10), 2865-2872.

22. Zong, L., Jiao, Y., Li, S., Zhang, G., Zhang, J., He, L., ... $\mathrm{Hu}, \mathrm{Z}$. (2015). Spatial and temporal variability of soil moisture in water source region of Hani Rice Terraces. Chinese Journal of Ecology, 34(6), 1650-1659.

23. Zong, L., Jiao, Y., Hua, H., Xiang, D., He, L., Hu, Z., \& Wang, D. (2014). Vertical changes of soil moisture and holding capacity of soil water in the water source area of Hani rice terraces landscape. Bulletin of Soil and Water Conservation, 34(4), 59-64.

24. Herath, S., Diwa, J., Jiao, Y., \& Castro, P. P. (2015). Overview of rice terrace farming systems in Hani and Ifugao: Water management and current threats (Working Paper No. 1). Tokyo: United Nations University Institute for the Advanced Study of Sustainability. Retrieved from http://collections.unu.edu/eserv/ UNU:3333/Overview_of_Rice_Terrace_Farming.pdf

25. Herath, S., Jayaraman, A., \& Diwa, J. (2015). Ensuring Water security for the sustainability of the Hani Rice Terraces, China against climate and land use changes (Working Paper No. 2). Tokyo: United Nations University Institute for the Advanced Study of Sustainability. Retrieved from http://collections.unu.edu/eserv/ UNU:3334/Ensuring_Water_Security.pdf

26. Herath, S., Soriano, M., \& Diwa, J. (2015). Bias-corrected daily precipitation estimates in the Ifugao Rice Terraces under climate change scenarios (Working Paper No. 3). Tokyo: United Nations University Institute for the Advanced Study of Sustainability. Retrieved from http://collections.unu.edu/eserv/UNU:3337/ Precipitation_Estimates.pdf

27. Herath, S., Tsusaka, K., \& Diwa, J. (2015). Assessment on the feasibility of REDD+ in Nagacadan Rice Terraces of Ifugao and its muyong forest (Working Paper No. 4). Tokyo: United Nations University Institute for the Advanced Study of Sustainability. Retrieved from http://collections.unu.edu/eserv/UNU:3335/ Assessment_on_the_feasibility_of_REDD.pdf

28. Herath, S., Jayaraman, A., \& Diwa, J. (2015). Study of institutional and governance arrangements for achieving water security in the Hani Rice Terraces (Working Paper No. 5). Tokyo: United Nations University Institute for the Advanced Study of Sustainability. Retrieved from http://collections.unu. edu/eserv/UNU:3336/Institutional_and_Governance_ Arrangements.pdf

29. Herath, S., Soriano, M., Diwa, J., \& Bucton, B. (2015). Surface and groundwater flow response to climatic change in the Ifugao Rice Terraces (Working Paper No. 6). Tokyo: United Nations University Institute for the Advanced Study of Sustainability. Retrieved from http://collections.unu.edu/eserv/UNU:3338/Surface_ and_Groundwater_Flow.pdf

\section{Impact of Climate Change on Mangroves Ecosystem in South Asia}

ARCP2011-14NMY-Salik, ARCP2012-04CMY-Salik

30. Salik, K. M., Hashmi, M. Z., Ishfaq, S., \& Zadhi W. (2016). Environmental flow requirements and impacts of climate-change-induced river flow changes on ecology of the Indus Delta, Pakistan. Regional Studies in Marine Science, 7, 185-195.

31. Salik, K. M., Jahangir, S., Zahdi, W. ul Z., \& Hasson, S. ul. (2015). Climate change vulnerability and adaptation options for the coastal communities of Pakistan. Ocean \& Coastal Management, 112, 61-73.

32. Salik, K.M., Hasan, M.M., \& Ishfaq, S. (2014). Socioeconomic vulnerability of mangrove ecosystem to climate change in South Asia: A case study of the Indus and Ganges Deltas. APN Science Bulletin (4), Asia Pacific Network for Global Change Research, ISSN 2185-761X.

33. Zafar, W., \& Kashif M. S. (2014). Mangrove forests and changing policy concerns in Pakistan. Policy review, climate change special. Sustainable Development Policy Institute (SDPI), Islamabad, Pakistan.

34. Zafar, W. (2014). Climate change \& policy failures: Case of mangrove forests. Research \& News Bulletin, 21(2). Sustainable Development Policy Institute (SDPI), Islamabad, Pakistan .

35. Salik, K. M., Mohammad, M. H., \& Sadia, I. (2014). Socioeconomic vulnerability of mangrove ecosystems to climate change in South Asia: A case study of the Indus and Ganges Deltas. APN Science Bulletin, 4. Retrieved from http://www.apn-gcr.org/resources/items/ show/1932

36. Salik, K. M., \& Sehrish J. (2013). Coastal population more at risk; Socio-economic vulnerability assessment of Indus Delta under climate change. Sustainable Development Policy Institute (SDPI), Islamabad, Pakistan, Research \& News Bulletin, 20(2). 
An International Geosphere-Biosphere Programme Synthesis Theme on: Global Environment Change and Sustainable Development: Needs of Least Developed Countries

\section{ARCP2011-16NMY-IGBP, ARCP2012-06CMY-IGBP}

37. Ataur Rahman, M., \& Rahman, S. (2015). Natural and traditional defense mechanisms to reduce climate risks in coastal zones of Bangladesh. Weather and Climate Extremes, 7, 84-95. doi:10.1016/j.wace.2014.12.004

38. Basak, S. R., Basak, A. C., \& Rahman, M. A. (2015). Impacts of floods on forest trees and their coping strategies in Bangladesh. Weather and Climate Extremes, 7, 43-48. doi:10.1016/j.wace.2014.12.002

39. Dastagir, M. R. (2015). Modeling recent climate change induced extreme events in Bangladesh: A review. Weather and Climate Extremes, 7, 49-60. doi:10.1016/j. wace.2014.10.003

40. Dewan, T. H. (2015). Societal impacts and vulnerability to floods in Bangladesh and Nepal. Weather and Climate Extremes, 7, 36-42. doi:10.1016/j. wace.2014.11.001

41. Dube, P. (2015). Growing with IGBP. Retrieved from Global Change Magazine No. 84. Retrieved from http:// www.igbp.net/publications/globalchangemagazine/ globalchangemagazine/globalchangemagazineno84. html

42. IGBP. (2015). IGBP co-sponsored AGU sessions. Retrieved from https://agu.confex.com/agu/fm15/meetingapp. cgi/Index/CB_CoSection IGBP:\%20International\%20 Geosphere-Biosphere\%20Programme

43. Karim, M. R., \& Rahman, M. A. (2015). Drought risk management for increased cereal production in Asian Least Developed Countries. Weather and Climate Extremes, 7, 24-35. doi:10.1016/j.wace.2014.10.004

44. Kuruppu, N., \& Willie, R. (2015). Barriers to reducing climate enhanced disaster risks in Least Developed Country-Small Islands through anticipatory adaptation. Weather and Climate Extremes, 7, 72-83. doi:10.1016/j.wace.2014.06.001

45. Miyan, M. A. (2015). Droughts in Asian Least Developed Countries: Vulnerability and sustainability. Weather and Climate Extremes, 7, 8-23. doi:10.1016/j. wace.2014.06.003

46. Pauline Dube, O., \& Sivakumar, M. (2015). Global environmental change and vulnerability of Least Developed Countries to extreme events: Editorial on the special issue. Weather and Climate Extremes, 7, 2-7. doi:10.1016/j.wace.2015.03.003

47. Rahman, S., \& Rahman, M. A. (2015). Climate extremes and challenges to infrastructure development in coastal cities in Bangladesh. Weather and Climate Extremes, 7, 96-108. doi:10.1016/j.wace.2014.07.004

48. Shohidullah Miah, M. (2015). Climatic and anthropogenic factors changing spawning pattern and production zone of Hilsa fishery in the Bay of
Bengal. Weather and Climate Extremes, 7, 109-115. doi:10.1016/j.wace.2015.01.001

49. Smyth, K. (2016). Bringing early-career scientists to the fore: Lessons learned from International GeosphereBiosphere Programme (IGBP) landmark synthesis event. APN Science Bulletin, 6, 59-62.

50. Thoeun, H. C. (2015). Observed and projected changes in temperature and rainfall in Cambodia. Weather and Climate Extremes, 7, 61-71. doi:10.1016/j. wace.2015.02.001

51. IGBP. (2015). Open-access video of the key session "What's the Big Deal About the Anthropocene?" Retrrieved from https://vts.inxpo.com/scripts/Server. nxp?LASCmd=Al:4;F:QS!10100\&ShowKey=27470

\section{Tracing Nitrogen and Carbon Biogeochemical Processes in the Inter-tidal Mangrove Ecosystem (Sundarban) of India and Bangladesh: Implications of the Global Environmental Change} ARCP2011-17NMY-Mathukumalli, ARCP2012-07CMYRamanathan

52. Prasad, M. B. K. (2012). Nutrient biogeochemistry of coastal ecosystems: Implications of climate change and land-use. Presented at the National Conference on Mangrove Wetlands and Near Shore Marine Ecosystems-From Sustainability Issues to Management \& Restoration, New Delhi, India.

53. Prasad, M. B. K. (2012). Nutrient stoichiometry and eutrophication in Indian mangroves. Environmental Earth Sciences, 67(1), 293-299. doi:10.1007/s12665011-1508-8

54. Prasad, M., Kumar, A., Datta, D. K., \& Ramanathan, L. (2014). Spectrofluorometric analysis of organic matter in the Sundarban mangrove, Bangladesh. Indian Journal of Geo-Marine Sciences, 43(6), 9991006. Retrieved from http://nopr.niscair.res. in/bitstream/123456789/28971/3/IJMS\%20 43\%286\%29\%201005-1012.pdf

\section{Improving the Robustness, Sustainability, Productivity and Eco-Efficiencies of Rice Systems throughout Asia}

ARCP2012-09NMY-Meinke, ARCP2013-04CMY-Meinke, ARCP2014-01CMY-Meinke

55. Awan, M. I., van Oort, P. A. J., Ahmad, R., Bastiaans, L., \& Meinke, H. (2015). Farmers' views on the future prospects of aerobic rice culture in Pakistan. Land Use Policy, 42, 517-526. doi:10.1016/j. landusepol.2014.09.006

56. Kadiyala, M. D. M., Jones, J. W., Mylavarapu, R. S., Li, Y. C., \& Reddy, M. D. (2015). Identifying irrigation and nitrogen best management practices for aerobic rice-maize cropping system for semi-arid tropics using CERES-rice and maize models. Agricultural Water Management, 149, 23-32. doi:10.1016/j. agwat.2014.10.019 
57. Amarasingha, R. P. R. K., Suriyagoda, L. D. B., Marambe, B., Gaydon, D. S., Galagedara, L. W., Punyawardena, R., ... Howden, M. (2015). Simulation of crop and water productivity for rice (Oryza sativa L.) using APSIM under diverse agro-climatic conditions and water management techniques in Sri Lanka. Agricultural Water Management, 160, 132-143. doi:10.1016/j. agwat.2015.07.001

58. Amarasingha, R. P. R. K., Suriyagoda, L. D. B., Marambe, B., Galagedara, L. W., Silva, G. L. L. ., Punyawardena, R., ... Howden, M. (2015). Modelling the impact of changes in rainfall distribution on the irrigation water requirement and yield of short and medium duration rice varieties using APSIM during Maha season in the dry zone of Sri Lanka. Tropical Agricultural Research, 26(2), 274. doi:10.4038/tar.v26i2.8091

59. Amarasingha, R. P. R. K., Galagedara, L. W., Marambe, B., Silva, G. L. L. P., Punyawardena, R., Nidumolu, U., ... Suriyagoda, L. D. B. (2015). Aligning sowing dates with the onset of rains to improve rice yields and water productivity: Modelling rice (Oryza sativa L.) yield of the Maha season in the Dry Zone of Sri Lanka. Tropical Agricultural Research, 25(3), 277. doi:10.4038/tar. V25i3.8038

60. Awan, M. I., Meinke, H., \& van Oort, P. (2015). Entry points for eco-efficient alternative rice production system in Punjab, Pakistan. In Proceedings of the 17th Australian Agronomy Conference 2015, 21 - 24 September 2015. Hobart, Tasmania.

61. Amarasingha, R. K., Suriyagoda, L. D. B., Marambe, B., Galagedara, L. W., Silva, G. L. L. P., Punyawardena, R., ... Meinke, H. (2015). Yield advantage and water productivity of maize-mungbean inter-cropping systems in the Dry Zone of Sri Lanka; a modelling approach. In Proceedings of the 17th Australian Agronomy Conference 2015, 21 - 24 September 2015. Hobart, Tasmania.

62. Fernando, M. E. K. K., Amerasekara, D. A. B. N., Amarasingha, R. K., Suriyagoda, L. D. B., Marambe, B., Galagedara, L. W., ... Meinke, H. (2015). Validation of APSIM for long duration rice varieties in different agro-climatic zones of Sri Lanka. In Proceedings of the 17th Australian Agronomy Conference 2015, 21 - 24 September 2015. Hobart, Tasmania.

\section{Carbon Fluxes and Emission from the Red River (Viet Nam and China): Human Activities and Climate Change}

ARCP2012-11NMY-Quynh, ARCP2013-06CMY-Quynh, ARCP2014-03CMY-Quynh

63. Le, T. P. Q., Da Le, N., Dao, V. N., Rochelle-Newall, E., Nguyen, T. M. H., Marchand, C., ... Phung, T. X. B. (2018). Change in carbon flux (1960-2015) of the Red River (Vietnam). Environmental Earth Sciences, 77(18), 658. doi:10.1007/s12665-018-7851-2

64. Nguyen, H. T. M., Billen, G., Garnier, J., Le, T. P. Q., Pham, Q. L., Huon, S., \& Rochelle-Newall, E. (2018). Organic carbon transfers in the subtropical Red River system (Viet Nam): insights on $\mathrm{CO} 2$ sources and sinks. Biogeochemistry, 138(3), 277-295. doi:10.1007/ s10533-018-0446-x

65. Le, T. P. Q., Marchand, C., Ho, C. T., Le, N. D., Duong, T. T., Lu, X., ... Vu, D. A. (2018). CO2 partial pressure and $\mathrm{CO} 2$ emission along the lower Red River (Vietnam). Biogeosciences, 15(15), 47994814. doi:10.5194/bg-15-4799-2018

66. Nguyen, H. T. M., Billen, G., Garnier, J., Rochelle-Newall, E., Ribolzi, O., Servais, P., \& Le, Q. T. P. (2016). Modelling of faecal indicator bacteria (FIB) in the Red River basin (Vietnam). Environmental Monitoring and Assessment, 188(9). doi:10.1007/s10661-016-5528-4

67. Nguyen, H. T. M., Le, Q. T. P., Garnier, J., Janeau, J.-L., \& Rochelle-Newall, E. (2016). Seasonal variability of faecal indicator bacteria numbers and die-off rates in the Red River basin, North Viet Nam. Scientific Reports, 6, 21644. doi:10.1038/srep21644

68. Lu, X. X., Oeurng, C., Le, T. P. Q., \& Thuy, D. T. (2015). Sediment budget as affected by construction of a sequence of dams in the lower Red River, Viet Nam. Geomorphology, 248, 125-133. doi:10.1016/j. geomorph.2015.06.044

69. Duong, Thi Thuy, Le, Thi Phuong Quynh, Ho, Tu Cuong, Vu, Thi Nguyet, Hoang, Thi Thu Hang, Dang, Dinh Kim, \& Lu, Xixi. (2014). Phytoplankton community structure and water quality of Red River, Vietnam. Journal of Vietnamese Environment, 6(1), 27-33. doi:10.13141/jve. vol6.no1.pp27-33

70. Le, T. P. Q., Billen, G., Garnier, J., \& Chau, V. M. (2014). Long-term biogeochemical functioning of the Red River (Vietnam): past and present situations. Regional Environmental Changes 15, 329-339 doi:10.1007/ s10113-014-0646-4

71. Le, Thi Phuong Quynh, Ho, Tu Cuong, Duong, Thi Thuy, Nguyen, Thi Bich Ngoc, Vu, Duy An, Pham, Quoc Long, \& Seidler, Christina. (2014). Water quality of the Red River system in the period 2012 - 2013. Journal of Vietnamese Environment, 6(3), 191-195. doi:10.13141/ jve.vol6.no3.pp191-195

72. Thi Thuy, Duong, Vu, Thi Nguyet, Le, Thi Phuong Quynh, Ho, Tu Cuong, Hoang, Trung Kien, Nguyen, Trung Kien, \& Dang, Dinh Kim. (2014). Seasonal variation of phytoplankton assemblage in Hoa Binh reservoir, north of Vietnam. Journal of Vietnamese Environment, 6(1), 22-26. doi:10.13141/jve.vol6.no1. pp22-26

73. Nguyen, T. M. H., Le, T. P. Q., Phung, T. X. B., RochellNewall, E., Janeau, J. L., Garnier, J., \& Billen, G. (2015). Relationship between bacteria and environmental factors in the Red River water of the section from Hanoi to Hung Yen. Journal of Science and Technology, Hanoi University of Industry, 28-2015, 61 - 65.

74. Nguyen, T. B. N., Nguyen, B. T., Nguyen, T. M. H., Vu, D. A., Duong, T. T., Ho, T. C., \& Le, T. P. Q. (2014). Preliminary monitoring results of total coliforms and fecal coliform in the Red river system, in the section from Yen Bai to Hanoi. Vietnam Journal of Biology, 36(2). doi:10.15625/0866-7160/v36n2.5122 
75. Nguyen, T. B. N., Nguyen, T. M. H., Nguyen, B. T., Vu, D. A., Duong, T. T., Ho, T. C., \& Le, T. P. Q. (2014). Preliminary monitoring results on contents of some heavy metals in the Red River system. Vietnam Journal of Science and Technology, 53(1), 64-76.

76. Vu, D. A., Le, T. P. Q., Nguyen, T. B. N., Nguyen, B. T., Pham, Q. L., Seilder, C., \& Phung, T. X. B. (2014). Wastewater quality of the agricultural region (vegetables - flowers - fruit trees) at Phu Dien and Tay Tuu wards (Hanoi). Journal of Science and Technology Development, M2-2014(17), 13-21.

77. Nguyen, T. B. N., Le, T. P. Q., Nguyen, B. T., Nguyen, T. M. H., Vu, D. A., Duong, T. T., \& Ho, T. C. (2014). Agricultural wastewater quality of a vegetable growing area Van Noi commune, Dong Anh district, Hanoi city. Vietnam Agriculture and Rural development, 21, 65-71.

78. Le Thi Phuong Quynh Nguyen Thi Mai Huong, Nguyen Thi Bich Ngoc, Duong Thi Thuy, \& Ho Tu Cuong. (2012). Preliminary results on the ratio of particulate organic carbon and chlorophyll a (POC/CHL-A) of the Red River system. Vietnam Journal of Chemistry. Vol. 50(4A): 387390

79. Le Thi Phuong Quynh Nguyen Thi Mai Huong, Nguyen Thi Bich Ngoc, Duong Thi Thuy, \& Ho Tu Cuong. (2012). Preliminary results of carbon contents in the water environment of the Red River system. Vietnam Journal of Science and Technology, 50(3B): 47-52

80. Le, T. P. Q., Lu, X., Garnier, J., Gilles, B., Etcheber, H., Duong, T. T., ... Pham, Q. L. (2014). Seasonal variation of dissolved and particulate organic carbon in the Red River system (Vietnam) (pp. 391-398). Presented at The First International Conference of the Vietnam Bulgaria Scientific Cooperation, Ha Long City: Vietnam Academy of Science and Technology.

81. Le, T. P. Q., Nguyen, T. B. N., Nguyen, B. T., Tran, T. B. N., Garnier, J., Duong, T. T., ... Phung, T. X. B. (2014). Observation of organic carbon contents in the Red River water (Vietnam) (pp. 703-710). Presented at the 2nd Vietnam National Conference on Marine Biology and Sustainable Development, Quang Ninh City: Publishing house of Natural Science and technology.

82. Phung, T. X. B., Le, T. P. Q., Nguyen, T. B. N., \& Vu, D. A. (2014). Assessment of suspended solids in the Hoa Binh and Son La reservoirs (pp. 200-205). Presented at the National Electric conference of Science and Technology, Hanoi: Vietnam Association of Electricity.

83. Le, T. P. Q., Garnier, J., Billen, G., Tran, T. B. N., Pham, Q. L., Nguyen, T. B. N., \& Phung, T. X. B. (2013). Impact of the Hoa Binh reservoir on water quality of the downstream Da river over the period 1960 - 2009 (pp. 219-224). Presented at The Third International Science Conference on Sustainable Energy Development, Hanoi-Ninh Binh: Publishing House for Science and Technology.
Coastal Ecosystem and Changing Economic Activities: Challenges for Sustainability Transition

ARCP2012-12NMY-Roy, ARCP2013-07CMY-Roy

84. Roy, J., Ratnasiri, J., Miah, G., Islam, R., Rao, S., Guha, I., . . L Lokuhetti, C. S.(2015). Coastal ecosystem and changing economic activities: Challenges for sustainability transition along the South Asian coasts. Kobe:APN.

\section{$\square$ A Study on Loss of Land Surface and Changes to Water Resources Resulting from Sea Level Rise and Climate Change}

ARCP2012-13NMY-DeCosta, ARCP2013-08CMY-DeCosta

85. Bamunawala, R. M., Hettiarachchi, S., Samarawickrema, G., \& De Costa, G. S. (2014). Assessing the risk of sea level rise and the wave climate of Sri Lanka. In Proceedings of the 19th Congress of the IAHR APD. Hanoi, Viet Nam.

86. Tutulic, M. R., Shamseldin, A., \& De Costa, G. S. (2015). Changes to water resources resulting from sea level rise and climate change. In E-proceedings of the 36th IAHR World Congress. The Hague, Netherlands.

87. Tutulic, M. R., Shamseldin, A., Liefting, R., \& De Costa, G. S. (2015). Loss of land resulting from the sea level rise and climate change. In E-proceedings of the 36th IAHR World Congress. The Hague, Netherlands.

88. Li, J., De Costa, G. S., \& Philips, D. (2016). Simplified method forecasting changes to groundwater table and land lost due to sea level rise. In Proceedings of the 20th Congress of the IAHR APD. Colombo, Sri Lanka.

89. De Costa, G. S., \& Dassanayake, W. (2016). Estimation of impact of sea level rise on land and water resources when data is sparse - Case of Colombo. Environment and Ecology Research, 4(5), 244-250. doi:10.13189/ eer.2016.040502

\section{Coral Reef and Water Quality Status and Community Understanding of Threats in the Eastern Gulf of Thailand}

ARCP2012-14NMY-Carter, ARCP2013-09CMY-Carter

90. Carter, R. B., O’Rourke, V., Livingstone, T., McKenzie, T., Lyell, M., Brown, J., . . Kelly, K. (2013). Strategic guidelines for sustainable tourism on the Khmer coast. Report to the Ministry of Tourism, Royal Government of Cambodia.

91. Carter, R. B., Kelly, K., Beazley, H., Tindale, N., Worachananant, S. Y., Worachananant, P. J., \& Thok, S. (2014). Coral reef and water quality status and community understanding of threats in the Eastern Gulf of Thailand. APN. 
GEOSS/Asian Water Cycle Initiative/Water Cycle Integrator (GEOSS/AWCI/WCI)

ARCP2012-16NMY-Yabe, ARCP2013-11CMY-Yabe

92. Yabe, S., Koudelova, P., Goda, A., Ochiai, O., Tomizawa, N., ... Koike, T. (2014). GEOSS Asian Water Cycle Initiative/Water Cycle Integrator (GEOSS/AWCI/WCI), APN Science Bulletin, 4.

93. Koike, T., Koudelova, P., Jaranilla-Sanchez, P. A., Bhatti, A. M., Nyunt, C. T., \& Tamagawa, K. (2014). River management system development in Asia based on Data Integration and Analysis System (DIAS) under GEOSS. Science China Earth Sciences, 58(1), 76-95. doi:10.1007/s11430-014-5004-3

Assessing the Impact of Climate Change and Development Pressures on Nutrient Inputs into the Mekong River and Tonle Sap

ARCP2012-17NMY-Burnett, ARCP2013-12CMY-Burnett

94. Burnett, W. C. (2015). assessing the impact of climate change and development pressures on nutrient inputs into the Mekong River and Tonle Sap. APN.

95. Burnett, W. C., Wattayakorn, G., Supcharoen, R., Sioudom, K., Kum, V., Chanyotha, S., \& Kritsananuwat, R. (2017). Groundwater discharge and phosphorus dynamics in a flood-pulse system: Tonle Sap Lake, Cambodia. Journal of Hydrology, 549, 79-91. doi:10.1016/j.jhydrol.2017.03.049

96. Chanyotha, S., Kranrod, C., \& Burnett, W. C. (2014). Assessing diffusive fluxes and pore water radon activities via a single automated experiment. Journal of Radioanalytical and Nuclear Chemistry, 301(2), 581-588. doi:10.1007/s10967-014-3157-3

97. Kum, V., \& Burnett, W. C. (2013). Modeling Phosphorus Dynamics of Tonle Sap Lake. International Journal of Environment and Resource (IJER), 2(1), 14-23.

Dynamics of Sulphur Derived from Atmospheric Deposition and its Possible Impacts on the East Asian Forests

ARCP2012-18NMY-Sase, ARCP2013-13CMY-Sase

98. Sase, H., Yamashita, N., Luangjame, J., Garivait, H., Kietvuttinon, B., Visaratana, T., ... Matsuda, K. (2016). Alkalinization and acidification of stream water with changes in atmospheric deposition in a tropical dry evergreen forest of northeastern Thailand: Alkalinization and acidification of stream water in a tropical forest. Hydrological Processes. doi:10.1002/ hyp.11062

99. Yamashita, N., Sase, H., Kobayashi, R., Leong, K.-P., Hanapi, J. M., Uchiyama, S., ... Chappell, N. A. (2014). Atmospheric deposition versus rock weathering in the control of streamwater chemistry in a tropical rain-forest catchment in Malaysian Borneo. Journal of Tropical Ecology, 30(5), 481-492. doi:10.1017/ S0266467414000303
Assessing Climate Change Impacts on Salt Marsh and Seagrass Ecosystems in the South and South East Asian Coasts

ARCP2012-19NSY-Kamal

100. Masum, M. B. (2013). Peoples' perception about the climate change impacts on the salt marsh and seagrass ecosystems in the South Eastern coast of Bangladesh. Institute of Marine Sciences and Fisheries, University of Chittagong, Bangladesh.

$\square$ Toward CarboAsia: Integration and Syntheses of Terrestrial Ecosystem Flux Data in Tropics/ Subtropics and Croplands in Asia by Activating Regional Tower-based Observation Networks

ARCP2013-14NMY-Miyata ARCP2014-04CMY-

Miyata ARCP2015-01CMY-Miyata

101. Kim, W., Miyata, A., Ashraf, A., Maruyama, A., Chidthaisong, A., Jaikaeo, C., . . O Oki, T. (2015). Flux Pro as a real time monitoring and surveilling system for eddy covariance flux measurement. Journal of Agricultural Meteorology, 71(1), 32-50.

\section{Coordinated Regional Climate Downscaling} Experiment (CORDEX) in Monsoon Asia

ARCP2013-15NMY-Manton, ARCP2014-05CMY-Ailikun (Manton), ARCP2015-02CMY-Ailikun

102. Salinger, M. J., Shrestha, M. L., Ailikun, Dong, W., Mcgregor, J. L., \& Wang, S. (2013). Climate in Asia and the Pacific: Climate variability and change. Advances in Global Change Research Climate in Asia and the Pacific, 17-57. doi:10.1007/978-94-007-7338-7_2

103. Sheikh, M. M., Manzoor, N., Ashraf, J., Adnan, M., Collins, D., Hameed, S., . . Shrestha, M. L. (2014). Trends in extreme daily rainfall and temperature indices over South Asia. International Journal of Climatology, 35(7), 1625-1637. doi:10.1002/joc.4081

Assessing Spatiotemporal Variability of NPP, NEP and Carbon Sinks of Global Grassland Ecosystem in Response to Climate Change in 1911-2011

ARCP2013-16NMY-Li, ARCP2014-06CMY-Li, ARCP2015-03CMY$L i$

104. Yang, Y., Wang, Z., Li, J., Gang, C., Zhang, Y., Odeh, I., \& Qi, J. (2017). Assessing the spatiotemporal dynamic of global grassland carbon use efficiency in response to climate change from 2000 to 2013. Acta Oecologica, 81, 22-31. doi:10.1016/j.actao.2017.04.004

105. Wang, Z., Yang, Y., Li, J., Zhang, C., Chen, Y., Wang, K., ... Qi, J. (2017). Simulation of terrestrial carbon equilibrium state by using a detachable carbon cycle scheme. Ecological Indicators, 75, 82-94. doi:10.1016/j. ecolind.2016.12.014

106. Gang, C., Zhang, Y., Wang, Z., Chen, Y., Yang, Y., Li, J., .. Odeh, I. (2017). Modeling the dynamics of distribution, extent, and NPP of global terrestrial ecosystems in response to future climate change. Global and 
Planetary Change, 148, 153-165. doi:10.1016/j. gloplacha.2016.12.007

107. Chen, Y., Mu, S., Sun, Z., Gang, C., Li, J., Padarian, J., ... Li, S. (2016). Grassland carbon sequestration ability in China: A new perspective from terrestrial aridity zones. Rangeland Ecology \& Management, 69(1), 84-94. doi: 10.1016/j.rama.2015.09.003

108. Wang, Z., Zhang, Y., Yang, Y., Zhou, W., Gang, C., Zhang, Y., ... Qi, J. (2016). Quantitative assess the driving forces on the grassland degradation in the QinghaiTibet Plateau, in China. Ecological Informatics, 33, 32-44. doi:10.1016/j.ecoinf.2016.03.006

109. Yang, Y., Wang, Z., Li, J., Gang, C., Zhang, Y., Zhang, Y., ... Qi, J. (2016). Comparative assessment of grassland degradation dynamics in response to climate variation and human activities in China, Mongolia, Pakistan and Uzbekistan from 2000 to 2013. Journal of Arid Environments, 135, 164-172. doi:10.1016/j. jaridenv.2016.09.004

110. Zhang, Y., Zhang, C., Wang, Z., Chen, Y., Gang, C., An, R., \& Li, J. (2016). Vegetation dynamics and its driving forces from climate change and human activities in the Three-River Source Region, China from 1982 to 2012. Science of The Total Environment, 563-564, 210-220. doi:10.1016/j.scitotenv.2016.03.223

111. Gang, C., Wang, Z., Zhou, W., Chen, Y., Li, J., Chen, J., ... Groisman, P. Y. (2015). Assessing the spatiotemporal dynamic of global grassland water use efficiency in response to climate change from 2000 to 2013. Journal of Agronomy and Crop Science, 202(5), 343-354. doi:10.1111/jac.12137

112. Gang, C., Zhou, W., Wang, Z., Chen, Y., Li, J., Chen, J., ... Groisman, P. Y. (2015). Comparative assessment of grassland npp dynamics in response to climate change in China, North America, Europe and Australia from 1981 to 2010. Journal of Agronomy and Crop Science, 201(1), 57-68. doi:10.1111/jac.12088

113. Gang, C., Wang, Z., Zhou, W., Chen, Y., Li, J., Cheng, J., ... Chen, C. (2015). Projecting the dynamics of terrestrial net primary productivity in response to future climate change under the RCP2.6 scenario. Environmental Earth Sciences, 74(7), 5949-5959. doi:10.1007/s12665-015-4618-x

114. Gang, C., Zhou, W., Li, J., Chen, Y., Mu, S., Ren, J., ... Groisman, P. Y. (2013). Assessing the spatiotemporal variation in distribution, extent and NPP of terrestrial ecosystems in response to climate change from 1911 to 2000. PLOS ONE, 8(11), e80394. doi:10.1371/journal. pone.0080394

115. Mu, S. J., Chen, Y. Z., Li, J. L., Ju, W. M., Odeh, I. O. A., \& Zou, X. L. (2013). Grassland dynamics in response to climate change and human activities in Inner Mongolia, China between 1985 and 2009. The Rangeland Journal, 35(3), 315-329.

116. Mu, S., Zhou, S., Chen, Y., Li, J., Ju, W., \& Odeh, I. O. A. (2013). Assessing the impact of restoration-induced land conversion and management alternatives on net primary productivity in Inner Mongolian grassland, China. Global and Planetary Change, 108, 29-41. doi:10.1016/j.gloplacha.2013.06.007

117. Sun, Z., Sun, C., Zhou, W., Ju, W., \& Li, J. (2013). Evaluating the net primary productivity in the grasslands of southern China from 2001 to 2010 using a new land portfolio assessment model. Plant Ecology, 214(10), 1223-1232. doi:10.1007/s11258-0130246-2

118. Wang, Z., Gang, C., Li, X., Chen, Y., \& Li, J. (2015). Application of a normalized difference impervious index (NDII) to extract urban impervious surface features based on Landsat TM images. International Journal of Remote Sensing, 1-15. doi:10.1080/01431161 .2015 .1007250

119. Zhou, W., Gang, C., Zhou, L., Chen, Y., Li, J., Ju, W., \& Odeh, I. (2014). Dynamic of grassland vegetation degradation and its quantitative assessment in the northwest China. Acta Oecologica, 55, 86-96. doi:10.1016/j.actao.2013.12.006

120. Yizhao, C., Jianyang, X., Zhengguo, S., Jianlong, L., Yiqi, L., Chengcheng, G., \& Zhaoqi, W. (2015). The role of residence time in diagnostic models of global carbon storage capacity: model decomposition based on a traceable scheme. Scientific Reports, 5, 16155. doi:10.1038/srep16155

121. Zhou, W., Gang, C., Zhou, F., Li, J., Dong, X., \& Zhao, C. (2015). Quantitative assessment of the individual contribution of climate and human factors to desertification in northwest China using net primary productivity as an indicator. Ecological Indicators, 48 , 560-569. doi:10.1016/j.ecolind.2014.08.043

122. Zhou, W., Gang, C., Chen, Y., Mu, S., Sun, Z., \& Li, J. (2014). Grassland coverage inter-annual variation and its coupling relation with hydrothermal factors in China during 1982-2010. Journal of Geographical Sciences, 24(4), 593-611. doi:10.1007/s11442-014-11080

123. Zhou, W., Gang, C., Li, J., Zhang, C., Mu, S., \& Sun, Z. (2014). 1982-2010 nian Zhongguo caodi fugaidu de shikong dongtai ji qi dui qihou bianhua de xiangying [Spatial-temporal dynamics of grassland coverage and its response to climate change in China during 1982-2010]. Journal of Geographical Sciences, 69(1), 15-30. doi:10.11821/dlxb201401002

124. Zhou, W., Gang, C., Zhou, L., Chen, Y., Li, J., Ju, W., \& Odeh, I. (2014). Dynamic of grassland vegetation degradation and its quantitative assessment in the northwest China. Acta Oecologica, 55, 8696. doi:10.1016/j.actao.2013.12.006

125. Zhou, W., Li, J. L., Mu, S. J., Gang, C. C., \& Sun, Z. G. (2013). Effects of ecological restoration-induced land-use change and improved management on grassland net primary productivity in the Shiyanghe River Basin, north-west China. Grass and Forage Science. doi:10.1111/gfs.12073

126. Zhou, W., Sun, Z., Li, J., Gang, C., \& Zhang, C. (2013). Desertification dynamic and the relative roles of climate change and human activities in desertification 
in the Heihe River Basin based on NPP. Journal of Arid Land, 5(4), 465-479. doi: 10.1007/s40333-013-0181-z

127. Yang, H. F., Gang, C. C., Mu, S. J., Zhang, C. B., Zhou, W., \& Li, J. L. (2014). Analysis of the spatio-temporal variation in net primary productivity of grassland during the past 10 years in Xinjiang. Acta Prataculturae Sinica, 3, 39-50. doi:10.11686/cyxb20140305

\section{Southeast Asia Regional Climate Downscaling Project (SEACLID)}

ARCP2013-17NMY-Tangang, ARCP2014-07CMY-Tangang, ARCP2015-04CMY-Tangang

128. Cruz, F. T., Narisma, G. T., Dado, J. B., Singhruck, P., Tangang, F., Linarka, U. A., ... Aldrian, E. (2017). Sensitivity of temperature to physical parameterization schemes of RegCM4 over the CORDEX-Southeast Asia region. International Journal of Climatology. doi:10.1002/joc.5151

129. Juneng, L., Tangang, F., Chung, J., Ngai, S., Tay, T., Narisma, G., ... Aldrian, E. (2016). Sensitivity of Southeast Asia rainfall simulations to cumulus and air-sea flux parameterizations in RegCM4. Climate Research, 69(1), 59-77. doi:10.3354/cr01386

130. Ngai, S. T., Juneng, L., Tangang, F., Chung, J. X., Salimun, E., Tan, M. L., \& Amalia, S. (2020). Future projections of Malaysia daily precipitation characteristics using bias correction technique. Atmospheric Research, 240, 104926. doi:10.1016/j.atmosres.2020.104926

131. Ngai, S. T., Tangang, F., \& Juneng, L. (2017). Bias correction of global and regional simulated daily precipitation and surface mean temperature over Southeast Asia using quantile mapping method. Global and Planetary Change, 149, 79-90. doi:10.1016/j. gloplacha.2016.12.009

132. Ngo-Duc, T., Tangang, F. T., Santisirisomboon, J., Cruz, F., Trinh-Tuan, L., Nguyen-Xuan, T., ... Aldrian, E. (2016). Performance evaluation of RegCM4 in simulating extreme rainfall and temperature indices over the CORDEX-Southeast Asia region. International Journal of Climatology. doi:10.1002/joc.4803

133. Nguyen-Thi, T., Ngo-Duc, T., Tangang, F. T., Cruz, F., Juneng, L., Santisirisomboon, J., ... Narisma, G. (2020). Climate analogue and future appearance of novel climate in Southeast Asia. International Journal of Climatology. doi:10.1002/joc.6693

134. Supari, Tangang, F., Juneng, L., \& Aldrian, E. (2017). Observed changes in extreme temperature and precipitation over Indonesia. International Journal of Climatology, 37(4), 1979-1997. doi:10.1002/joc.4829

135. Supari, Tangang, F., Salimun, E., Aldrian, E., Sopaheluwakan, A., \& Juneng, L. (2017). ENSO modulation of seasonal rainfall and extremes in Indonesia. Climate Dynamics. doi:10.1007/s00382-0174028-8

136. Tan, M. L., Juneng, L., Tangang, F. T., Chan, N. W., \& Ngai, S. T. (2019). Future hydro-meteorological drought of the Johor River Basin, Malaysia, based on CORDEXSEA projections. Hydrological Sciences Journal, 64(8), 921-933. doi:10.1080/02626667.2019.161290

137. Tangang, F., Farzanmanesh, R., Mirzaei, A., Supari, Salimun, E., Jamaluddin, A. F., \& Juneng, L. (2017). Characteristics of precipitation extremes in Malaysia associated with El Niño and La Niña events. International Journal of Climatology. doi:10.1002/joc.5032

138. Tangang, F., Juneng, L., Cruz, F., Chung, J. X., Ngai, S. T., Salimun, E., ... Ngo-Duc, T. (2020). Multi-model projections of precipitation extremes in Southeast Asia based on CORDEX-Southeast Asia simulations. Environmental Research, 109350. doi:10.1016/j. envres.2020.109350

139. Tangang, F., Chung, J.X., Juneng, L. et al. Projected future changes in rainfall in Southeast Asia based on CORDEX-SEA multi-model simulations. Clim Dyn (2020). doi:10.1007/s00382-020-05322-2

140. Tangang, F., Santisirisomboon, J., Juneng, L., Salimun, E., Chung, J., Supari, S., ... Narisma, G. (2019). Projected future changes in mean precipitation over Thailand based on multi-model regional climate simulations of CORDEX Southeast Asia. International Journal of Climatology, 39(14), 5413-5436. doi:10.1002/ joc.6163

141. Tangang, F., Supari, S., Chung, J. X., Cruz, F., Salimun, E., Ngai, S. T., ... Hein-Griggs, D. (2018). Future changes in annual precipitation extremes over Southeast Asia under global warming of $2^{\circ} \mathrm{C}$. APN Science Bulletin, $8(1)$. doi:10.30852/sb.2018.436

142. Trinh-Tuan, L., Matsumoto, J., Tangang, F. T., Juneng, L., Cruz, F., Narisma, G., . . Ngo-Duc, T. (2019). Application of quantile mapping bias correction for mid-future precipitation projections over Vietnam. SOLA, 15, 1-6. doi:10.2151/sola.2019-001

143. Tan, M. L., Juneng, L., Tangang, F. T., Samat, N., Chan, N. W., Yusop, Z., \& Ngai, S. T. (2020). SouthEast Asia HydrO-meteorological droughT (SEA-HOT) framework: A case study in the Kelantan River Basin, Malaysia. Atmospheric Research, 105155. doi:10.1016/j. atmosres.2020.105155

144. Ngai, S. T., Sasaki, H., Murata, A., Nosaka, M., Chung, J. X., Juneng, L., .. . Tangang, F. (2020). Extreme Rainfall Projections for Malaysia at the end of 21st Century using the high resolution Non-Hydrostatic Regional Climate Model (NHRCM). SOLA. doi:10.2151/sola.2020023

\section{Boreal and Tropical Forest and Forest-Steppes in East Asia: A Comparative Study on Climate Impacts and Adaptation}

ARCP2013-19NMY-Gomboev, ARCP2014-09CMY-Gomboev

145. Gomboev, B. O., Puntsukova, S. D., Andreev, A. B. Vasileva, L. S., Jamsran, T., Tsendsuren, D., \& Dong, S. (2016). The impact of climate change on boreal and tropical forests in East Asia (In Russian). Scientific Review, 5, 50-54. 
146. Tulokhonov, A. K., Mikheeva, S. A., Puntsukova, S. D., Sanjeev, E. D., Batomunkuyev, V. S., Zamanov, D. D., \& Darbaeva. (2016). Ecological and economic approaches to rational nature management in the transboundary Selenga river basin (In Russian). Scientific Review, 5, 54-57.

147. Puntsukova, S. D., \& Andreev, A. B. (2015). Механизм рационального лесопользования на основе оценки лесоресурсной ренты. [The mechanism of rational forest management on the basis of the forest resource rent]. Общество: политика, экономика, право. [Society: politics, economics, law], 6, 38-45.

148. Puntsukova, S. D., Gomboev, B. O., Akhmetzyanova, M. ramilievna, Jamsran, T., Dagdan, T., \& Dong, S. (2015). Comparative analysis of different forest ecosystems response to global climate change and economic activity (In Russian). Journal of Resources and Ecology, 6(2), 106-109.

149. Puntsukova, S. D., \& Osodoev, P. V. (2015). Механизм стимулирования эколого-безопасного лесопользования на основе оценок экологических издержек лесозаготовительного производства. [Mechanism of stimulating ecologically safe forestry on the basis of evaluation of ecologic costs in forestry production (Russia, Ulan-Ude)]. Проблемы Современной Экономики. [Problems of Modern Economics], 3(55), 344-348.

150. Puntsukova, S. D., Zamanov, D. D., \& Darbaeva, D. A. (2015). Proposals to improve the regional financial mechanism on the use, protection and reproduction of forest resources (In Russian). Problems of Regional Ecology, 4, 72-77.

151. Li, F., Dong, S., Li, F., \& Yang, L. (2014). Is there an inverted U-shaped curve? Empirical analysis of the Environmental Kuznets Curve in agrochemicals. Frontiers of Environmental Science \& Engineering. doi:10.1007/s11783-014-0700-y

152. Puntsukova, S. D. (2014). Evaluation of the effectiveness of the methods of regulating forest management and conservation of forest environment (In Russian). Vestnik of ESSUTM, 2(47), 94-100.

153. Puntsukova, S. D. (2014). A study of the principles of formation of forest resource rents in the region and order of its calculation (In Russian). Economic Revival of Russia, 2, 157-165.

154. Puntsukova, S. D. (2014). Методы экономической оценки лесной экосистемы региона. [Regional forestry eco-system: methods of evaluation (Russia, Ulan-Ude)]. ПРОБЛЕМЫ СОВРЕМЕННОЙ эКОНОМИКИ.[Problems of Modern Economics], 3(51), 314-319.

155. Puntsukova, S. D., Akhmetzyanova, M. Ramilievna, Osodoev, P. V., Borisovich, A., Darbalaeva, D. A., \& Zhamyanov, D.-T. D. (2014). Лесоэкономическое районирование территории республики Бурятия - основа создания эффективной системы лесных рентных платежей. [Forest economic zoning of the territory of the Republic of Buryatia as a basis for creating an effective system of forest rent payments]. Научное Мнение [Scientific Opinion], 9(3), 172-179.

156. Puntsukova, S. D., Gomboev, B. O., Akhmetzyanova, M. R., Jamsran, T., Tsendsuren, D., \& Dong, S. (2014). Comparative analysis of different forest ecosystem response on global climate change and economic activity. In International Conference on Ecology, Environment and Sustainable Development of Silk Road Economic Zone, Beijing, 15 - 16 June 2014 (pp. 119-125).

157. Puntsukova, S. D. (2014). Economic value of the forest ecosystem of the region. In International Conference on Ecology, Environment and Sustainable Development of Silk Road Economic Zone, Beijing, 15 - 16 June 2014 (pp. 129-134).

\section{Runoff Scenario and Water Based Adaptation Strategies in South Asia}

ARCP2013-20NMY-Shrestha, ARCP2014-10CMY-Shrestha

158. Khatiwada, K., Panthi, J., Shrestha, M., \& Nepal, S. (2016). Hydro-climatic variability in the Karnali River Basin of Nepal Himalaya. Climate, 4(2), 17. doi:10.3390/ cli4020017

159. The Small Earth Nepal. (2017). Climate and hydrology of Karnali River Basin. Policy brief, Kathmandu, Nepal. (in Nepali language) Retrieved from https:// smallearthnepal.files.wordpress.com/2017/06/flyre_ hig.pdf

160. The Small Earth Nepal. (2017). Good water-based adaptation practices in Karnali River Basin. Retrieved from https://youtu.be/LWwozj5bXY0

\section{$\square$ Adaptation of Solid Waste Management to Frequent Floods in Vulnerable Mid-Scale Asian Cities}

ARCP2013-21NMY-Yamada, ARCP2014-11CMY-Yamada

161. Ishigaki, T., \& Kawai, K. (2015). Evaluation of resiliency of solid waste management against flood. Presented at the Sardinia_2015 - 15th International Waste Management and Landfill Symposium, Forte Village, S. Margherita di Pula (CA), Italy.

162. Kubota, R., \& Wangyao, K. (2015). Guideline for flood waste management in Bangkok. Presented at the Sardinia_2015 - 15th International Waste Management and Landfill Symposium, Forte Village, S. Margherita di Pula (CA), Italy.

163. Pham, K. L. (2015). Technical and administrative countermeasures for flood waste in Hue, Hanoi. Presented at the Sardinia_2015 - 15th International Waste Management and Landfill Symposium, Forte Village, S. Margherita di Pula (CA), Italy.

164. Tajima, R. (2015). Capacity building for local administration officers on flood waste management. Presented at the Sardinia_2015 - 15th International Waste Management and Landfill Symposium, Forte Village, S. Margherita di Pula (CA), Italy. 
165. Yamada, M. (2015). Coordination of investigation on flood waste management in Southeast Asia. Presented at the Sardinia_2015 - 15th International Waste Management and Landfill Symposium, Forte Village, S. Margherita di Pula (CA), Italy.

\section{Assessing Community Risk Insurance Initiatives and Identifying Enabling Policy and Institutional Factors for Maximizing Climate Change Adaptation and Disaster Risk Reduction Benefits from Risk Insurance}

ARCP2013-18NMY-Prabhakar, ARCP2014-08CMY-Prabhakar

166. Abu-Bakar, A., Prabhakar, S. V. R. K., \& Pereira, J. J. (2017). Cost-benefit analysis of the risk insurance and other risk management strategies. Sintok, Kedah: Universiti Utara Malaysia.

167. Cummins, J., \& Mitchell, I. (2017). Cost-benefit analysis of the risk insurance and other risk management strategies. Adelaide, Australia: International Agriculture for Development.

168. Cummins, J., \& Mitchell, I. (2017). Promoting risk insurance and other risk management approaches in Australia. Adelaide, Australia: International Agriculture for Development.

169. Cummins, J., Lipman, A., \& Feetham, H. (2014). Preliminary focus group study: Australian farmer attitude to on-farm risk management and insurance. Adelaide, Australia: International Agriculture for Development.

170. IGES, UKM-SEADPRI, UPLB, eeMausam, \& IAFD. (2014). Evidence for disaster risk reduction and climate change adaptation effectiveness of insurance: Challenges and opportunities (IGES Workshop Proceedings). Hayama, Japan: Institute for Global Environmental Strategies.

171. Pereira, J. J., Baker, A. A., Choi, E. A., \& Prabhakar, S. V. R. K. (2017). Promoting disaster risk insurance: Challenges and opportunities in Malaysia. (SEAPDRI Report). Bangi, Malaysia: SEADPRI.

172. Prabhakar, S. V. R. K., \& Ozawa, N. (2014). Crop insurance performance in Japan: Some preliminary observations. Presented at the Regional Consultation Workshop on Evidence for Disaster Risk Reduction and Climate Change Adaptation Effectiveness of Insurance: Challenges and Opportunities. Bangi, Malaysia, 4-5 July 2014, Bangi, Malaysia: IGES-SEADPRI-eeMausam-IAFDUPLB.

173. Prabhakar, S. V. R. K., Abu-Bakar, A., Claudio, C. P. B., Hung, H. V., \& Solomon, D. S. (2015). What ails the effectiveness of crop insurance? Emerging bottomup issues and solutions. In P. Sawney \& M. A. Perkins, Emerging Climate Change Adaptation Issues in the Asia-Pacific Region. Bangkok, Thailand: Asia Pacific Adaptation Network.

174. Prabhakar, S. V. R. K., Abu-Bakar, A., Claudio, C. P. B., Hung, H. V., \& Solomon, D. S. (2013). Scaling up risk financing in Asia and the Pacific region: Bottomup lessons from agriculture insurance in Malaysia,
Philippines and Vietnam. Bangkok, Thailand: Asia Pacific Adaptation Network.

175. Prabhakar, S. V. R. K., Ofei-Manu, P., Solomon, D. S., \& Shivakoti, B. S. (2015). Evidence for climate change adaptation and disaster risk reduction synergies of interventions: An inductive approach. Bangkok, Thailand: Asia Pacific Adaptation Network.

176. Prabhakar, S. V. R. K., Pereira, J. J., Pulhin, J. M., Rao, G. S., Scheyvens, H., \& Cummins, J. (2015). Effectiveness of Insurance for Disaster Risk Reduction and Climate Change Adaptation: Challenges and Opportunities (IGES Research Report No. 2014-04). Hayama, Japan: Institute for Global Environmental Strategies.

177. Prabhakar, S. V. R. K., Solomon, D. S., Abu-Bakar, A., Cummins, J., Pereira, J. J., \& Pulhin, J. M. (2017). Case Studies in Insurance Effectiveness: Some Insights into Costs and Benefits (Research Report No. SEADPRI-2017-02). Malaysia: Southeast Asia Disaster Prevention Research Institute (SEADPRI). Retrieved from https://pub.iges.or.jp/pub/case-studiesinsurance-effectiveness-some

178. Solomon, D. S., Prabhakar, S. V. R. K., \& Rao, G. S. (2017). Costs and benefits of agriculture insurance in India. Hyderabad, India: eeMausam Weather Risk Management Solutions, In S. V. R. K., Prabhakar, D. S., Solomon, A., Abu-Bakar, J., Cummins, J. J. Pereira, \& J.M. Pulhin (Eds). Case Studies in Insurance Effectiveness: Some Insights into Costs and Benefits. Bangi, Malaysia: Southeast Asia Disaster Prevention Research Institute (SEADPRI). Retrieved from http://www.apn-gcr.org/resources/files/original/ b9bf42b70e2cb12ac17b0b3236d70196.pdf\#page=37

179. Mia, M. S., Choi, E. A., Prabhakar, S. V. R. K., \& Pereira, J. J. (2015). Disaster risks and insurance in the agriculture sector in Asia: A review. Journal of Food, Agriculture and Environment, 13(2), 245-249. Retrieved from https://www.researchgate.net/profile/ Joy_Pereira/publication/282209952_Disaster_risks_ and_insurance_in_the_agriculture_sector_in Asia_A_review/links/598290a90f7e9b9ebaab1e76/ Disaster-risks-and-insurance-in-the-agriculture-sectorin-Asia-A-review.pdf

180. Prabhakar, S. V. R. K. (2014). Insurance effectiveness: Objectives and expectations. Presented at the Regional Consultation Workshop on Evidence for Disaster Risk Reduction and Climate Change Adaptation Effectiveness of Insurance: Challenges and Opportunities, Bangi, Malaysia, 4-5 July 2014, Bangi, Malaysia: IGES-SEADPRI-eeMausam-IAFD-UPLB.

181. Prabhakar, S. V. R. K. (2014). Insurance for long-term post-disaster recovery and adaptation. Presented at the International Conference on Mountain People Adapting to Change: Solutions Beyond Boundaries Bridging Science, Policy and Practice, Kathmandu, Nepal, 9-12 November 2014, Kathmandu, Nepal: ICIMOD.

182. Prabhakar, S. V. R. K. (2015). Insurance effectiveness: Climate change adaptation and disaster risk reduction. Presented at the International Forum for Sustainable Asia and The Pacific, 28-29th July 2015, Pacifico, 
Yokohama, Japan: Institute for Global Environmental Strategies.

183. Prabhakar, S. V. R. K. (2016). Financial inclusion for risk reduction: Current evidence. Presented at the ACTS Workshop on Risk Management Innovations for Weather-Related Natural Disasters, 17-18th October, Taipei, Taiwan: APEC Research Center for Typhoon and Society.

184. Prabhakar, S. V. R. K. (2016). Insurance effectiveness for disaster risk reduction and climate change adaptation. Presented at the Agricultural Risk Management and Insurance Workshop, Taiwan Agricultural Research Institute, Nanjing, Taiwan, 5-6 Dec 2016, Taichung, Taiwan: Taiwan Agricultural Research Institute.

185. Solomon, D. S., \& Prabhakar, S. V. R. K. (2014). Assessing the disaster risk reduction and climate change adaptation synergies of risk insurance: Impact pathway framework for assessing risk insurance (IPFARI). Poster presented at the International Forum for Sustainable Asia and The Pacific, 23-24th July 2015, Pacifico Yokohama, Japan.

186. Prabhakar, S. V. R. K. (2017). Vulnerability reduction efficacy of financial inclusion to climate and economic changes: Evidences, bottlenecks and way forward. In E. Y. Mohammad \& Z. B. Uraguchi, Vulnerability Reduction Efficacy of Financial Inclusion to Climate and Economic Changes: Evidences, Bottlenecks and Way Forward (pp. 212-227). UK: Routledge-Earthscan.

187. Prabhakar, S. V. R. K., Rao, G. S., Fukuda, K., \& Hayashi, S. (2013). Promoting risk insurance in the Asia-Pacific region: Lessons from the ground for the future climate region under UNFCCC. In P. Schmidt-Thome \& J. Knieling, Implementing Climate Change Adaptation Strategies (p. 327). London, UK: Blackwell Publishers.

188. Prabhakar, S. V. R. K. (2015). Agricultural insurance [Video Training Material]. Los Banos, Laguna, Philippines: SEARCA and UPLB. Retrieved from http:// fmds.upou.edu.ph/index.php/academics/cep?id=344

189. Prabhakar, S. V. R. K. (2015). Risk insurance: addressing loss and damage. Asian Disaster Management News: Disaster Recovery: The Governance, Economics and Social Impacts, 22, 32-33.

190. Prabhakar, S. V. R. K., Pereira, J. J., Pulhin, J. M., Rao, G. S., \& Cummins, J. (2015). Assessing the climate change adaptation and disaster risk reduction effectiveness of risk insurance approaches. APN Science Bulletin, 5, 46-47.

191. Prabhakar, S. V. R. K., Rao, G. S., Cummins, J., Pereira, J. J., \& Pulhin, J. M. (2014). Scaling up risk insurance in the Asia-Pacific region: Issues and way forward. APN Science Bulletin, 4, 103-105.

\section{Mega-Regional Development and Environmental Change in China and India}

\section{ARCP2013-22NMY-Sellers ARCP2014-12CMY-Sellers}

192. Ramachandra, T. V., Sellers, J., Bharath, H. A., Vinay, S., \& Brigit, M. B. (2018). Geo-visualisation of landscape dynamics in the proposed mega industrial corridor. Abstract submitted to the BDCC 2018 2nd International Workshop on Biodiversity and Climate Change, IIT Kharagpur, West Bengal, India.

193. Ramachandra, T. V., Sellers, J., Bharath, H. A., \& Bharath, S. (2018). Micro level analyses of environmentally disastrous urbanisation in Bangalore. Presented at the BDCC 2018 2nd International Workshop on Biodiversity and Climate Change, IIT Kharagpur, West Bengal, India.

194. Liu, Y., Fan, P., Yue, W., \& Song, Y. (2018). Impacts of land finance on urban sprawl in China: The case of Chongqing. Land Use Policy, 72, 420-432. doi:10.1016/j. landusepol.2018.01.004

195. Bharath, H. A., Vinay, S., Chandan, M. C., Gouri, B. A., \& Ramachandra, T. V. (2018). Green to gray: Silicon Valley of India. Journal of Environmental Management, 206, 1287-1295. doi:10.1016/j.jenvman.2017.06.072

196. Liu, Y., Yue, W., Fan, P., Zhang, Z., \& Huang, J. (2017). Assessing the urban environmental quality of mountainous cities: A case study in Chongqing, China. Ecological Indicators, 81, 132-145. doi:10.1016/j. ecolind.2017.05.048

197. Sellers, J., \& Wang, H. (2017). The emerging face of suburban India: The geography of housing markets (working paper). Los Angeles, California: Lusk Center for Real Estate Research, University of Southern California.

198. Huang, J., Wang, C., \& Sellers, J. (2017). Difference measuring of coastal and inland urban agglomerations: A comparison between Wuhan metropolitan area and Yangtze River Delta urban agglomeration based on urban flows (In Chinese). Modern Urban Research, 2017(7), 114-123.

199. Huang, J., Chen, S., Sellers, J., \& Xing, X. (2017). An exploration of multi-scale network structure of the Yangtze River middle reaches urban agglomerations based on an interlocking model (In Chinese). Urban and Rural Planning, 2017(5), 65-75.

200. Ramachandra, T. V., Sellers, J., Bharath, H. A., Vinay, S., \& Brigit, M. B. (2017). Spatial pattern of land use dynamics in Mumbai Pune Express corridor (ENVIS Technical Report No. 137). Bangalore, India: Indian Institute of Sciences.

201. Brigit, M. B., Bharath, H. A., Nityanandam, Y., \& Ramachandra, T. V. (2017). Analysis of landscape dynamics in the Pune-Mumbai industrial corridor. In Proceedings of International Conference on Urban Geoinformatics, February 2017. New Delhi, India: TERI University.

202. Yue, W., Zhang, L., \& Liu, Y. (2016). Measuring sprawl in large Chinese cities along the Yangtze River via combined single and multidimensional metrics. Habitat International, 57, 43-52. doi:10.1016/j. habitatint.2016.06.009

203. Ramachandra, T. V., Sellers, J., Bharath, H. A., Vinay, S., \& Brigit, M. B. (2016). Urban dynamics in the proposed Mangalore-Bangalore-Chennai industrial 
corridor (ENVIS Technical Report No. 115). Bangalore, India: Indian Institute of Sciences.

204. Ramachandra, T. V., Aithal, B. H., \& Sreejith, K. (2015). GHG footprint of major cities in India. Renewable and Sustainable Energy Reviews, 44, 473-495. doi:10.1016/j. rser.2014.12.036

205. Ramachandra, T. V., Chandan, M. C., Bharath, H. A., Vinay, S., Sellers, J. M., \& Venugopal, K. R. (2015). Monitoring and modelling patterns of urban growth in Chennai, India. In Proceedings of NRSC UIM 2015. Hyderabad, Telangana, India.

206. Ramachandra, T. V., Bharath, H. A., Vinay, S., Sellers, J. M., \& Venugopal, K. R. (2015). Monitoring and modelling patterns of urban growth in Chennai, India. In Proceedings of IISC - STC 2015. Bangalore, Karnataka, India.

207. Ramachandra, T. V., Aithal, B. H., \& Beas, B. (2014). Urbanisation pattern of incipient mega region in India. Tema. Journal of Land Use, Mobility and Environment. doi:10.6092/1970-9870/2202

208. Ramachandra, T. V., Bharath, H. A., \& Sowmyashree, M. V. (2014). Urban footprint of Mumbai - The commercial capital of India. Journal of Urban and Regional Analysis, 6(1), 71-94.

209. Aithal, B. H., Vinay S, Venugopal Rao K., \& Ramachandra T.V. (2014). Prediction of spatial patterns of urban dynamics in Pune, India. 2014 Annual IEEE India Conference (INDICON). doi:10.1109/ indicon.2014.7030404

\section{Developing Scientific and Management Tools to Address Impacts of Changing Climate and Land Use Patterns on Water Quality in East Asia's River Basins}

ARCP2013-23NMY-Sthiannopkao, ARCP2014-13CMY-

Sthiannopkao

210. Ligaray, M., Kim, H., Sthiannopkao, S., Lee, S., Cho, K., \& Kim, J. (2015). Assessment on hydrologic response by climate change in the Chao Phraya River Basin, Thailand. Water, 7(12), 6892-6909. doi:10.3390/ w7126665

211. Tungsawat, T., Vinitnantharat, S., \& Phoolphund, S. (2015). Water quality in irrigated field and surface water. In PACCON 2015: Innovative Chemistry for Sustainability of the AEC and Beyond. Amari Watergate Hotel, Bangkok, Thailand. Retrieved from http://paccon2015. kmutt.ac.th/

212. Wiriyaphong, N., \& Vinitnantharat, S. (2015). Water quality and organic loads along the Chao Phraya River in Nakhon Sawan municipality. In PACCON 2015: Innovative Chemistry for Sustainability of the AEC and Beyond. Amari Watergate Hotel, Bangkok, Thailand. Retrieved from http://paccon2015.kmutt.ac.th/

213. Thongsamer, T., Vinitnantharat, S., \& Phoolphundh, S. (2015). Effect of water depth, season and land use on the microbial numbers along the Chao Phraya River. The 5th National and International Graduate
Study Conference 'Creative Education: Intellectual Capital toward ASEAN'. Princess Mahachakri Sirindhon Anthropology Centre, Thailand. Retrieved from http:// www.graduate.su.ac.th/images/proceedings/2015/ proceedings.pdf

214. Chantaraprabha, K., \& Vinitnantharat, S. (2014). Effect of drought on water resource: a case study of Chao Phraya River. Presented at the the 5th International Conference on Sustainable Energy and Environment (SEE 2014): Science, Technology and Innovation for ASEAN Green Growth, Anantara Bangkok Riverside Resort and Spa, Bangkok, Thailand.

215. Pookang, N., Vinitnantharat, S., \& Buddhawong, S. (2014). Investigation of nutrient and coliform bacteria from non-point source on the Chao Phraya river bank in dry season. Presented at the The 5th International Conference on Sustainable Energy and Environment (SEE 2014): Science, Technology and Innovation for ASEAN Green Growth, Anantara Bangkok Riverside Resort and Spa, Bangkok, Thailand.

\section{Supporting Governance Institutions for Adaptive Capacity to Environmental Change}

ARCP2013-24NSY-Fidelman

216. Fidelman, P., Van Tuyen, T., Nong, K., \& Nursey-Bray, M. (2017). The institutions-adaptive capacity nexus: Insights from coastal resources co-management in Cambodia and Vietnam. Environmental Science \& Policy, 76, 103-112. doi:10.1016/j.envsci.2017.06.018

217. Fidelman, P., Truong, V. T., Kim, N., \& Nursey-Bray, M. (2016). Institutional adaptive capacity of coastal resources co-management in Cambodia and Vietnam. Presented at The Australian Political Studies Association Conference 2016, Sydney, Australia. (Awarded Pete Hay Environmental Politics Prize).

\section{Climate Change Vulnerability and Adaptation in Ground water-dependent Irrigation System in Asia-Pacific Region}

ARCP2013-25NSY-Shahid

218. Shahid, S., Alamgir, M., Wang, X., \& Eslamian, S. (n.d.). Climate change impacts and adaptation to groundwater. In Handbook of Drought and Water Scarcity: Environmental Impacts and Analysis of Drought and Water (Vol. 2). Taylor and Francis.

219. Shahid, S., Wang, X.-J., Keramat, M., Akhter, G., Farooq, S.H., \& Lubis, R.F. (2014). Vulnerability and adaptation to climate change in groundwater-dependent irrigation systems in Asian countries. APN Science Bulletin, 4, 124-126.

220. Wang, X., Zhang, J., Shahid, S., Guan, E., Wu, Y., Gao, J., \& He, R. (2016). Adaptation to climate change impacts on water demand. Mitigation and Adaptation Strategies for Global Change, 21(1), 81-99. doi:10.1007/s11027014-9571-6 
Characterizing Public and Private Adaptation to Climate Change and Implications for Long-Term Adaptive Capacity in Asian Megacities

ARCP2013-26NSY-Patankar

221. Patankar, A. (2019). Impacts of natural disasters on households and small businesses in India. Retrieved from https://www.adb.org/publications/naturaldisasters-households-small-businesses-india

222. Ananta, A., Bauer, A., \& Thant, M. (Eds.). (2013). The environments of the poor in Southeast Asia, East Asia and the Pacific. Institute of Southeast Asian Studies.

223. Cutter, S. L., Ismail-Zadeh, A., Alcantara-Ayala, I., Altan, O., Baker, D. N., Briceno, S., . . O Ogawa, Y. (2015). Global risks: Pool knowledge to stem losses from disasters. Nature News, 522(7556), 277.

224. Gotangco, C., See, J., Dalupang, J., Ortiz, M., Porio, E., Narisma, G., .. . Dator-Bercilla, J. (2015). Quantifying resilience to flooding among households and local government units using system dynamics: A case study in Metro Manila. Journal of Flood Risk Management, 9(3), 196-207. doi:10.1111/jfr3.12222

225. Patankar, A. (2015). The exposure, vulnerability, and ability to respond of poor households to recurrent floods in Mumbai. The World Bank. http://crossasiarepository.ub.uni-heidelberg.de/3894/1/Poor\%20 Households\%20Flood\%20Mumbai.pdf

226. Patankar, A., \& Patwardhan, A. (2016). Estimating the uninsured losses due to extreme weather events and implications for informal sector vulnerability: a case study of Mumbai, India. Natural Hazards, 80(1), 285310. doi:10.1007/s11069-015-1968-3

227. Patankar, A., Patwardhan, A., Marome, W., \& Porio, E. (2013). Impacts of extreme weather events and implications for adaptation planning for coastal cities. APN Science Bulletin 3, 16-75.

228. Porio, E., Dator-Bercilla, J., Narisma, G., Cruz, F., \& Yulo-Loyzaga, A. (2019). Drought and urbanization: The case of the Philippines. In Urban Drought (pp. 183-208). Springer, Singapore.

229. Porio, E. (2016). Prosperity and inequality in metro Manila: Reflections on housing the poor, climate risk, and governance of cities. In Globalization and Democracy in Southeast Asia (pp. 177-197). Palgrave Macmillan, London.

230. Porio, E. (2014). Climate change vulnerability and adaptation in Metro Manila: Challenging governance and human security needs of urban poor communities. Asian Journal of Social Science, 42(1-2), 75-102.

231. Porio, E. (2014). Climate change adaptation in metro manila: Community risk assessment and power in community interventions. In Community Intervention (pp. 149-166). Springer, New York, NY.

232. Porio, E. (2013). Life along Manila's flooding rivers in the environments of the poor in Southeast Asia, South Asia and the Pacific, In A. Bauer, \& A. Ananta (Eds.),
Singapore: Institute of Southeast Asian Studies (ISEAS) Press.

233. Shaw R., Chan E., Lian F., Lu L., Shi P., \& Wong, J. (2017). Co-designing DRR solutions: Towards participatory action and communication in science, technology and academia, ASTAAG, IRDR and CCOUC, Hong Kong, China, 98 pages.

The Impact of Global Warming on OceanAtmosphere Feedback Strength at Tropical Indian Ocean

ARCP2013-27NSY-Liu

234. Liu, L., Xie, S.-P., Zheng, X.-T., Li, T., Du, Y., Huang, G., \& Yu, W.-D. (2014). Indian Ocean variability in the CMIP5 multi-model ensemble: the zonal dipole mode. Climate Dynamics, 43(5-6), 1715-1730. doi:10.1007/s00382-0132000-9

235. Zheng, X.-T., Xie, S.-P., Du, Y., Liu, L., Huang, G., \& Liu, Q. (2013). Indian Ocean dipole response to global warming in the CMIP5 multimodel ensemble*. Journal of Climate, 26(16), 6067-6080. doi:10.1175/ JCLI-D-12-00638.1

Influence of Mangrove Biodiversity on Accumulation of Carbon and Resilience to Sea Level Rise: A Comparative Assessment among Disturbed, Restored and Intact Mangrove Systems

ARCP2014-14NMY(B\&ES)-Salmo

236. Fortes, M.D. \& Salmo, S.G. III. (2016). Proceedings of the first national seagrass-mangrove bioshield conference. Department of Science and Technology, Asia-Pacific Network for Global Change Research, and the Department of Environmental Science (DES) of the School of Science and Engineering (SOSE) of Ateneo de Manila University, and National Research Council of the Philippines, U.P. Marine Science Institute CS. Quezon City, Philippines. 43 pp.

Developing an operational water security index, and its application in selected diverse regions of Asia

ARCP2014-16NMY-Babel, ARCP2015-07CMY-Babel

237. Babel, M., Haarstrick, A., Ribbe, L., Shinde, V., \& Dichtl, N. (Eds.). (2018). Water security in Asia: Opportunities and challenges in the context of climate change (1st ed.). Springer International Publishing.

238. Shinde, V., Babel, M., \& Acharya, S. (2017). Evaluating citizen support for water security enhancement. Presented at the 2017 Water Security and Climate Change Conference, Cologne, Germany.

239. Babel, M., Onsomkri, A., \& Shinde, V. (2016). Framework for water security assessment at city scale. In Proceedings of the 7th International Conference on Water Resources and Environment Research (ICWRER2016). Kyoto, Japan. 
240. Onkomsrit, A., Babel, M., Shinde, V., \& Pandey, V. P. (2016). Assessing water security at district level: A case of Bangkok. In Proceedings of the Water Security and Climate Change: Challenges and Opportunities in Asia. Bangkok, Thailand.

\section{Impacts of Crop Residue Removal for Biomass Energy on Soil Function: Studies to recommend Climate Adaptive Agricultural Waste Management \\ ARCP2014-17NMY-Dey, ARCP2015-08CMY-Dey}

241. Dey, D. Gyelshen, T \& Juico, P.P (2018). Impacts of agro-waste biomass reapplication against open burning on soil function and crop productivity - An assessment study. Paper accepted in 26th European Biomass Conference \& Exhibition (http://www.eubce.com/).

242. Dey, D. Gyelshen, T, \& Juico, P.P (2017). Reusing crop residues for enhanced soil function and emission reduction towards climate adaptive agricultural waste management. Proceedings of Fourth 3R International Scientific Conference on Material Cycles and Waste Management (3RINCs); March 8-10, 2017, New Delhi, India.

\section{Development of an Evidence-Based Climate Change Adaptation Toolkit to Help Improve Community Resilience to Climate Change Impacts in Uttarakhand, India}

\author{
ARCP2014-18NMY-Heath, ARCP2015-09CMY-Heath
}

243. Heath, L., Tiwari, P., Sadhukhan, B., Tiwari, S., Joshi, B., Ailikun, ... Yan, J. (2018). Using a participatory-based toolkit to build resilience and adaptive capacity to climate change impacts in rural India: A new paradigm shift for rural communities in the Himalaya. APN Science Bulletin, 8(1). doi:10.30852/sb.2018.292

\section{Coastal Forest Management in the Face of Global Change Based on Case Studies in Japan, Myanmar and the Philippines}

\section{ARCP2014-19NMY(B\&ES)-Liang, ARCP2015-10CMY(B\&ES)-} Liang

244. Chen, B \& Nakama, Y. (2019). Dimensions and conservation of remnant homestead windbreaks on a small island-A case study of Taketomi Island, Okinawa Prefecture, Japan. Journal of the Japanese Society of Coastal Forest, 18(1):7-12.

245. Chen, B., \& Liang, L. (2019). Old-growth trees in homesteads on the Ryukyu Archipelago, Japan: Uses, Management, and Conservation. Small-scale Forestry, $1-18$.

246. Chen, B. (2016). The state of conservation and management of old Garcinia subelliptica trees: a case study in Aguni Island, Okinawa Prefecture. Journal of the Japanese Society of Coastal Forest, 15(1).

247. Chen, B., \& Nakama, Y. (2015). Residents' preference and willingness to conserve homestead woodlands: Coastal villages in Okinawa Prefecture, Japan.
Urban Forestry \& Urban Greening, 14(4), 919931. doi:10.1016/j.ufug.2015.08.008

248. Chen, B., \& Nakama, Y. (2018). Dimensions and spatial distribution of remnant Garcinia subelliptica tree belts surrounding homesteads in a coastal village: A case study of Shiraho Village, Okinawa Prefecture, Japan. 海 岸林学会誌 [Journal of the Japanese Society of Coastal Forest], 17(1), 11-16.

249. Chen, B., Nakama, Y., \& Urayama, T. (2016). Dimensions and management of remnant Garcinia subelliptica tree belts surrounding homesteads- a case study from two villages in the Sakishima Islands, Okinawa Prefecture, Japan. Journal of the Japanese Society of Coastal Forest, 15(2), 29-36.

250. Chen, B., Nakama, Y., \& Zhang, Y. (2017). Traditional village forest landscapes: Tourists' attitudes and preferences for conservation. Tourism Management, 59, 652-662. doi:10.1016/j.tourman.2016.09.007

251. Gevaña, D. T., Camacho, L. D., \& Camacho, S. C. (2017). Stand density management and blue carbon stock of monospecific mangrove plantation in Bohol, Philippines. Forestry Studies, 66(1), 75-83. doi:10.1515/ fsmu-2017-0008

252. Gevaña, D. T., Camacho, L. D., \& Pulhin, J. M. (2018). Conserving mangroves for their blue carbon: insights and prospects for community-based mangrove management in Southeast Asia. In Threats to Mangrove Forests (pp. 579-588). Springer, Cham. doi:10.1007/9783-319-73016-5_26

253. Liang, L., Yiu, E., Camacho, L., Gevaña, D., Oo, T., Sein, C., ... Nagata, A. (2017). Coastal forest management in the face of global change: Experience of four Asian countries. APN Science Bulletin, 7(1). doi:10.30852/ sb.2017.70

254. Nakama, Y., Kurima, G., \& Chen, B. (2017). A study of sacred site landscape conservation- Fukugi (Garcinia subelliptica) tree cutting and pruning issues in Uchimaudun, Nishihara Town (In Japanese). The Science bulletin of the Faculty of Agriculture, University of the Ryukyus, 61, 1-18.

255. Nakama, Y., Kurima, G., Nakada, E. \& Chen, B. (2018). A study of Utaki (sacred place) forests on Tarama Island, Okinawa Prefecture, Japan (In Japanese). The Science Bulletin of the Faculty of Agriculture, University of the Ryukyus 65, 1-18.

256. Sein, C. C., Oo, T. N., Win, B. N., \& Chen, B. (2015). Assessing different land use pattern and livelihood of the local people in the mangrove area (Case study in Pyapon Township). Global Journal of Wood Science, Forestry and Wildlife, 3(2), 052-058.

257. Chen, B. (2019). Ryukyu fengshui and village landscape (In Japanese). Yoju Shorin, pp. 236.

258. Chen, B, \& Ota, I. (2019). Conservation and utilization of homestead woodlands in Ryukyu Archipelagoresidents' perceptions based on in-depth interviews (In Japanese). In D. Ikegami, Y. Sugimura, Y. Fujita, \& M. Motomura (Eds.), Challenges of Island Studies, 49-66. 
259. Chen, B. (2015). Function of traditional forests for disaster prevention from landscape design perspective. In Toward New Island Studies: Okinawa as an Academic Node Connecting Japan, East Asia, and the Oceania (pp. 67-70). International Institute for Okinawan Studies (IIOS), University of the Ryukyus.

260. Camacho, L., Gevana, D., \& Camacho, S. (2017, April). Economic valuation for sustainable mangrove ecosystems management in the Philippines. Presentation presented at the International Conference on Sustainable Mangrove Ecosystems 2017, Bali, Indonesia.

261. Camacho, S., Gevana, D., \& Camacho, L. (2017, April). Potential costs and benefits of carbon sequestration in mangrove forest in Bohol, Philippines. Poster presented at the International Conference on Sustainable Mangrove Ecosystems 2017, Bali, Indonesia.

262. Gevana, D. T., Camacho, L. D., Camacho, S. C. \& Im, S. (2017). How plant spacing influences survival and sediment carbon stock production: The case of Rhizophora plantation in the Philippines. Paper presented during the 2nd ASEAN Mangrove Congress: Sustainable Management of Mangroves in the Course of Climate Change, Conrad Hotel, Manila, Phil., September 4-8, 2017.

263. Gevana, D., Camacho, L., \& Camacho, S. (2016). Carbon sequestration of mangroves. Presented at the Symposium on Mangroves for Climate Adaptive and Resilient Communities, Waterfront Cebu City Hotel, Lahug, Cebu City, Philippines.

264. Gevana, D., Camacho, L., \& Camacho, S. (2017, April). Stand density management and blue carbon stock potential of Rhizophora stylosa plantation in Bohol, Philippines. Poster presented at the International Conference on Sustainable Mangrove Ecosystems 2017, Bali, Indonesia.

265. Gevana, D., Camacho, L., Camacho, S., \& Im, S. (2016). Reconciling the environment and economic potentials of community-managed mangroves for timber and blue carbon stocks: The case of Bohol, Philippines. Presented at the International Conference on Sustainable Forest Development in view of Climate Change (SDFCC2016), Kuala Lumpur, Malaysia. Conference Proceedings.

266. Gevana, D., Pulhin, J., \& Pulhin, F. (2017, April). Community-based mangrove management in the Philippines: Experiences and challenges of forest governance in the context of climate change. Presentation presented at the International Conference on Sustainable Mangrove Ecosystems 2017, Bali, Indonesia.

\section{Climate Change Adaptation through Optimal Stormwater Capture Measures: Towards a New Paradigm for Urban Water Security}

ARCP2014-20NMY-Mishra, ARCP2015-11CMY-Mishra

267. Mishra, B. K., Chakraborty, S., Kumar, P., \& Saraswat, C. (2020). Sustainable solutions for urban water security:
Innovative studies. Water Science and Technology Library. Springer Nature. doi:10.1007/978-3-030-53110-2

268. Mishra, B., Mansoor, A., Saraswat, C., \& Gautam, A. (2019). Climate change adaptation through optimal stormwater capture measures. APN Science Bulletin, 9(1). doi:10.30852/sb.2019.590

269. Rehan, M. M., Weesakul, S., Chaowiwat, W., \& Charoensukrungruang, W. (2017). Development of design storm pattern with climate change in Monsoon Asia. In Proceeding Report - THA 2017 International Conference on 'Water Management and Climate Change Towards Asia's Water-Energy-Food Nexus' (pp. 46-51). Bangkok, Thailand. Retrieved from http:// aseanacademicnetwork.com/sites/default/files/ report/Proceeding_THA2017.pdf

270. Weesakul, U., Chaowiwat, W., Rehan, M. M., \& Weesakul, S. (2017). Modification of a design storm pattern for urban drainage systems considering the impact of climate change. Engineering and Applied Science Research (EASR), 44(3), 161-169. doi:10.14456/ easr.2017.24

271. Saraswat, C., Kumar, P., \& Mishra, B. K. (2016). Assessment of stormwater runoff management practices and governance under climate change and urbanization: An analysis of Bangkok, Hanoi and Tokyo. Environmental Science \& Policy, 64, 101-117. doi:10.1016/j.envsci.2016.06.018

272. Mansoor, A., Mishra, B. K., \& Herath, S. (2015). Assessing impacts of climate change on rainfall extremes for sustainable stormwater management in Yato Watershed, Tokyo (pp. 213-223). Presented at the International Expert Workshop 'Towards Urban Water Security in Southeast Asia: Managing Risk of Extreme Events', Phnom Penh, Cambodia.

\section{$\square$ Integrated Solid Waste Management System Leading to Zero Waste for Sustainable Resource Utilization in Rapid Urbanized Areas in Developing Countries}

ARCP2014-21NMY-Sharp, ARCP2015-12CMY-Sharp

273. Nguyen, T., Sharp, A., \& Babel, S. (2020). Challenges and opportunities to approach zero waste for municipal solid waste management in Ho Chi Minh City. APN Science Bulletin, 10(1). doi:10.30852/ sb.2020.966

274. Nguyen, T. P. L., Tran, T. M. D., Le, T. K. O., Sharp, A., \& Babel, S. (2019). Possibilities and challenges to approach zero waste for municipal solid waste management in Ho Chi Minh City. In Waste Management and Resource Efficiency: Proceedings of the 6th IconSWM 2016 (p. 980). Kolkata, India: Springer Singapore. 
Assessment of Climate-Induced Long-term Water Availability in Ganges Basin and Impacts on Energy Security in South Asia

ARCP2014-22NMY-Zhou, ARCP2015-13CMY-Zhou

275. Sharp, A., Babel, S., Gyeltshen, T., Pelden, T., \& Dorji, D. (2016). Establishment of integrated solid waste management system in Mongar Town, Bhutan. In Proceedings of Chemical Biological and Environmental Engineering (Vol. 92, pp. 98-102). Hong Kong.

276. Mitra, B. K., Zhou, X., Sharma, D., Jhonson, B., \& Herran, D. S. (2018). Integrating spatial variability of water resources in long-term power infrastructure planning: An illustration from Ganga River Basin. Paper presented at Nexus 2018: Water, Energy Food and Climate, 16-18 April 2018, North Carolina.

277. Mitra, B. K. (2018). Tracing synergies and trade-offs across water-energy nexus: Practical benefits and challenges. Presentation at the Symposium on Towards Sustainable Development of Semi-arid Area in India: From the View Point of Food-Water-Energy Nexus. 21 December, Aoyama Gakuin University, Tokyo.

278. Mitra, B. K., Zhou, X., \& Islam, G. M. T. (2018). Managing water-energy nexus for sustainable power infrastructure planning in Bangladesh. Presentation at the Workshop on Harnessing of Climate-Water-Energy Nexus for Resource Security in the Ganges River Basin, 18 November 2018, Bangladesh University of Technology, Dhaka.

279. Islam, G. M. T., Mitra, B. K., Zhou, X., \& Hosain, M. S. (2018). Water resource availability in Ganga basin of Bangladesh. Presentation at the Workshop on Harnessing of Climate-Water-Energy Nexus for Resource Security in the Ganges River Basin, 18 November 2018, Bangladesh University of Technology, Dhaka.

280. Mitra, B. K., Zhou, X., Sharma, D., Jhonson, B., \& Herran, D. S. (2018). Impact of spatial variability of water supply and demand on sustainability of thermal power generation in four sub-basins of Ganga. Presentation at the Workshop on Harnessing of Climate-Water-Energy Nexus for Resource Security in the Ganges River Basin, 20 November 2018, Central University of Rajasthan, India.

281. Sharma, D., Mitra, B. K., \& Zhou, X. (2018). Water availability in selected sub-basins of Ganga. Presentation at the Workshop on Harnessing of Climate-Water-Energy Nexus for Resource Security in the Ganges River Basin, 20 November 2018, Central University of Rajasthan, India.

282. Zhou, X., Mitra, B., Harma, D., Islam, G., Malla, R., \& Herran, D. (2019). An integrated assessment of climateaffected longterm water availability and its impacts on energy security in the Ganges subbasins. APN Science Bulletin, 9(1). doi:10.30852/ sb.2019.612
Scoping Workshop to Develop Proposal: Assessing the Health Effects of Extreme Temperatures and the Development of Adaptation Strategies to Climate Change in the Asia Pacific Region

ARCP2014-23NSG-Huang

283. Huang, C., A. Barnett, X. Wang, C. Chu. (2015). Scoping workshop to develop proposal: assessing the health effects of extreme temperatures and the development of adaptation strategies to climate change in the AsiaPacific region. In J. Boonjawat, L.A. Stevenson, \& L. Tupas (Eds.), APN Science Bulletin (5). Retrieved from https://www.apn-gcr.org/resources/files/original/ d00f4b82600b7c089e042d2170357f78.pdf

284. Huang, C., Chu, C., Wang, X., \& Barnett, A. G. (2015). Unusually cold and dry winters increase mortality in Australia. Environmental Research, 136, 1-7. doi:10.1016/j.envres.2014.08.046

$\square$ Scoping Workshop to Develop Proposal: Identification of the best agricultural management practices with better greenhouse gas benefits in salinity affected areas of South Asia

ARCP2014-24NSG-Lokupitiya

285. Lokupitiya, E., Agrawal, M., Ahamed, T., Pandey, D., Mustafa, N., \& Paustian, K. (2015). Scoping workshop to develop proposal: Identification of the best agricultural management practices with better GHG benefits in salinity-affected areas of South Asia. In J. Boonjawat, L.A. Stevenson, \& L. Tupas, (Eds.), APN Science Bulletin (5). Retrieved from https://www.apn-gcr.org/resources/files/original/ d00f4b82600b7c089e042d2170357f78.pdf

\section{$\square$ Risk and Resilience in the Pacific: Influence of Peripherality on Exposure and Responses to Global Change}

CRRP2016-03MY-Nunn

286. Fink, M., Klöck, C., Korovulavula, I., \& Nunn, P. D. (in review). Community participation situated knowledge and climate change (mal-)adaptation in rural island communities: evidence from artificial shorelineprotection structures in Fiji. In S. Moncada, L. Briguglio, H. Bambrick, I. Kelman, C. Iorns, \& L. Nurse (Eds.), Climate Change and Development in Small Island Developing States. Berlin: Springer.

287. Klöck, C., \& Nunn, P. D. (2019). Adaptation to climate change in Small Island Developing States: A systematic literature review of academic research. The Journal of Environment \& Development, 28(2), 196-218. doi:10.1177/1070496519835895

288. Korovulavula, I., Nunn, P. D., Kumar, R., \& Fong, T. (2019). Peripherality as key to understanding opportunities and needs for effective and sustainable climate-change adaptation: A case study from Viti Levu Island, Fiji. Climate and Development, 1-11. doi:10.1080 /17565529.2019.1701972 
289. Martin, P. C. M., Nunn, P. D., Leon, J., \& Tindale, N. (2018). Responding to multiple climate-linked stressors in a remote island context: the example of Yadua Island, Fiji. Climate Risk Management, 21, 7-15. doi:10.1016/j.crm.2018.04.003

290. Nunn, P. (2017, May 17). Sidelining God: why secular climate projects in the Pacific Islands are failing. The Conversation. Retrieved from http://theconversation. com/sidelining-god-why-secular-climate-projects-inthe-pacific-islands-are-failing-77623

291. Nunn, P., Joseph, E., Korovulavula, I., \& Kumar, R. (2019). Peripherality as key to understanding climateassociated risk and resilience for Pacific island communities. APN Science Bulletin, 9(1). doi:10.30852/ sb.2019.888

292. Nunn, P. D., \& Kumar, R. (2018). Understanding climatehuman interactions in Small Island Developing States (SIDS): implications for future livelihood sustainability. International Journal of Climate Change Strategies and Management, 10(2), 245-271. doi:10.1108/ IJCCSM-01-2017-0012

293. Nunn, P. D., \& Kumar, R. (2019). Cashless adaptation to climate change: Unwelcome yet unavoidable? One Earth, 1(1), 31-34. doi:10.1016/j.oneear.2019.08.004

294. Nunn, P.D. \& McNamara, K.E. (2019). Failing adaptation in island contexts: the growing need for transformational change. In C. Klöck, \& M. Fink (Eds.), Dealing with Climate Change on Small Islands: Towards Effective and Sustainable Adaptation? Göttingen: Göttingen University Press, pp 19-44.

295. Nunn, P. D., McLean, R. F., Dean, A., Fong, T., lese, V., Katonivualiku, M., ... Tabe, T. (2020). Adaptation to climate change: contemporary challenges and perspectives. In L. Kumar (Ed.), Climate Change and Impacts in the South Pacific. doi:10.1007/978-3-03032878-8

296. Nunn, P., \& Kumar, R. (2017, March). Through the lens of peripherality: climate-driven changes to ecosystem services for communities in Bua, western Vanua Levu Island (Fiji). Presented at the Oceania Ecosystem Services Forum, Brisbane, Australia. Retrieved from https://oceaniaecosystemservicesforum.files. wordpress.com/2016/07/nunn-oceaniaesforum20min. pdf

297. Nunn, P.D., \& Kumar, R. (2019). Measuring peripherality as a proxy for autonomous community coping capacity: a case study from Bua Province, Fiji Islands, for improving climate change adaptation. Social Sciences, 8, \#225. doi:10.3390/socsci8080225

298. Piggott-McKellar, A., McNamara, K. E., Nunn, P. D., \& Sekinini, S. (2019). Moving people in a changing climate: lessons from two case studies in Fiji. Social Sciences, 8, \#133. doi:10.1080/13549839.2019.1580688

299. Piggott-McKellar, A., McNamara, K., Nunn, P. D., \& Watson, J. (2019). What are the barriers to successful community-based climate change adaptation? A review of grey literature. Local Environment. doi:10.1080/13549839.2019.1580688
300. Nunn, P.D. (2017). Sustaining ecosystem services under a changing climate: an agenda for younger people. Keynote Address, Oceania Ecosystem Services Forum, Brisbane, Australia.

301. Nunn, P.D., \& Kumar, R. (2017). Through the lens of peripherality: climate-driven changes to ecosystem services for communities in Bua, western Vanua Levu Island (Fiji). Oceania Ecosystem Services Forum, Brisbane, Australia.

302. Nunn, P.D., \& Kumar, R. (2017). Capturing community diversity for adaptation in the Pacific Islands: the role of peripherality. 11th Conference of the European Society for Oceanists, Munich, Germany.

303. Nunn, P.D., \& Betzold, C. (2017). False promises: seawalls as maladaptations throughout the rural Pacific Islands. 11th Conference of the European Society for Oceanists, Munich, Germany.

304. Nunn, P.D. (2017). Maladaptation in Pacific Island countries: why the widespread and sustained failure of externally-sponsored interventions for climate-change adaptation in rural communities? Institute of Australian Geographers' Conference, University of Queensland.

305. Nunn, P.D. (2018). Climate-Human Interactions in Fiji. Ministry of iTaukei (Indigenous) Affairs, Government of Fiji, Suva.

306. Nunn, P.D. (2018). Améliorer la préparation aux catastrophes et l'adaptation au changement climatique en Australie et dans les îles du Pacifique: le rôle des histoires anciennes (Improving disaster preparedness and climate-change adaptation in Australia and the Pacific Islands: the role of ancient stories). Faculté des Lettres, Langues et Sciences humaines, Université du Maine, France.

307. Nunn, P.D. (2018). Changements côtiers Holocènes rappelés dans les histoires anciennes: exemples de l'Australie, du Pacifique Sud-Ouest et du Nord-Ouest de la France (Holocene coastal change recalled in ancient stories: examples from Australia, the Southwest Pacific, and Northwest France). Faculté des Lettres et Langages, Université de Nantes, France.

308. Nunn, P.D. (2018). Barriers have two sides: the challenges of transformational adaptation in island contexts. Keynote Speech, Adaptation Futures 2018, Cape Town, South Africa [June 2018].

309. Nunn, P.D. (2018). Failing adaptation in island contexts: the growing need for transformational change. Opening Keynote Address, Symposium on Dealing with Climate Change on Small Islands, Hannover, Germany.

310. Nunn, P.D. (2018). Improving the effectiveness and sustainability of climate-change adaptation outcomes in the Pacific Islands: A role for faith-engaged approaches? Griffith University Climate Change Response Program (Gold Coast Campus), Australia .

311. Nunn, P.D. (2018). Climate change and faith in the Pacific Islands. Griffith University, Multi-Faith Centre (Nathan Campus), Australia. 
312. Nunn, P.D., \& Kumar, R. (2019). Climate-human interactions in the Federated States of Micronesia. Public Talk, Conservation Society of Pohnpei, Pohnpei, Federated States of Micronesia.

313. Nunn, P.D. (2019). Is Policy Necessary? A climate scientist's reflections on climate-driven relocations in the Pacific Islands. Monash University Centre for Commercial Law and Regulatory Studies, Melbourne, Australia.

314. Lykins, A., Kumar, R., \& Nunn, P.D. (2017). Climate change and mental health in rural Fiji (Southwest Pacific). University of the Sunshine Coast, USC Research Showcase (July 2017).

315. Nunn, P.D. (2017). Harnessing spiritual wellbeing for effective climate-change adaptation in Pacific Islands. University of the Sunshine Coast, USC Research Showcase (July 2017).

316. Nunn, P.D. (2017). Underestimating God: spiritual beliefs and climate-change adaptation in the Pacific ... and the pitfalls of ignoring them. Institute of Australian Geographers' Conference, University of Queensland.

317. Scott-Parker, B., \& Kumar, R. (2017). Fiji adolescents understanding of climate change: the importance of bringing it closer to scientific projections. Institute of Australian Geographers' Conference, University of Queensland.

\section{$\square$ Assessing Land Use Functions for Sustainable Land Management in Asian Countries \\ CRRP2016-04MY-Zhen}

318. Miah, M. G., Rahman, M. M., Rahman, M. A., \& Abdullah, H. M. (2018). Land use functions assessment for sustainable land management: A case study in Barind Tract of Bangladesh. Annals of Bangladesh Agriculture, 22(1): 1-16.

319. Shoyama, K. Xue, Z., Zhen, L. \& Miah, M. G. (2020). Sustainable land management in Asia: Applying a land-use function approach (UNU-IAS Policy Brief No. 20). Retrieved from https://ias.unu.edu/en/ news/news/policy-brief-provides-approaches-andrecommendations-for-sustainable-land-managementin-asia.html

320. Shoyama, K., Kamiyama, C., Morimoto, J., Ooba, M., \& Okuro, T. (2017). A review of modeling approaches for ecosystem services assessment in the Asian region. Ecosystem Services, 26, 316-328. doi:10.1016/j. ecoser.2017.03.013

321. Shoyama, K., Matsui, T., Hashimoto, S., Kabaya, K., Oono, A., \& Saito, O. (2019). Development of landuse scenarios using vegetation inventories in Japan. Sustainability Science, 14(1), 39-52. doi:10.1007/ s11625-018-0617-7

322. Xue, Z. \& Zhen, L. (2019). Factors affecting farmers choice of abandoning agricultural land in loess hilly and gully region: A case study in Guyuan, Western China. Environmental Development. (Under revision).
323. Xue, Z., \& Zhen, L. (2018). Impact of rural land transfer on land use functions in western China's Guyuan based on a multi-level stakeholder assessment framework. Sustainability, 10(5), 1376. doi:10.3390/su10051376

324. Xue, Z., Zhen, L., Miah, M. G., \& Shoyama, K. (2019). Impact assessment of land use functions on the sustainable regional development of representative Asian countries-A comparative study in Bangladesh, China and Japan. Science of The Total Environment, 133689. doi:10.1016/j.scitotenv.2019.133689

325. Zhichao, X. \& Lin, Z. (2019). Simulating spatiotemporal changes in land-use functions in Guyuan, China, using an agent-based model dependent on multi-level stakeholder participation. APN Science Bulletin 9(1). doi:10.30852/sb.2019.705

\section{Managing Organic Amendments to Reduce Greenhouse Gas Emissions and Supplement Fertiliser Nitrogen Inputs in Tropical Indian and Sri Lankan Agricultural Soils}

CRRP2016-05MY-Rowlings

326. Liyanage, A., Grace, P.R., Rowlings, D.W., \& Scheer, C. (2016). Influence of nitrogen fertilizer and compost mix application on greenhouse gas emissions from humid subtropical soils. In Proceedings of the 2016 International Nitrogen Initiative Conference, "Solutions to improve nitrogen use efficiency for the world", 4-8 December 2016, Melbourne, Australia. Retrieved from http://www.ini2016.com/1837

327. Rowlings, D., Liyanage, A., Kholova, J., Jagadabhi, S., Ranwala, S., \& Whitbread, A. (2019). Developing an economic, environmental and agronomic case for the increased use of organic amendments in South Asia. APN Science Bulletin, 9(1). doi:10.30852/ sb. 2019.780

328. Thornton, P.K., Whitbread, A., Baedeker, T., Cairns, J., Claessens, L., Baethgen, W., ... Keating, B. (2018). Ex-ante priority setting for climate-smart agriculture research. Agricultural Systems 167, 161175. doi:10.1016/j.agsy.2018.09.009

\section{$\square$ Development of new water supply strategies in two major cities of India and Sri Lanka in the context of climate change, rapid urbanization and population growth: a vulnerability assessment approach}

CRRP2016-06MY-Kumar

329. Kumar, M., Chaminda, C.G.T. \& Honda, R. (2020). Seasonality impels the antibiotic resistance in Kelani River of the emerging economy of Sri Lanka. Clean Water, 3(12). doi:10.1038/s41545-020-0058-6

330. Gogoi, A., Mazumder, P., Tyagi, V. K., Chaminda, G. T., An, A. K., \& Kumar, M. (2018). Occurrence and fate of emerging contaminants in water environment: A review. Groundwater for Sustainable Development, 6 , 169-180. doi:10.1016/j.gsd.2017.12.009 
331. Kumar, M., Chaminda, T., Honda, R., \& Furumai, H. (2019). Vulnerability of urban waters to emerging contaminants in India and Sri Lanka: Resilience framework and strategy. APN Science Bulletin, 9(1). doi:10.30852/sb.2019.799

332. Kumar, M., Jain, V., Yamanaka, T., Li, Y., \& Bhattacharya, P. (2018). Contaminant transport and fate in freshwater systems - Integrating the fields of geochemistry, geomorphology and nanotechnology. Groundwater for Sustainable Development, 7, 336-342. doi:10.1016/j. gsd.2018.09.001

333. Patel, A. K., Das, N., \& Kumar, M. (2019). Multilayer arsenic mobilization and multimetal co-enrichment in the alluvium (Brahmaputra) plains of India: A tale of redox domination along the depth. Chemosphere, 224, 140-150. doi:10.1016/j.chemosphere.2019.02.097

334. Taki, K., Gogoi, A., Mazumder, P., Bhattacharya, S. S., \& Kumar, M. (2019). Efficacy of vermitechnology integration with Upflow Anaerobic Sludge Blanket (UASB) and activated sludge for metal stabilization: A compliance study on fractionation and biosorption. Journal of environmental management, 236, 603-612. doi:10.1016/j.jenvman.2019.01.006

335. Kumar, M., Ram, B., Honda, R., Poopipattana, C., Canh, V. D., Chaminda, T., \& Furumai, H. (2019). Concurrence of antibiotic resistant bacteria (ARB), viruses, pharmaceuticals and personal care products (PPCPs) in ambient waters of Guwahati, India: Urban vulnerability and resilience perspective. Science of The Total Environment, 133640. doi:10.1016/j. scitotenv.2019.133640

336. Das, A., Gupta, A.K., Mazumder, P., \& Kumar, M. (2018, March 15). A water quality sustainability strategy for Brahmaputra and Kelani rivers through health risk assessment and identification of spatial distribution of nutrient, heavy metal and antibiotic resistant bacteria. In Conference Proceeding of 6th International Symposium on "Advances in Civil and Environmental Engineering Practices for Sustainable Development" (ACEPS-2018), pp: 93-97, ISSN: 2279-1329, Galle, Sri Lanka.

337. Gupta, O. \& Kumar, M (2018, March 15). Climate governance and sustainability, climate proofing and water resilience of Guwahati City. In Conference Proceeding of 6th International Symposium on "Advances in Civil and Environmental Engineering Practices for Sustainable Development” (ACEPS-2018), ISSN: 2279-1329, Galle, Sri Lanka.

338. Kehelella, K.H., Chaminda, G.G.T., Silva, G.H., Honda, R. \& Kumar, M. (2018, March 15). Water quality modeling in Kelani river downstream. In Conference Proceeding of 6th International Symposium on "Advances in Civil and Environmental Engineering Practices for Sustainable Development" (ACEPS-2018), pp: 104-109, ISSN: 2279-1329, Galle, Sri Lanka.

339. Kumar, A., \& Kumar, M (2018, December 13 - 15). Mobility of arsenic and the potential for co-occurrence in sediments of three upper bank tributaries of the Brahmaputra river in Lakhimpur, Assam, India. Paper presented at the 20th National Symposium on Environment, IIT Gandhinagar. Proceedings of Twentieth National Symposium on Environment, pp 317.

340. Kumar, M. Lee, S. A., Upadhyay, R. \& Furumai, H. (2018, March 15). Climate change reproduction by Global Climate Model using models CSIRO-Mk and MIROC5: A case study of Brahmaputra River watershed. In Conference Proceeding of 6th International Symposium on "Advances in Civil and Environmental Engineering Practices for Sustainable Development" (ACEPS-2018), ISSN: 2279-1329, Galle, Sri Lanka.

341. Patel, A. K., Das, N. \& Kumar, M. (2018, December 1315). A comparative health risk assessment due to arsenic contaminated water in the Ganga and the Brahmaputra floodplain, India. Paper presented at the 20th National Symposium on Environment, IIT Gandhinagar. Proceedings of Twentieth National Symposium on Environment, pp 313- 314.

342. Patel, A.K., Goswami, R. \& Kumar, M. (2018, March 15). Evaluation of groundwater quality with emphasis on Arsenic and fluoride concentration in Guwahati: Economic hub of Northeast India. In Conference Proceeding of 6th International Symposium on "Advances in Civil and Environmental Engineering Practices for Sustainable Development" (ACEPS-2018), pp: 87-91, ISSN: 2279-1329, Galle, Sri Lanka.

343. Singh, A. \& Kumar, M. (2018, December 13 - 15). Estimation of surface temperature of Sahibi River in Alwar, Rajasthan using thermal band of LANDSAT 8 satellite as a mean for assessing the variation in Dissolved Oxygen (DO) along the reach. Paper presented at the 20th National Symposium on Environment, IIT Gandhinagar. Proceedings of Twentieth National Symposium on Environment, pp 107-108.

344. Somartha, R.P., Silva, G.H., Chaminda, G.G.T., Weragoda, S.K. \& Kumar, M. (2018, March 15). Identifying groundwater recharge zones through MIKE modeling approach: a case study at mid Kelani river, Sri Lanka. In Conference Proceeding of 6th International Symposium on "Advances in Civil and Environmental Engineering Practices for Sustainable Development" (ACEPS-2018), pp: 247-254, ISSN: 2279-1329, Galle, Sri Lanka.

345. Upadhyay, R. \& Kumar, M. (2018, March 15). Microplastic and heavy evaluation in the riverbed sediment of Sabarmati River Gujarat, India and Kelani River Sri Lanka. In Conference Proceeding of 6th International Symposium on "Advances in Civil and Environmental Engineering Practices for Sustainable Development" (ACEPS-2018), ISSN: 2279-1329, Galle, Sri Lanka.

\section{Appropriate Solid Waste Management Towards Flood Risk Reduction Through Recovery of Drainage Function in Tropical Asian Urban Cities}

\section{CRRP2016-07MY-Ishigaki}

346. Nakamura, K., Noppharit, S., Ishigaki, T., Yamada, M., \& Thaweesub, R. (2018). Chart Chiemchaisri, Numerical dynamic model on canal clogging by waste 
(in Japanese), Spring Conference of Japan Society of Material Cycles and Waste Management.

347. Nakamura, K., Thaweesub, R., Noppharit, S., Chiemchaisri, C., Ishigaki, T., \& Yamada, M. (2018). Solid debris composition analysis for numerical model of canal clogging, Spring Conference of Korean Society of Waste Management.

348. Ishigaki, T. (2018). Situation of construction waste management generated in public works in Bangkok Metropolitan Administration (in Japanese), 2018 Symposium on Recycling of Construction Waste and Byproducts.

349. Ishigaki, T., Thaweesub, R., Kubota, R., Tajima, R., Lieu, P. K., \& Chiemchaisri, C. (2018). Investigation on solid debris in urban drainage system in tropical Asian cities. In Proceedings of the Annual Conference of Japan Society of Material Cycles and Waste Management The 29th Annual Conference of Japan Society of Material Cycles and Waste Management (p. 541). Japan Society of Material Cycles and Waste Management.

350. Tajima, R., Kubota, R., Tin, H. C., Jarusombat, S., Janamporn, S., \& Ishigaki, T., (2018). Factors related to waste disposal behavior of residents near canals, ISWA World Congress 2018.

\section{$\square$ Assessing the health effects of extreme temperatures and the development of adaptation strategies to climate change in the Asia-Pacific region}

CRRP2016-10MY-Huang

351. Bao, J., Guo, Y., Wang, Q., He, Y., Ma, R., Hua, J., . . . Huang, C. (2019). Effects of heat on first-ever strokes and the effect modification of atmospheric pressure: A time-series study in Shenzhen, China. Science of The Total Environment, 654, 1372-1378. doi:10.1016/j. scitotenv.2018.11.101

352. Cheng, L., \& Huang, C. (2019). Assessing the health effects of extreme temperature and development of adaptation strategies to climate change in selected countries in the Asia-Pacific region. APN Science Bulletin, 9(1). doi:10.30852/sb.2019.854

353. Dang, T. N., Honda, Y., Van Do, D., Pham, A. L. T., Chu, C., Huang, C., \& Phung, D. (2019). Effects of extreme temperatures on mortality and hospitalization in Ho Chi Minh City, Vietnam. International journal of environmental research and public health, 16(3), 432. doi:10.3390/ijerph16030432

354. He, Y., Ma, R., Ren, M., Liao, W., Zhang, N., Su, Y., ... Huang, C. (2019). Public health adaptation to heat waves in response to climate change in China. In Ambient Temperature and Health in China (pp. 171-190). Springer, Singapore. doi:10.1007/978-981-132583-0_11

355. Liao, W., Yang, L., Zhong, S., Hess, J. J., Wang, Q., Bao, J., \& Huang, C. (2019). Preparing the next generation of health professionals to tackle climate change: Are China's medical students ready?. Environmental research, 168, 270-277. doi:10.1016/j.

envres.2018.10.006

356. Liu, T., Ren, Z., Zhang, Y., Feng, B., Lin, H., Xiao, J., ... Xu, Y. (2019). Modification effects of population expansion, ageing, and adaptation on heat-related mortality risks under different climate change scenarios in Guangzhou, China. International journal of environmental research and public health, 16(3), 376. doi:10.3390/ijerph16030376

357. Ma, R., Zhong, S., Morabito, M., Hajat, S., Xu, Z., He, Y., ... Huang, C. (2019). Estimation of workrelated injury and economic burden attributable to heat stress in Guangzhou, China. Science of the total environment, 666, 147-154. doi:10.1016/j. scitotenv.2019.02.201

358. Wang, Q., Liang, Q., Li, C., Ren, M., Lin, S., Knibbs, L. D., ...Wang, X. (2019). Interaction of air pollutants and meteorological factors on birth weight in Shenzhen, China. Epidemiology, 30, S57-S66. doi:10.1097/ EDE.0000000000000999

359. Sheng, R., Li, C., Wang, Q., Yang, L., Bao, J., Wang, K., ... Bi, P. (2018). Does hot weather affect workrelated injury? A case-crossover study in Guangzhou, China. International journal of hygiene and environmental health, 221(3), 423-428. doi:10.1016/j. ijheh.2018.01.005

360. Huang, C., Cheng, J., Phung, D., Tawatsupa, B., Hu, W., \& Xu, Z. (2018). Mortality burden attributable to heatwaves in Thailand: A systematic assessment incorporating evidence-based lag structure. Environment international, 121, 41-50. doi:10.1016/j.envint.2018.08.058

361. Phung, D., Chu, C., Tran, D. N., \& Huang, C. (2018). Spatial variation of heat-related morbidity: A hierarchical Bayesian analysis in multiple districts of the Mekong Delta Region. Science of the Total Environment, 637, 1559-1565. doi:10.1016/j. scitotenv.2018.05.131

362. Phung, D., Chu, C., Rutherford, S., Nguyen, H. L. T., Do, C. M., \& Huang, C. (2017). Heatwave and risk of hospitalization: A multi-province study in Vietnam. Environmental Pollution, 220, 597-607. doi:10.1016/j. envpol.2016.10.008

363. Wang, Q., Li, C., Guo, Y., Barnett, A. G., Tong, S., Phung, D., ... Huang, C. (2017). Environmental ambient temperature and blood pressure in adults: A systematic review and meta-analysis. Science of The Total Environment, 575, 276-286. doi:10.1016/j. scitotenv.2016.10.019

364. Zeng, J., Zhang, X., Yang, J., Bao, J., Xiang, H., Dear, K., ... Huang, C. (2017). Humidity may modify the relationship between temperature and cardiovascular mortality in Zhejiang Province, China. International journal of environmental research and public health, 14(11), 1383. doi:10.3390/ijerph14111383

365. Li, C., Wang, Q., Bao, J., Zhao, Q., \& Huang, C. (2017, September). Temperature variability may trigger spontaneous early delivery in Shenzhen, China: A case- 
crossover study. Oral presentation presented at the 29th Annual Scientific Conference of the International Society of Environmental Epidemiology, Sydney, Australia. doi:10.1289/isee.2017.2017-643

366. Sheng, R., \& Huang, C. (2017, September). Association between high temperature and work-related injuries in Guangzhou, China. Oral presentation presented at the 21st International Congress of Biometeorology, Durham, UK. doi:10.1136/oemed-2017-104636.80

367. Wang, K., \& Huang, C. (2016, October). Impact of urban climate on dengue transmission: A Review. Poster presented at the Second Annual Conference of Chinese Consortium of Universities for Global Health, Guangzhou, China.

368. Wang, Q., Li, C., \& Huang, C. (2017, September). Interaction of PM10 and relative humidity on birth outcomes in Shenzhen, China. Poster presented at the 29th Annual Scientific Conference of the International Society of Environmental Epidemiology, Sydney, Australia.

369. Zeng, J., \& Huang, C. (2017, May). Humidity may modify the relationship between temperature and cardiovascular mortality in Zhejiang Province, China. Oral presentation presented at the 3rd International Conference on Environmental Pollution and Health, Guangzhou, China.

\section{Understanding the opportunities and challenges of compliance to safe building codes for disaster resilience in South Asia - the cases of Bangladesh and Nepal \\ CRRP2017-09SY-Ahmed}

370. Ahmed, I., Gajendran, T., Brewer, G., Maund, K., von Meding, J., \& MacKee, J. (2018). Compliance to building codes for disaster resilience: Bangladesh and Nepal. Procedia Engineering, 212, 986-993. doi:10.1016/j. proeng.2018.01.127

371. Ahmed, I., Gajendran, T., Brewer, G., Maund, K., von Meding, J., \& Ahmed, E. (2018). APN/UON: Building codes for disaster resilience, Bangladesh \& Nepal. [Video File]. Retrieved from https://www.youtube.com/ watch?v=apZ-y1nYRxY

372. Ahmed, I., Gajendran, T., Brewer, G., Maund, K., Von Meding, J., Kabir, H., \& Sitoula, N. (2019). Opportunities and challenges of compliance to safe building codes: Bangladesh and Nepal. APN Science Bulletin, 9(1). doi:10.30852/sb.2019.834

\section{CAPACITY DEVELOPMENT PROGRAMME (CAPaBLE)}

Building Scientific Capacity in Seasonal Climate Forecasting (SCF) for Improved Risk Management Decisions in a Changing Climate

CBA2012-01CMY-Abawi, CBA2011-07NMY-Abawi

373. Abawi, Y., \& White, S. (2013). Identifying key climate drivers in Southeast Asia to improve climate forecasting and risk management decision-making. APN Science Bulletin, 3(March 2013), 130-132. Retrieved from https://www.apn-gcr.org/resources/files/ original/6af921c4ebfdcc24991a0c7f98e287cb.pdf

\section{Impact of Climate Change on Glacier Melting and Water Cycle Variability in Asian River Basins}

CBA2012-03NMY-Rasul, CBA2013-01CMY-Rasul

374. Bhatti, A. M., Koike, T., Jaranilla-Sanchez, P. A., Rasmy, M., Yoshimura, K., \& Ahmad, B. (2014). Climate change impact assessment on the hydrology of a semi-arid river basin. Journal of Japan Society of Civil Engineers, Ser. B1 (Hydraulic Engineering), 70(4). doi:10.2208/ jscejhe.70.i_121

Global Environmental Change and Human Health: Extreme Events and Urbanization in the APN Region

CBA2012-09NMY-Hashim, CBA2013-02CMY-Hashim

375. Hashim, J. H., \& Hashim, Z. (2016). Climate change, extreme weather events, and human health implications in the Asia Pacific Region. AsiaPacific Journal of Public Health, 28(2 Suppl). doi:10.1177/1010539515599030

376. Hashim, J. H., \& Hashim, Z. (2014). Global environmental change and human health [Video file]. Retrieved from https://www.youtube.com/ watch?v=GrRNEunQwWU

ACRE SE Asia - Towards New Weather and Climate Baselines for Assessing Weather and Climate Extremes, Impacts and Risks over SE Asia

CBA2013-03NMY-D'Arrigo, CBA2014-01CMY-D'Arrigo

377. Allan, R., Endfield, G., Damodaran, V., Adamson, G., Hannaford, M., Carroll, F., ... Hendy, E. (2016). Toward integrated historical climate research: the example of Atmospheric Circulation Reconstructions over the Earth. Wiley Interdisciplinary Reviews: Climate Change, 7(2), 164-174. doi:10.1002/wcc.379

378. D’Arrigo, R., \& Ummenhofer, C. C. (2015). The climate of Myanmar: evidence for effects of the Pacific Decadal Oscillation. International Journal of Climatology, 35(4), 634-640. doi:10.1002/joc.3995

379. D’Arrigo, R., Davi, N., Jacoby, G., Wilson, R., \& Wiles, G. (2014). Dendroclimatic Studies: Tree Growth and Climate Change in Northern Forests. John Wiley \& Sons. 
380. Williamson, F. (2015). History and climate science: A collaborative relationship for the twenty-first century. e-Bangi, 12(4).

381. Williamson, F. (2015). Weathering the empire: meteorological research in the early British straits settlements. The British Journal for the History of Science, 48(3), 475-492. doi:10.1017/ S000708741500028X

382. Williamson, F., Allan, R., Switzer, A. D., Chan, J. C., Wasson, R. J., D’Arrigo, R., \& Gartner, R. (2015). New directions in hydro-climatic histories: observational data recovery, proxy records and the atmospheric circulation reconstructions over the earth (ACRE) initiative in Southeast Asia. Geoscience Letters, 2(1), 1-12. doi:10.1186/s40562-015-0018-z

383. Allan, R. \& ACRE (2015). Introduction, 8th Annual ACRE Workshop. University of Santiago, Chile, October 2015.

384. Allan, R., ACRE, INDARE, \& GFCS (2015). 8th Annual ACRE Workshop, University of Santiago, Chile, October 2015.

385. D’Arrigo, R. \& MADA (2015). Monsoon Asia Tree-Ring Data Network (MADA), 8th Annual ACRE Workshop, University of Santiago, Chile, October 2015.

386. Williamson, F. (2015). ACRE Southeast Asia: Regional data recovery and linkages. 8th Annual ACRE Workshop, University of Santiago, Chile, October 2015.

\section{$\square$ International Conference on Regional Climate CORDEX 2013 \\ CBA2013-04NSY-WCRP}

387. WCRP CORDEX. (2013). International Conference on Regional Climate - CORDEX 2013. Retrieved from http:// wcrp.ipsl.jussieu.fr/cordex2013/index.shtml

\section{Enhancing the Groundwater Management} Capacity in Asian Cities through the Development and Application of Groundwater Sustainability Index in the Context of Global Change

CBA2013-06NSY-Shrestha

388. Shrestha, S., Pandey, V., Thatikonda, S., \& Shivakoti, B. (2016). Groundwater Environment in Asian Cities (1st ed.). Elsevier. doi:10.1016/C2014-0-02217-4

Building Capacity for Socio-Ecological Resilience to Coral Bleaching Events in Indonesia, Malaysia, and Thailand

CBA2013-09NSY-Pascoe

389. Pascoe, S., Doshi, A., Thébaud, O., Thomas, C. R., Schuttenberg, H. Z., Heron, S. F., ... Calgaro, E. (2014). Estimating the potential impact of entry fees for marine parks on dive tourism in South East Asia. Marine Policy, 47, 147-152. doi:10.1016/j. marpol.2014.02.017
Promoting the Sustainability Science in Monsoon Asian Region

CBA2013-12NSY-MAIRS

390. MAIRS. (2014). Program of MAIRS Open Science Conference, April 7-10 2014, Beijing, China, 64pp. Retrieved from https://www.apn-gcr.org/resources/ items/show/1907

391. MAIRS. (2014). Abstracts of MAIRS Open Science Conference, April 7-10 2014, Beijing, China, 263pp. Retrieved from https://www.apn-gcr.org/resources/ items/show/1907

Building Capacity for Adaptive Governance through Participatory Modelling: Rural and Urban Flooding in India

CBA2013-13NSY-Varma

392. Varma, N., Kelkar, U., Bhardwaj, S., Singh, P., \& Mishra, A. (2014). Climate change, disasters and development: Testing the waters for adaptive governance in India. Vision: The Journal of Business Perspective, 18(4), 327-338. doi:10.1177/0972262914551664

393. Varma, N. (2014). Towards adaptive governance of flood risks in India: Enabling shared vision [Policy Brief]. The Energy and Resources Institute. Retrieved from https://www.apn-gcr.org/resources/files/ original/200fab1885d6494e1189ed9bba52291b.pdf

Strengthening the Capability of Colleges of Agriculture in Incorporating Food and Water Security and Climate Change and Climate Variability into Curricular Programmes, Research and Extension Projects and Teaching Modules CBA2013-16NSY-Dargantes

394. Dargantes, B.B., Maas, A., Suharnoto, Y.,Wibowo, A., Ek, S., Huon, T., \& Batistel, C. (2014). University initiatives for food and water security in a changing climate. APN Science Bulletin (4), 177-180. Retrieved from https:// www.apn-gcr.org/resources/items/show/1932

Promoting Algaculture in Trapped Waters as Sustainable Aquafarming and Adaptive Climate Mitigation in Inundated Coastal Areas

CBA2013-14NSY-Maity

395. SAFE, \& CIFRI. (2014). Mitigation and adaptation strategies in WETLANDS A Community leadership perspective: extended abstracts (pp. 1-88). Retrieved from https://www.apn-gcr.org/resources/files/ original/393c3363baef1c4486f7daa471e005cb.pdf

Building Capacity on Marine Litter Management in the NOWPAP (Northwest Pacific Action Plan) Region

CBA2013-15NSY-Heinrich-Sanchez

396. Okinawa O.C.E.A.N. (2014, May 22). Over 12 million pounds of trash collected during international coastal 
cleanup. Japan Update. Retrieved from http://www. japanupdate.com/2014/05/over-12-million-pounds-oftrash-collected-during-international-coastal-cleanup/

\section{Capacity Building for Conservation of Biodiversity and Ecosystem Services of Wetlands in Relation to Global Change}

CBA2014-05NSY(B\&ES)-Gopal

397. Center for Inland Waters in South Asia. (n.d.). Wetland biodiversity and ecosystem services database. Retrieved from http://www.aquaticecosystems.org/network/

398. Gopal, B. (2015). Integrating wetland conservation into development projects needs assessment of biodiversity and ecosystem services. Policy Brief. National Institute of Ecology, New Delhi.

399. Gopal, B. (Ed.). (2015). Guidelines for rapid assessment of biodiversity and ecosystem services of wetlands. National Institute of Ecology, New Delhi.

400. Gopal, B., Sharma, A. P. , Sharma, S. , Chatterjee, S., Marothia, D. K., ... Rao, K.S. (2016). Capacity building in the assessment of biodiversity and ecosystem services for conserving wetlands for future. APN Science Bulletin, (6) 34-40. Retrieved from https://www. apn-gcr.org/resources/items/show/2037

401. Sarkar, P., \& Das, T. (2016). Wetland ecosystem services and its valuation with special reference to India-A review. In K. Upadhaya (Ed.), Biodiversity and Environmental Conservation. Discovery Publishing House Pvt.: New Delhi, India, 59-76.

402. Parven, S., Sarkar, P., \& Das, T. (2018). Do floodplain wetlands enhance the potential of fish ponds? Assessing supporting ecosystem service of Chatla wetland of Barak Valley, Assam, India. CURRENT SCIENCE, 114(12), 2434-2436.

\section{WCRP-ICTP Summer School on Climate Extremes} CBA2014-08NSY-Koshy

403. Avila, F. B., Dong, S., Menang, K. P., Rajczak, J., Renom, M., Donat, M. G., \& Alexander, L. V. (2015). Systematic investigation of gridding-related scaling effects on annual statistics of daily temperature and precipitation maxima: A case study for south-east Australia. Weather and Climate Extremes, (9), 6-16. doi:10.1016/j. wace.2015.06.003

404. Bador, M., Naveau, P., Gilleland, E., Castellà, M., \& Arivelo, T. (2015). Spatial clustering of summer temperature maxima from the CNRM-CM5 climate model ensembles \& E-OBS over Europe. Weather and Climate Extremes, (9), 17-24. doi:10.1016/j. wace.2015.05.003

405. Bellprat, O., Lott, F. C., Gulizia, C., Parker, H. R., Pampuch, L. A., Pinto, I., ... Stott, P. A. (2015). Unusual past dry and wet rainy seasons over Southern Africa and South America from a climate perspective. Weather and Climate Extremes, (9), 36-46. doi:10.1016/j.wace.2015.07.001
406. Carlson, D. (2015). Weather and Climate Extremes. Weather and Climate, (9), 1. doi:10.1016/j. wace.2015.08.004

407. Mueller, B., Hauser, M., Iles, C., Rimi, R. H., Zwiers, F. W., \& Wan, H. (2015). Lengthening of the growing season in wheat and maize producing regions. Weather and Climate Extremes, (9) 47-56. doi:10.1016/j. wace.2015.04.001

408. Pepler, A. S., Díaz, L. B., Prodhomme, C., Doblas-Reyes, F. J., \& Kumar, A. (2015). The ability of a multi-model seasonal forecasting ensemble to forecast the frequency of warm, cold and wet extremes. Weather and Climate Extremes, (9), 68-77. doi:10.1016/j. wace.2015.06.005

409. Seneviratnea, S. I. \& Zwiersb, F. W. (Eds.). (2015). Attribution and prediction of extreme events: Editorial on the special issue. Weather and Climate Extremes (9), pp 2-5. doi:10.1016/j.wace.2015.08.003

410. Sippel, S., Mitchell, D., Black, M. T., Dittus, A. J., Harrington, L., Schaller, N., \& Otto, F. E. L. (2015). Combining large model ensembles with extreme value statistics to improve attribution statements of rare events. Weather and Climate Extremes, (9), 25-35. doi:10.1016/j.wace.2015.06.004

411. Whan, K., Zscheischler, J., Orth, R., Shongwe, M., Rahimi, M., Asare, E. O., \& Seneviratne, S. I. (2015). Impact of soil moisture on extreme maximum temperatures in Europe. Weather and Climate Extremes, (9), 57-67. doi:10.1016/j.wace.2015.05.001

IMBER ClimEco4 Summer School - Delineating the Issues of Climate Change and Impacts to Marine Ecosystems: Bridging the Gap between Research, Assessment, Policy and Management

CBA2014-11NSY(B\&ES)-Zhang

412. IMBER Capacity Building Task Team. (2016). IMBER capacity building legacy and perspectives. IMBER Report No.9. Retrieved from http://www.imber.info/ resources/images/prosjekter/imber/CBTT-Legacy-andPerspectives.pdf

413. Maddison, L., van Putten, I., \& Zuo, F. (2015). IMBER ClimEco4 Summer School - Delineating the issues of climate change and impacts on marine ecosystems: Bridging the gap between research, assessment, policy and management. APN Science Bulletin, (5) 75. Retrieved from http://www.apn-gcr.org/resources/ files/original/d00f4b82600b7c089e042d2170357f78.pdf

414. Maddison, L., van Putten, I., \& Zuo, F. (2015). Indicators to address climate change impacts on marine ecosystems. PAGES Magazine, 23(1) 33. doi:10.22498/ pages.23.1.33

415. Suprenand, P. (2015). Where are they now? June 2015 IMBER Update Newsletter No. 28, pp.22. Retrieved from https://www.researchgate.net/publication/279851857_ Observing_changes_in_the_surface_ocean_carbon_ inventory_autonomously 
416. IMBER. (2014). Presentations and lectures were given at the IMBER ClimEco4 summer school. Retrieved from https://youtu.be/V5kGaYBvWNY

\section{Scoping Workshop to Develop an APN Proposal on Capacity Building in Climate Change Mitigation through Precision Agriculture}

CBA2014-12NSY-Bora

417. Bora, G. C., Baruah, D., Soni, P., Alam, M. M., Ha, L. T. C., \& Hazarika, M. (2016). Adaptation of precision agriculture to increase crop yield and mitigating climate change in developing countries. American Society of Agricultural and Biological Engineers (ASABE) international conference on "Engineering and Technology Innovation for Global Food Security" Oct 24-27, 2016 at Cape Town, Stellenbosch, South Africa.

\section{Pan-Asia Risk Reduction (PARR) Fellowship Program}

CBA2014-13NSY-PARR

418. Abedin, M. A., \& Shaw, R. (2015). The role of university networks in disaster risk reduction: perspective from coastal Bangladesh. International journal of disaster risk reduction, (13), 381-389. doi:10.1016/j. ijdrr.2015.08.0

419. Aparna. (2016). Flood risk vulnerability of peri-urban communities: The case of Surat. Knowledge Brief No 3. Pan Asia Risk Reduction Fellowship Program.

420. Dietrich, K. \& Virji, H. (2015). Collaborative learning to inform action on risk reduction: The Pan-Asia Risk Reduction (PARR) Fellowship Programme. APN Science Bulletin (5), 77-78. Retrieved from https://www.apn-gcr.org/resources/files/original/ d00f4b82600b7c089e042d2170357f78.pdf

421. Narisma, G. T. (2016). Design and framework for a decision support system for highly urbanized megacities: Case study Metro Manila. Knowledge Brief No 1. Pan Asia Risk Reduction Fellowship Program.

422. Oktari, R. S. (2016). Exploring the existing schoolcommunity network and enabling environment for enhancing community resilience to disaster. Knowledge Brief No 2. Pan Asia Risk Reduction Fellowship Program.

423. Oktari, R. S., Shiwaku, K., Munadi, K., \& Shaw, R. (2015). A conceptual model of a school-community collaborative network in enhancing coastal community resilience in Banda Aceh, Indonesia. International journal of disaster risk reduction, 12, 300310. doi:10.1016/j.ijdrr.2015.02.006

424. Otsuyama K., Shikada M., DasGupta R., Oo T.H., \& Shaw R. (2017). Degeneration of mangroves in a changing policy environment: Case study of Ayeyarwady Delta, Myanmar. In R., DasGupta \& R. Shaw (Eds.), Participatory Mangrove Management in a Changing Climate. Disaster Risk Reduction (Methods, Approaches and Practices). Springer, Tokyo. doi:10.1007/978-4-43156481-2_11
425. Rusydy, I., Muksin, U., Mulkal, Idris, Y., Akram, M. N., \& Syamsidik. (2018, July). The prediction of building damages and casualties in the Kuta Alam sub-districtBanda Aceh caused by different earthquake models. In AlP Conference Proceedings (Vol. 1987, No. 1, p. 020012). AIP Publishing. doi:10.1063/1.5047297

426. Rusydy, I., Faustino-Eslava, D. V., Muksin, U., GallardoZafra, R., Aguirre, J. J. C., Bantayan, N. C., .. . Dakey, S. (2017, February). Building vulnerability and human loss assessment in different earthquake intensity and time: a case study of the University of the Philippines, Los Baños (UPLB) Campus. In IOP Conference Series: Earth and Environmental Science (Vol. 56, No. 1, p. 012006). IOP Publishing. doi:10.1088/1755$1315 / 56 / 1 / 012006$

427. Rusydy, I., Faustino-Eslava, D. V., Muksin, U., Gallardo-Zafra, R., Aguirre, J. J. C., Bantayan, N. C., ... Dakey, S. (2018). GIS-based earthquake damage prediction in different earthquake models: A case study at the University of the Philippines Los Baños, Philippines. Philippine Journal of Science, 147(2), 301316. Retrieved from http://philjournalsci.dost.gov.ph/ images/pdf_upload/pjs2018/2ndQtr/a_GIS_based_ earthquake_damage_prediction_in_different_models. pdf

428. Sagala, S., Syahbid, M., \& Wibisono, H. (2018). The role of leaders in risk governance in Jakarta. In Jakarta (pp. 104-119). Routledge.

Training workshop and edited volume on "Green Growth: Political Ideology, Political Economy and Policy Alternatives"

CBA2014-09NSY-Mathai

429. Dale, G, Mathai, M. V., \& Oliveira, P. (Eds.). (2016). Green growth: Political ideology and political economy. London: Zed Books.

430. Dale, G., \& Mathai, M. V. (2017). Green growth: Ideology, political economy and the alternatives. Delhi: Aakar Books.

Collaborative Monitoring System for Enhanced Watershed Management in the Philippines

CBA2014-03NSY-Cruz

431. FEED. (2014). Baroro watershed participatory management training launched with UPLB, DENR and La Union Province. Retrieved from http://feed.org. $\mathrm{ph} /$ media-centre/2014-2/2014-baroro-watershedparticipatory-management-training-launched-withuplb-denr-and-la-union-province/

$\square$ A Comprehensive Capacity Building Program on Urban Climate Change Resilience in India

CBA2014-04NSY-Divya Sharma

432. TERI. (2015). Capacity building for building sustainable and smart urban India. Retrieved from http://www. teriin.org/eventdocs/files/capacity-Briefing-paper.pdf 


\section{Developing a Training Module to Monitor Forest Cover and Deforestation using Advanced Remote Sensing Techniques under UN-CECAR Framework in Support of REDD+ MRV System}

CBA2015-04NSY-Avtar

433. Avtar, R., Mukherjee, S., Abayakoonc, S. B. S., Sophal, C., \& Thapad, R. (2018). Integrating ALOS-PALSAR and ground based observations for forest biomass estimation for REDD+ in Cambodia. APN Science Bulletin, 8(1), 52-58. doi:10.30852/sb.2018.414

434. Farswan, S., Vishwakarma, C. A., Mina, U., Kumar, V., \& Mukherjee, S. (2019). Assessment of rainwater harvesting sites in a part of North-West Delhi, India using geomatic tools. Environmental Earth Sciences, 78(11), 329. doi:10.1007/s12665-019-8332-y

435. Kumari, R., Datta, P. S., Rao, M. S., Mukherjee, S., \& Azad, C. (2018). Anthropogenic perturbations induced groundwater vulnerability to pollution in the industrial Faridabad District, Haryana, India. Environmental Earth Sciences, 77(5), 187. doi:10.1007/s12665-018-7368-8

436. Mukherjee, S. (2018). Hydrogeochemical processes controlling fluoride enrichment within alluvial and hard rock aquifers in a part of a semi-arid region of Northern India. Environmental Earth Sciences, 77(12), 475. doi:10.1007/s12665-018-7656-3

437. Singh, P., Asthana, H., Rena, V., Kumar, P., Kushawaha, J., \& Mukherjee, S. (2018). Hydrogeochemical processes controlling fluoride enrichment within alluvial and hard rock aquifers in a part of a semi-arid region of Northern India. Environmental Earth Sciences, 77(12), 475. doi:10.1007/s12665-018-7656-3

438. Avtar, R., Kumar, P., Oono, A., Saraswat, C., Dorji, S., \& Hlaing, Z. (2017). Potential application of remote sensing in monitoring ecosystem services of forests, mangroves and urban areas. Geocarto International, 32(8), 874-885. doi:10.1080/10106049.2016.1206974

439. Mukherjee, S. (2017). Tectonic and manmade changes in hydrological system. International Journal of Hydrology, 1(1). doi:10.15406/ijh.2017.01.00003

440. Sheikh, M. A., Azad, C., Mukherjee, S., \& Rina, K. (2017). An assessment of groundwater salinization in Haryana state in India using hydrochemical tools in association with GIS. Environmental Earth Sciences, 76(13), 465. doi:10.1007/s12665-017-6789-0

441. Singh, P., Javed, S., Shashtri, S., Singh, R. P., Vishwakarma, C. A., \& Mukherjee, S. (2017). Influence of changes in watershed landuse pattern on the wetland of Sultanpur National Park, Haryana using remote sensing techniques and hydrochemical analysis. Remote Sensing Applications: Society and Environment, 7, 84-92. doi:10.1016/j.rsase.2017.07.002

442. Avtar, R. (2016). Tropical forest, geospatial data and REDD+. New York, NY: Nova Science Publishers.

443. Mukherjee, S. (2015). Climate change induces variation in groundwater quality. Journal of Earth Science \& Climatic Change, S3. doi:10.4172/2157-7617.s3-005
444. Mukherjee, S. (2009). Sensible measures to guard India's groundwater supply. Nature, 462(7271), 276. doi:10.1038/462276d

445. Avtar, R. (2016, October). Spatial modelling and scenario analysis to estimate aboveground forest biomass in Cambodia using high-resolution SAR data. Paper presented at Green Talents Alumni Conference-2016, Berlin, Germany.

446. Avtar, R., Saito, O., Thapa, R. \& Aggarwal, R. (2016, August). Spatial modeling and scenario analysis to simulate forest cover in Cambodia. Paper presented at International Conference on Scenarios and Models of Biodiversity and Ecosystem Services in support of Decision Making, CORUM, Montpellier, France.

447. Aggarwal R. \& Avtar, R. (2016, March). Monitoring forest biomass using L- Band SAR data in Cambodia for REDD+. Paper presented at ICSS 2016, Stellenbosch, South Africa.

\section{International Geosphere-Biosphere Programme (IGBP) Landmark Synthesis Event}

CBA2015-05NSY-Seitzinger

448. IGBP. (2015). IGBP co-sponsored AGU sessions on the 2015 Fall Meeting website. Retrieved from https:// agu.confex.com/agu/fm15/meetingapp.cgi/Index/ CB_CoSection IGBP:\%20International\%20GeosphereBiosphere\%20Programme

449. IGBP. (2015). Open-access video of the key session "What's the Big Deal About the Anthropocene?". Retrieved from https://vts.inxpo.com/scripts/Server. nxp?LASCmd=Al:4;F:QS!10100\&ShowKey $=27470$

450. IGBP. (2015). The final issue of the magazine Global Change from IGBP. Retrieved from http://www. igbp.net/publications/globalchangemagazine/ globalchangemagazine/globalchangemagazineno84. html

451. Fahim, A. M., Shen, R., Yue, Z., Di, W., \& Mushtaq Shah, S. (2015, December). Study variability of seasonal soil moisture in ensemble of CMIP5 models over South Asia during 1950-2005. In AGU Fall Meeting Abstracts.

452. Gaire, N. P., Bhandari, S., Kunwar Thapa, U., Bhuju, D. R., Shah, S. K., Koirala, M., . . Carrer, M. (2015, December). Past climatic variations in nepal himalaya as reconstructed using ring-width chronologies. In $A G U$ Fall Meeting Abstracts.

453. Kamal, A. H. M. (2015, December). Vulnerability of coastal crop land to climate change in the northern part of Bay of Bengal: Issues, challenges and future prospects. In AGU Fall Meeting Abstracts.

454. Kumar, S., Singh, A. K., \& Singh, R. P. (2015, December). High black carbon (BC) concentrations along Indian national highways. In AGU Fall Meeting Abstracts.

455. Muangsong, C., Cai, B., \& Pumijumnong, N. (2015, December). A potential of multi-proxy approach for studying Thailand summer monsoon rainfall based on 
tree rings and stalagmite from northwestern Thailand. In AGU Fall Meeting Abstracts.

456. Ram, K., Sarin, M., \& Tripathi, S. N. (2015, December). Physicochemical properties of aerosols over the indo-Gangetic Plain, Northern India: Implications to air-quality. In AGU Fall Meeting Abstracts.

457. Sharshenova, D., \& Zhamangulova, N. (2015, December). Assessment of local biodiversity loss in Uranium mining-tales and its projections on global scale. In AGU Fall Meeting Abstracts.

458. Shi, F., Ge, Q., Yang, B., Li, J., Yang, F., Ljungqvist, F. C., ... Xu, C. (2015). A multi-proxy reconstruction of spatial and temporal variations in Asian summer temperatures over the last millennium. Climatic Change, 131(4), 663676. doi:10.1007/s10584-015-1413-3

459. Sanyal, P., \& Rakshit, S. (2015, December). How reliable is the bulk delta13c value of soil organic matter in paleovegetational reconstruction?. In AGU Fall Meeting Abstracts.

460. Xie, Y., Nie, W., Ding, A., \& Huang, X. (2015, December). HONO and inorganic fine particle composition in typical monsoon region with intensive anthropogenic emission: In-situ observations and source identification. In AGU Fall Meeting Abstracts.

\section{Escalating Small Hydropower Development and Aquatic Biodiversity of Mountain Streams in Sri Lanka}

\section{CBA2015-06NSY-Sila}

461. Silva, E.I.L. (2016). Small hydropower and hydrological networks in mountain landscape in Sri Lanka. The Environment Monitor XVI (1-3), 17-26.

462. Silva, E.I.L., Jayawardhana, R.A.S.N., Liyanage, N. P.P., \& Silva, E.N.S. (2015). Effects of construction and operation of mini-hydropower plants on fish fauna endemic to Sri Lanka - A case study on Kelani River basin, Proceedings of the Water Professional Day 2015 (pp. 45-55).

463. Silva, E.I.L., \& Silva, E.N.S. (2016). Handbook on small hydropower development and environment - A case study on Sri Lanka. Sri Lanka: Water Resources Science and Technology (WRST). Retrieved from https://www.apn-gcr.org/resources/files/original/ ee74f51d9cac104230f85b4acfdd4618.pdf

\section{Integrated, Resilience-based Planning for Climate Change Mitigation and Adaptation in Asia-Pacific Cities}

CBA2015-08NSY-Sharifi

464. Moloney, S., Olazabal, M., Yumagulova, L., \& Chelleri, L. (2016). Challenges in assessingand measuring urban resilience. Retrieved from https://ugecviewpoints. wordpress.com/2016/02/23/challenges-in-assessingandmeasuring-urban-resilience/

465. Olazabal, M., Sharifi, A., \& Yamagata, Y. (2016). Workshop on tools and indicators for assessing urban resilience: Workshop report. Retrieved from http://www. cger.nies.go.jp/cgernews/201604/304004_en.html

466. Sharifi, A., Chelleri, L., Fox-Lent, C., Grafakos, S., Pathak, M., Olazabal, M., ... Yamagata, Y. (2017). Conceptualizing dimensions and characteristics of urban resilience: Insights from a co-design process. Sustainability, 9(6), 1032. doi:10.3390/su9061032

467. Sharifi, A. (2016). A critical review of selected tools for assessing community resilience. Ecological Indicators, 69, 629-647. doi:10.1016/j.ecolind.2016.05.023

468. Sharifi, A., \& Yamagata, Y. (2016). On the suitability of assessment tools for guiding communities towards disaster resilience. International Journal of Disaster Risk Reduction, 18, 115-124. doi:10.1016/j.ijdrr.2016.06.006

469. Sharifi, A., \& Yamagata, Y. (2016). Principles and criteria for assessing urban energy resilience: A literature review. Renewable and Sustainable Energy Reviews, 60, 1654-1677. doi:10.1016/j.rser.2016.03.028

470. Yamagata, Y., \& Sharifi, A. (Eds.). (2018). Resilienceoriented urban planning. Lecture Notes in Energy. doi:10.1007/978-3-319-75798-8

Facilitating the attendance, interaction and training of young and developing nation scientists from Asia Pacific at the International Conference on Regional Climate - CORDEX 2016 (ICRC-CORDEX 2016)

CBA2016-05SY-Kang

471. Lake, I., Kang, H., Tangang, F., Gutowski, W., Lee, B., Kjellström, E., \& Langendijk, G. (2017). The International Conference on Regional Climate CORDEX 2016. APN Science Bulletin, 7(1). doi:10.30852/ sb.2017.192

472. WCRP CORDEX. (2016). International Conference on Regional Climate - CORDEX 2016. Retrieved from https://www.icrc-cordex2016.org/

IMBeR IMBIZO V Workshop: Management Strategy Evaluation: Achieving Transparency in Natural Resource Management by Quantitatively Bridging Social and Natural Science Uncertainties

CBA2017-06SY-Hofmann

473. Hofmann, E., Maddison, L., \& Van Putten, I. (2019). Management strategy evaluation: Transdisciplinary and transparent natural resource management. APN Science Bulletin, 9(1). doi:10.30852/sb.2019.895

Adapting groundwater of Asian cities to climate change: bridging the science and policy interface CBA2016-07SY-Shrestha

474. Aslam, R. A., Shrestha, S., \& Pandey, V. P. (2018). Groundwater vulnerability to climate change: A review of the assessment methodology. Science of The Total Environment, 612, 853-875. doi:10.1016/j. scitotenv.2017.08.237 
475. AIT. (2016). Proceedings of 1st Regional workshop on Adapting groundwater of Asian cities to climate change: bridging the science and policy interface. Asian Institute of Technology, Thailand, December 13-14, 2016.

476. AIT. (2016). Proceedings of 2nd Regional workshop on Adapting groundwater of Asian cities to climate change: bridging the science and policy interface. Asian Institute of Technology, Thailand, September 8-9, 2017.

477. Shrestha, S., Hoang, N., Shrestha, P., \& Bhatta, B. (2018). Climate change impact on groundwater recharge and suggested adaptation strategies for selected Asian cities. APN Science Bulletin, 8(1). doi:10.30852/sb.2018.499

\section{Ecosystem Based Adaptation Approach for Sustainable Management and Governance of Coastal Ecosystems (ENGAGE) \\ CBA2016-09SY-NGO}

478. Nagabhatla, N., Hung, N., Tuyen, L., Cam, V., Dhanraj, J., Thien, N., \& Swierczek, F. (2019). Ecosystembased approach for planning research and capacity development for integrated coastal zone management in Southeast Asia. APN Science Bulletin, 9(1). doi:10.30852/sb.2019.537

\section{Rapid mapping technique for disaster observation and environmental change data acquisition}

CBA2016-10SY-Sutrisno

479. Chaipimonplin, T. (2016). Global navigation satellite system in Thailand. Retrieved from http://mapin.or.id/ wp-content/uploads/2016/11/Tawee-Chaipimonplin_ Global-Navigation-Satellite-System-in-Thailand.pdf

480. Nurul, Fahmi, \& Muhammad. (2016). Assessment of forest change using Normalized Difference Vegetation Index (NDVI) from satellite Landsat 8 imagery (Case study at Garut, West Java). Retrieved from http://mapin.or.id/wp-content/uploads/2016/11/ Paper_Fahmi_Muhammad-Nurul_Assessmentof-Forest-Change-Using-Normalized-DifferenceVegetation-Index-NDVI-from-Satellite-Landsat-8Imagery-Case-Study-at-Garut-WestJava.pdf

481. Niep, S. (2016). Natural flooding detection using Sentinel $1 A$ in Phnom Penh, Cambodia. Retrieved from http://mapin.or.id/wp-content/uploads/2016/11/SeilaNhiep_Natural-flooding-detection-using-Sentinel-1Ain-Phnom-Penh-Cambodia.pdf

482. Yanuarsyah, I. (2016). The current condition of GNSS in Indonesia to support Indonesian one map policy. Retrieved from http://mapin.or.id/wp-content/ uploads/2016/11/IksalYanuarsyah_The-CurrentCondition-of-GNSS-in-Indonesia.pdf

483. Che'Man, N. (2016). Global navigation satellite system application in Malaysia. Retrieved from http:// mapin.or.id/wp-content/uploads/2016/11/NoordinibintiChe\%E2\%80\%99Man_Global-Navigation-SatelliteSystem-application-in-Malaysia.pdf
484. Firdaus, C. A. (2016). Observation GNSS data BAKO stations quality with RTKLIB. Retrieved from http:// mapin.or.id/wp-content/uploads/2016/11/CecepAndritela_Observation-GNSS-Data-BAKO-StationsQuality-With-RTKLIB_2016_1.compressed.pdf

\section{CLIMATE ADAPTATION FRAMEWORK (CAF)}

\section{Enhancing Capacity of Policy Makers and Practitioners in India, Sri Lanka and Nepal on Loss and Damage Related to Slow Onset Events in the Region}

CAF2014-CD01-Wijenayake, CAF2015-CD01-CMY-Vashist (Previously Wijenayake)

485. Wijenayake, V. (2014). Loss and damage and migration. Retrieved from http://outreach.stakeholderforum.org

486. Wijenayake, V. (2014). Addressing loss and damage and climate displacement. Asia Pacific Forum on Loss and Damage Special Edition COP20. Retrieved from http:// lossanddamageforum.org

487. Wijenayake, V. (2014). Addressing loss and damage in South Asia. Asia Pacific Forum on Loss and Damage. Retrieved from http://lossanddamageforum.org

488. Singh, H. (2014). A people-centred approach to assess and address loss and damage. Asia Pacific Forum on Loss and Damage. Retrieved from http:// lossanddamageforum.org

489. Bolland, J. (2015). A people-centred approach to addressing loss and damage. Asia Pacific Forum on Loss and Damage. Retrieved from http:// lossanddamageforum.org

Capacity Building for National, Provincial Stakeholders and Local Communities on Loss and Damage Related to Disaster Risk Reduction and Climate Change Adaptation

CAF2014-CD02-NMY-Nhat CAF2015-CD02-CMY-Nhat

490. Nhat, L. M., Lien, M. K., My, P. T., \& Toan, N. K. (2015). The relationship between climate change adaptation and disaster risk reduction from the context of loss and damage. Vietnam's Natural Resources and Environment Journal, 4-11.

491. Ministry of Agriculture and Rural Development, \& Ministry of Planning and Investment. (2015). Circular No. 43/2015 / TTLT-BNNPTNT-BKHDT dated 23 November 2015 guiding the statistics and assessment of damage caused by natural disasters. 
Building Capacity for Reducing Loss and Damage Resulting from Slow and Rapid Onset Climatic Extremes through Risk Reduction and Proactive Adaptation within the Broader Context of Sustainable Development

CAF2014-CD03-NMY-Ibrahim, CAF2015-CD03-CMY-Ibrahim

492. Ahmad Shabudin, A. F., Syed Azhar, S. N. F., \& Ng, T. F. (2017). Learning lab on disaster risk management for sustainable development (DRM-SD): An evaluation. International Journal of Climate Change Strategies and Management, 9(5), 600-625. doi:10.1108/ IJCCSM-08-2016-0114

493. Ibrahim, K., Koshy, K. C., Azhar, S. N. F. S., Ahmad Shabudin, A. F., ... Radzi, S. F. (2016). Building capacity for reducing loss \& damage by natural hazards: A guidance manual for good practices. Centre for Global Sustainability Studies, Universiti Sains Malaysia.

494. Osman, O., Ibrahim, K., Koshy, K. C., Ahmad Shabudin, A. F., \& Azhar, S. N. F. S. (2016). Empowerment of communities towards disaster resilience through disaster risk management for sustainable development. In Together We Stand. Tudor Rose. pp156-159. Retrieved from https://www.researchgate. net/publication/303859603_Empowerment_of communities_towards_disaster_resilience_through_ disaster_risk_management_for_sustainable_ development

495. UNESCO. (n.d.). Disaster risk management for sustainable development. Retrieved from http:// en.unesco.org/greencitizens/stories/disaster-riskmanagement-sustainable-development

\section{Can Traditional Livelihoods and Mining Co-exist in a Changing Climate: Strengthening Public- Private Partnerships in Mongolia to Reduce Risk and Address Loss and Damage}

CAF2014-CD04-NSY-Sharma

496. Sharma, V., Dalaibuyan, B., Erdenebileg, O., Natsag, M. \& Adiya, S. (2016). Traditional livelihoods and mining in Mongolia's changing climate: Exploring the potential of cross-sectoral partnerships in achieving sustainability. APN Science Bulletin, 6, 8-12. Retrieved from https:// www.apn-gcr.org/resources/items/show/2037

497. Sharma, V. (2015, June 29). Mining and Traditional Livelihoods: Mongolia's Future in a Changing Climate. Retrieved July 8, 2020, from https://library.eccplatform.org/news/mining-and-traditional-livelihoodsmongolia's-future-changing-climate- 0

\section{Developing Climate Inclusive Potential Loss and Damage Assessment Methodology for Flood Hazards}

CAF2014-RR01-NMY-Basnayake, CAF2015-RR01-CMYBasnayake, CAF2016-RR01-CMY-Basnayake

498. Basnayake, S., Punyawardena, B.V.R., Jayasinghe, S., Gupta, N., Shrestha, M.L. \& Premalal, K.H.M.S. (2019). Climate smart disaster risk reduction interventions in agriculture sector - flood hazard - a report. Asian Disaster Preparedness Center.

499. Basnayake, S., Punyawardena, B. V. R., Jayasinghe, S., Gupta, N., Shrestha, M. L. \& Premalal, K. H. M. S. (2019). Climate smart disaster risk reduction interventions in agriculture sector - flood hazard - a practitioner's handbook. Asian Disaster Preparedness Center (ADPC).

500. Guven, C., Rahaman, M.H., Ulubasoglu, M., Basnayake S., \& Jayasinghe, S. (n.d.). Effects of floods on life satisfaction among Sri Lankan farmers in a randomized controlled trial (under Review).

501. Guven, C., Rahaman, M.H., Ulubasoglu, M., Tong, L. A., Basnayake S. \& Jayasinghe, S. (n.d.). Floods and agricultural productivity: Natural field experimental evidence from micro plot-level data on Sri Lanka (under Review).

\section{Integrating CCA, DRR and L+D to Address Emerging Challenges due to Slow Onset Processes}

CAF2014-RR03-NMY-Pereira, CAF2015-RR03-CMY-Pereira, CAF2016-RR03-CMY-Pereira

502. Hoeurn, C. (2015). Impacts of disasters on agricultural sector: a case of Kampong Speu Province, Cambodia. In J.J. Pereira, M.K.Z. Ismail, S.K. Satari, N. Derodofa, \& R. Pairunan (Eds.), SEADPRI series no.1: Laying the foundation for enhancing climate change adaptation in Southeast Asia. (pp. 41-42). Bangi, Malaysia: LESTARI Publishers.

503. Khin, M.C. \& Lwin, T. (2015). Priorities for Myanmar. In J.J. Pereira, M.K.Z. Ismail, S.K. Satari, N. Derodofa, \& R. Pairunan (Eds.), Seadpri Series No.1: Laying the Foundation for Enhancing Climate Change Adaptation in Southeast Asia. (pp. 63). Bangi, Malaysia: LESTARI Publishers.

504. Nurfashareena, M., Lim, C. S., Reza, M. I. H., \& Pereira, J. J. (2015). Urban hazards management: a case study of Langat River Basin, Peninsular Malaysia. In Proceedings of the 2015 International Conference on Space Science and Communication (pp 438-443). doi:10.1109/ IconSpace.2015.7283776

505. Nurul Syazwani, Y., Lim, C. S., Taha, M. R., \& Pereira, J.J. (2016). Exposure of municipal solid waste disposal sites to climate related geohazards: case study of Selangor. Bulletin of the Geological Society of Malaysia, 62, 53-59. Retrieved from https://gsm.org.my/ products/702001-101693-PDF.pdf

506. Pereira, J.J., Pulhin, J., Nyda, C., Tran, D.T., \& Satari, S. K. (2019). Appraising slow onset hazards for loss and damage: case studies in Southeast Asia. APN Science Bulletin 9(1), 45-51. doi:10.30852/sb.2019.720

507. Pereira, J.J., Pulhin, J, Nguyen V.T., Nyda, C., Lwin, T. \& Prabhakar, S.V.R.K. (2015). Integrating climate change adaptation, disaster risk reduction and loss and damage to address emerging challenges due to slow onset processes. APN Science Bulletin, Issue 5, pp. 92. In J. Boonjawat, L.A. Stevenson, \& L. Tupas (Eds.), 
(2015). APN Science Bulletin (5). AsiaPacific Network for Global Change Research. ISSN 2185-761X

508. Pereira, J.J. (2015). Integrating DRR, CCA and L+D: issues and challenges in the Klang Valley. In J.J. Pereira, M.K.Z. Ismail, S.K. Satari, N. Derodofa, \& R. Pairunan (Eds.), SEADPRI series no.1: Laying the foundation for enhancing climate change adaptation in Southeast Asia. (pp. 48-51). Bangi, Malaysia: LESTARI Publishers.

509. Pereira, J.J., Ismail, M.K.Z., Satari, S.K., Derodofa, N. \& Pairunan, R. (2015). SEADPRI series no.1: Laying the foundation for enhancing climate change adaptation in Southeast Asia. Bangi, Malaysia: LESTARI Publishers.

510. Pulhin, J. (2015). Loss and damage assessment on land and forest degradation: Overview of the Philippines. In J.J. Pereira, M.K.Z. Ismail, S.K. Satari, N. Derodofa, \& R. Pairunan (Eds.), SEADPRI series no.1: Laying the foundation for enhancing climate change adaptation in Southeast Asia. (pp. 45-47). Bangi, Malaysia: LESTARI Publishers.

511. Rahman, T., Reza, M.I.H., Choy, E.A. \& Pereira J.J. (2016). Measuring loss and damage: approaches and challenges. Bulletin SEADPRI, 13, 4.

512. Tran, D.T. (2015). Studies of natural disasters, slow onset events and loss and damage in Quang Ngai, Vietnam. In J.J. Pereira, M.K.Z. Ismail, S.K. Satari, N. Derodofa, \& R. Pairunan (Eds.), SEADPRI series no.1: Laying the foundation for enhancing climate change adaptation in Southeast Asia. (pp. 43-44). Bangi, Malaysia: LESTARI Publishers.

513. Umi, A.J., Yaakob, J., Suratman, S. \& Pereira, J.J. (2016). Threats faced by groundwater: a preliminary study in Kuala Selangor. Bulletin of the Geological Society of Malaysia, 62, 61-68. Retrieved from https://gsm.org. my/products/702001-101692-PDF.pdf

514. Umi, A.J., Lim, C.S. \& Pereira, J. J. (2018). Implikasi perubahan iklim terhadap zon pesisir pantai di Kuala Selangor, Malaysia [Implications of climate change on the coastal zone in Kuala Selangor, Malaysia]. Bulletin of the Geological Society of Malaysia, 66, 107-119. Retrieved from http://ancst.org/apn/wp-content/ uploads/2019/03/702001-101749-PDF_2.pdf

\section{$\square$ An analysis of longer-term (5-10 years) recovery following major disasters in the Asia Pacific Region: Lessons for resilient development}

CAF2014-RR04-NMY-Thomalla, CAF2015-RR04-CMYThomalla

515. Boyland, M., Nugroho, A., \& Thomalla, F. (2017). The Role of the Panglima Laot Customary Institution in the 2004 Indian Ocean Tsunami Recovery in Aceh. In R. Djalante, M. Garschagen, F. Thomalla, \& R. Shaw (Eds.), Disaster Risk Reduction in Indonesia (pp. 357-376). Cham: Springer International Publishing. doi:10.1007/978-3-319-54466-3_14

516. Marks, D., \& Thomalla, F. (2017). Responses to the 2011 floods in Central Thailand: Perpetuating the vulnerability of small and medium enterprises? Natural
Hazards, 87(2), 1147-1165. doi:10.1007/s11069-0172813-7

517. Thomalla, F., Lebel, L., Boyland, M., Marks, D., Kimkong, H., Tan, S. B., \& Nugroho, A. (2017). Longterm recovery narratives following major disasters in Southeast Asia. Regional Environmental Change. doi:10.1007/s10113-017-1260-z

518. Thomalla, F. (2017). CAF2015-04CMY-Thomalla Project Description. In Posters: APN Booth at ISAP 2017. APN E-Lib, accessed February 6, 2018, Retrieved from http://www.apn-gcr.org/resources/items/show/2080

519. Marks, D. (2017, May). The Politics of 2011 Bangkok Floods. Presentation presented at the Center for Social and Development Studies (CSDS) Chulalongkorn University Public Seminar, Bangkok, Thailand.

520. Thomalla, F. (2017, May). Disaster recovery narratives in Southeast Asia. Project synthesis paper presented at the SEI Science Forum 2017, Bangkok, Thailand.

521. Thomalla, F. (2017, April). The role of the panglima laot customary institution in the 2004 Indian Ocean tsunami recovery in Aceh. Presentation on chapter from the book 'Disaster Risk Reduction in Indonesia: Progress, Challenges and Issues' presented at the 4th TWINSEA International Workshop - Lessons Learnt and Outlook (organized by UNU-EHS and LIPI), Bali, Indonesia.

522. Boyland, M. (2016, May). An analysis of longer-term (5-10 years) recovery following major disasters in the Asia-Pacific region: lessons for resilient development. Presentation presented at the Linking Climate Change Adaptation, Disaster Risk Reduction, and Loss \& Damage: Lessons toward Resilient Asia-Pacific Region Adaptation Futures 2016, Rotterdam, The Netherlands.

523. Marks, D. (2016, April). Longer-term recovery following major disasters in the Asia-Pacific: Insights for climate resilient development. Presentation presented at the 8th International Conference on Climate Change: Impacts and Response, Hanoi, Viet Nam.

524. Thomalla, F. (2016, January). Building resilience through disaster recovery - Aceh 10 years on from the Tsunami. Poster presented at the United Nations Office for Disaster Risk Reduction (UNISDR) Science and Technology Conference on the Implementation of the Sendai Framework for Disaster Risk Reduction 2015-2030, Geneva, Switzerland. Retrieved from https://www.sei-international.org/mediamanager/ documents/Initiatives/SEI-2016-UNISDR-LT-recoveryposter.pdf

525. Lebel, L. (2014, September). Analysis of longerterm recovery following disasters: opportunities for collaboration and methodological issues. Presentation presented at the Loss and Damage Workshop, Asia Pacific Forum on Loss and Damage, Kuala Lumpur, Malaysia.

526. Thomalla, F., Boyland, M., Johnson, K., \& Lebel, L. (2014, December 3). Taking a longer view of recovery in the world's most disaster-prone region. Outreach Magazine - Stakeholder Forum for a Sustainable Future. 
$\square$ Assessing the Linkages between Climate Change Adaptation (CCA), Disaster Risk Reduction (DRR), and Loss and Damage (L\&D): Case Studies in the Low-Lying Coastal Cities of Indonesia, Philippines, Thailand and Vietnam

CAF2014-RR05-NMY-LasCo, CAF2015-RR05-CMY-LasCo

527. Gabriel, A.V., Pulhin, P. M., \& Lasco, R. (nd). State of loss and damage assessment system in the Philippines and the proposed $L \& D$ framework (submitted to the Climate and Development Journal for review). Retrieved fromhttps://drive.google.com/open?id=0B4hwFOVJ_ jlkQ3Y2UEVsRnROWm8

528. Hop H.T.B, Ninh N.H, \& Hien L.T.T. (2017). The role of traditional ecological knowledge in the disaster risk management strategies of island communities in Cat Hai, Vietnam. Climate, Disaster and Development Journal, 2(2). 23-32. doi:10.18783/cddj.v002.i02.a03

529. Gabriel, A.V., Pulhin, P., \& Lasco, R. (2015). Assessing the linkages between CCA, DRR, and loss and damage in the Philippines. In Proceedings of the Resilient Cities 2015 Congress. Retrieved from http://resilient-cities. iclei.org/fileadmin/sites/resilientcities/files/Resilient_ Cities_2015/RC2015_congress_proceedings_Gabriel__ Pulhin__Lasco.pdf

530. Hop, H.T.B. (2016). Linkage between risk perspective and disaster risks in Cat Hai Island story. Paper presented at the 2016 Summer Institute for Disaster and Risk Research. Beijing Normal University, China.

531. Ninh, N. H., \& Hop, H.T.B. (2016). Vietnam ENSO study. Paper presented at the ThinkShop- a side event of COP 22. University of Colorado, Marrakech, Morocco.

532. Gabriel, A.V., Pulhin, P. M., Lasco, R., \& Baclayo, T. P. (2015). Development implications of assessing loss and damage in the Philippines. Science-Policy Brief Vol. 3 Issue 3. The Oscar M. Lopez Center for Climate Change Adaptation and Disaster Risk Management Foundation, Inc. Pasig City, Philippines. 2 pp. Retrieved from https://drive.google.com/file/d/0B_ VqwmZCEk80MWdOT2JXcmR6cVU/view

533. Gabriel, A.V., Pulhin, P. M., \& Lasco,R. D. (2015). Workshop report on linking loss and damage with climate change adaptation, and disaster risk reduction in the Philippines. The Oscar M. Lopez Center for Climate Change Adaptation and Disaster Risk Management Foundation Inc. Retrieved fromhttps://drive.google.com/file/ d/OB3IBWrvXyOuqR2gtbF90ekdVWnM/view

534. Ninh, N. H., \& Hop, H.T.B. (2015). Linkage between climate change adaptation (CCA), disaster risk reduction (DRR), loss and damage (L\&D) - Vietnam case. Center for Environment Research, Education and Development (CERED). Retrieved fromhttps://drive.google.com/ open?id=0B4hwFOVJ_jlkNF9UQ1dzOHRIR0E

535. The Oscar M. Lopez Center for Climate Change Adaptation and Disaster Risk Management Foundation Inc. (2017). The links between loss and damage, climate change adaptation, and disaster risk reduction briefer. Retrieved from https://drive.google.com/file/ d/OBzbudTixMEIZWjR5Tlo0UEdvb2M/view
536. Gabriel, A.V., Pulhin, P. M., Lasco, R., \& Baclayo, T. P. (2015). Development Implications of Assessing Loss and Damage in the Philippines. Poster presentation at the Asia-Pacific Economic Cooperation (APEC)'s Senior Disaster Management Officials Forum, Iloilo City, Philippines, 22-23 September 2015 and at the 4th National Climate Conference, Pasay City, 23 September 2015. The Oscar M. Lopez Center for Climate Change Adaptation and Disaster Risk Management Foundation, Inc. Retrieved from https://drive.google.com/file/ d/0B4hwFOVJ_jlkbTkyZkdlMHItb2s/view

537. Ninh, N. H., \& Hop, H.T.B. (2016). The assessment of L\&D for reducing disaster risks: Handbook. Hanoi, 12p (in Vietnamese). Retrieved from https://drive.google.com/ open?id=0B4hwFOVJ_jlkNWQ3enp0R0hqazQ

538. The Oscar M. Lopez Center for Climate Change Adaptation and Disaster Risk Management Foundation Inc. (2016). Infographic Part 1 - General knowledge on loss and damage. Retrieved from https://drive.google. com/open?id=0Bx1jC_Sg7aqMQ0xPUkc1WU83aGs

539. The Oscar M. Lopez Center for Climate Change Adaptation and Disaster Risk Management Foundation Inc. (2016). Infographic Part 2 - Loss and damage in Southeast Asia. Retrieved from https://drive.google. com/open?id=0Bx1jC_Sg7aqMVIRsdXhJenA5TGc

540. The Oscar M. Lopez Center for Climate Change Adaptation and Disaster Risk Management Foundation Inc. (2016). Infographic Part 3 - Loss and damage in the Philippines. Retrieved from https://drive.google.com/ open?id=0Bx1jC_Sg7aqMZTNTTIhlYlcteHM

541. The Oscar M. Lopez Center for Climate Change Adaptation and Disaster Risk Management Foundation Inc. (2016). Infographic Part 4 - Ways to reduce loss and damage. Retrieved from https://drive.google.com/ open?id=0Bx1jC_Sg7aqMU2V6M01ZcIMyNU0

\section{Methods Toolbox for Assessing Loss and Damage at Local Level}

CAF2014-RR07-NMY-Lotia CAF2015-RR07-CMY-Lotia

542. Van der Geest, K. \& Zeb, A. (2014). A toolbox for assessing loss and damage. Asia Pacific Forum on Loss and Damage, 5: 9-10.

543. Van der Geest, K. \& A. Zeb (2015). A toolbox for assessing loss and damage. South Asia Disasters 126: 5-6

544. Van der Geest, K., \& Markus, S. (2016). Case study report: Loss and damage from a catastrophic landslide in Sindhupalchok District, Nepal (Report No. 17). Bonn: United Nations University Institute for Environment and Human Security (UNU-EHS). Retrieved from http:// collections.unu.edu/view/UNU:5854

545. Van der Geest, K., \& Schindler, M. (2016). Brief communication: Loss and damage from a catastrophic landslide in Nepal. Natural Hazards and Earth System Sciences, 16(11), 2347-2350. doi:10.5194/ nhess-16-2347-2016

546. Van der Geest, K., \& Schindler, M. (2017). Handbook for assessing loss and damage in vulnerable 
communities (Research Report No. 21) (p. 112). Bonn, Germany: United Nations University Institute for Environment and Human Security. Retrieved from http://collections.unu.edu/view/UNU:6032

\section{Addressing Non-Economic Losses and Damages Associated with Climate Change: Learning from the Recent Past Extreme Climatic Events for Future Planning}

CAF2015-RR08-CMY-Chiba CAF2014-RR08-NMY-Chiba

547. Chiba, Y., \& Prabhakar, S. (2017). Priority practices for addressing non-economic loss and damage caused by typhoons in Japan: Case Study of Nachikatsuura Town. IGES Research Report. Kanagawa, Japan: Institute for Global Environmental Strategies (IGES). Retrieved from https://pub.iges.or.jp/system/files/publication documents/pub/researchreport/5986/0519\%20RR\%20 NELD_JP.pdf

548. Chiba, Y., Prabhakar, S., \& Islam, M. (2019). Addressing non-economic loss and damage associated with climatic events: Cases of Japan and Bangladesh. APN Science Bulletin, 9(1). doi:10.30852/sb.2019.740

549. Chiba, Y., Prabhakar, S. V. R. K., \& Task, A. (n.d.) Challenges in assessing non-economic loss and damages of climatic disasters. Retrieved from http:// www.asiapacificadapt.net/adaptationforum/sites/ default/files/3-Yohei\%20Chiba\%20ppt_iges\%20v5.pdf

550. Chiba, Y., Shaw, R., \& Prabhakar, S. (2017). Climate change-related non-economic loss and damage in Bangladesh and Japan. International Journal of Climate Change Strategies and Management, 9(2), 166183. doi:10.1108/IJCCSM-05-2016-0065

551. Bahinipati, C. S. (2017). Can planned adaptation measures reduce loss and damage from droughts in western India [PowerPoint slides]. The INSEE Panel on 'Climate Variability, Environmental Changes and Rural Livelihood' in 5th Annual Conference the Network of Rural Agrarian Studies, Nabakrushna Choudhury Centre for Development Studies, Bhubaneswar, India, October 27-29.

552. Bahinipati, C. S. (2017). Economic and non-economic loss and damage from droughts in western India: Role of crop-insurance and irrigation [PowerPoint slides]. The 8th Annual Conference on Climate Change, titled 'Climate Action: Mitigation and Adaptation in a post Paris World', Tata Institute of Social Sciences (TISS), Mumbai, India, August 4-5.

553. Bahinipati, C. S. (2015). Loss and damage associated with climatic extremes in India: Identification and methodological challenges [PowerPoint slides]. The International Conference on 'Meeting equity in Climate Change: Paris and the Post-2015 Agenda', organized by and held at Tata Institute of Social Sciences (TISS), Mumbai, India, July 31 - August 1.

554. Institute for Global Environmental Strategies. (IGES). (2015). The Paris Climate Agreement and beyond: Linking short-term climate actions to long-term goals. Kanagawa, Japan: IGES.
555. Nishat, A. (2014). Challenges in assessing non-economic L\&D of salinity in Bangladesh [PowerPoint slides]. AsiaPacific Climate Change Adaptation Forum 2014, Kuala Lumpur, Malaysia, October 1-3.

556. Prabhakar, S. (2016). Addressing non-economic losses and damages associated with climate change: Learning from recent past extreme climatic events for future planning [PowerPoint slides]. The session on 'SC 6.6 Linking climate change adaptation, disaster risk reduction, and loss \& damage: lessons toward resilient Asia-Pacific region' in Adaptation Futures 2016, Rotterdam, The Netherlands, May 10-13.

557. Prabhakar, S. V., Kamat, K., Hakimov, A., Chiba, Y., \& Nakata, M. (2016). Loss and damage associated with climate change: What and why, stakeholder perspectives, and a way forward. The Paris Climate Agreement and Beyond, 103-128. Retrieved from https://www.jstor.org/stable/pdf/resrep02928.14.pdf

558. Prabhakar, S., Kojima, S. Chiba, Y., \& Endo, I. (2015). Addressing Non-economic Loss and Damage: Toward resilient society to climate change and natural disasters. In Climate Updates, IGES Climate. Kanagawa, Japan: Institute for Global Environmental Strategies (IGES).

559. Shrestha, M., \& Shrestha, S. (2016). Identifying and Addressing Economic and Non-Economic Loss and Damages Associated with Climate Events in Thailand [Poster]. The Conference on 'Decision Support System for Water and Environment Management: Improving the Understanding and Minimizing the Socioeconomic, Health and Environmental Impacts', Hanoi, Vietnam, May 19.

560. Chiba, Y., \& Prabhakar, S.V.R.K. (Eds.). (2017). Addressing Non-economic Losses and Damages Associated with Climate Change: Learning from the Recent Past Extreme Climatic Events for Future Planning. Kobe, Japan: Asia-Pacific Network for Global Change Research (APN) and Institute for Global Environmental Strategies (IGES). Retrieved from https://pub.iges.or.jp/system/files/publication_ documents/pub/researchreport/5986/0519\%20RR\%20 NELD_JP.pdf

561. Bahinipati, C. S. (2020). Assessing the costs of droughts in rural India: a comparison of economic and noneconomic loss and damage. Current Science 110(11). doi:10.18520/cs/v118/i11/1832-1841

\section{$\square$ Optimizing Climate Change Adaptation through Enhanced Community Resilience}

CAF2015-RR18-NSY-Jacobson

562. Jacobson, C., Crevello, S., Chea, C., \& Jarihani, B. (2019). When is migration a maladaptive response to climate change? Regional environmental change, 19(1), 101-112. doi:10.1007/s10113-018-1387-6

563. Jacobson, C. L., \& Chanseng, N. (2016). Community resilience assessment and climate change adaptation planning: a Cambodian guidebook. 
564. Jacobson C., Crevello S., Nguon C., \& Chea, C. (2018). Resilience and vulnerability assessment as the basis for adaptation dialogue in informationpoor environments: A Cambodian example. In S. Serrao-Neumann, A. Coudrain, \& L. Coulter (Eds.), Communicating Climate Change Information for Decision-Making. Springer Climate. Springer, Cham. doi:10.1007/978-3-319-74669-2_11

565. Jacobson, C., Tuu, T., Tran, P., Sieng, E., Nguon, C., Nong, K., ... Smith, T. (2017). Community resilience assessment to support climate change adaptation in Cambodia and Viet Nam. APN Science Bulletin, 7(1). doi:10.30852/sb.2017.15

566. Jacobson, C., \&Ngoun, C. (2016). Community resilience assessment and climate change adaptation planning, a guidebook (in English and Khmer). University of the Sunshine Coast, University of Battambang. ISBN 10: 1-925476-04-9, ISBN-13: 978-1-925476-04-0. 96 pages.

567. Tran, T., Tran, P., Anh, A.T., \& Jacobson, C. (2016). Community resilience assessment and climate change adaptation planning, a guidebook (in English and Vietnamese). University of the Sunshine Coast, Hue University of Economics. ISBN-10: 1-925476-05-7 ISBN13: 978-1-925476-05-7. 76 pages.

\section{$\square$ Understanding Urban Heat Island Effect and Its Implications to Climate Change Adaptation Strategies in Major Southeast Asian Cities}

CAF2015-RR17-NMY-Arifwidodo, CAF2016-RR12-CMY-

Arifwidodo

568. Arifwidodo, S., Chandrasiri, O., Abdulharis, R., \& Kubota, T. (2019). Exploring the effects of urban heat island: A case study of two cities in Thailand and Indonesia. APN Science Bulletin, 9(1). doi:10.30852/ sb.2019.539

569. Abdulharis, R., Deliar, A., Harto, A. B., \& Handayani, A. P. (2018). Climate change in Bandung from the perspective of geospatial engineering: Evidences, causes, impacts and ways forward (Working Paper). Bandung: ITB.

570. Arifwidodo, S., \& Chandrasiri, O. (2015). Urban heat island and household energy consumption in Bangkok, Thailand. Energy Procedia, 79, 189-194. doi:10.1016/j. egypro.2015.11.461

571. Arifwidodo, S. (2015). Factors contributing to urban heat island in Bangkok, Thailand. ARCP Journal of Engineering and Applied Sciences, 10(15), 6435-6439.

572. Arifwidodo, S. D. (n.d.). Integrating micro-climate mitigation strategies into urban planning practices: Assessment of the urban heat island effect of Bangkok Master Plan 2013 (Working Paper). Bangkok: Kasetsart University.

573. Arifwidodo, S. D., \& Nilkamheang, N. (2018). Perceived health effects and urban heat island in Bangkok, Thailand. In Proceeding of the 14th International Urbanization Conference. Bangkok, Thailand.

574. Arifwidodo, S. D., \& Chandrasiri, O. (2016). Urban heat island and health effects in Bangkok, Thailand.
In Proceedings of the International Conference on Humanities and Technology. Melaka, Malaysia.

Developing life-supporting marine ecosystems along the East Asia's coasts: A synthesis of physical and biological data regarding coral reef ecosystems for the science-based management and socio-ecological policy making in terms of global sustainability

CAF2015-RR13-NMY-Dautova, CAF2016-RR08-CMY-Dautova

575. Dautova, T. N. (2018). Deep-water Octocorallia (Cnidaria: Anthozoa) of the temperate Northern Pacific: Notes on the distribution and new bathyal-abyssal taxa from the Sea of Okhotsk. In Deep Sea Research Part II: Topical Studies in Oceanography. doi:10.1016/j. dsr2.2018.04.002

576. Dautova, T. N. (2018). Two new species of deep-water Calcigorgia gorgonians (Anthozoa: Octocorallia) from the Kurile Islands, Sea of Okhotsk, with a review of distinctive characters of the known species of the genus. European Journal of Taxonomy, (408). doi:10.5852/ejt.2018.408

577. Kamenev, Y. O., \& Dolmatov, I. Y. (2017). Anterior regeneration after fission in the holothurian Cladolabes schmeltzii (Dendrochirotida: Holothuroidea): Kamenev and Dolmatov. Microscopy Research and Technique, 80(2), 183-194. doi:10.1002/jemt.22786

578. Silchenko, A., Kalinovsky, A., Avilov, S., Kalinin, V., Andrijaschenko, P., Dmitrenok, P., ... Dautova, T. (2017). Nine new triterpene glycosides, magnumosides A1-A4, B1, B2, C1, C2 and C4, from the Vietnamese Sea Cucumber Neothyonidium (=Massinium) magnum: Structures and activities against tumor cells independently and in synergy with radioactive irradiation. Marine Drugs, 15(8), 256. doi:10.3390/ md15080256

579. Dautov, S. S., \& Dautova, T. N. (2016). The larvae of Diadema setosum (Leske, 1778) (Camarodonta: Diadematidae) from South China Sea. Invertebrate Reproduction \& Development, 60(4), 290-296. doi:10.10 $80 / 07924259.2016 .1238411$

580. Silchenko, A. S., Kalinovsky, A. I., Avilov, S. A., Andryjaschenko, P. V., Dmitrenok, P. S., Yurchenko, E. A., ... Kalinin, V. I. (2016). Colochiroside E, an unusual non-holostane triterpene sulfated trioside from the Sea Cucumber Colochirus robustus and evidence of the impossibility of a 7(8)-double bond migration in lanostane derivatives having an 18(16)-lactone. Natural Product Communications, 11(6), 741-746.

581. Dautov, S. S., \& Dautova, T. N. (2017). Research of larvae development of Asia-Pacific sea urchins and its importance for science-based aquaculture. In T. N. Dautova, X. Sun, \& A. V. Adrianov (Eds.), Life-supporting Asia-Pacific Marine Ecosystems, Biodiversity and their Functioning (pp. 47-50). Beijing: Science Press.

582. Dautova, T. N., \& Kiyashko, S. I. (2017). Feeding mode diversity in Octocorallia can reflect their evolutionary determined taxa and morphology diversity. In T. N. 
Dautova, X. Sun, \& A. V. Adrianov (Eds.), Life-supporting Asia-Pacific Marine Ecosystems, Biodiversity and their Functioning (pp. 51-57). Beijing: Science Press.

583. Dautov, S. S., \& Dautova, T. N. (2016). Mariculture of holothurians and sea urchins - new trends. In T. N. Dautova (Ed.), Developing life-supporting marine ecosystems along with the Asia-Pacific coasts - a synthesis of physical and biological data for the science-based management and socio-ecological policy making. Proceedings International APN Workshop 2122 December 2015, Nha Trang, Vietnam (pp. 120-124). Vladivostok: Dalnauka.

584. Dautova, T. N. (2016). Soft corals in the ecosystems of South China Sea. In T. N. Dautova (Ed.), Developing life-supporting marine ecosystems along with the AsiaPacific coasts - a synthesis of physical and biological data for the science-based management and socioecological policy making. Proceedings International APN Workshop 21-22 December 2015, Nha Trang, Vietnam (pp. 27-33). Vladivostok: Dalnauka.

585. Dautov, S. S., Vo, S. T., \& Dautova, T. N. (2016). Larval development of Diadema setosum (Leske, 1778) (Camarodonta: Diadematidae) from Nha Trang Bay (South China Sea). In Proceeding of 'Progress and trends in Science and Technology' commemorating 10 years of partnership between the VAST and the Russian Foundation for Basic Research, Hanoi. February 2016 (pp. 438-442). Hanoi: The Gioi Publishers.

586. Dautova, T. N. (2016). Octocorals Alcyonacea in tropical and cold water ecosystems: biodiversity and pathways for dispersal. In International Conference 'Unique Marine Ecosystems: Modern Technologies of Exploration and Conservation for Future Generations', Vladivostok, Russia, August 4-7 2016 (pp. 40-41). Vladivostok.

587. Dautova, T. N. (2018). Soft corals Alcyiniidae of Vietnam. Vladivostok: Dalnauka.

588. Dautova, T. N., Sun, X., \& Adrianov, A. V. (Eds.). (2017). Life-supporting Asia-Pacific marine ecosystems, biodiversity and their functioning. Beijing: Science Press.

589. Dautova, T. N. (Ed.). (n.d.). Developing life-supporting marine ecosystems along with the Asia-Pacific coasts - a synthesis of physical and biological data for the science-based management and socio-ecological policy making. Proceedings International APN Workshop 2122 December 2015, Nha Trang, Vietnam. Vladivostok: Dalnauka.

\section{FOCUSED ACTIVITY: ECOSYSTEMS, BIODIVERSITY \& LAND USE (EBLU)}

\section{Critical analysis of effectiveness of REDD+ for forest communities and shifting cultivation based on lessons learnt from conservation efforts in Laos and Thailand}

EBLU2010-02NMY(R)-Takeuchi, EBLU2011-01CMY(R)Takeuchi, EBLU2012-01CMY(R)-Takeuchi

590. Bhadauria, T., Kumar, P., Kumar, R., Maikhuri, R. K., Rao, K. S., \& Saxena, K. G. (2012). Earthworm populations in a traditional village landscape in Central Himalaya, India. Applied Soil Ecology, 53, 83-93.

591. Semwal, R. L., Nautiyal, S., Maikhuri, R. K., Rao, K. S. \& Saxena, K. G. (2013). Growth and carbon stocks of multipurpose tree species plantations in degraded lands in Central Himalaya, India. Forest ecology and management, 310, 450-459.

\section{Participatory Approaches to Forest Carbon Accounting to Mitigate Climate Change, Conserve Biodiversity, and Promote Sustainable Development}

EBLU2010-03NMY(R)-Scheyvens, EBLU2011-04CMY(R)Scheyvens, EBLU2012-02CMY(R)-Scheyvens

592. Gené, E. I., Scheyvens, H., \& López-Casero, F. (2012). Community forest management and REDD+: Opportunities and challenges. Greening Governance, 85. IGES White Paper IV 2012 (pp. 85-114). Hayama: Institute of Global Environmental Strategies.

593. Scheyvens, H. (2012). Community-based forest monitoring for REDD+: lessons and reflections from the field. IGES-Policy Brief, (22). Retrieved from http://enviroscope.iges.or.jp/modules/envirolib/ upload/4124/attach/PB_22_E_final.pdf

594. Scheyvens, H., Ibarra-Gene, E., Yamanoshita, M., \& Hyakumura, K. (2012). Participatory approaches to forest carbon accounting to mitigate climate change, conserve biodiversity and promote sustainable development. APN Science Bulletin, (2).

595. Scheyvens, H., Fujisaki, T., \& Yamanoshita, M. (2012). Forestry: Importance of local participation in REDD+ In K. Koakutsu, K. Usui, A. Watarai, \& Y. Takagi (Eds.), Measurement, Reporting and Verification (MRV) for low carbon development: Learning from experience in Asia (pp. 122-127). Hayama: Japan.

596. Scheyvens, H., Yamanoshita, M., Fujisaki, T., Avtar, R. Bun, Y. A., Winai, M., ... Nhan, M. T. (2014). Communitybased forest biomass monitoring: Action research in PNG, Cambodia, Indonesia, Laos and Vietnam (Research Report 2013/5). Hayama: IGES.

597. Scheyvens, R. (Ed.). (2014). Development fieldwork: $A$ practical guide. Sage. 


\section{LOW CARBON INITIAITVES (LCI) FRAMEWORK}

\section{Capacity Building for Implementing a "Measurable, Verifiable and Reportable (MRV)" Model in a Mid-Sized Thai Municipality LCI2012-01NSY(C)-Maeda}

598. IGES, \& Phitsanulok Municipality. (2015). Inaugural GHG inventory of Phistanulok Municipality 2013/14. Retrieved from https://iges.or.jp/en/pub/inauguralghg-emissions-annual-inventory

599. Teoh, W. C. (2015). Policy brief: Practical Approaches to supporting city-level GHG emissions accounting by local governments (LCD-04). Retrieved from https://www. apn-gcr.org/resources/items/show/1913

600. Akagi, J. (2014). Capacity building support of MRV for local governments by IGES/KUC. Paper presented at The 12th Workshop on GHG Inventories in Asia (WGIA12) Session IV: Enhancement of Network for Supporting Measurement, Reporting and Verification (MRV) at various level, Bangkok, Thailand. Retrieved from http://www-gio.nies.go.jp/wgia/wgiaindex-e.html

601. Shom, T., Huntrakul, S., Sriwiroj, P., Kanthong, C., Akagi, J. \& Maeda, T. (2014). Phitsanulok Municipality inaugural greenhouse gas emissions annual inventory report 2012/13. Office of the Mayor, Phitsanulok Municipality, Thailand.

602. Teoh, W. C. (2018). Early views of ASEAN's 'Frontrunner Cities' on the Sustainable Development Goals (SDGs) and local data management. IGES Policy Report. Retrieved from https://www.iges.or.jp/en/ publication_documents/pub/policyreport/en/6359/ IGES+Policy+Brief+-+ASEAN+Cities+Early+Reactions+to +SDGs++\%28Final+7May2018\%29_FINAL.pdf

603. Teoh, W. C., Maeda, T., Akagi, J., Tubkrai, P., \& Gilby, S. (November 2015). Recommendations for capacity building of MRV in Thai municipalities based on case studies in Phitsanulok and Nonthaburi Municipality. APN's Policy Brief LCD-04. Retrieved from https:// www.apn-gcr.org/2015/11/16/policy-brief-practicalapproaches-to-supporting-city-level-ghg-emissionsaccounting-by-local-governments-lcd-04/

\section{Identification of Policy and Institutional Gaps, Drivers and Strategies to Scale-up Low Carbon and Energy Efficient Technology Application in the Construction and Infrastructure Sectors in South Asia}

LCI2012-01NMY(R)-Vashist, LCI2013-01CMY(R)-Vashist

604. Development Alternatives. (2015). Low carbon and resource efficient technology: Scaling-up of fly ash brick technology in India.

605. Development Alternatives. (2015). Bamboo: Green construction material in India.

606. LEAD. (2015). Bamboo construction: Low carbon and disaster resilient alternative in Pakistan.
607. LEAD. (2015). Energy efficient brick production: Vertical shaft brick kilns in Pakistan.

608. LEAD. (2015). Use of hydraulic lime and earth in disaster risk management in Pakistan.

609. Clean Energy Nepal. (2015). Low carbon construction technologies in Nepal.

610. Dandapani, V., Nagrath, K., Acharya, S., Lotia, H., \& Siddiqi, S. (2015). Towards upscaling the application of low-carbon and energy-efficient technology in the construction sector (Policy brief No. LCD-06). Asia-Pacific Network for Global Change Research (APN). Retrieved from http://www.apn-gcr.org/2015/11/30/policy-brieftowards-upscaling-the-application-of-low-carbonand-energy-efficient-technology-in-the-constructionsector-lcd-06/

611. Vashist, S., Varsha, D., Nagrath, K., Dhakal, M., Lotia, H., \& Siddiqui, S. (2016). Upscaling the application of low-carbon and energy-efficient technology in the construction sector. Asia-Pacific Network for Global Change Research (APN), APN Science Bulletin (6), 54-58. doi:10.30852/sb.2016.54

\section{$\square$ Understanding and Quantifying the Water- Energy-Carbon Nexus for Low Carbon Development in Asian Cities}

LCI2012-02NMY(R)-Dhakal, LCI2013-02CMY(R)-Dhakal

612. Ghosh, R., Kansal, A., \& Aghi, S. (2016). Implications of end-user behaviour in response to deficiencies in water supply for electricity consumption - A case study of Delhi. Journal of Hydrology, 536, 400-408. doi:10.1016/j.jhydrol.2016.03.012

613. Singh, P., Kansal, A., \& Carliell-Marquet, C. (2016). Energy and carbon footprints of sewage treatment methods. Journal of Environmental Management, 165, 22-30. doi:10.1016/j.jenvman.2015.09.017

614. Dhakal, S., Shrestha, S., Shrestha, A., \& Kaneko, S. (2015). Towards a better water-energy-carbon nexus in cities (APN Global Change Perspectives Policy Brief No. LCD-01). Kobe: Asia Pacific Network for Global Change Research (APN). Retrieved from http://www.apn-gcr. org/2015/10/26/policy-brief-towards-a-better-waterenergy-carbon-nexus-in-cities-lcd-01/

615. Dhakal, S., Shrestha, A., Shrestha, S., Kansal, A., \& Kaneko, S. (2015). Water-Energy-Carbon nexus in cities. Presented at the APN Side Event at Regional Forum on Climate Change (RFCC), 2 July 2015, Asian Institute of Technology (AIT) Conference Center, Thailand.

616. Dhakal, S., Shrestha, A., Shrestha, S., Kansal, A., \& Kaneko, S. (2015). Water-energy-carbon nexus in cities- Cases from New Delhi and Bangkok. Presented at the International Expert Workshop on Water Energy Food Nexus: Challenges and Opportunities in Mekong Region, 22-23 January 2015, Thailand: SEA-EU-Net and Asian Institute of Technology (AIT).

617. Shrestha, S., Dhakal, S., Shrestha, A., Kansal, A., \& Kaneko, S. (2015). Water-energy-carbon nexus in cities: Cases from Bangkok, New Delhi, Tokyo. Presented at the 
Workshop on 'Water Energy Food Nexus: International Cooperation and Technology Transfer', 18 March 2015, Paris.

618. Shrestha, A., Dhakal, S., Shrestha, S., Kansal, A., \& Kaneko, S. (2014). Understanding and quantifying the water, energy and carbon nexus for low carbon development in Asian cities. Presented at the APN's Low Carbon Initiative ( $\mathrm{LCl}$ ) session in 3rd Annual Meeting of Low Carbon Asia Research Network, 24-26 November 2014, Indonesia.

\section{Integrated Sustainability Assessment of Bioenergy Potentials in Asia: An Application of a Hybrid Approach on Trade-offs and Pathways}

LCI2012-04NMY(R)-Macandog, LCI2013-03CMY(R)-Macandog

619. Acosta, L., Magcale-Macandog, D., Kumar, K., Cui, X., Eugenio, E., Macandog, P., ... Eugenio, J. (2016). The role of bioenergy in enhancing energy, food and ecosystem sustainability based on societal perceptions and preferences in Asia. Agriculture, 6(2), 19. doi:10.3390/agriculture6020019

620. Eugenio, E., Acosta, L., Enano Jr., N. H., Macandog, D. B., Macandog, P., Talubo, J. P. P., ... Eugenio, J. (2016). What influences awareness of farmers on sustainability of bioenergy feedstock in the Philippines? APN Science Bulletin, (6). Retrieved from https://www.apn-gcr.org/ resources/items/show/2037

621. Acosta, L., Macandog, D. B., Kumar, K., Cui, X., Eugenio, E., Macandog, P., ... Eugenio, J. (2015). The role of bioenergy in energy-food-ecosystem nexus in Asia (APN Global Change Perspectives Policy Brief No. LCD-03). Kobe: Asia Pacific Network for Global Change Research (APN). Retrieved from http://www.apn-gcr.org/ resources/items/show/2020

622. Kumar, K., Soundar Rajan, R. S., \& Manivasagan, R. (2015). Biofuel feedstock cultivation in India: Implications for food security and rural livelihoods (MSE Working Paper No. 105/2015). Chennai, India: Madras School of Economics. Retrieved from https://ideas. repec.org/p/mad/wpaper/2015-105.html

623. Acosta, L. A., Eugenio, E. A., Enano, N. H., MagcaleMacandog, D. B., Vega, B. A., Macandog, P. B. M., ... Lucht, W. (2014). Sustainability trade-offs in bioenergy development in the Philippines: An application of conjoint analysis. Biomass and Bioenergy, 64, 20-41. doi:10.1016/j.biombioe.2014.03.015

624. Acosta, L. A., Macandog, D. B., Eugenio, E. A., Macandog, P. B. M., Cui, X., \& Kumar, K. (2014). Knowledge and opinion on the sustainability of bioenergy production in Asia: Cases in China and the Philippines. APN Science Bulletin, 4.

625. Eugenio, E. A., Acosta, L. A., Enano Jr., N. H., Macandog, D. B., Macandog, P. B. M., Talubo, J. P. P., ... Eugenio, J. M. A. (2014). Typology of farmers' awareness on sustainability of alternative bioenergy feedstocks in the Philippines (Sustainability TRade-offs and Pathways (STRAP) Working Paper No. 001-2014).
626. Acosta, L. A., Eugenio, E. A., Enano Jr., N. H., Macandog, D. B., Vega, B. A., Macandog, P. B. M., ... Lucht, W. (2014). Sustainability trade-offs in bioenergy development in the Philippines: An application of conjoint analysis (Sustainability TRade-offs and Pathways (STRAP) Working Paper No. 002-2014).

627. Kumar, K., Soundar Rajan, R. S., \& Manivasagan, R. (2014). Biofuel feedstock cultivation in India: Implications for food security and rural livelihoods (Sustainability TRade-offs and Pathways (STRAP) Working Paper No. 003-2014).

628. Acosta, L. A., Cui, X., Macandog, D. B., Eugenio, E. A., Macandog, P. B. M., Eugenio, J. M. A., \& Kumar, K. (2014). Comparative analysis of knowledge and opinions of local communities on sustainability of bioenergy in the Philippines and China (Sustainability TRade-offs and Pathways (STRAP) Working Paper No. 004-2014).

629. Kumar, K. (2014). Jatropha cultivation for biodiesel: Food security and rural livelihoods. Presented at the Fourth MSE Faculty Seminar Series, 27-28 February 2014, Central University of Tamil Nadu, Thiruvarur.

630. Eugenio, E. A., Acosta, L. A., Enano Jr., N. H., Macandog, D. B., Macandog, P. B. M., \& Talubo, J. P. P. (2013). Typology of farmers' awareness on sustainability of alternative bioenergy feedstocks in the Philippines. Presented at the 2013 International ISSAAS Congress, 11-15 November 2013, Muntinlupa City, Philippines.

\section{$\square$ Low Carbon Urban Infrastructure Investment: Cases of China, Indonesia, and Japan}

LC12012-05NMY(R)-Jupesta, LC12013-05CMY(R)-Jupesta

631. Jupesta, J. (2015). Green investment in Asian cities: Lessons from the People's Republic of China, Indonesia, and Japan. ADBI Blog: http://www.asiapathways-adbi. org/2015/01/green-investment-in-asian-cities-lessonsfrom-the-peoples-republic-of-china-indonesia-andjapan/

632. Wakiyama, T., \& Jupesta, J. (2014). Green investment in Asian cities to reduce natural disaster risks, Our World 2.0. Retrieved from http://ourworld.unu.edu/en/greeninvestment-in-asian-cities-to-reduce-natural-disasterrisks

633. Suwa, A., \& Jupesta, J. (2013). Illuminating Japans energy future. East Asia Forum, Retrieved from http:// www.eastasiaforum.org/2013/12/14/illuminatingjapans-energy-future/

634. Mathai, M. V., \& Kartikasari, K. (2015). Institutional framework for low-carbon urban infrastructure investment: Some evidence and lessons from DKI Jakarta, Indonesia. Journal of Comparative Asian Development, 14(2), 319-349. doi:10.1080/15339114.20 15.1059056

635. Wakiyama, T., \& Jupesta, J. (2013). Green investment in Asian cities. In Urbanization and Global Environment Changes (UGEC) Viewpoints Issue No.9 July 2013. Retrieved from http://ugec.org/docs/ugec/viewpoints/ Viewpoints9-July2013.pdf 
636. Jupesta, J. (November, 2015). Green investment in Asian cities (Policy Brief: LCD-05). Retrieved from https:// www.apn-gcr.org/2015/11/23/policy-brief-greeninvestment-in-asian-cities-lcd-05/

\section{OTHER ACTIVITY}

\section{International Conference on Climate Change Impacts and Adaptation for Food and Environmental Security \\ AOA2012-08NSY-Lansigan}

637. Domingo, I. V., Cadiz, M. C., Saguiguit Jr., G. C., \& Ticsay, M. V. (2013). International conference on climate change impacts and adaptation for food and environmental security: Conference summary report. Los Baños: Southeast Asian Regional Center for Graduate Study and Research in Agriculture (SEARCA). Retrieved from http://icciafes.searcabackup.org/downloads/icciafesconference-report.pdf

\section{Capacity Building for Research in Relation to IPCC, SDGs and the Paris Agreement AOA2018-01SY-Pereira}

638. Pereira, J.J. \& Hunt, J.C.R. (Eds.). (2019). Climate science \& technology in Asia: Current status and future needs. In Report of the Workshop on Status of Climate Science and Technology in Asia, 15-16 November 2018, Kuala Lumpur, Malaysia. LESTARI Publishers, Bangi, Malaysia. Retrieved from http://ancst.org/wp-content/ uploads/2019/10/AncstWshpRep_Final.pdf

\section{COMPREHENSIVE RESEARCH FOR YOUNG SCIENTISTS (CRYS)}

\section{Rainwater Harvesting for Mitigating Drought in Western Nepal}

CRYS2017-01MY-Panthi

639. Panthi, J., Khatiwada, K. R., Shrestha, M. L., \& Dahal, P. (2019). Water poverty in the context of climate change: a case study from Karnali river basin in Nepal Himalaya. International Journal of River Basin Management, 17(2), 243-250. doi:10.1080/15715124.20 18.1531412

640. The Small Earth Nepal. (2018, October 14). SEN at Mtn Climate International Conference in Rocky Mountain, USA. Retrieved from http://www.smallearth.org.np/ sen-at-mtnclimate-international-conference-in-rockymountain-usa/

641. APN. (2018, October 29). Mobile application for rainwater harvesting systems in Nepal. Retrieved from http://www.apn-gcr.org/2018/10/29/mobileapplication-for-rainwater-harvesting-systems-in-nepal/

642. Codearks Inc. (2018). Aakaashepani (Mobile application). Retrieved from https://play.google.com/ store/apps/details?id=com.rwh.app
Urban Biodiversity and Human Well-Being in Asia's Megacities

CRYS2017-03SY-Sing

643. Sing, K. W., Luo, J., Wang, W., Jaturas, N., Soga, M., Yang, X., ... Wilson, J. J. (2019). Ring roads and urban biodiversity: distribution of butterflies in urban parks in Beijing city and correlations with other indicator species. Scientific reports, 9(1), 7653. Retrieved from https://www.nature.com/articles/s41598-019-43997-8

Multidimensional Indicators of Adaptive Capacity of Rice Farming Households to Address Salt Water Intrusion in the Philippines and Viet Nam

CRYS2017-02SY-Almaden

644. Almaden, C. R. C., Rola, A. C., Baconguis, R. D., Pulhin, J. M., Camacho Jr, J. V., \& Ancog, R. C. (2019). Determinants of adaptation for slow-onset hazards: The case of rice-farming households affected by seawater intrusion in Northern Mindanao, Philippines. Asian Journal of Agriculture and Development, 16(13622019-2696), 117-132. Retrieved from https://ajad. searca.org/read-articles/13-view-article?aid=963

645. Almaden, C. R. C., Diep, T. T., Rola, A. C., Baconguis, R. D., Pulhin, J. M., Camacho, J. V., \& Ancog, R. C. (2020). Factors influencing measure-based adaptation of rice farmers for slow-onset hazard: the Case of saltwater inundation in the Philippines and Vietnam. Environmental Management, 1-15. doi:10.1007/s00267020-01332-2

646. Almaden, C. R. C, Diep, T. T., Rola, A. C., Baconguis, R. D. T., Pulhin, J. M., Camacho, J. V., \& Ancog, R. C. (2019). Meso-level analysis on rice-farmers' adaptive measures for slow onset hazard: The case of saltwater intrusion in the Philippines and Vietnam. SEARCA Agriculture and Development Notes, 9(2). Retrieved from https://www. searca.org/pubs/briefs-notes?pid=447

647. Almaden, C. R. C. (2018). Salting the earth. Weathering the storms fostering our understanding of climate-related risks and our capacity to respond: A compendium of essays for the Allianz Climate Risk Research Award 2018. Allianz Climate Solutions, Munich, Germany. Retrieved from https://www.allianz. com/content/dam/onemarketing/azcom/Allianz_com/ responsibility/documents/Compendium-ACRRA-2018Final.pdf

648. Almaden, C. R. C. (2018). Multidimensional indicators of adaptive capacity of rice farming households to address salt water intrusion in the Philippines and Vietnam. Fourth Asia Future Conference, Seoul, South Korea. August 24-28, 2018.

649. Almaden, C. R. C. (2018). Meso-level analysis on ricefarmers' adaptation measures for slow onset hazard: The case of saltwater intrusion in the Philippines and Vietnam. Workshop on Status of Climate Science and Technology in Asia - for IPCC AR6. Kuala Lumpur, Malaysia. November 15-16, 2018.

650. Almaden, C. R. C. (2019). Rice-farmers' adaptive measures for slow onset hazard: The case of saltwater 
intrusion in the Philippines and Vietnam. Ocean Visions 2019 Climate Summit. Georgia Tech, Atlanta, Georgia, USA. April 1-4, 2019.

\section{Special Issue on Climate Impacts, Vulnerability and Adaptation}

AOA2019-01SY-Shrestha

651. Shrestha, S., Stevenson, L. A., Shaw, R., \& Pulhin, J. (2020). Editorial of Special Issue on Climate Change Impacts, Vulnerability and Adaptation: Asian Perspective. Environmental Research, 109826. doi:10.1016/j.envres.2020.109826

652. Adhikari, R. K., Mohanasundaram, S., \& Shrestha, S. (2020). Impacts of land-use changes on the groundwater recharge in the Ho Chi Minh city, Vietnam. Environmental Research, 185, 109440. doi:10.1016/j. envres.2020.109440

653. Arifwidodo, S. D., \& Chandrasiri, O. (2020). Urban heat stress and human health in Bangkok, Thailand. Environmental Research, 185, 109398. doi:10.1016/j. envres.2020.109398

654. Babel, M. S., Shinde, V. R., Sharma, D., \& Dang, N. M. (2020). Measuring water security: A vital step for climate change adaptation. Environmental Research, 185, 109400. doi:10.1016/j.envres.2020.109400

655. Dahal, P., Shrestha, M. L., Panthi, J., \& Pradhananga, D. (2020). Modeling the future impacts of climate change on water availability in the Karnali River Basin of Nepal Himalaya. Environmental Research, 185, 109430. doi:10.1016/j.envres.2020.109430

656. Dey, D., Gyeltshen, T., Aich, A., Naskar, M., \& Roy, A. (2020). Climate adaptive crop-residue management for soil-function improvement; recommendations from field interventions at two agro-ecological zones in South Asia. Environmental Research, 183, 109164. doi:10.1016/j.envres.2020.109164

657. Grefalda, L. B., Pulhin, J. M., Tapia, M. A., Anacio, D. B., Luna, C. C., Sabino, L. L., . . . Inoue, M. (2020). Building institutional resilience in the context of climate change in Aurora, Philippines. Environmental Research, 186, 109584. doi:10.1016/j.envres.2020.109584

658. Heath, L. C., Tiwari, P., Sadhukhan, B., Tiwari, S., Chapagain, P., Xu, T., ... Yan, J. (2020). Building climate change resilience by using a versatile toolkit for local governments and communities in rural Himalaya. Environmental Research, 188, 109636. doi:10.1016/j. envres.2020.109636

659. Jacobson, C. (2020). Community climate resilience in Cambodia. Environmental Research, 186, 109512. doi:10.1016/j.envres.2020.109512
660. Ngin, C., Chhom, C., \& Neef, A. (2020). Climate change impacts and disaster resilience among micro businesses in the tourism and hospitality sector: The case of Kratie, Cambodia. Environmental Research, 186, 109557. doi:10.1016/j.envres.2020.109557

661. Pham, N. T., Nguyen, C. T., \& Vu, H. H. (2020). Assessing and modelling vulnerability to dengue in the Mekong Delta of Vietnam by geospatial and time-series approaches. Environmental Research, 186, 109545. doi:10.1016/j.envres.2020.109545

662. Shrestha, S., Neupane, S., Mohanasundaram, S., \& Pandey, V. P. (2020). Mapping groundwater resiliency under climate change scenarios: A case study of Kathmandu Valley, Nepal. Environmental Research, 183, 109149. doi:10.1016/j.envres.2020.109149

663. Su, Y., Cheng, L., Cai, W., Lee, J. K. W., Zhong, S., Chen, S., ... Huang, C. (2020). Evaluating the effectiveness of labor protection policy on occupational injuries caused by extreme heat in a large subtropical city of China. Environmental Research, 186, 109532. doi:10.1016/j. envres.2020.109532

664. Supari, Tangang, F., Juneng, L., Cruz, F., Chung, J. X., Ngai, S. T., ... Sopaheluwakan, A. (2020). Multi-model projections of precipitation extremes in Southeast Asia based on CORDEX-Southeast Asia simulations. Environmental Research, 184, 109350. doi:10.1016/j. envres.2020.109350

665. Uchiyama, C., Stevenson, L. A., \& Tandoko, E. (2020) Climate change research in Asia: A knowledge synthesis of Asia-Pacific Network for Global Change Research (2013-2018). Environmental Research, 188, 109635. doi:10.1016/j.envres.2020.109635

666. Yue, W., Lin, L., \& Xiaotong, Z. (2020). Influence of El Niño events on sea surface salinity over the central equatorial Indian Ocean. Environmental Research, 182, 109097. doi:10.1016/j.envres.2019.109097 


\section{Appendix 3. Hyogo activities}

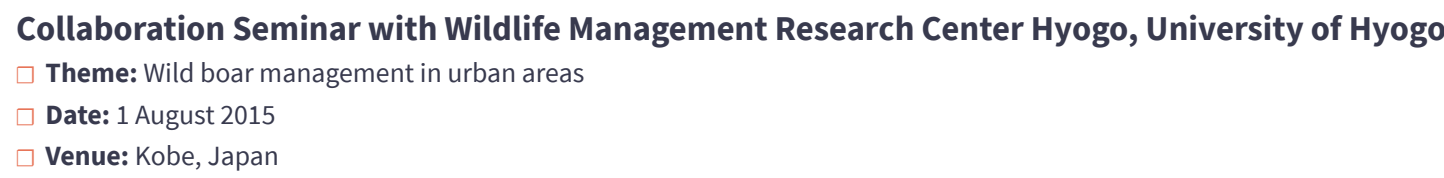

Collaboration Seminar with Hanshin-Kita District Administration Office: Hokusetsu SATOYAMA International Seminar

$\square$ Theme: Raising awareness and efforts in sustaining SATOYAMA-like ecosystems/landscapes

Date: $27-28$ November 2015

$\square$ Venue: Takarazuka, Japan

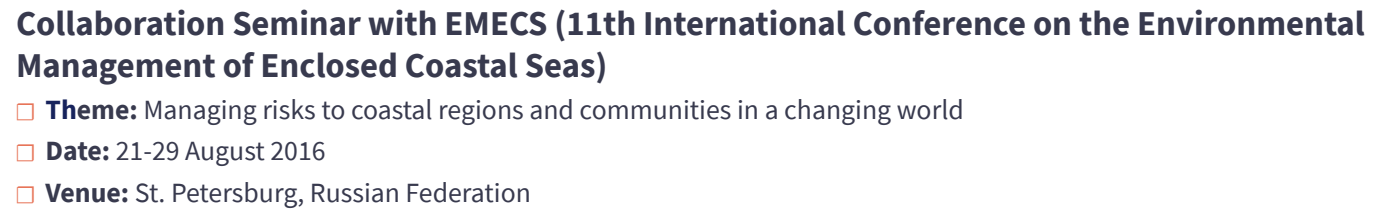

Collaboration Seminar with Hanshin-Kita District Administration Office: Hokusetsu SATOYAMA International Seminar

$\square$ Theme: Sustainable coexistence of people and nature in Hokusetsu: The value of SATOYAMA and future outlook

Date: 12 November 2016

$\square$ Venue: Takarazuka, Japan

\section{Collaboration Seminar with Hyogo Environmental Advancement Association}

Theme: Air Pollution Due to PM2.5 and its Health Effects: Reports from China and the Present Status in Japan

Date: 8 September 2017

$\checkmark$ Venue: Kobe, Japan

$\square$ Theme: Circulation of the regional assets and revitalization utilizing Satoyama assets

Date: 18 November 2017

$\square$ Venue: Takarazuka, Japan

\section{Collaboration Seminar with EMECS (12th International Conference on the Environmental} Management of Enclosed Coastal Seas)

$\square$ Theme: Cooperative stewardship for integrated management toward resilient coastal seas

$\square$ Date: 4-8 November 2018

$\square$ Venue: Pattaya, Thailand

$2018 \square$ Webpage: https://www.apn-gcr.org/news/wastewater-degrades-coral-reefs-in-the-eastern-andaman-sea-experts-at-emecs12confirmed/

Collaboration Seminar with Hanshin-Kita District Administration Office: Hokusetsu SATOYAMA International Seminar

$\square$ Theme: Passing down SATOYAMA conservation activities to the next generation

Date: 10 November 2018

$\square$ Venue: Takarazuka, Japan

\section{Collaboration Symposium with EMECS and Kobe University}




\section{Appendix 4. Top 50 project products by downloads, Jan 2015 - Dec 2019}

\begin{tabular}{|c|c|c|c|c|}
\hline Rank & Title & Type & Downloads & $\begin{array}{l}\text { Year } \\
\text { Published }\end{array}$ \\
\hline 1 & Bamboo: Green Construction Material & Case study & 10,642 & 2015 \\
\hline 2 & $\begin{array}{l}\text { The Effects of Climate Change on Pests and Diseases of Major Food Crops in the Asia } \\
\text { Pacific Region }\end{array}$ & Project report & 8,373 & 2011 \\
\hline 3 & The Role of Bioenergy in Energy-Food-Ecosystem Nexus in Asia & Policy brief & 7,775 & 2015 \\
\hline 4 & $\begin{array}{l}\text { Increasing National Capacity of Adaptation for Climate Change through Cross } \\
\text { Sectoral and Regional Cooperation }\end{array}$ & Proceedings & 6,248 & 2008 \\
\hline 5 & $\begin{array}{l}\text { Inventory of Glaciers, Glacial Lakes and the Identification of Potential Glacial Lake } \\
\text { Outburst Floods (GLOFs) Affected by Global Warming in the Mountains of India, } \\
\text { Pakistan and China/Tibet Autonomous Region }\end{array}$ & Project report & 6,101 & 2005 \\
\hline 6 & An Assessment of the Socio-Economic Impacts of Floods in Large Coastal Areas & Project report & 4,888 & 2004 \\
\hline 7 & $\begin{array}{l}\text { The } 2005 \text { Open Meeting of the Human Dimensions of the Global Environmental } \\
\text { Change Research Community }\end{array}$ & Proceedings & 4,715 & 2005 \\
\hline 8 & $\begin{array}{l}\text { TÀI LIẸU HƯớNG DẪN: Lựa chọn công nghệ trong Quản lý chất thải rắn bền } \\
\text { vưng - Nghiên cứu điển hình tại Thành phố Hồ Chí Minh, Việt Nam (Guidelines for } \\
\text { Technology Selection for Sustainable Solid Waste Management in Ho Chi Minh City, } \\
\text { Viet Nam) }\end{array}$ & Guidebook & 4,013 & 2015 \\
\hline 9 & $\begin{array}{l}\text { Sustainable gasification-biochar systems? A case-study of rice-husk gasification in } \\
\text { Cambodia, Part I: Context, chemical properties, environmental and health and safety } \\
\text { issues }\end{array}$ & Journal article & 3,994 & 2012 \\
\hline 10 & Mangrove wetland ecosystems in Ganges-Brahmaputra delta in Bangladesh & Journal article & 3,907 & 2008 \\
\hline 11 & $\begin{array}{l}\text { A guide for improving municipal solid waste management and promoting urban } \\
\text { organic waste utilization in Lao PDR }\end{array}$ & Guidebook & 3,868 & 2012 \\
\hline 12 & APN Science Bulletin, 2014 & Science Bulletin & 3,661 & 2014 \\
\hline 13 & $\begin{array}{l}\text { A Guide for Sustainable Urban Organic Waste Management in Thailand: Combining } \\
\text { Food, Energy, and Climate Co-Benefits }\end{array}$ & Guidebook & 3,518 & 2012 \\
\hline 14 & $\begin{array}{l}\text { Wetland Conservation for Biodiversity and Ecosystem Services Needs a Shift in Land } \\
\text { and Water Resources Policies }\end{array}$ & Policy brief & 3,381 & 2015 \\
\hline 15 & $\begin{array}{l}\text { Analysis on Urban Land-use Changes and Its Impacts on Food Security in Different } \\
\text { Asian Cities of Three Developing Countries Using Modified CA Model }\end{array}$ & Project report & 3,252 & 2012 \\
\hline 16 & $\begin{array}{l}\text { Towards Upscaling the Application of Low-carbon and Energy-efficient Technology in } \\
\text { the Construction Sector - Cases of India, Nepal and Pakistan }\end{array}$ & Policy brief & 3,213 & 2012 \\
\hline 17 & $\begin{array}{l}\text { The Mega-Deltas of Asia: A Conceptual Model and its Application to Future Delta } \\
\text { Vulnerability }\end{array}$ & Project report & 3,149 & 2004 \\
\hline 18 & $\begin{array}{l}\text { Impact of Climate Change on Food Security and Biosecurity of Crop Production } \\
\text { Systems in Small Pacific Nations }\end{array}$ & Project report & 3,097 & 2011 \\
\hline 19 & APN Fourth Strategic Plan & Institutional & 3,120 & 2015 \\
\hline
\end{tabular}




\begin{tabular}{|c|c|c|c|c|}
\hline Rank & Title & Type & Downloads & $\begin{array}{l}\text { Year } \\
\text { Published }\end{array}$ \\
\hline 20 & Case studies in insurance effectiveness: some insights into costs and benefits & Case study & 3,067 & 2017 \\
\hline 21 & $\begin{array}{l}\text { A Guide for Technology Selection and Implementation of Urban Organic Waste } \\
\text { Utilization Projects in Cambodia }\end{array}$ & Guidebook & 3,007 & 2011 \\
\hline 22 & Guidelines for Rapid Assessment of Biodiversity and Ecosystem Services of Wetlands & Guidebook & 2,950 & 2015 \\
\hline 23 & Infographic Part 3 - Loss and damage in the Philippines & Infographic & 2,930 & 2015 \\
\hline 24 & $\begin{array}{l}\text { Pakistan Case Study_Bamboo Construction: Low Carbon and Disaster Resilient } \\
\text { Alternative }\end{array}$ & Case study & 2,872 & 2015 \\
\hline 25 & $\begin{array}{l}\text { Proceedings of international symposium on coastal zones and climate change: } \\
\text { assessing impacts and developing adaptation strategics }\end{array}$ & Proceedings & 2,809 & 2010 \\
\hline 26 & $\begin{array}{l}\text { Case Study On Hollow Concrete Block Housing, Bamboo Housing and Other } \\
\text { Traditional Housing Technologies in Nepal }\end{array}$ & Case study & 2,656 & 2016 \\
\hline 27 & National Climate Change Public Awareness and Outreach in Sri Lanka & Project report & 2,607 & 2005 \\
\hline 28 & $\begin{array}{l}\text { Coastal Marine Biodiversity of Viet Nam: Regional and Local Challenges and Coastal } \\
\text { Zone Management for Sustainable Development }\end{array}$ & Project report & 2,565 & 2012 \\
\hline 29 &  & Guidebook & 2,488 & 2011 \\
\hline 30 & $\begin{array}{l}\text { Community Relocation as an Option for Adaptation to the Effects of Climate Change } \\
\text { and Climate Variability in Pacific Island Countries (PICs) }\end{array}$ & Project report & 2,430 & 2006 \\
\hline 31 & $\begin{array}{l}\text { Institutionalizing Agroforestry as a Climate Change Adaptation Strategy through } \\
\text { Local Capacity and Policy Development in Southeast Asia }\end{array}$ & Project report & 2428 & 2012 \\
\hline 32 & Proceedings of the 21st Intergovernmental Meeting & Institutional & 2,355 & 2017 \\
\hline 33 & APN Science Bulletin, 2016 & Science Bulletin & 2,283 & 2016 \\
\hline 34 & CLIMATE IN ASIA AND THE PACIFIC: A Synthesis of APN Activities & $\begin{array}{l}\text { Synthesis } \\
\text { report }\end{array}$ & 2,187 & 2011 \\
\hline 35 & Land Use Change and the Terrestrial Carbon Cycle in Asia & Proceedings & 2,173 & 2001 \\
\hline 36 & $\begin{array}{l}\text { Community resilience assessment and climate change adaptation planning: A } \\
\text { Vietnamese Guidebook }\end{array}$ & Guidebook & 2,143 & 2016 \\
\hline 37 & $\begin{array}{l}\text { Biochar for Carbon Reduction, Sustainable Agriculture and Soil Management } \\
\text { (BIOCHARM) }\end{array}$ & Project report & 2,064 & 2009 \\
\hline 38 & $\begin{array}{l}\text { Collaborative Studies in Tropical Asian Dendrochronology: Addressing Challenges in } \\
\text { Climatology and Forest Ecology }\end{array}$ & Project report & 2,051 & 2009 \\
\hline 39 & Annual Report FY 2015 & Institutional & 1,978 & 2016 \\
\hline 40 & Flood Waste Management Guidelines for Bangkok & Guidebook & 1,924 & 2015 \\
\hline 41 & $\begin{array}{l}\text { Critical Analysis of Effectiveness of REDD + for Forest Communities and Shifting } \\
\text { Cultivation, based on Lessons Learnt from Conservation Efforts in Laos and Thailand }\end{array}$ & Project report & 1,912 & 2012 \\
\hline 42 & $\begin{array}{l}\text { Strategic Rice Cultivation for Sustainable Low Carbon Society Development in South } \\
\text { East Asia }\end{array}$ & Project report & 1,881 & 2013 \\
\hline
\end{tabular}




\begin{tabular}{|c|c|c|c|c|}
\hline Rank & Title & Type & Downloads & $\begin{array}{l}\text { Year } \\
\text { Published }\end{array}$ \\
\hline 43 & Monitoring deforestation in Sarawak, Malaysia using multitemporal Landsat data & Journal article & 1,879 & 2011 \\
\hline 44 & $\begin{array}{l}\text { Handbook on Small Hydropower Development and Environment: A Case Study on } \\
\text { Sri Lanka }\end{array}$ & Case study & 1,842 & 2016 \\
\hline 45 & $\begin{array}{l}\text { Community resilience assessment and climate change adaptation planning: A } \\
\text { Cambodian Guidebook }\end{array}$ & Guidebook & 1,807 & 2016 \\
\hline 46 & $\begin{array}{l}\text { Impact of Global Change on the Availability of Fodder \& Forage and Performance of } \\
\text { Livestock in South Asia }\end{array}$ & Project report & 1,756 & 2005 \\
\hline 47 & $\begin{array}{l}\text { Climate Change Impacts on the Ecology of the Rice Pest Complex and the Resulting } \\
\text { Threat to Food Security and Farming Economy in South Asia }\end{array}$ & Project report & 1,557 & 2005 \\
\hline 48 & $\begin{array}{l}\text { Promoting Algaculture in Trapped Waters as Sustainable Aquafarming and Adaptive } \\
\text { Climate Mitigation in Inundated Coastal Areas }\end{array}$ & Project report & 1,501 & 2014 \\
\hline 49 & The Role of Governance in Managing Ecosystem Service Trade-offs & Journal article & 1,239 & 2009 \\
\hline 50 & Annual Report FY 2014 & Institutional & 1,074 & 2015 \\
\hline
\end{tabular}

\section{Appendix 5. Articles published in the media during the reporting period}

\begin{tabular}{|c|c|c|c|c|}
\hline Title & Media & Country & Date & URL \\
\hline $\begin{array}{l}\text { Diving for treasure to help protect the } \\
\text { world's great reefs }\end{array}$ & $\begin{array}{l}\text { The } \\
\text { Conversation }\end{array}$ & Australia & $2015-08-20$ & $\begin{array}{l}\text { https://theconversation.com/diving-for-treasure-to- } \\
\text { help-protect-the-worlds-great-reefs- } 45769\end{array}$ \\
\hline Click to post spatial data & The Hindu & India & $2015-08-22$ & $\begin{array}{l}\text { https://www.thehindu.com/news/national/tamil- } \\
\text { nadu/click-to-post-spatial-data/article7568512.ece }\end{array}$ \\
\hline $\begin{array}{l}\text { Seaweed cultivation ushers waves of } \\
\text { change in the Sundarbans }\end{array}$ & $\begin{array}{l}\text { Deutsche } \\
\text { Welle }\end{array}$ & Germany & $2015-11-26$ & $\begin{array}{l}\text { https://www.dw.com/en/seaweed- } \\
\text { cultivation-ushers-waves-of-change-in-the- } \\
\text { sundarbans/a-18861596 }\end{array}$ \\
\hline $\begin{array}{l}\text { IT sector behind Bengaluru's high CO2 } \\
\text { emissions }\end{array}$ & Live Mint & India & 2016-03-29 & $\begin{array}{l}\text { https://www.livemint.com/Politics/ } \\
\text { feO2rxZiEiEAPZKqyZHp1H/IT-sector-behind- } \\
\text { Bengalurus-high-CO2-emissions.html }\end{array}$ \\
\hline $\begin{array}{l}\text { Climate change in Sri Lanka: Food } \\
\text { security alert! }\end{array}$ & $\begin{array}{l}\text { Sunday } \\
\text { Observer }\end{array}$ & Sri Lanka & 2016-07-31 & $\begin{array}{l}\text { http://www.sundayobserver.lk/2016/07/31/fea10. } \\
\text { asp }\end{array}$ \\
\hline $\begin{array}{l}\text { Change and dispossession: Lack of data } \\
\text { prevents a planned response to climate } \\
\text { change in the Karnali river basin }\end{array}$ & $\begin{array}{l}\text { Himal } \\
\text { Southasian }\end{array}$ & Sri Lanka & $2016-08-12$ & $\begin{array}{l}\text { http://immersive.himalmag.com/ } \\
\text { change-and-dispossession }\end{array}$ \\
\hline $\begin{array}{l}\text { Home gardens - ensuring food security in } \\
\text { a changing climate }\end{array}$ & $\begin{array}{l}\text { Dhaka } \\
\text { Tribune }\end{array}$ & Bangladesh & 2016-08-31 & $\begin{array}{l}\text { http://www.dhakatribune.com/feature/2016/08/31/ } \\
\text { home-gardens-ensuring-food-security-changing- } \\
\text { climate/ }\end{array}$ \\
\hline $\begin{array}{l}\text { South Asian experts meet to address } \\
\text { global change issues }\end{array}$ & $\begin{array}{l}\text { The Daily } \\
\text { Observer }\end{array}$ & Bangladesh & $2016-12-20$ & https://www.observerbd.com/details.php?id=49063 \\
\hline
\end{tabular}




\begin{tabular}{|c|c|c|c|c|}
\hline Title & Media & Country & Date & URL \\
\hline $\begin{array}{l}\text { Home Gardens: A sound approach to } \\
\text { food security }\end{array}$ & $\begin{array}{l}\text { Pakistan } \\
\text { Today }\end{array}$ & Pakistan & 2017-01-14 & $\begin{array}{l}\text { https://www.pakistantoday.com.pk/2017/01/14/ } \\
\text { home-gardens-a-sound-approach-to-food-security/ }\end{array}$ \\
\hline $\begin{array}{l}\text { Home gardening a sound approach to } \\
\text { food security }\end{array}$ & The Nation & Pakistan & $2017-01-27$ & $\begin{array}{l}\text { https://nation.com.pk/27-Jan-2017/ } \\
\text { home-gardening-a-sound-approach-to-food-security }\end{array}$ \\
\hline Home gardening: It pays & My Republica & Nepal & 2017-03-14 & $\begin{array}{l}\text { https://myrepublica.nagariknetwork.com/ } \\
\text { news/16380/ }\end{array}$ \\
\hline $\begin{array}{l}\text { Sidelining God: why secular climate } \\
\text { projects in the Pacific Islands are failing }\end{array}$ & $\begin{array}{l}\text { The } \\
\text { Conversation }\end{array}$ & Australia & 2017-05-17 & $\begin{array}{l}\text { https://theconversation.com/sidelining-god-why- } \\
\text { secular-climate-projects-in-the-pacific-islands-are- } \\
\text { failing- } 77623\end{array}$ \\
\hline $\begin{array}{l}\text { Nepal earthquake reconstruction } \\
\text { won't succeed until the vulnerability of } \\
\text { survivors is addressed }\end{array}$ & $\begin{array}{l}\text { The } \\
\text { Conversation }\end{array}$ & Australia & $2017-11-24$ & $\begin{array}{l}\text { https://theconversation.com/nepal-earthquake- } \\
\text { reconstruction-wont-succeed-until-the- } \\
\text { vulnerability-of-survivors-is-addressed-87335 }\end{array}$ \\
\hline $\begin{array}{l}\text { SAARC Agricultural Experts Discuss Ways } \\
\text { to Address Impact of Climate Change on } \\
\text { Agriculture }\end{array}$ & Public Now & India & $2018-04-17$ & $\begin{array}{l}\text { http://www.publicnow.com/view/9F551F871F90E6A } \\
\text { 43EFD719DC27954ECC50DAAB2 }\end{array}$ \\
\hline Improve pollution measurement: Experts & $\begin{array}{l}\text { The Times of } \\
\text { India }\end{array}$ & India & $2018-12-15$ & $\begin{array}{l}\text { https://timesofindia.indiatimes.com/city/ } \\
\text { ahmedabad/improve-pollution-measurement- } \\
\text { experts/articleshow/67099671.cms }\end{array}$ \\
\hline Desperate times loom for NZ & $\begin{array}{l}\text { The New } \\
\text { Zealand } \\
\text { Herald }\end{array}$ & $\begin{array}{l}\text { New } \\
\text { Zealand }\end{array}$ & 2019-02-15 & $\begin{array}{l}\text { https://www.nzherald.co.nz/the- } \\
\text { university-of-auckland/news/article. } \\
\text { cfm?c_id=1504618\&objectid=12203181 }\end{array}$ \\
\hline $\begin{array}{l}\text { Sewage treatment plants can turn E Coli } \\
\text { into superbug }\end{array}$ & $\begin{array}{l}\text { Down } \\
\text { To Earth } \\
\text { Magazine }\end{array}$ & India & 2019-04-04 & $\begin{array}{l}\text { https://www.downtoearth.org.in/news/water/ } \\
\text { sewage-treatment-plants-can-turn-e-coli-into- } \\
\text { superbug- } 63830\end{array}$ \\
\hline Talking about the weather & $\begin{array}{l}\text { The News } \\
\text { International }\end{array}$ & Pakistan & $2019-04-30$ & $\begin{array}{l}\text { https://www.thenews.com.pk/ } \\
\text { print/465034-talking-about-the-weather }\end{array}$ \\
\hline
\end{tabular}




\section{Appendix 6. Acronyms}

\begin{tabular}{|c|c|}
\hline ACCCRN & Asian Cities Climate Change Resilience Network \\
\hline ACRE & Atmospheric Circulation Reconstructions over the Earth \\
\hline AGU & American Geophysical Union \\
\hline AIT & Asian Institute of Technology \\
\hline ALOS & Advanced Land Observing Satellite \\
\hline ANCST & Asian Network on Climate Science and Technology \\
\hline AOGEO & Asia-Oceania Group on Earth Observations \\
\hline APAN & Asia Pacific Adaptation Network \\
\hline APN & Asia-Pacific Network for Global Change Research \\
\hline ARCP & Annual Call for Regional Research Proposals \\
\hline ASEAN & Association of Southeast Asian Nations \\
\hline AUEDM & Asian University Network for Environment and Disaster Management \\
\hline B\&ES & Biodiversity and Ecosystems Services Framework \\
\hline CAF & Climate Adaptation Framework \\
\hline CAPaBLE & Scientific Capacity Development Programme \\
\hline $\mathrm{CCA}$ & Climate Change Adaptation \\
\hline CDC & Capacity Development Committee \\
\hline CDKN & Climate Development Knowledge Network \\
\hline CORDEX & Coordinate Regional Downscaling Experiment \\
\hline CRRP & Comprehensive Regional Research Programme \\
\hline CRYS & Collaborative Research for Young Scientists \\
\hline CSIRO & Commonwealth Scientific and Industrial Research Organisation \\
\hline DOI & Digital Object Identifier \\
\hline DRR & Disaster Risk Reduction \\
\hline ECS & Early-Career Scientist(s) \\
\hline EMECS & Environmental Management of Enclosed Coastal Seas \\
\hline ESG & Earth System Governance Project \\
\hline ESSP & Earth System Science Partnership \\
\hline FoPIA & Framework for Participatory Impact Assessment \\
\hline GCP & Global Carbon Project \\
\hline GECHH & Global Environmental Change and Human Health \\
\hline GEOSS-AP & Global Earth Observation System of Systems - Asia-Pacific \\
\hline GHG & Greenhouse Gas \\
\hline GLP & Global Land Programme (formerly Global Land Project) \\
\hline IAI & Inter-American Institute for Global Change Research \\
\hline ICCCAD & International Centre for Climate Change and Development \\
\hline ICLEI & Local Governments for Sustainability \\
\hline ICTP & International Centre for Theoretical Physics \\
\hline IGAC & International Global Atmospheric Chemistry \\
\hline IGBP & International Geosphere-Biosphere Programme \\
\hline IGES & Institute for Global Environmental Strategies \\
\hline IGM & Intergovernmental Meeting \\
\hline IHDP & International Human Dimensions Programme \\
\hline IMBER & $\begin{array}{l}\text { Integrated Marine Biosphere Research (formerly Integrated Marine Biogeochemistry and Ecosystem } \\
\text { Research) }\end{array}$ \\
\hline IPBES & Intergovernmental Platform on Biodiversity and Ecosystem Services \\
\hline IPCC & Intergovernmental Panel on Climate Change \\
\hline ISAP & International Forum for Sustainable Asia and the Pacific \\
\hline ISC & International Science Council \\
\hline
\end{tabular}




\begin{tabular}{|c|c|}
\hline IUCN & International Union for the Conservation of Nature \\
\hline JAMSTEC & Japan Agency for Marine-Earth Science and Technology \\
\hline KII & Key Informant Interview \\
\hline KMA & Korea Meteorological Administration \\
\hline L\&D & Loss \& Damage \\
\hline $\mathrm{LCl}$ & Low Carbon Initiatives Framework \\
\hline LDCs & Least Developing Countries \\
\hline LEAD & Leadership for Environment and Development \\
\hline LoCARNet & Low Carbon Asia Research Network \\
\hline LUF & Land use function \\
\hline MAIRS & Monsoon Asia Integrated Regional Study \\
\hline MEL & Monitoring, Evaluation and Learning \\
\hline MOEJ & Ministry of the Environment, Japan \\
\hline MRV & Measurement, Reporting and Verification \\
\hline NGO & Non-Governmental Organization \\
\hline NIMS & National Institute of Meteorological Sciences, Republic of Korea \\
\hline NMS & National Meteorological Services \\
\hline NSF & National Science Foundation \\
\hline NWP & Nairobi Work Programme \\
\hline $\mathrm{OA}$ & Open Access \\
\hline PAGES & Past Global Changes \\
\hline PARR & Pan-Asia Disaster Risk Reduction Fellowship Program \\
\hline PDTW & Proposal Development Training Workshop \\
\hline PPP & Public-Private Partnership \\
\hline PRA & Participatory Rural Appraisal \\
\hline REDD & Reducing Emissions from Deforestation and Forest Degradation \\
\hline RRC.AP & Regional Resource Centre for Asia and Pacific \\
\hline RUSD & Resources Utilization and Pathways for Sustainable Development \\
\hline SAARC & South Asia Association for Regional Cooperation \\
\hline SBSTA & Subsidiary Body for Scientific and Technological Advice \\
\hline SC & Steering Committee \\
\hline SEN & Small Earth Nepal \\
\hline SIDS & Small Island Development States \\
\hline SLD & Shared Learning Dialogue \\
\hline SOLAS & Surface Ocean - Lower Atmosphere Study \\
\hline SPG & Scientific Planning Group \\
\hline SPG-SC & SPG Sub-Committee \\
\hline SRC & Subregional Committee \\
\hline START & SysTem for Analysis, Research and Training \\
\hline SWM & Solid Waste Management \\
\hline UNCBD & United Nations Convention on Biodiversity \\
\hline UN-CECAR & University Network for Climate \& Ecosystems Change Adaptation Research in Asia \\
\hline UNEP & United Nations Environment Programme \\
\hline UNEP-IETC & United Nations Environment Programme - International Environmental Technology Centre \\
\hline UNFCCC & United Nations Framework Convention on Climate Change \\
\hline UNU-IAS & United Nations University Institute for the Advanced Study of Sustainability \\
\hline USAID & United States Agency for International Development \\
\hline VAST & Viet Nam Academy for Science and Technology \\
\hline WCRP & World Climate Research Programme \\
\hline WFP & World Food Programme \\
\hline WSSD & World Summit on Sustainable Development \\
\hline
\end{tabular}




\section{DT $\begin{aligned} & \text { ASIA-PACIFIC NETWORK FOR } \\ & \text { GLOBAL CHANGE RESEARCH }\end{aligned}$}

\section{APN Fourth Strategic Phase Report}

ISBN: 978-4-9902500-4-1

DOI: https://doi.org/10.30852/spr.4

(c) 2020 Asia-Pacific Network for Global Change Research (APN)

Citation: Asia-Pacific Network for Global Change Research. (2020).

APN Fourth Strategic Phase Report. Kobe: APN.

\section{APN Secretariat}

4th Floor, East Building,

1-5-2 Wakinohama Kaigan Dori,

Chuoku, Kobe 651-0073, JAPAN

Tel: $+81-78-230-8017$

Fax: +81-78-230-8018

Email: info@apn-gcr.org

Website: www.apn-gcr.org 